\title{
Opening Doors. \\ Guiding teachers to intentionally facilitate science for young children.
}

BY

Sola Jane Freeman

\author{
A thesis \\ submitted to the Victoria University of Wellington \\ in fulfilment of the requirement for the degree of \\ Doctor of Philosophy
}

School of Education

Victoria University of Wellington

2021 


\section{Abstract}

Research has acknowledged the limited range of scientific opportunities for young children in New Zealand early childhood education (ECE) services. The identified reasons include a lack of confidence by ECE teachers, their narrow understanding of science, and their pedagogical approaches to teaching. A complex and non-prescriptive curriculum and dominance of developmental theories in ECE has resulted in science learning via osmosis through a process of a hands-off play-based philosophy of practice. Many have argued for pedagogical approaches that can accommodate scientific learning within a play-based sociocultural-historical setting (e.g., Broström, 2015; Fleer \& Pramling, 2015; Kumar \& Whyte, 2018). This study investigated the things that influence the occurrence of scientific experiences in ECE. It explored how participating in collaborative action research (CAR) and the involvement of a critical friend influences scientific experiences in centres.

This study involved two phases: a national survey and CAR with teaching teams in six centres. The researcher took on the role of a critical friend through the CAR process, guiding teachers to critically examine their practice and their centre programme. Action plans were achieved collaboratively within each teaching team. Data was collected over 12 weeks in each centre through focus groups, reflective journals, observations, field notes, and through two research hui with participating teachers from all centres.

The findings highlighted the importance of the teachers recognising and fostering children's scientific experiences. It found that science was enabled in a variety of ECE settings by a shift in teachers' pedagogical practices, adjustments to centre environments, and recognising and responding to children's interests. Teachers enabled rich, authentic, and meaningful scientific interactions with children by their active participation in supporting and extending children's science interests with intentional teaching practices and provocations.

This thesis argues for the value of CAR and the role of a critical friend to facilitate teachers' motivation, engagement, learning and reflection on practice. Seeking a change in practice through professional learning and CAR, brought about ownership of their goals and action plans, and the eventual shifts in teachers' pedagogy of practice. 
The shift towards intentional teaching practices, provocations, and opening doors to knowledge, validated and forefronted the importance of the teachers' role and emphasised their value in noticing, recognising, and responding to children's scientific interests in authentic and meaningful ways. 


\section{Acknowledgements}

I wish to thank the many whose advice, guidance and support meant completing this thesis was not as daunting as it could have been. The five-year effort was worth it because of my experience in each of the six wonderful centres who participated in the study. I was warmly welcomed by each of the centres' families, teachers, and children. The enthusiasm and commitment from the teachers involved was considerable and I am deeply grateful to them. I truly appreciated each word they wrote and spoke to me, their honesty and courage to share and be challenged. They are all true professionals, reflective practitioners, and passionate teachers.

Thank you to Mary Jane Shuker and Kate Thornton, my supervisors, who were the perfect team. I am indebted to their strong and knowledgeable advice and guidance throughout this study, I have learnt so much from them both. Their encouragement and warm support were significant, and I appreciated it greatly.

I am also grateful to those in Victoria University's School of Education who have been there for me in various ways, an encouraging hug, on-going conversations, supportive advice, words of wisdom or sneaky tips.

Thank you to my fabulous ECE colleagues who have backed me for many years and been my biggest supporters. To all those in C Block Waiteata road your company at lunchtime, advice and encouragement was greatly appreciated. Also thank you to the Faculty's administration team. An extra special mention to the following who have been by my side, either inspiring or distracting me with wonderful conversations or random creative endeavours! Big hugs to Lisa Terreni, Bronwyn Wood, Ann Pairman, Rachel Denee, Amy Austin, Jess Tupou, Arna Jensen, Souktisak (Tui) Veekhoonthong, Barbara Ferguson and Ira Iversen.

This thesis would not have been possible without the award of a Victoria University Doctoral Scholarship, which not only confirmed the decision to take on this project but allowed me to focus full-time on research and writing for three years. Additionally, the financial support of the Wellington Doctoral Submission Scholarship was greatly appreciated.

I wish to thank my family. The topic for this thesis was inevitable, given a scientist father who influenced my desire to find out about stuff and a mother who is a 
passionate teacher. Thank you, Phill and Barb. I am grateful for my extended whanau who provided ongoing support, especially in times of need.

Thanks to my children, Fiann, Cared, Nea and Cashel. They have provided practical and emotional support throughout the last five years, fitting 'the $\mathrm{PhD}$ ' into our family life. Their joy in the good times and their love and care when it was hard. And to Mark, my husband, who has always supported and encouraged me. I am hugely thankful for his patience in listening, and especially appreciative of his editing skills of the final thesis. 


\section{Table of Contents}

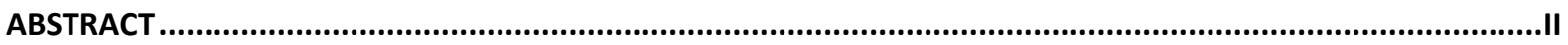

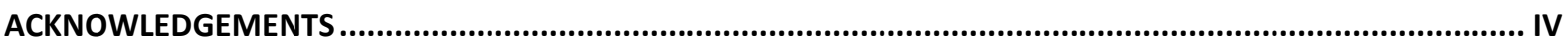

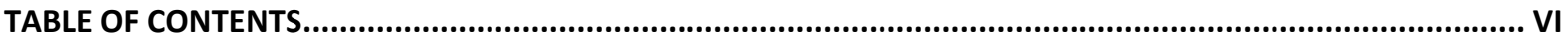

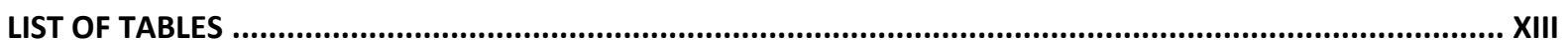

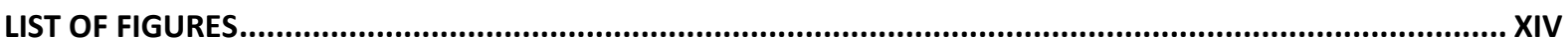

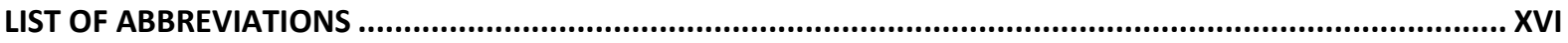

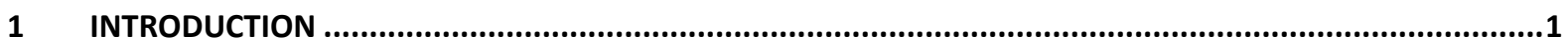

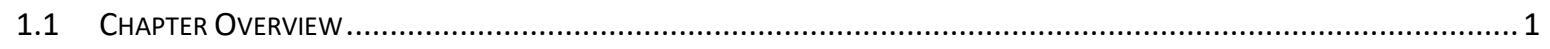

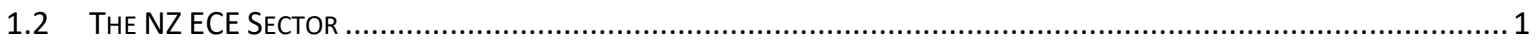

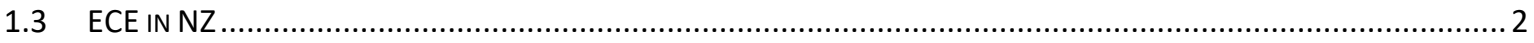

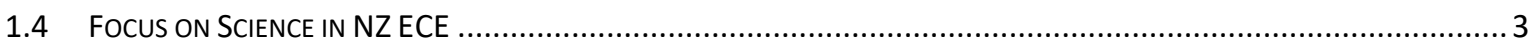

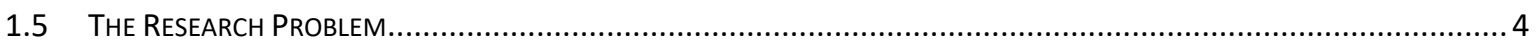

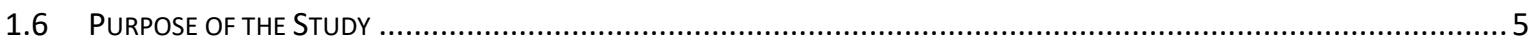

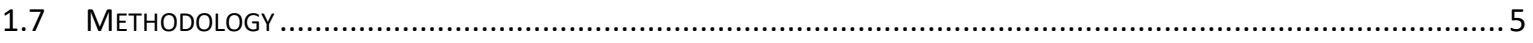

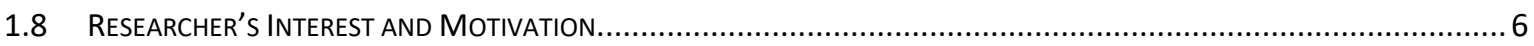

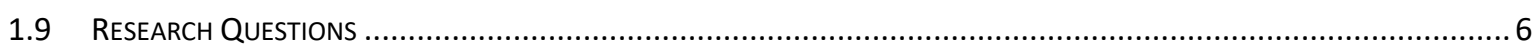

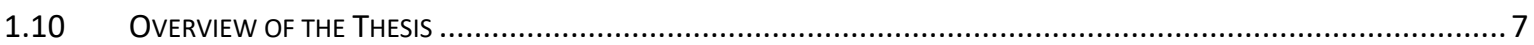

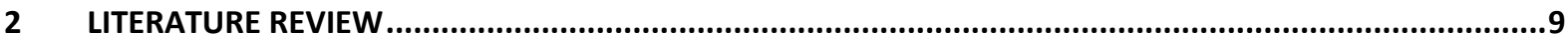

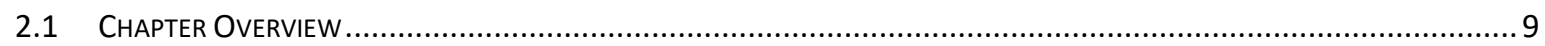

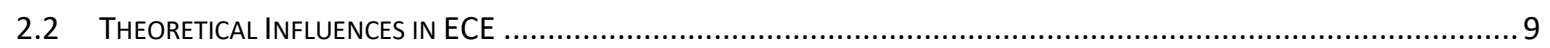

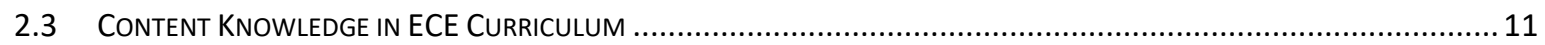

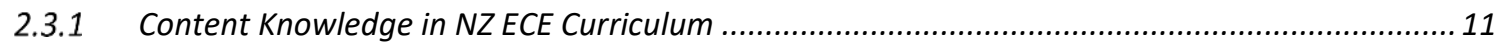

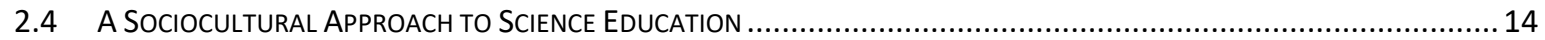

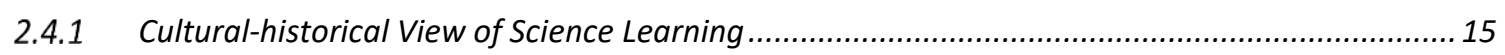

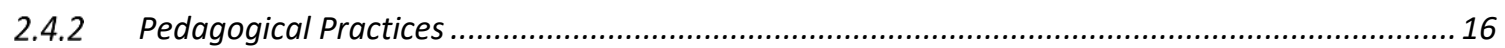

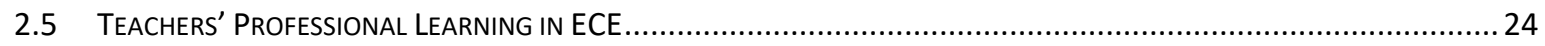

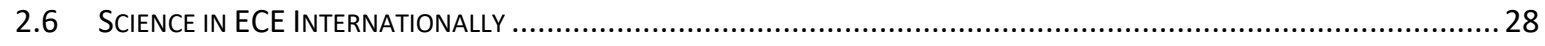

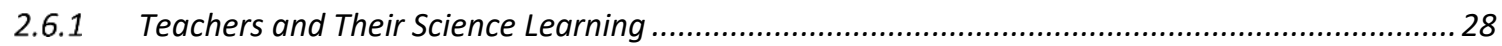

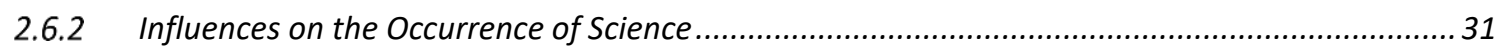

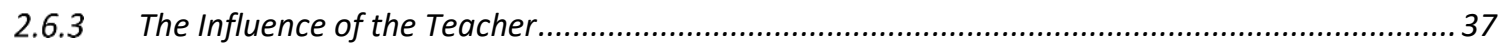

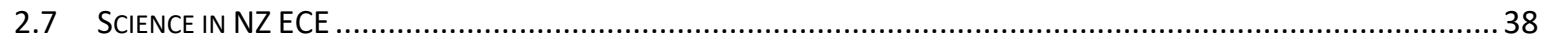

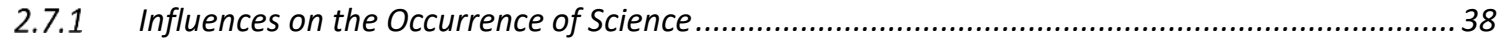

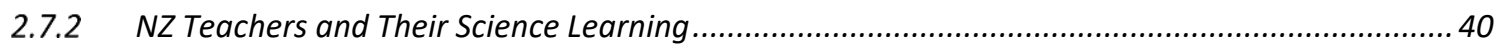




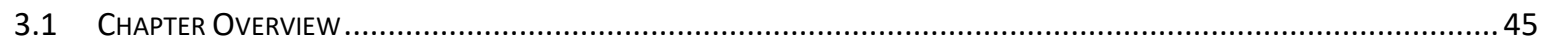

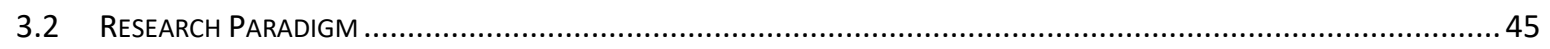

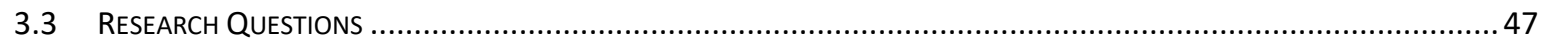

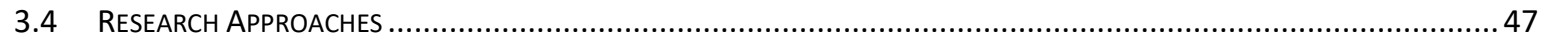

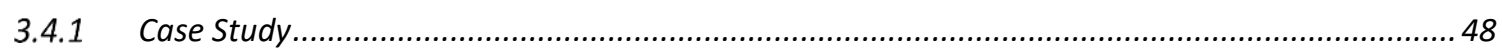

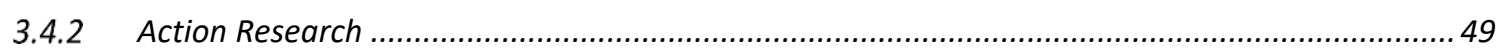

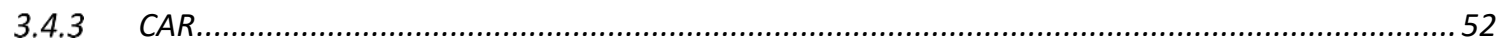

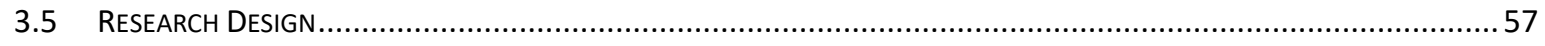

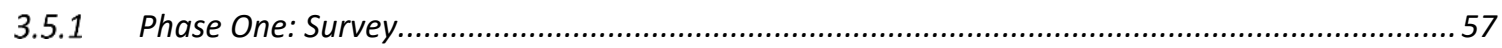

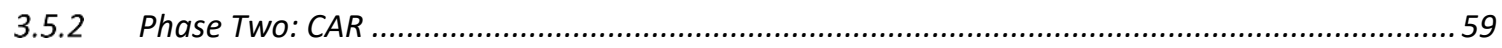

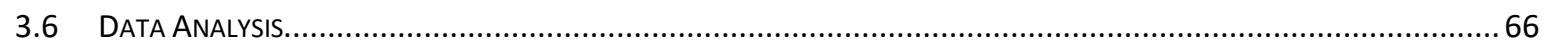

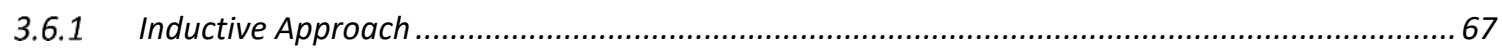

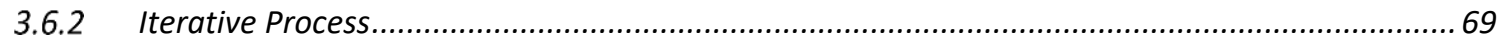

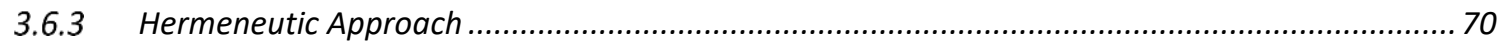

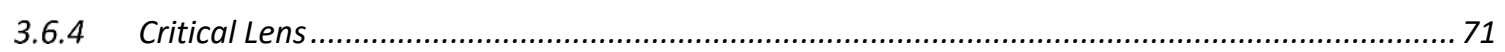

3.6.5 Summary of how Data Sources Informed Research Questions ............................................. 71

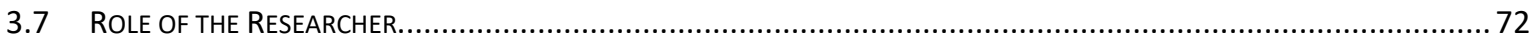

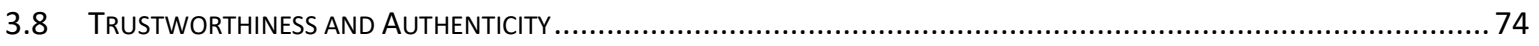

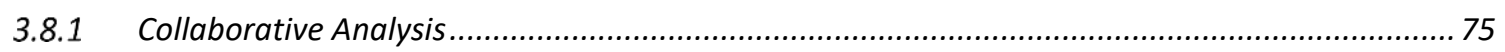

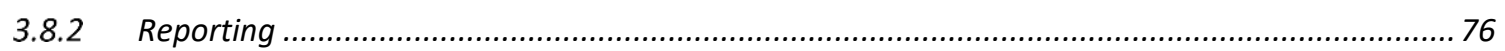

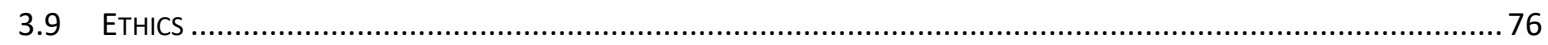

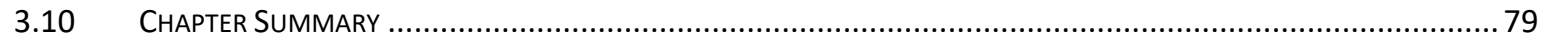

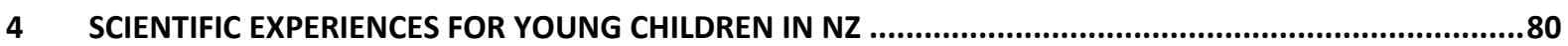

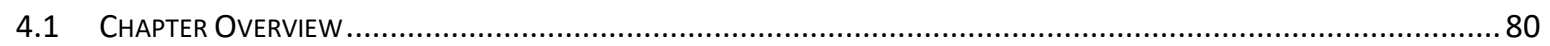

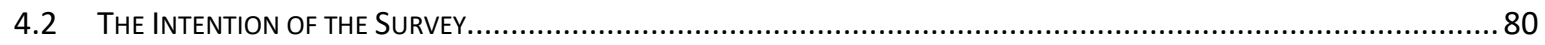

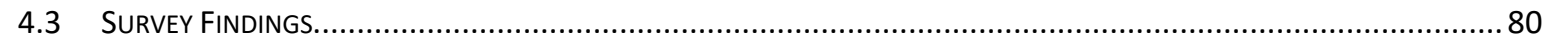

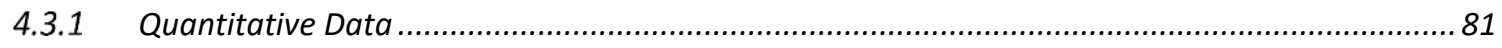

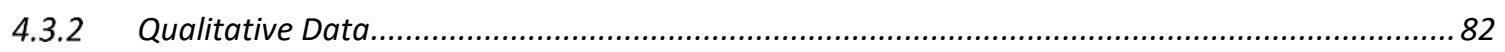

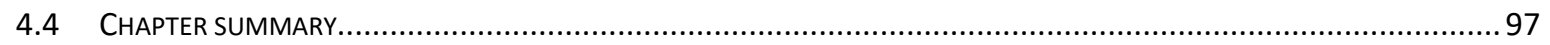

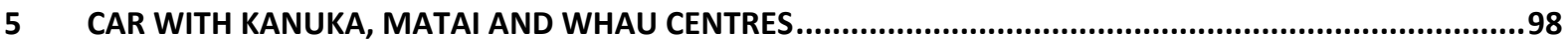

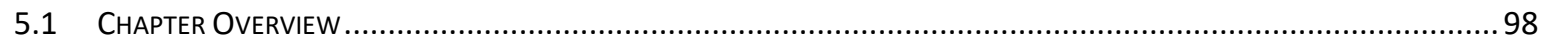

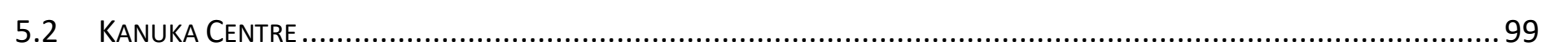

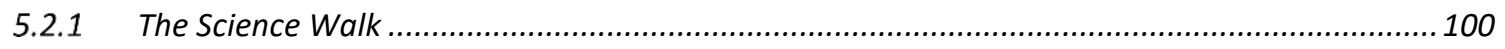

5.2.2 First Focus Group - Reflections on the Science Walk.......................................................... 100 


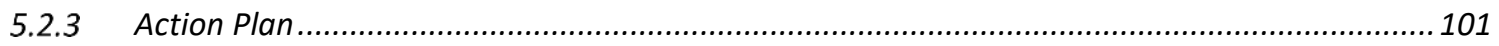

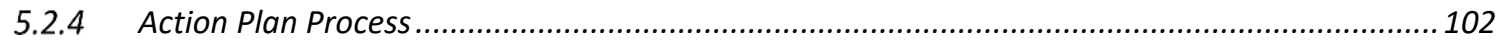

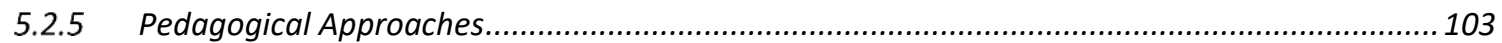

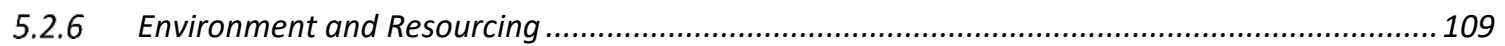

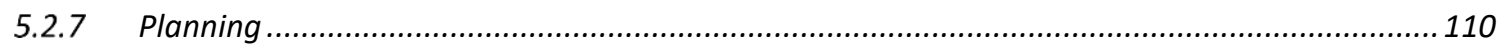

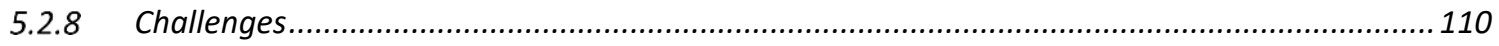

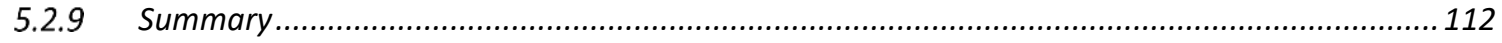

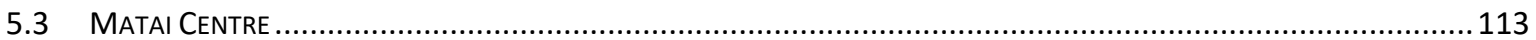

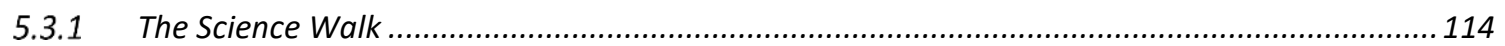

5.3.2 First Focus Group - Reflections on the Science Walk .......................................................... 115

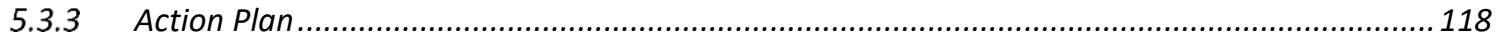

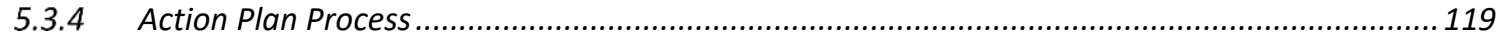

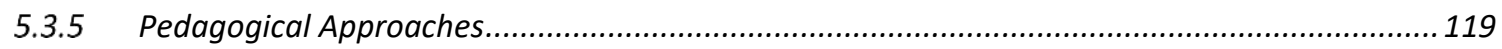

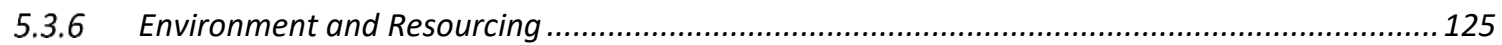

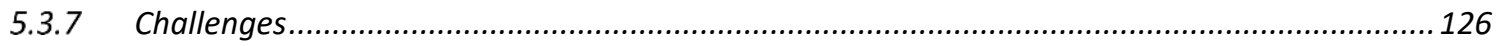

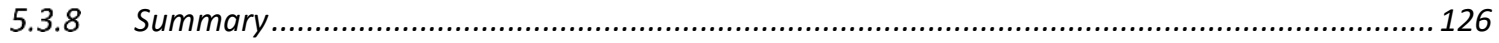

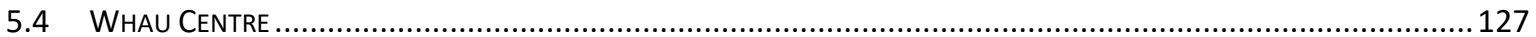

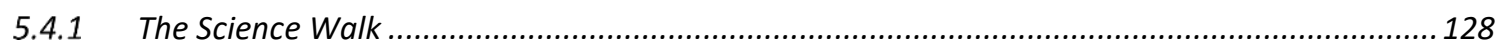

5.4.2 First Focus Group - Reflections on the Science Walk........................................................ 129

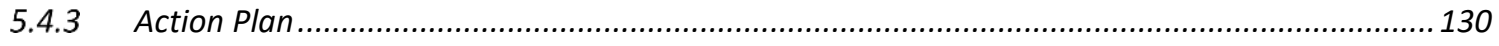

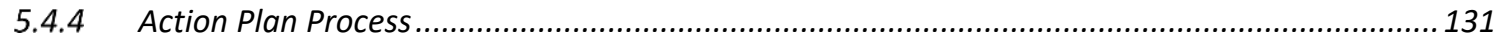

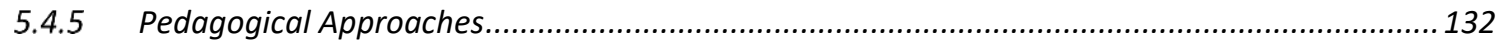

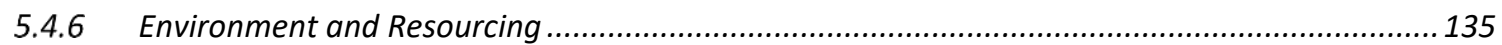

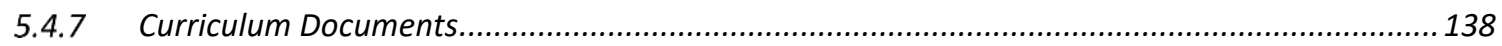

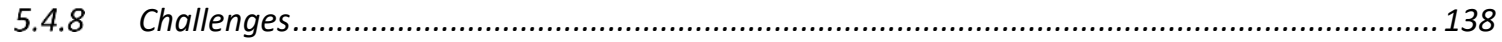

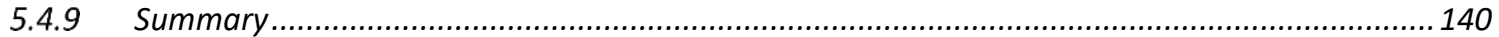

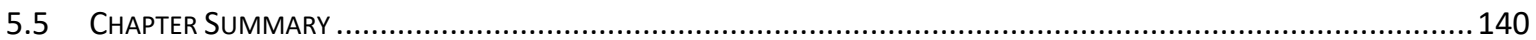

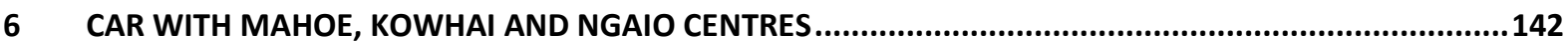

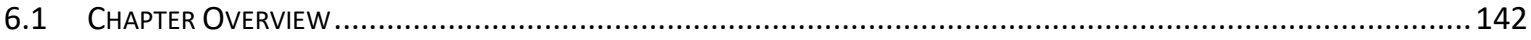

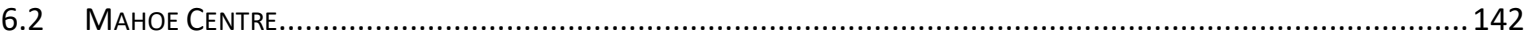

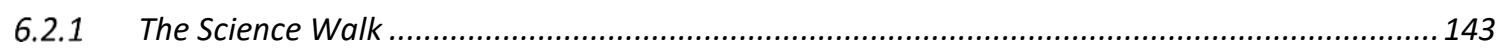

6.2.2 First Focus Group - Reflections on the Science Walk........................................................ 144

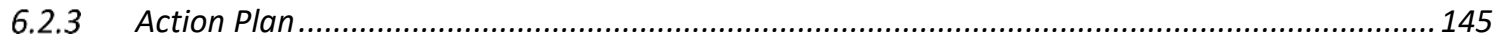

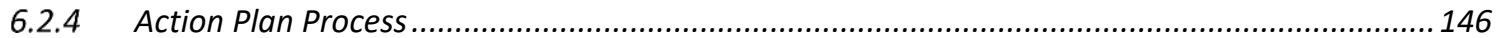

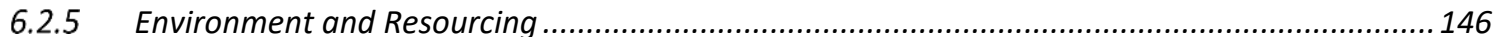

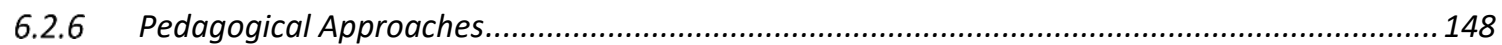

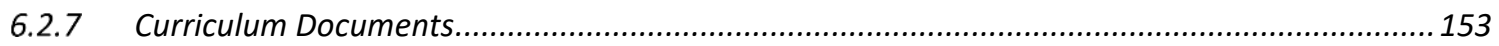




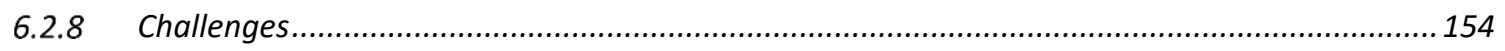

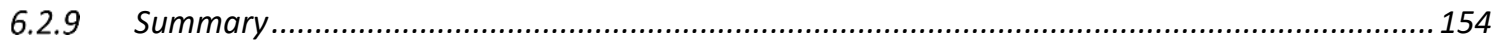

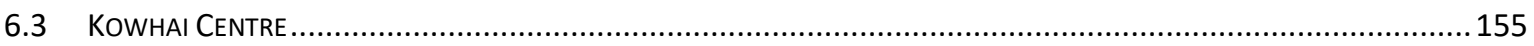

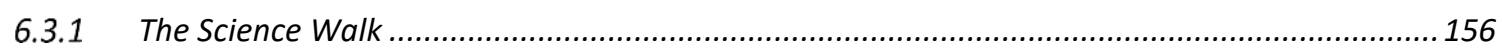

6.3.2 First Focus Group - Reflections on the Science Walk................................................................157

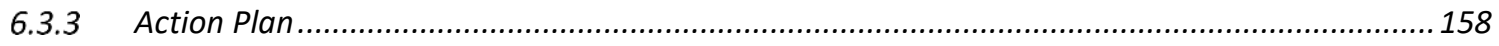

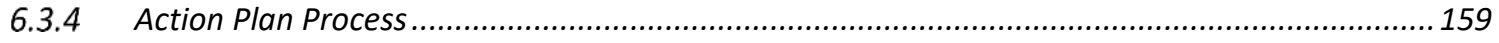

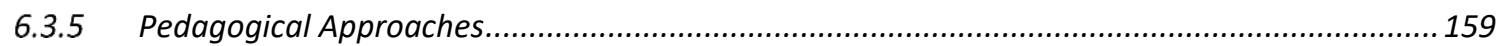

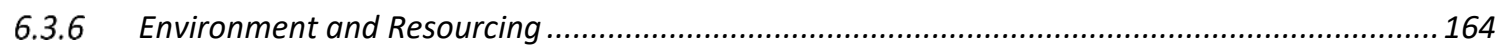

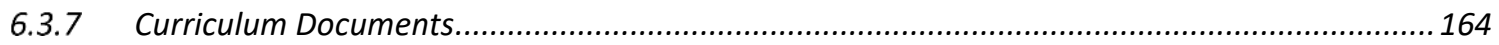

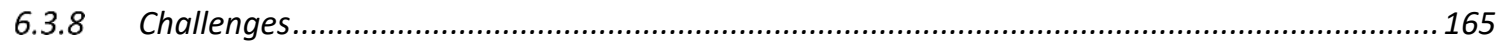

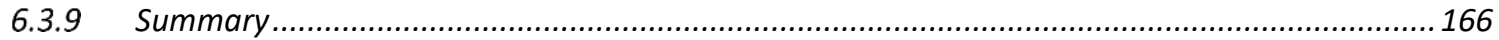

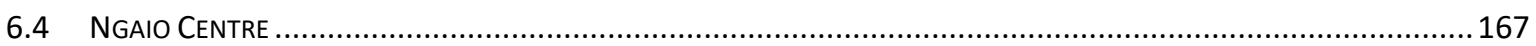

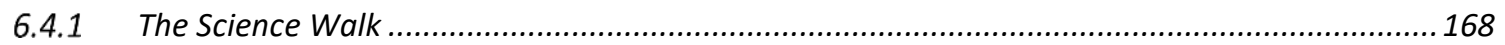

6.4.2 First Focus Group - Reflections on the Science Walk.......................................................... 170

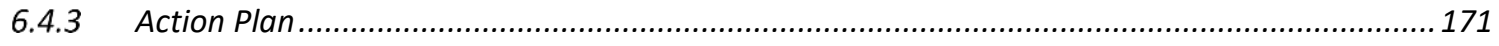

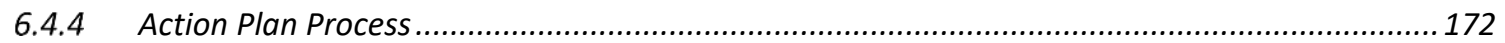

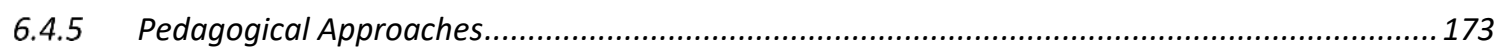

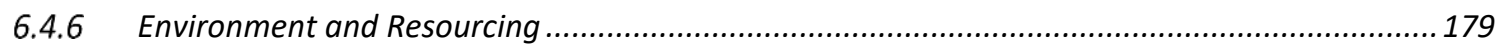

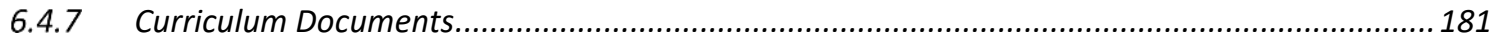

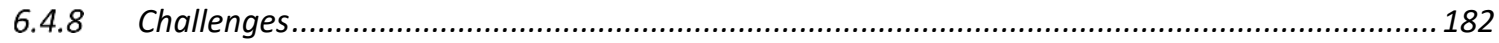

6.4 .9 Summary

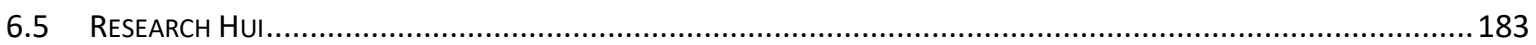

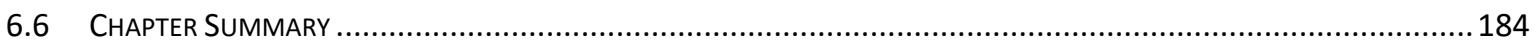

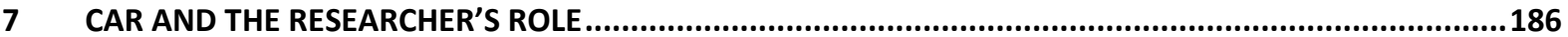

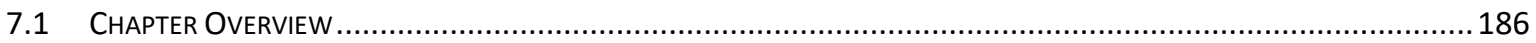

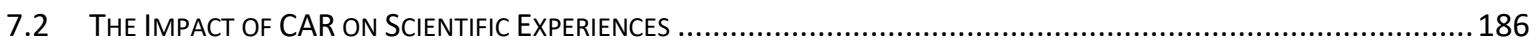

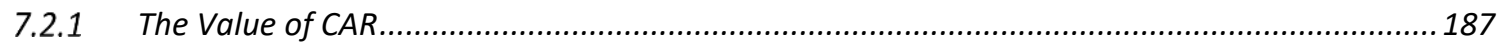

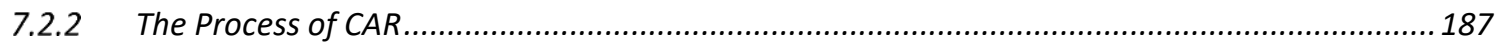

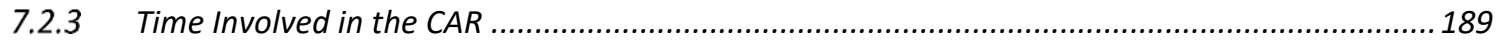

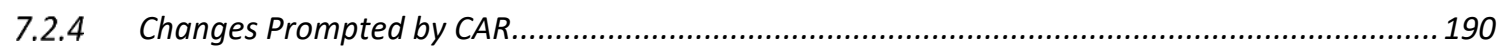

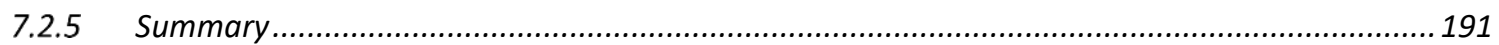

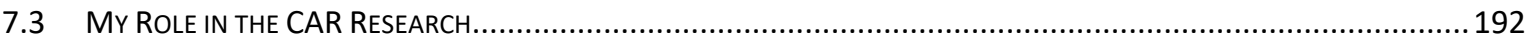

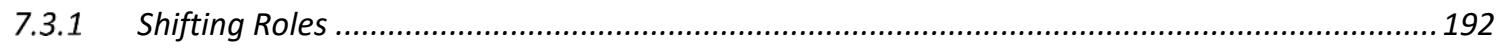

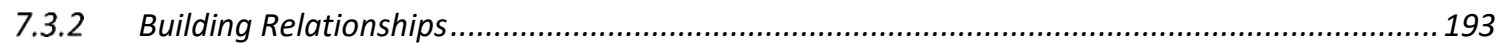

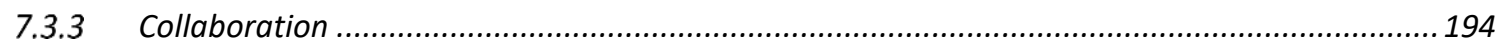

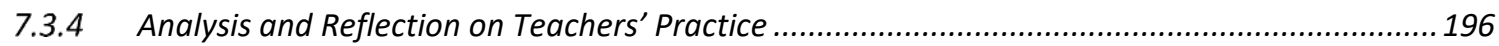




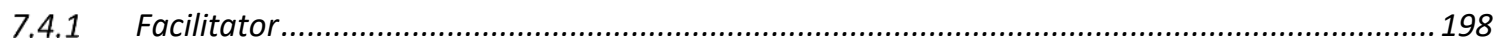

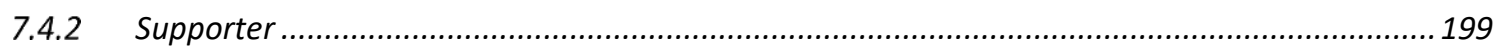

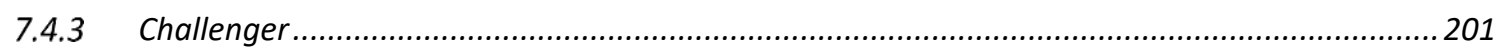

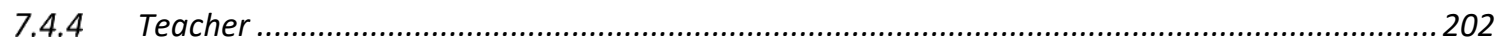

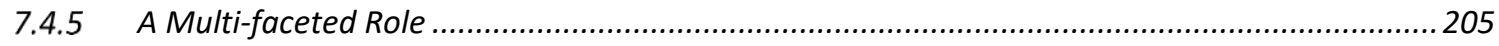

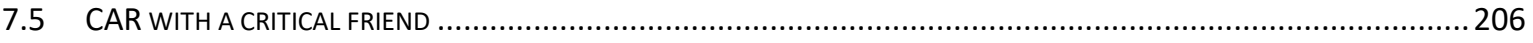

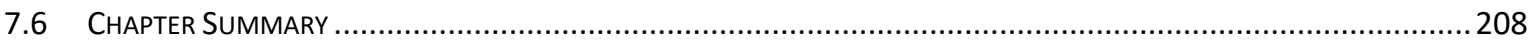

8 PEDAGOGICAL APPROACHES THAT ENABLED SCIENTIFIC EXPERIENCES .........................................209

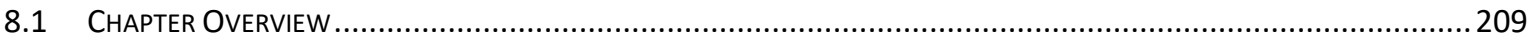

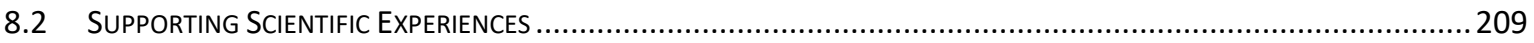

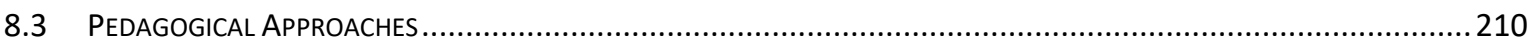

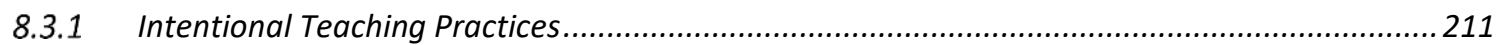

8.3.2 Questioning, Sustained Conversations and Using Scientific Language ....................................212

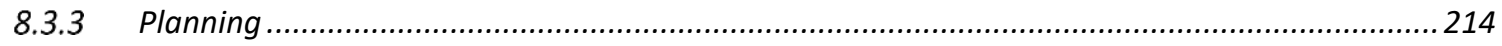

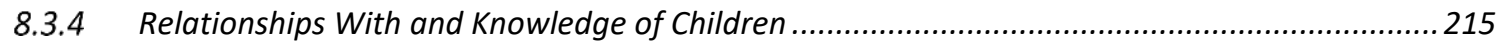

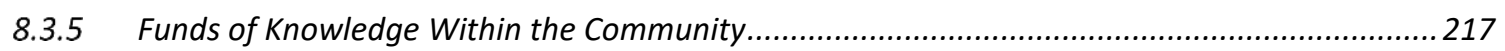

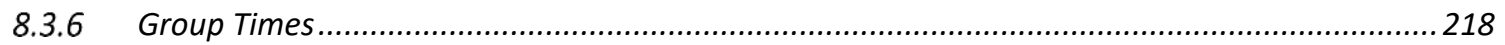

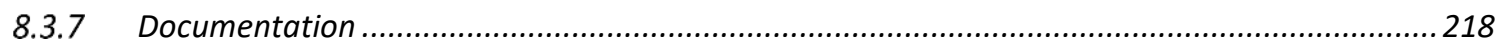

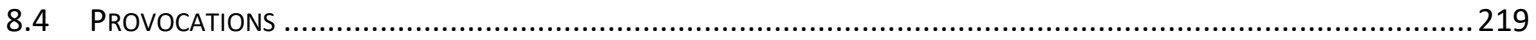

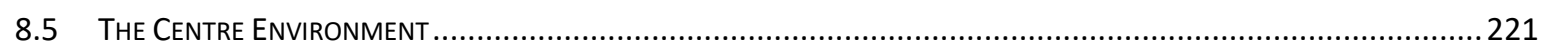

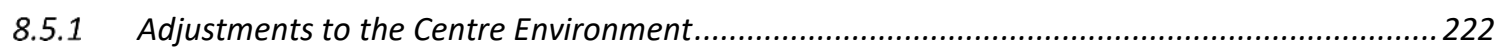

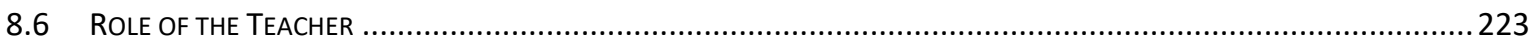

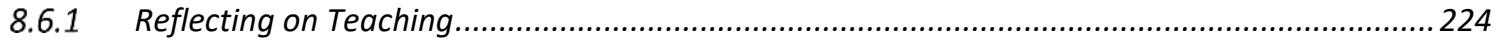

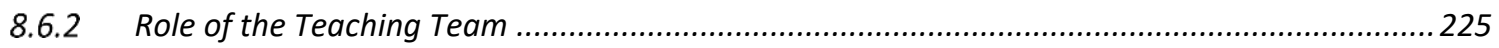

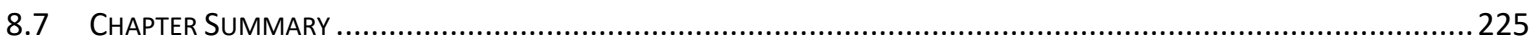

9 ENABLERS AND CHALLENGES TO SCIENTIFIC EXPERIENCES .....................................................227

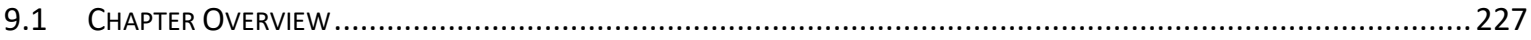

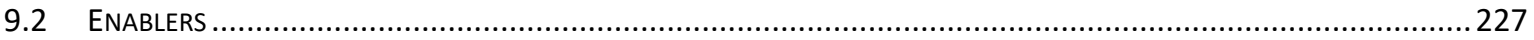

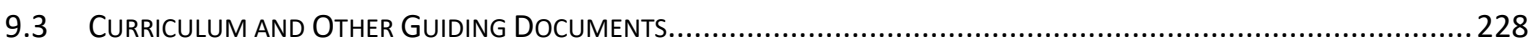

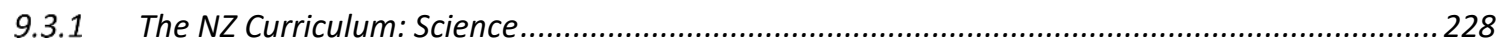

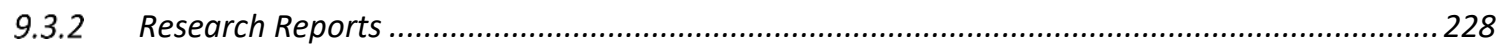

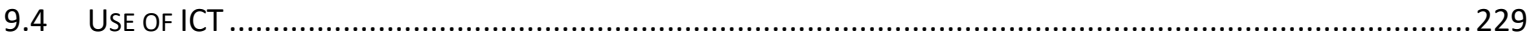

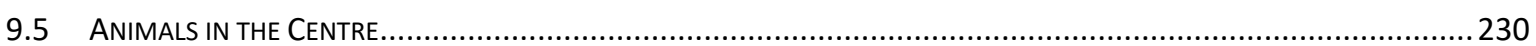

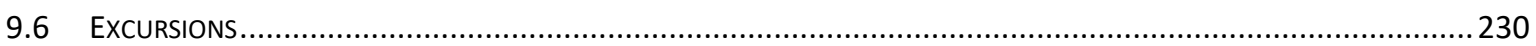

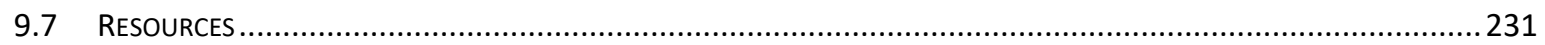

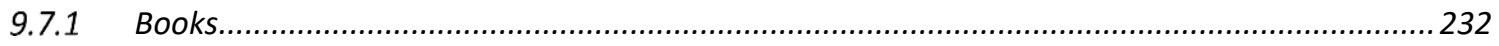




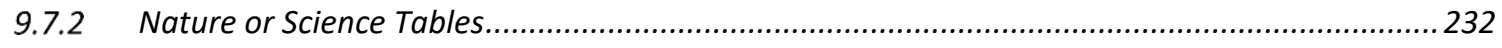

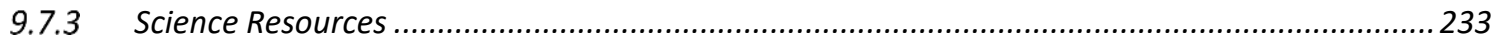

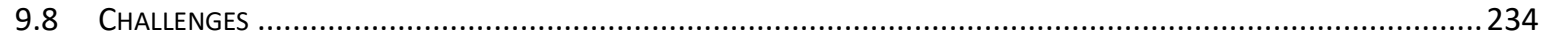

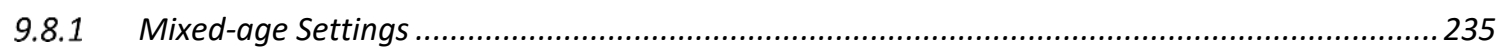

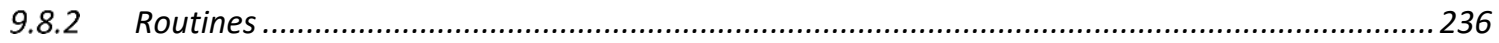

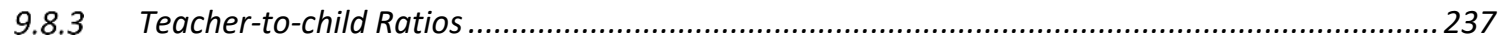

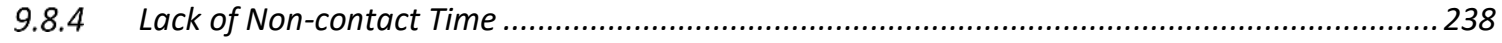

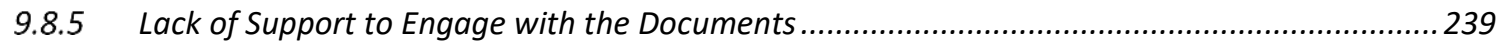

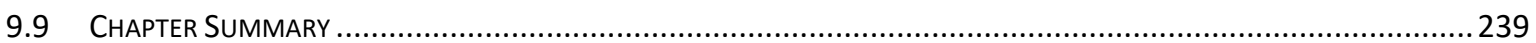

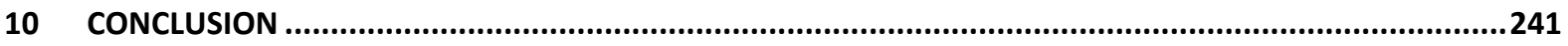

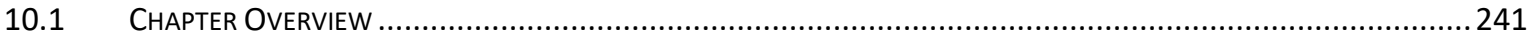

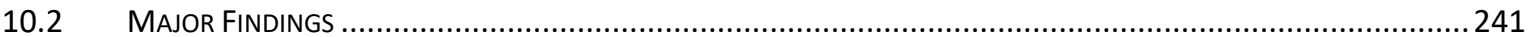

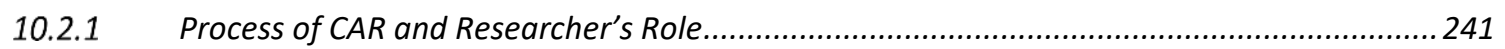

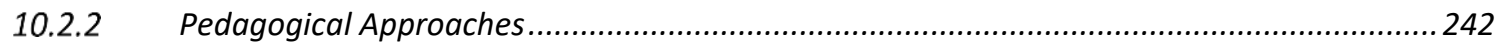

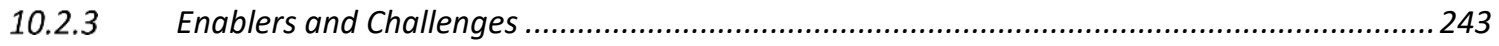

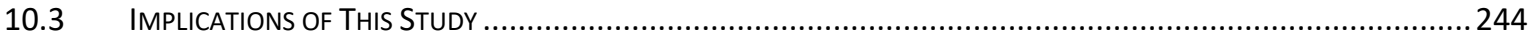

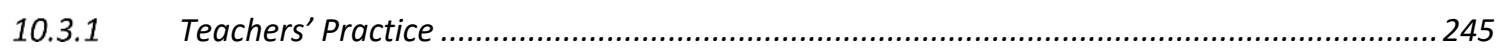

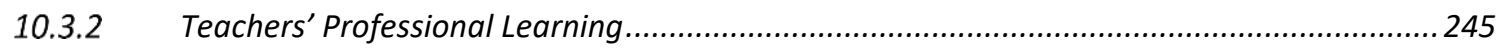

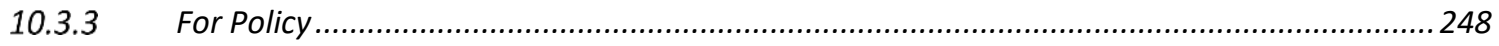

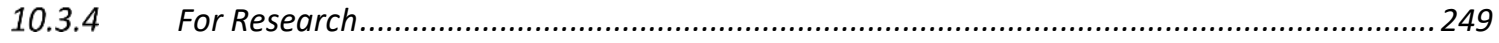

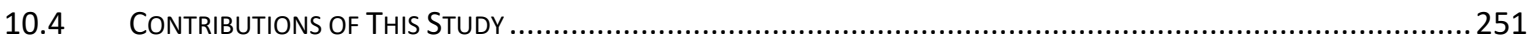

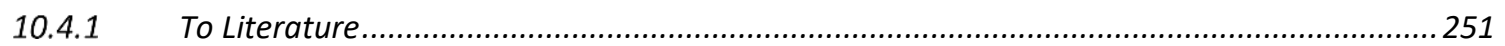

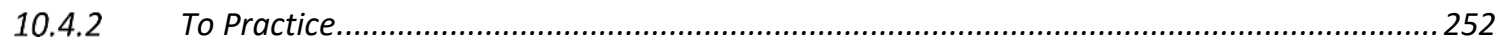

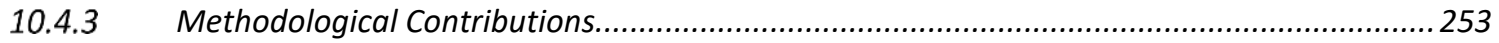

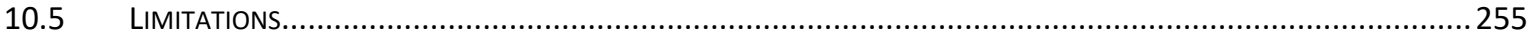

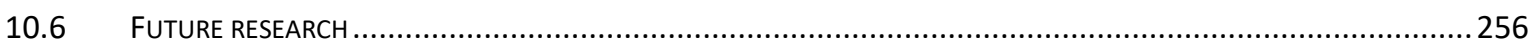

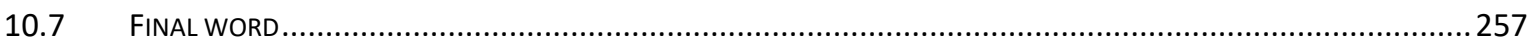

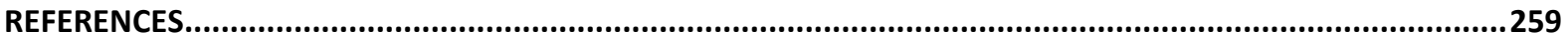

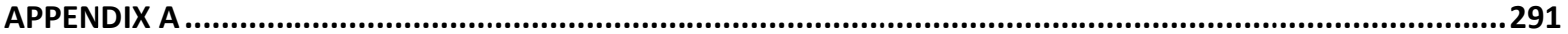

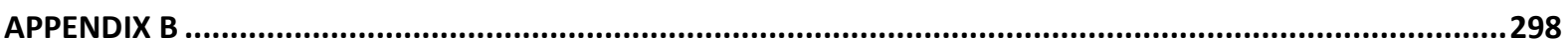

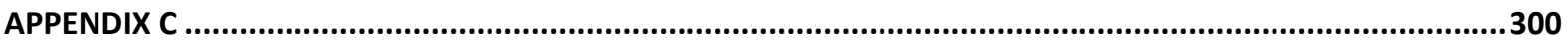

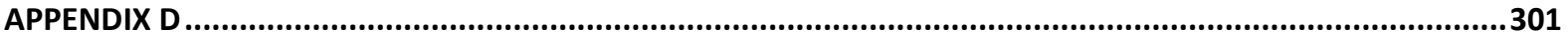

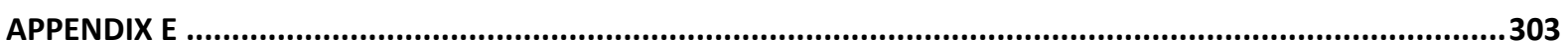

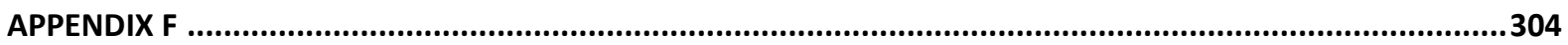

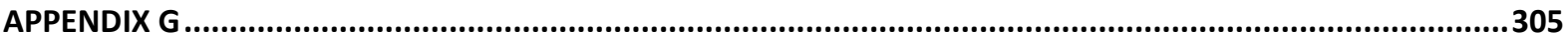


APPENDIX H.

APPENDIX I

APPENDIX J 


\section{List of Tables}

Table 3.1: Number of emails sent, and responses received............................................59

Table 3.2: Action research data collection techniques............................................63

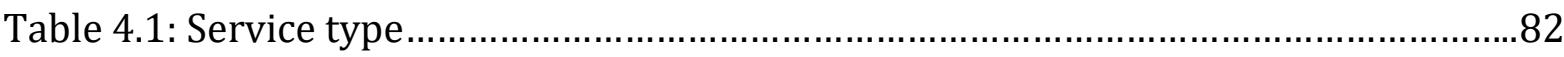

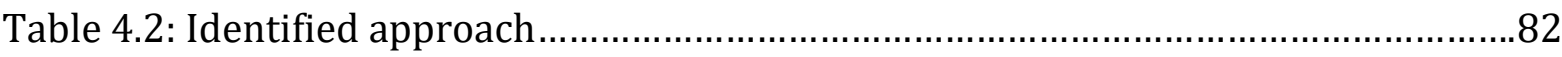

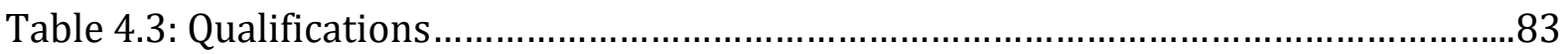

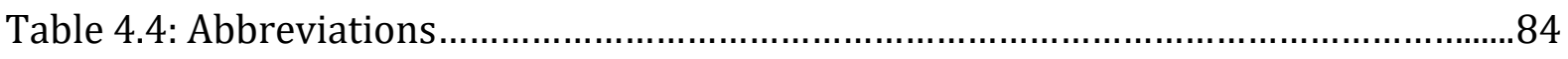

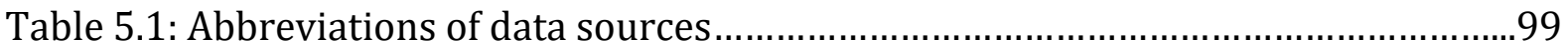

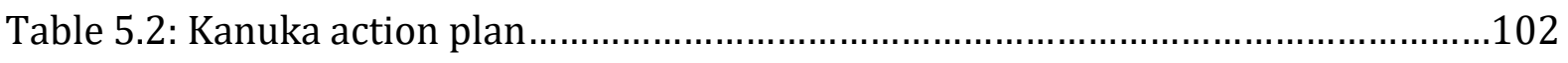

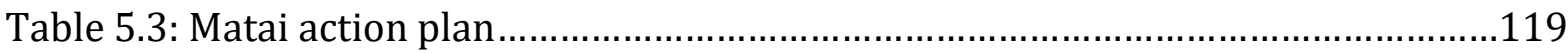

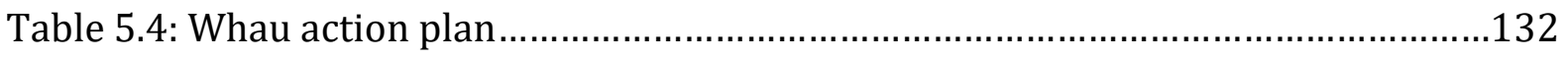

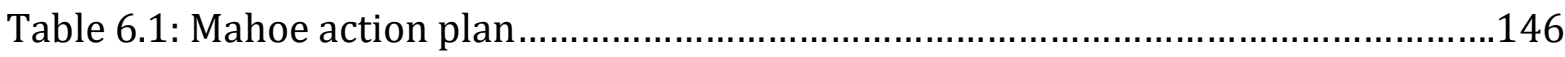

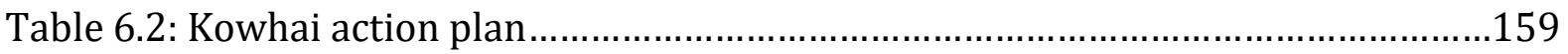

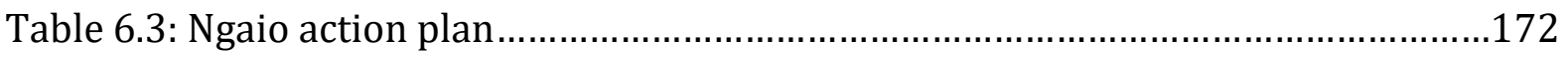




\section{List of Figures}

Figure 3.1: Collaborative action research cycle .........................................................54

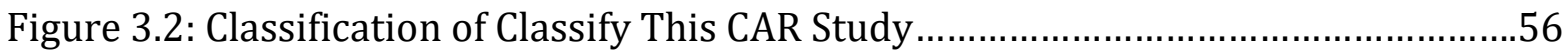

Figure 3.3: Timeline for the first three CAR centres: Kanuka, Matai and Whau..............61

Figure 3.4: Timeline for the second three CAR centres: Mahoe, Kowhai and Ngaio.........62

Figure 3.5: Components of data analysis: Interactive model .........................................68

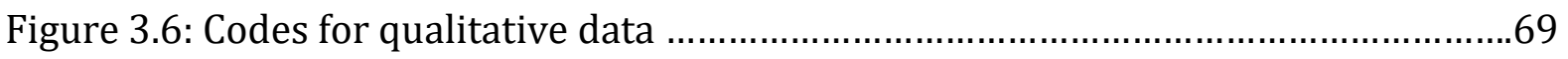

Figure 3.7: How data sources met research questions....................................................

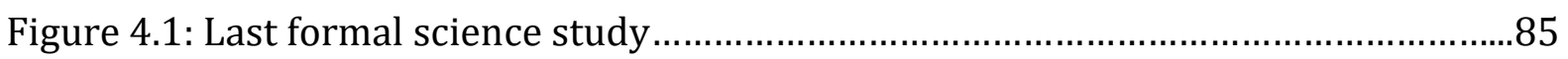

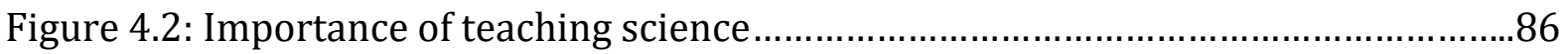

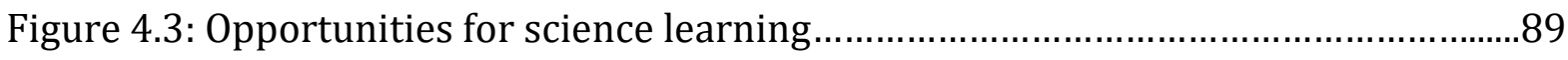

Figure 4.4: Supports helpful to scientific learning in ECE centres...............................96

Figure 5.1: Photos and explanations of science explorations into puddles, air and ice

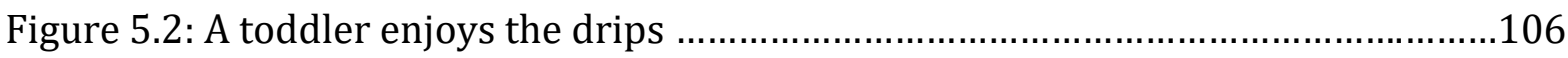

Figure 5.3: Children's pictures of Māui's waka ..............................................................122

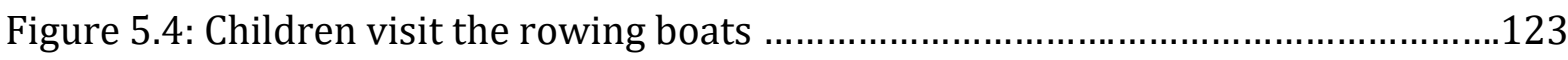

Figure 5.5: Experimenting with capsicum seeds ......................................................137

Figure 5.6: Experiencing puddles in the outside area ...........................................138

Figure 6.1: Using the insect basket to identify a slater...............................................148

Figure 6.2: Using the catapult board to explore force on the tennis ball .......................150

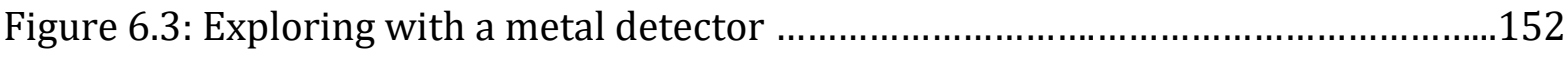

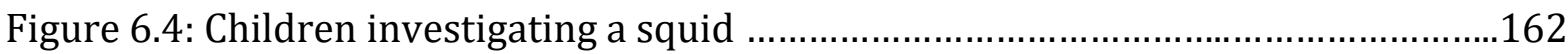

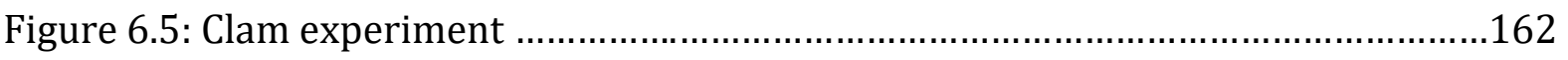


Figure 6.6: Exploring ice .163

Figure 6.7: Examining the bumble bee with the iPad............................................175

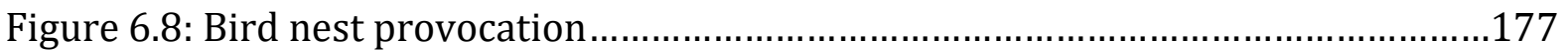

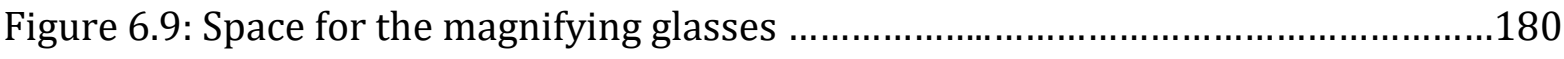

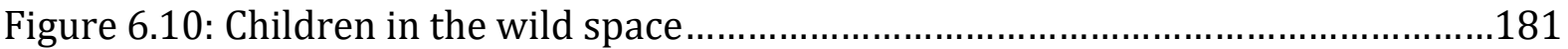

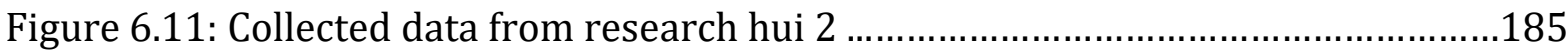

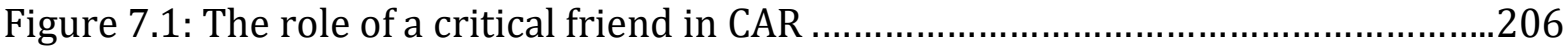

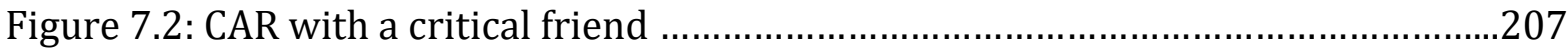




\section{List of Abbreviations}

CAR - Collaborative action research

COI - Centres of Innovation

DAP - Developmentally appropriate practice

DEEWR - Department of Education Employment and Workplace Relations

ECE - Early childhood education

ECLS-K - Early Childhood Longitudinal Study - Kindergarten

EPPE - - Effective Provision of Preschool Education

ERO - Education Review Office

EYLF - Early Years Learning Framework (Australia's ECE curriculum)

ICT $\quad-$ Information and communication technology

MOE - Ministry of Education

NCES - National Center for Education Statistics

NOS - Nature of Science

PLCs - - Professional learning communities

PLD - Professional learning and development

TLRI - - Teaching and Learning Research Initiative

VUW - - Victoria University of Wellington 


\section{Introduction}

\subsection{Chapter Overview}

This chapter provides an overview of this thesis investigating the influences of scientific experiences in early childhood centres in Aotearoa New Zealand (NZ). This study examines the ways teaching teams foster and support young children's scientific experiences in early childhood settings. To provide context to this study, a brief outline of the ECE sector in NZ is presented first. The chapter then discusses the nature of, and theoretical influences on, the practice of early childhood education (ECE) in NZ. The following discussion explores the expectations of how teachers might offer science opportunities and how children might experience them. The problem of limited science experiences in ECE is outlined, then the purpose of the study and the research questions. Next follows a brief explanation of the methodology, then a background to the researcher's interests and motivation. The chapter concludes with an outline of the structure of the thesis.

\subsection{The NZ ECE Sector}

The NZ early childhood sector has evolved in a fragmented way, firstly responding to social needs, with a more educative focus emerging over the last 50 years (May, 2019). Currently the ECE sector includes "diverse institutions providing a range of services, care, education and support, with different cultural and philosophical traditions, for children and their families" (May, 2019, p. 296). NZ ECE involves children from birth to starting school, which is usually after their fifth birthday. They are legally required to start at 6-years-old. Therefore, most services cater for children before they start school, although some centres such as Montessori have children stay until six. According to the ECE Census in 2020, 72\% of teachers in NZ are qualified. While this sector is not compulsory to attend, $91.5 \%$ of 4-year-olds were participating in an ECE service (Ministry of Education (MOE), n.d.-a). As of June 2020, there were 4,662 licenced ECE centres in NZ, with 3, 786 identified as teacher-led: kindergarten, home-based or education and care services. Others are parent-led providers such as playcentre or Kōhanga Reo ${ }^{1}$. Within education and care there are a wide range of programmes. These include sessional to full day, privately or community owned, and/or those with a

\footnotetext{
${ }^{1}$ An ECE centre where all education and instruction is delivered in te reo māori (Māori language).
} 
language, cultural or philosophical focus such as Steiner or Montessori. To acknowledge the diversity within the sector, this study was designed to work within a variety of teacher-led centres.

Internationally the NZ ECE sector is considered a world leader due to its bilingual curriculum Te Whāriki (MOE, 1996, 2017) and the integration of education and care in its administration, policy, and training of teachers (May, 2019; Te One, 2013). One contested area is the implementation of the curriculum. The first version has been critiqued for not providing enough guidance for teachers in how and what to teach (e.g., Cullen, 1996; Nuttall, 2002). An evaluation by the Education Review Office (ERO) (2013) of the implementation of Te Whāriki (MOE, 1996) showed 90\% of the 627 centres reviewed were making use of the principles and strands of the document. Following the release of the revised Te Whäriki (MOE, 2017) in April 2017, professional learning and development (PLD) was provided through workshops, online webinars and resources to ECE centre leaders and teachers to understand and engage with the curriculum (MOE, n.d.-b). However, three reviews by ERO showed while the initial flurry of interest indicated a confidence to implement the document, a year later half of the centres reviewed were not prepared to implement the revised curriculum (ERO, 2018a, 2018b, 2019). Therefore, it is worth examining how teachers might implement the expectations of the revised curriculum in their centre as well as explore their pedagogical practices within the strengthened emphasis on sociocultural approaches and content knowledge such as science.

\subsection{ECE in NZ}

The term ECE describes both the age of the children it serves, and the curriculum, philosophies, and pedagogies of the sector. ECE curriculum and pedagogy are intertwined and complex, and differentiating between the two is difficult (SirajBlatchford, 2008; Wood, 2008). However, there is an expectation that curricula guide pedagogy and give direction to how experiences for young children should be implemented (Wood, 2008). The first NZ early childhood curriculum Te Whāriki (MOE, 1996) sought to provide shared principles and a framework for the ECE sector (Te One, 2013). The theoretical underpinnings of the document were intended to move the influences in NZ ECE practice away from a reliance on developmental ideas to more sociocultural views (May, 2009; Te One, 2013). The shift from viewing children's 
learning as individualistic and linear towards a belief that the social and cultural contexts of children's learning and development needed to be acknowledged was also occurring internationally (e.g., Bloch, 1991; Kessler, 1991; Walsh, 1991). The influence of developmental theories on how children might learn content knowledge has been critiqued (e.g., Bennett, 2005; Hedges \& Cullen, 2005; Krieg, 2011). The deliberately broad and un-prescriptive nature of Te Whāriki (MOE, 1996) meant there was little direction for teachers of how and what content to include in their programmes (Hedges, 2004; Hedges \& Cullen, 2005; Nuttall, 2005a). According to Hedges and Cullen (2005) the philosophical belief that a subject-based curriculum is inappropriate for children in ECE has led to the exclusion of specific teaching and learning of content in the curriculum document. The updated edition of Te Whāriki (MOE, 2017) provides a stronger expectation that ECE practice will reflect a more sociocultural approach to learning and development, drawing on Vygotsky, Bruner, Rogoff and others, with more emphasis on an active role of the teacher in supporting children's engagement in content knowledge (McLachlan, 2017).

\subsection{Focus on Science in NZ ECE}

Science is defined in the New Zealand Curriculum for primary schools, "as a way of investigating, understanding, and explaining our natural, physical world and the wider universe" (MOE, 2007, p. 28). This document sets expectations for learning about firstly, the processes through which scientific knowledge is generated, i.e., the Nature of Science, and secondly the knowledge generated by these processes, which in this study is referred to as science concepts. For the purposes of this study scientific experiences are viewed as activities or conversations that involve children investigating and making sense of the living, physical, material, and technological aspects of their environment.

Research over the last 15 years exploring science in NZ ECE and internationally is discussed fully in the literature review (chapter 2). The research indicates the occurrence of scientific learning situations for children is limited (Hedges, 2004; Tu,N 2006; Zhang \& Birdsall, 2016). Studies have investigated the various factors that could account for this. These studies showed that the occurrence of scientific learning in early childhood settings is affected by the teacher's knowledge (or lack of), their beliefs and attitudes towards science, and their view of children's ability to engage with scientific ideas (Edwards \& Loveridge, 2011; Garbett, 2003). Hedges (2004) discovered that 
teachers support children's learning in planned situations but not in spontaneous situations. Other studies identify that in most play-based programmes teachers organise open-ended experiences, where the content knowledge tends to occur through osmosis; via unconscious engagement with the environment or activities (Hedges \& Cullen, 2005). In this study science content knowledge is viewed as the awareness and understanding of the discipline of science, of science concepts and of the processes of learning in a scientific way.

While evidence suggests the influence of the teachers' scientific knowledge is significant in how much scientific learning occurs, the nature of our curriculum is a contributing factor. As Nuttall (2002) put it, due to the lack of direction in how to incorporate science in Te Whāriki (MOE, 1996), there was a reliance on teachers having a strong understanding of scientific concepts to be able to support children's science experiences effectively. More recently, studies have shown the philosophy of play and freedom to explore, which drives the pedagogy of most centres, means teachers take a hands-off approach and this results in little scientific learning occurring (Zhang \& Birdsall, 2016). Backshall (2016) argues the intervention and support for teachers' own science knowledge is needed to facilitate richer engagement in children's science experiences. A recent review of science by ERO (2021a) in 147 ECE centres across NZ identified only $10 \%$ of services were weaving science through their programme "very well" (p. 14). They assessed this as teachers deliberately including science by using "almost all" indications of good practice such as planning opportunities, responding to children's interests, and using intentional pedagogies (p. 14).

\subsection{The Research Problem}

Limited occurrences of scientific learning in NZ ECE services appears to have resulted from the lack of confidence and capabilities with science amongst ECE teachers, a complex and non-prescriptive curriculum and a (still dominating) hands-off play-based philosophy of practice. Therefore, science education research in ECE deserves attention, specifically the identification of solutions to the challenges ECE teachers face supporting young children's scientific learning (Fleer \& Robbins, 2003). Fleer and Robbins argued that research in science education in ECE has been dominated by a postmodern perspective which has limited usefulness for young children. They contend that using a sociocultural perspective in science education research provides a more inclusive way 
to capture children's thinking and learning around scientific concepts. Additionally, literature reveals a lack of content knowledge within pedagogical practices in NZ ECE centres and that teachers' beliefs, their attitudes, their confidence in and knowledge of science appears to be significant to the teaching strategies teachers use when supporting scientific learning. Therefore, there is room to investigate pedagogical approaches such as taking a fearless approach to science (Bond et al., 2010), accessing communities' funds of knowledge (Hedges, 2007), participatory learning theories (Hedges \& Cullen, 2012) or the cultural-historical approach conceptualised by Fleer and Pramling (2015). These have all been shown to have a positive influence on scientific learning for children.

\subsection{Purpose of the Study}

This study was designed to investigate what influences the occurrence of science in ECE, with the researcher working alongside teachers as they explored how they fostered science within their centre's context. The research sought to capture the changes teachers made to their practice, their environments, and how they used resources and curriculum documents to enable more scientific experiences. The study investigated what supports such as curriculum, resources, the environment and what teacher capabilities or pedagogies are needed to help foster scientific learning. An authentic investigation into science in NZ ECE was allowed by using a sociocultural theoretical approach and a critical lens to view the lived experiences of teachers and children in their own centres.

\subsection{Methodology}

This research used a national survey to assess the broader view of science in NZ ECE and a case study methodology with six ECE centres as the units of analysis. The approach of collaborative action research (CAR) was used to work collaboratively with teaching teams within each centre. The aim of CAR is to encourage critical reflection with the intention that teachers are empowered to explore a shift in their professional practice (MacNaughton \& Hughes, 2008). My role as a critical friend involved motivating teachers to contribute throughout the study. I facilitated three focus groups with each centre. I worked with teachers to set the action plan and revisited it and assessed its impact. I encouraged teachers to critically reflect on their practice through our 
discussions and their reflection journals. My weekly visits provided both observational notes and opportunities to challenge their practice, model and suggest pedagogical approaches that might enable more scientific experiences in their programmes.

\subsection{Researcher's Interest and Motivation}

I have been involved in ECE since returning to NZ 25 years ago. I worked for several years in Montessori ECE centres following my Montessori training in England. Time out of the work force to raise four children continued my passion and interest in young children and how they learn. I believe science is not just the content knowledge of science, it is also the nature of sciencing ("wondering, questioning and formulating ideas and theories" (Tu, 2006, p. 245)). Being interested in the world around you, knowing about things, how they work and why, gains an appreciation and gratitude for all that is around us. I think that wondering and a love of all that is science creates people who care.

My return to paid employment as a Lecturer in the ECE initial teaching education programme at Victoria University of Wellington (VUW) reignited my interest in science and ECE curriculum implementation through the courses I taught. I wanted to find out why the research was saying there was little science happening in ECE centres. What could initial teacher education programmes do to ensure this did not continue? I am interested in exploring what curriculum means in an early childhood context and the possible ways pedagogical approaches, curriculum documents and the environment might support teachers' scientific learning, and how they might then foster this with children in their ECE setting. I wanted my research to be empowering for the participants involved. As I did not see myself as the expert with all the answers, CAR was an appropriate methodology to explore how to increase scientific experiences within ECE, alongside teachers and children in their centres.

\subsection{Research Questions}

What resources and practices influence scientific experiences for children in early childhood education (ECE) centres?

Sub-questions: 
1. How did the process of action research, including the researcher's role, influence the occurrence of scientific experiences?

2. How do teachers' pedagogical approaches enable children's scientific experiences?

3. What are the enablers/challenges to scientific experiences in ECE centres?

\subsection{Overview of the Thesis}

This thesis is organised into 10 chapters. This chapter has outlined the context, rationale, and significance of the study, and presented the main research questions. Chapter 2 examines research exploring the theoretical influences in ECE and how this has affected the teaching of content knowledge. Studies of teachers' professional learning are reviewed to background how to best facilitate effective teacher PLD. Understanding how a sociocultural approach facilitates science learning is explored through research on pedagogical practices that enable science experiences. Research specific to science in ECE internationally and in NZ is then examined to identify the influences on teachers and their science knowledge and on the occurrence of science in ECE contexts. The chapter finishes by outlining the gap in the research that is explored in this study.

Chapter 3 discusses the methodology used in this study. Explanation is provided for the research design and the choice of an interpretive case study to examine the phenomenon of scientific experiences in ECE through a national survey and CAR in six ECE centres. The data collection and analysis methods are explained and justified.

Chapter 4, 5 and 6 provide the study's findings. Chapter 4 presents the survey results, while the following two chapters outline the findings from the centres involved in the CAR. The first three centres are discussed at the outset, with chapter 6 examining both the findings from the final three centres who participated, and the research hui ${ }^{2}$ some teachers were involved in.

The focus of chapter 7 is the process of CAR and my role as a critical friend in enabling scientific experiences in the centres. The chapter seeks to answer the first research subquestion. The second research question regarding how teachers' pedagogical

\footnotetext{
2 Meeting or social gathering of people.
} 
approaches influence the occurrence of science experiences is explored in chapter 8. Chapter 9 discusses the other enablers of scientific experiences and what challenges the teachers faced in their efforts to increase the opportunities for science in their programmes. This thesis concludes with chapter 10 which examines the major findings, implications, and contributions of this research. There are wide ranging implications for teaching practice, teacher professional learning, policy, and research. Finally, the contributions and limitations of the study are discussed with options for future research identified. 


\section{Literature Review}

\subsection{Chapter Overview}

There are six sections in this review of literature relevant to my study. I firstly discuss literature exploring theoretical influences in ECE and secondly the effect these have had on the realisation of content knowledge within ECE. The third section examines the research on professional learning and development for teachers in ECE. The sociocultural approach to teaching science in education is then explored by outlining the pedagogical practices that enable scientific experiences. The fifth section analyses the international research in science in ECE, exploring teachers' understandings and knowledge of science, plus examining what influences the occurrence of science. The final section discusses NZ based research related to science in ECE, including what influences scientific experiences for children, teachers' knowledge of science and science teaching. This section concludes with an outline of the gap in the literature in relation to scientific experiences for children in ECE.

Literature for this study was identified initially through course material provided to students in the ECE initial teacher education programme at VUW. Finding studies that had been referred to by others provided a useful pathway to previous research. The VUW library search engine Te Waharoa, plus search engines such as Google, Google Scholar and DuckDuckGo were used to explore literature and studies available internationally and within NZ. Searches were initially broad using words such as science and early childhood but became more specific as I narrowed my focus. There was a large amount of international research, so searches focussed on areas related to this study such as sociocultural theories and practices associated with scientific experiences in ECE and research methodologies that influenced teachers' pedagogical approaches.

\subsection{Theoretical Influences in ECE}

Within ECE the nature of curriculum and pedagogy is complex and is influenced by the dominant theoretical discourse of the time (Fleer, 2013; Wood, 2008). One of the most influential theories in ECE over the 20th century came from developmental theorist, Jean Piaget (Bloch, 1991; File et al., 2012; Walsh, 1991). He believed a child's early development could be mapped in stages where predetermined skills or cognitive abilities are achieved by all at the same time. Piaget also saw children as active learners, 
constructing meaning and learning from their experiences with their environment. Piaget believed they moved in and out of these experiences and that construction of meaning was an individualistic process (Hatch, 2010; Lee \& Johnson, 2007; McLachlan et al., 2013). Therefore, ECE policy and practice was based on "developmental views that ... sought to explain how children develop, how knowledge is acquired, and therefore how early childhood education should most usefully ... proceed" (Edwards, 2003b, p. 252, italics in original).

Critique of the developmental approach in ECE began during the 1990s, with many arguing that the way children explored ideas and their engagement with people and their environment needed to be accounted for when analysing children's development and learning. Cullen (1996), for example, argued the developmental ideas of Piaget did not link theory with practice easily, nor acknowledge the dynamic nature of children's learning occurring within social and cultural contexts. Similarly, Alan et al. (2007) stated a developmental approach assumes children's lives occur "as a linear movement along a biologically driven sequence of stages" (p. 15) and decontextualises the child from all that is around them. Others have also critiqued Piaget's ideas, offering an alternative way to approach early childhood practice, acknowledging the sociocultural context of children's learning and development, and reflecting the ideas of theorists such as Vygotsky, Bruner and Bronfenbrenner (Bloch, 1991; Kessler, 1991). Walsh (1991) highlighted the mismatch between the individualistic notion of development suggested by Piaget (1968) and the social process of learning children experience proposed by Vygotsky (1978) and Bruner (1996). Acknowledging the cultural and social dimensions of children's learning, Vygotsky's concept of the zone of proximal development identifies how children's learning occurs via another more knowledgeable person (Fleer \& Hedegaard, 2010). Bruner (1996) also saw learning as a social experience situated within communities where the making and sharing of meaning is done with and alongside others. He argued for interactions to occur between the child and a more experienced other, such as a teacher, who scaffolded their learning (Smidt, 2011).

The discourse of sociocultural theory as a significant influence on ECE has been discussed by many (e.g., Edwards, 2003b; Farquhar \& Fleer, 2007; McLachlan et al., 2013). The impact of Vygotsky's sociocultural view of education has meant a shift to 
seeing children's learning as coming before their development and a view that their learning happens within communities through interactions with others. A young child's learning is "therefore considered a function of social interaction contextualised according to the particular cultural setting in which it occurred" (Edwards, 2003b, p. 255). The view that content knowledge is acquired through osmosis, for example, via children's interactions in activities on their own or in play with others has been challenged (Hedges \& Cullen, 2005, 2012). The influence of the sociocultural ideas of Bruner (1996) and Vygotsky (1978) have gained traction within recent research and literature on pedagogies in ECE that seek to offer practices that introduce knowledge and ideas in authentic and meaningful ways (e.g., Anning et al., 2009; Siraj-Blatchford, 2010). These ideas in relation to science are examined more closely in section 2.5.

\subsection{Content Knowledge in ECE Curriculum}

Discussion and research have explored how domain or content knowledge can be realised within ECE settings. The role of content knowledge in curriculum in ECE is contentious and has occupied a "tenuous place in early childhood pedagogy" (Krieg, 2011, p. 47), where debate has centred around the significant influence of developmental theory on early childhood practice and curricula (Farquhar \& Fleer, 2007). Some argue this has provided a barrier to teaching content knowledge in early childhood settings as it would be developmentally inappropriate, particularly when content knowledge is seen to be only delivered in a top-down, teacher-directed, schoollike way (Bennett, 2005; Hatch, 2010; Laevers, 2005). This has led to a problematic positioning of the child and teacher in relation to content knowledge (Bennett, 2005; Krieg, 2011). Research and discourse have explored what other theoretical approaches could offer to include content knowledge in ECE (e.g., Cullen, 1996; Hatch, 2012). For many, a sociocultural framework is seen as a way to utilise content knowledge appropriately and relevant to children's interests and sits comfortably within early childhood practice (e.g., Fleer et al., 2009; Hedges, 2004; Krieg, 2011).

\subsubsection{Content Knowledge in NZ ECE Curriculum}

Researchers have identified the lack of content knowledge within curriculum documents and consequently within curriculum practice in NZ, as the hidden or null curriculum of ECE (Hedges, 2002; Hedges \& Cullen, 2005; Stephenson, 2009). When released in 1996, Te Whāriki (MOE, 1996) was seen as an innovative curriculum 
framework. The authors intended shifting the theoretical influences from a reliance on developmental ideas to an approach incorporating the ideas of multiple curricular theorists such as Piaget, Erikson, Bronfenbrenner, Bruner, and Vygotsky (May, 2009; Te One, 2013). It was deliberately broad and open-ended to include the various approaches within the NZ ECE sector, however this meant it avoided articulating how to teach or what to teach (Hedges \& Cullen, 2012). Due to the non-prescriptive nature of the first edition of the ECE curriculum the lack of emphasis on content knowledge left the practice of teaching subject content knowledge open to interpretation (Garbett \& Yourn, 2002; Hedges, 2004; Nuttall, 2005a).

Reflecting on the 1996 version, Nuttall (2002) noted the complexity in implementing Te Whāriki and the lack of clear content directives meant there had been a heavy reliance on ECE teachers' understanding of scientific concepts. This has meant a reliance on teachers interpreting how curriculum can be enacted, with Nuttall (2002) arguing their ability to successfully support children's scientific or content learning was impaired. Nuttall (2005b) argued teachers' theory of practice did not reflect "what they actually did from day to day" (p. 12, italics in original). Nuttall proposed this was an area requiring further research; specifically identifying how teachers use Te Whäriki to support or affect children's learning.

In the revised Te Whäriki, the definition of curriculum has remained much the same and has been interpreted "broadly" as including "all the experiences, activities and events, both direct and indirect, that occur within the ECE setting" (MOE, 2017, p. 7). This provides no clarity about what constitutes the contents of all experiences, activities, or events, although by reducing the number of learning outcomes from 118 to 20 there is the intention to "provide a focus for learning and development in young children" (McLachlan, 2017, p. 10). This change was meant to show teachers more clearly where they could bring content learning into their practice. As Smorti (2005) put it, research based on the 1996 edition found some early childhood student teachers asking if they were "allowed to do science" in their centres, suggesting science was not a part of the ECE curriculum (p. 13).

There is an intention in the revised Te Whäriki (MOE, 2017) for scientific learning to occur through the Exploration strand. For example, the goals indicate children will be expected to "learn strategies for active exploration, thinking and reasoning" and use 
working theories to make sense of their world (p. 47). The learning outcomes in both the Belonging and Exploration strands are linked to the NZ Curriculum: Science learning areas (MOE, 2007, pp. 53-57). While the 1996 Te Whāriki reflected the increasing influence of sociocultural and constructivist perspectives, it was in its implementation that the challenges emerged (Nuttall, 2013). As Te One (2013) noted, the discourses within NZ ECE were centred around "how to recognise learning, what to record, and how to document" (p. 25, italics in original). One significant thread throughout the analysis of the implementation of Te Whāriki has been exploring the role of content knowledge in ECE and the pedagogy to best extend children's learning (e.g., Fleer et al., 2009; Hedges \& Cullen, 2012; Zhang \& Birdsall, 2016). Research over the last 20 years was incorporated into the revised edition resulting in a stronger sociocultural position. In the Exploration strand there is also more emphasis on content knowledge and supporting children's ways of gaining knowledge through their use of working theories, their critical and scientific thinking (McLachlan, 2017; MOE, 2017).

Being left to negotiate the intentions of the curriculum means teachers need to interpret what and how content knowledge could occur in practice, often resulting in planned experiences only (Garbett \& Yourn, 2002; Hedges, 2002). It has been suggested that philosophy, beliefs, confidence in and understanding of content knowledge play a significant role in how and how much teachers recognise, and support children's interests and extend their conceptual learning (Alexander, 2000; Hedges, 2002; Zhang \& Birdsall, 2016). Very little research has investigated how this may have changed with the revised Te Whāriki (MOE, 2017). A qualitative interpretivist case study by Hedges and Cooper (2018) did explore teachers' knowledge and skills in their engagements with children's interests. They made an argument for a relational play-based pedagogy that emphasises the teachers' expertise in supporting children's learning through their own knowledge and their relationship with children. In their study teachers from two mixed-age ECE centres worked with two university researchers to examine teachers' knowledge and decision-making when supporting children's interests and inquiries. However, as this study investigated the practice of teachers in only two ECE centres it is hard to identify if the recent update of Te Whāriki has influenced teachers' practice in what and how content knowledge in ECE could occur, or how teachers implement the expectations of the revised version across the rest of the ECE sector. Additionally, the reviews by ERO did not go beyond asking how confident teachers feel about 
implementing Te Whāriki (MOE, 2017). Their studies did not explore what curriculum might look like in practice.

McLachlan $(2017,2018)$ believes the key change for teachers in the revised Te Whäriki to a more intentional role will hopefully provide further direction for curriculum implementation. However, initial data from a recent study (McLachlan, 2019) shows some teachers felt any change to their practice was unlikely. Her study involving a survey with 43 respondents and interviews with 10 educational leaders explored teachers' responses to Te Whāriki (MOE, 2017) in relation to literacy. Data revealed teachers were only just beginning to explore the revised curriculum and that they had yet to "consider what types of pedagogies and assessment were needed for implementation" of Te Whāriki 2017 (2019, p. 5). Perhaps the relational pedagogy that enabled teachers to support children's working theories and conceptual knowledge explored by Hedges and Cooper's (2018) research indicates that some teachers are reflecting the intentional practice expected of Te Whāriki 2017 but as McLachlan's (2019) study indicated, not all teachers are.

The fraught position of content knowledge in ECE practice has been discussed in this section and research has identified the challenges for ECE teachers including content knowledge in their practice. The influence of developmental theory has meant content knowledge has been viewed by some as developmentally inappropriate for young children (Hatch, 2010). Implementing a non-prescriptive curriculum has relied on teachers' content and pedagogical knowledge to interpret how to incorporate content knowledge, however this was often only in planned and inauthentic ways (Garbett \& Yourn, 2002; Hedges, 2014; Nuttall, 2002). Others have therefore argued for a sociocultural approach to teaching content knowledge in ECE (Fleer \& Pramling, 2015).

\subsection{A Sociocultural Approach to Science Education}

This section discusses sociocultural pedagogical approaches identified in research that facilitate content knowledge such as science in ECE. These practices allow teachers to view children's acquisition of scientific knowledge within their cultural and social context. As discussed in section 2.3, research exploring the implementation of curriculum and content knowledge such as science highlights the importance of not only what teachers cover in their programmes but how they enact curriculum alongside 
children, their families, and the community. According to Fleer and Pramling (2015) the previous 30 years of literature on science education for children has been influenced by Piaget's developmental theories and constructivism. Children's views of science were considered to be at an intuitive level and therefore what to teach them was based on what they were perceived to understand or know. These authors have therefore suggested there needs to be a shift in science education for young children. Moving from the view of children's construction of knowledge as one where they learn in isolation through discovery in their environment to one where learning is seen within a social context. Such as the "cultural-historical reading of the thinking and learning child, where we go beyond the lone child's construction of knowledge, and consider the relations between the child and their social and material environment, where the teacher plays an important role" (Fleer, 2015, p. 9).

\subsubsection{Cultural-historical View of Science Learning}

A cultural-historical perspective of science views it as concepts and knowledge that are shared across people who collectively contribute to its formation (Fleer \& Pramling, 2015). This sees science education as a relationship between the child and teacher, concepts, and contexts and where the learner is influenced by, but also influences, the learning (Fleer \& Pramling, 2015). A cultural-historical or sociocultural approach (which both foreground children's development within family and community interactions) to the implementation of the ECE curriculum has been outlined by McLachlan et al. $(2013,2018)$, who argues that both the Australian and NZ ECE curriculums view children's learning as a process that involves children's interactions with people, places, and things, and these connections are mediated by teachers to help children acquire content knowledge and concept formation. The Early Years Learning Framework (EYLF) (Department of Education Employment and Workplace Relations (DEEWR), 2009), Australia's first national curriculum, and the revised Te Whāriki (MOE, 2017) highlight the role of the teacher in that learning, with both curricula identifying teaching practices to be intentional in their engagement with children (Leggett \& Ford, 2013; McLachlan, 2017).

Both Fleer (2015) and McLachlan et al. (2018) refer to Vygotsky's work on concept formation. Vygotsky (1987) states that concept formation occurs for children when mediation happens between the two levels, the everyday level and the scientific level. 
Children engage with their world directly and form everyday concepts and acquire scientific concepts through the help of more capable others, such as teachers.

Essentially children's development cannot be separated from the context in which they live and interact (Anning et al., 2009). Likewise, Lemke (2001) argued that science education should be viewed as a social activity "within institutional and cultural frameworks" (p. 296), while others have identified the most effective ECE programmes to be those that support the development of skills and dispositions as well as incorporating content knowledge and the learning of new concepts through a sociocultural framework (Hyson, 2003; Nyisztor \& Marcus, 2008; Robbins, 2005).

Drawing on Vygotsky's $(1978,1987)$ concepts of zone of proximal development and his work on concept formation, as well as Bruner's $(1983,1996)$ ideas of social acquisition of knowledge and scaffolding, many have argued for a shift towards sociocultural teaching practices that enable teachers to include content knowledge such as science in authentic and meaningful ways. The following section outlines the pedagogical practices that have been shown to best facilitate science experiences for young children.

\subsubsection{Pedagogical Practices}

Investigating how to implement curriculum, include content knowledge and exploring which practices support children's learning has been well researched (e.g., McLaughlin et al., 2015; Papatheodorou \& Moyles, 2008; Sylva et al., 2004). The pedagogies identified fit within a sociocultural approach to teaching and include many of the practices outlined in the following sections. In addition, many of these practices have been shown to be effective in facilitating scientific learning with children in ECE.

\section{Funds of Knowledge.}

Research examining the role of families and their experiences has been identified as funds of knowledge. This concept was introduced by Gonzalez et al. (2005) from their study where data from children's household background was used to influence how teachers instructed in their classrooms. They argue that children's life experiences have given them knowledge and ways of thinking (or funds of knowledge). Awareness of children's families and their backgrounds can help teachers better support children and build authentic partnerships with their families and communities. Working from a sociocultural perspective Hedges (2007) found that teachers needed to understand children's family and community experiences or funds of knowledge to better 
appreciate children's interests and know how best to support their learning. Her PhD explored pedagogy and interest-based curriculum in two ECE centres. A community of inquiry was formed to investigate how teachers co-construct curriculum with children. Hedges (2007) highlighted the value in using a funds of knowledge framework to help teachers extend the centre's curriculum and make connections with children and their families to "intentionally [co-construct] meaningful inquiry that links to their prior knowledge and interests" (p. 283).

\section{Working Theories.}

In both her PhD and a later study Hedges $(2007,2011)$ investigated pedagogical approaches to incorporate authentic scientific learning into ECE settings. Her $2007 \mathrm{PhD}$ explored ways teachers and children co-construct learning. It also raised the concept of working theories which she explored further in her 2011 study. Within Te Whāriki (MOE, 2017) working theories are used to recognise children's understandings, and how they use their existing knowledge to make sense of new experiences. The term originated from Claxton's idea of “'minitheories' used to interpret [how children gain] new information in light of current experience and understandings" (1990 as cited in Hedges, 2011, p. 273). Hedges' (2011) qualitative study highlighted the importance of working theories in practice within ECE settings. Her "work-in-progress definition" of working theories was that they can be seen "as ways children process intuitive, everyday, spontaneous knowledge, use this to interpret new information, and think, reason and problem solve" (p. 284) to connect their new understandings to experiences. The 15 teachers involved in two ECE centres in the study identified working theories as children's "snippets of knowledge" and their way to make connections between occurrences and ideas (p. 271). By focussing on children's working theories, teachers shifted their pedagogical practices towards a richer engagement in children's scientific thinking and learning.

\section{Relational Pedagogy.}

Pedagogy in NZ, influenced by Te Whāriki (MOE, 1996, 2017), is strongly relationshipsbased and relational pedagogy is highlighted as key to how teachers support children's learning (Papatheodorou \& Moyles, 2008; Peters, 2008). Relational pedagogy is defined by Papatheodorou (2008) as knowing oneself and others, oneself in relation to others and knowing that learning is shaped by others, culture, time, and place. While reciprocal 
and responsive relationships are a core part of teachers' pedagogy, they do not necessarily translate into intentional teaching practices that best support children's learning (McLaughlin et al., 2016). A similar finding was found earlier by Meade et al. (2012) who carried out two collective case studies involving five centres each; one case being centres with $100 \%$ qualified teachers and the other with $50-79 \%$ qualified teachers. The study used a mixed-methods approach to investigate quality teaching practices, features of children's learning and family participation in two differing cases. They found that while all 10 centres involved identified respectful relationships as part of their philosophy of practice, episodes of sustained shared thinking or teacher mediated concept learning was more likely to occur in centres with all qualified teachers.

Hedges and others have argued that teachers can better support children's working theories and make links between their everyday knowledge and scientific conceptual knowledge, through reciprocal and responsive relationships and by understanding the funds of knowledge that might influence children's interests (Hedges, 2007; Hedges et al., 2011). Hedges and Cooper (2018) contend relational play-based pedagogy should be a core practice in ECE. They explain "teacher knowledge, engagement and expertise are positioned centrally in the sophisticated blending of play, teaching and learning as a core practice" (p. 380). This approach draws on teachers' knowledge and skills, their indepth understanding of children's interests and their funds of knowledge through the strong relationships they have with children and their families.

\section{Sustained Shared Thinking.}

The notion of teachers as active participants in creating and being part of children's learning experiences has been argued for by many researchers both in NZ and internationally (e.g., Batchelar, 2016; Fleer \& Hedegaard, 2010; Meade, 2002). A 5-year longitudinal study in the United Kingdom (UK) by Sylva et al. (2004) found the role of the teacher as an active contributor to constructing curriculum with children created the most effective outcomes for children. The Effective Provision of Pre-school Education (EPPE) project explored the effects of pre-school provision for 3,000 children. They also investigated the features of effective ECE pedagogy in 12 case studies within settings providing positive outcomes for children. Specifically, they identified the blend of teacher-initiated experiences with child driven activities 
provided opportunities for interactions of sustained shared thinking between teachers and children, which were found to be the most effective for children's learning. The EPPE project team defined sustained shared thinking as occurring when

two or more individuals 'work together' in an intellectual way to solve a problem, clarify a concept, evaluate an activity, extend a narrative etc. Both parties must contribute to the thinking and it must develop and extend the understanding. (p. vi)

Drawing on this research Siraj-Blatchford (2008) has argued for teaching to be "considered a legitimate aspect of early childhood professional practice" (p. 155). The concept of sustained shared thinking as a mechanism for teachers' engagement with children has been identified as a significant factor in children's scientific concept formation (Fleer \& Hedegaard, 2010; Fleer \& Pramling, 2015; Siraj-Blatchford, 2007).

\section{Intentional Teaching.}

Epstein (2014) argues that the concept of intentional teaching originated through finding a balance between "child-initiated learning (passive teacher) against adultdirected instruction (scripted lessons)" (p. xii). In addition, the idea came from research identifying the value in teachers supporting children to follow their interests and to assist them through teacher-initiated activities (National Research Council et al., 2001). Within the United States of America (USA) there are several curriculum documents, research-based frameworks, or position statements from national organisations ${ }^{3}$ that provide guidance on how to use intentional teaching practices (McLaughlin et al., 2016). One USA study by Burns et al. (2012) explored intentional teaching within a community Head Start programme and its features. They define the practice as providing

learning opportunities designed to meet the individual needs, interests, and prior knowledge of all children ... through reciprocal, codirected conversation between teachers and children ... with all children ... on a consistent basis (high quantity as well as high quality). Children's ideas are developed and thinking demanded using rich curriculum content. (Burns et al., 2012, pp. 281, italics in original)

\footnotetext{
${ }^{3}$ Such as the National Association of Education for Young Children (NAEYC) statements on Developmentally Appropriate Practice (DAP).
} 
Similarly, Australia's EYLF (DEEWR, 2009) clearly articulates intentional teaching as a key part of ECE practice (Leggett \& Ford, 2013). Following the release of the EYLF several studies have investigated the role of teachers and teaching in ECE. For instance, two studies have assessed the role of intentional teaching in facilitating content knowledge in mathematics and science. Thomas et al. (2011) used a post-structural theoretical perspective to analyse two ECE teacher's conversations about how they incorporated children's play and intentional teaching practices to introduce mathematics concepts in their centre. Their findings indicate that teaching practices in relation to mathematics "place intentional teaching as an essential element of a pedagogy based on learning through play" (p. 74).

Another study, a curriculum investigation of two curriculum exemplars conducted in two ECE centres, explored how a teaching approach called Slowmation could enable intentional teaching practices. Fleer and Hoban (2012) investigated curriculum development alongside the pedagogical approaches used to effectively implement Slowmation. In one centre in Singapore they examined observations and photo documentation of interactions between one teacher and a 4-year-old child. In an Australian ECE centre they captured video footage of interactions between two teachers and 24 children in small groups of two-three creating a Slowmation as an assessment of previous science experiences they had done. Fleer and Hoban argued that Slowmation offers a way, through digital animations, for teachers to use intentional teaching to introduce new ideas to children, and an "opportunity for both children and staff to become aware of scientific concepts to help them explain their world" (p. 69).

Additional studies in Australia have identified the complexities and challenges in intentional teaching practices fitting within child-centred play-based programmes (e.g., Leggett \& Ford, 2013; Lewis et al., 2019). Leggett and Ford (2013) investigated six teachers' emerging identities as intentional teachers within three ECE centres. Through focus groups, field notes and reflective journals, they found teachers struggled to articulate what intentional practice meant for their role and often noted they were only intentional with groups of children rather than with individual children. In a study of two teachers in one ECE centre, Lewis et al. (2019) identified that teachers found it difficult to teach intentionally within a child-centred play-based programme. Data from video observations and interviews showed that teachers "nudge[d] [children] with 
open-ended questions but [did] not act as the 'more capable other' to enrich their understanding" (p. 12). They concluded that their study highlighted the tension between the passive or "below" position of teachers suggested in developmental theory and the more active or "above" position required to teach children conceptual content knowledge such as science (p. 17).

Similarly, Kilderry (2015) analysed the discourse within interview transcripts of three teachers involved in a study in 2005. The original study was set in a time when there were no curriculum requirements, and teachers could decide the centre's curriculum content and implementation. The 2015 study investigated how the dominant discourse of the time, Developmentally Appropriate Practice (DAP), influenced teachers' decisionmaking. Kilderry found the three teachers either legitimated, marginalised, or silenced teacher directed practice due to their belief in DAP being the most appropriate practice in ECE. Kilderry refers to Leggett and Ford's (2013) study and argues that acknowledging the influence of dominant discourses in ECE might help understand the reluctance of Australian ECE teachers to embrace the intentional teaching practices being asked of them by the EYLF. This is similar to the influence of Piaget's developmental theory in ECE and the hesitancy of ECE teachers to adopt sociocultural practices in their centres (see section 2.2) and may also account for the slow shift to intentional teaching practices following the release of Te Whāriki in 2017 (McLachlan, 2019).

As Te Whāriki (MOE, 2017) takes a stronger sociocultural view of learning, drawing on "Vygotsky, Bruner, Wertsch, Wenger, Rogoff and others" (McLachlan, 2017, p. 9), it places a stronger emphasis on the role of the teacher, seeing them as intentional in their approach to children's experiences in ECE (McLachlan, 2017; McLachlan et al., 2018; McLaughlin \& Cherrington, 2018). There is therefore a clear opportunity to explore if and how intentional teaching strategies can be incorporated into NZ ECE practice.

Recent studies support intentional teaching in NZ ECE settings. Batchelar (2016) investigated teachers' understanding of intentional teaching and what elements of their practice could be seen as intentional. Her use of constructivist grounded theory and data from her study developed a theoretical model of intentional teaching. She found that teachers demonstrated intentional teaching in planned and spontaneous situations and their intuitive responses to children's interests was "an holistic and dynamic 
process" (p. ii). Her study also revealed that teachers initially struggled or were hesitant to describe their practice as teaching. Involvement in the study meant they became aware of intentional teaching and more confident to describe their practice as intentional.

Cherrington's (2011) qualitative multiple-case study also found teachers struggled to articulate their reflections about their teaching practice and their reasons for the decisions they made in their interactions with children in their care. In group interviews 15 teachers from three ECE centres were asked to describe their practice and their thinking while watching a video of their interactions with children. Teacher and researcher journals, field notes and centre documentation were also analysed. They showed teachers held significant knowledge of children, and relational pedagogy was central to their practice. However, like Leggett and Ford's (2013) study, teachers realised it was difficult to reflect on their own teaching practice and articulate the teaching strategies they used.

Cherrington and others have therefore argued for teaching to become more visible and for intentional teaching practices to be used to support rich curriculum experiences for children (Cherrington, 2016, 2018; McLaughlin et al., 2016; McLaughlin \& Cherrington, 2018). Through a Teaching Practice project, McLaughlin et al. (2015) have suggested a list of practices that "promote children's learning and socio-emotional competence" in NZ ECE centres (p. 32). They found the initial phase of the study of 24 participating teachers from 10 different kindergartens identified building positive relationships with children and families as an essential practice for teachers which required active and intentional actions from teachers to form these relationships. Both McLaughlin and Cherrington (2018) have since argued for intentional teaching practices to "blend the use of learning experiences guided, led, or mediated by adults, peers and children to offer rich curriculum experiences" (p. 36).

The value of intentional teaching was also highlighted in an earlier study by Robinson and Bartlett (2011) who provided an account of their experiences with stone carving through a Teaching and Learning Research Initiative (TLRI) ${ }^{4}$ project. This larger project explored children's continuity of learning over time, looking at key learning

\footnotetext{
${ }^{4}$ TLRI is the Teaching and Learning Research Initiative who, funded by the NZ Ministry of Education, undertake various research projects in education in NZ.
} 
competencies. Within this Robinson and Bartlett discuss "Stone Crazy"; a "centre storyline" which outlines the succession of teaching and learning experiences connected by a theme (p. 10). The project began with an unusual stone found in the centre grounds which provoked an interest into what was inside. This investigation developed over time with a variety of experiences about carving. The intentional teacher and intentional learner were identified as key concepts that occurred often throughout the project. They argued that the position teachers take and how they view themselves in the experience "influences the children's experiences and learning outcomes" (p. 11). Interestingly, analysis by Robinson and Bartlett (2011) identified provocations as part of the intentional teaching strategies they used to sustain both children's and teachers' interest in the inquiry. Provocations offered a way for teachers to provide support intentionally and thoughtfully to children's interests or introduce new ones.

\section{Provocations and Incidental Sciencing.}

Provocations are a teaching strategy used in Reggio Emilia ${ }^{5}$ settings to prepare activities that provoke a response from children through interacting with resources, having conversations, asking questions, and exploring ideas (Biermeier, 2015; Edwards, 2002; Kashin, 2017). Provocations are used to invite children to explore ideas further (Edwards, 2002), and to introduce new ideas (Vecchi, 2010). Kashin (2017) explains that the term provocation can be used to describe activities or materials set up on tables, although she contends activities are invitations until they provoke a response from children and then they become provocations. Supporting children's interests has been a key practice in ECE curricula and pedagogy (Birbili, 2019; Hedges \& Cooper, 2016) and in the Reggio Emilia approach, the curriculum emerges from children's interests and with an emphasis on relationships (Biermeier, 2015; Davis \& Tsung-Hui, 2008). The environment is seen as the third teacher and is flexible and reflective of children's interests, inspiring creativity, and imaginative thinking (Biermeier, 2015).

Stegelin (2003) has argued for the integration of key concepts from the Reggio Emilia approach, identified as: the view of the child as a learner; the teacher-child relationship;

\footnotetext{
5 The Reggio Emilia approach is child-centred, emergent curriculum that uses self-directed, experiential learning in relationship-driven environments.
} 
an integrated curriculum based on project work; and documentation of children's thinking, as being consistent with an effective science programme in ECE.

Additionally, an ethnographic study by Inan et al. (2010) examined how a Reggioinspired ECE centre provided science experiences. Data from interviews, observations, documentation, and field notes of one centre with 18 children, 10 teachers and a programme director were analysed through different interpretive lenses. They found that opportunities for science experiences came through teachers' planned events such as provocations, children's play and interests and through what they termed "serendipitous events (e.g., unexpected changes in weather or one day finding a lizard in the classroom) [became] catalysts for science learning" (p. 1196). This resembles Neuman's (1972) concept of incidental sciencing. Neuman used sciencing to identify "science-related, process-oriented activities that are appropriate for young children" (p. 215). He categorised three types of sciencing: formal or planned activities, informal, such as individual open-ended exploration, and incidental. Neuman's (1972) idea of incidental sciencing is described as experiences that were:

unpredictable and open. It is not an everyday happening. It is not planned by the teacher. It is the result of some occurrence that has captured the imagination of one or more children and is capitalized upon by the alert teacher. (p. 224)

This concept was used by Tu (2006) and explored further by Fleer et al. (2014) in their research. Both studies are examined further in sections 2.6.2. Capturing opportunities provided by incidental sciencing or serendipitous events, such as an animal in the centre playground became valuable scientific learning occurrences when supported by a teacher with a sciencing attitude (Fleer et al., 2014).

\subsection{Teachers' Professional Learning in ECE}

The theoretical shift in ECE practice outlined in section 2.3 from a developmental to sociocultural pedagogy and the expectation for content knowledge to be included in teachers' practice in ways that fit a play-based, child-centred approach, requires teachers to critically reflect on their role and how it might change. The role of PLD to support teachers in implementing theoretical and curriculum changes are therefore discussed in this section. 
Research into NZ teachers' shift in practice through PLD in ECE was explored by Mitchell and Cubey (2003) in their Best Evidence Synthesis. They identified eight characteristics of quality PLD, including participants selecting their own goals and intentions, investigating pedagogy in their own settings, and engaging in critical reflection which brings about an awareness of the teachers' own thinking and actions and therefore a change in their practice. Mitchell and Cubey (2003) discussed the value of outside researchers' involvement in PLD or action research to help participants explore data to a greater depth and ensure a change in practice. This influenced the decision to use action research in the MOE funded Centres of Innovation (COI) programme (discussed further in section 2.7.2). Researchers ("research associates") worked in partnership alongside teacher-researchers in the centres (Meade, 2010, p. 3). Most of the research associates came from universities, their roles were collaborative in nature, and they helped with ethics applications and provided significant support through the first research cycle and often around dissemination of the research findings (Meade, 2010).

A range of literature in ECE discusses the role of a facilitator in ensuring that PLD is successful. For example, both Mitchell and Cubey (2003) and Cherrington and Thornton (2013) stated the importance of an outside facilitator, with Cherrington and Thornton noting the importance of "providing support and feedback, and challenging practice" (p. 128). Cherrington and Thornton contend that a trusting relationship between a facilitator (in bringing in new ideas) and a collaborative community of learners (to support and challenge each other) is vital to a change in teachers' practice. Goodfellow and Hedges (2007) also argue for an external facilitator in practitioner research as they can facilitate critical reflection and inquiry. Studies that had researchers working alongside teachers examining their practice helped guide the methodological decisions in this study. Therefore, the remainder of this section provides an outline of studies that involve action research in science or CAR and where the researcher has reflected on their role in the research process.

Two Canadian studies involve researchers reflecting on their role as university-based facilitators in action research studies looking at primary or secondary teachers' practice in science or technology. Pedretti (1996) was involved with an action research group of six teachers working collaboratively in science, technology, and society education. The 
group met every 2-3 weeks over a period of 8 months. The intention was to provide a lengthy timeframe to encourage teachers to critically reflect on practice, beliefs, theories, and curriculum implementation. Pedretti (1996) revealed that her role was "multi-layered ... a facilitator, a critic, a historian, a resource person, a support person and an 'expert'" (p. 310). She felt that she needed to provide guidance to the group and give them a "sense of purpose" (p. 311), to help them work out what they wanted from the process but also empower them to be active participants in the study.

Similarly, a qualitative case study by Goodnough (2003) outlined her critical selfreflection on her role as a researcher/facilitator in a CAR group of four primary and secondary teachers. The group were exploring Gardner's multiple intelligences theory and how it could make science teaching and learning more effective. As with Pedretti (1996), Goodnough found she adopted a variety of roles and identified the four key roles in her study as facilitator (the organiser), supporter (an encourager), challenger (to critique and stimulate reflection), and teacher (role-modelling and sharing experiences as a teacher). Reflecting on her role and the process of CAR specifically, she argued that university researchers and teachers critically reflecting together, exploring informed action and change in practice, can result in significant shifts in pedagogy and contribute to education knowledge.

Two additional studies explored the role of the researchers/facilitators in CAR projects in ECE. The first by Avgitidou (2009) discussed the processes she used to support a year-long CAR project in Greece with two teachers from two different kindergartens (this project was part of the wider Socrates programme ${ }^{6}$ investigating relational approaches to enhance social inclusion). Teachers were asked to reflect on their practices through three individual interviews and five joint meetings and "generate good practices regarding children's social inclusion and cooperative learning with the support of an outside researcher" (p. 588). Her and the teachers' reflections via interviews, classroom observations and diaries of the CAR process were analysed and Avgitidou concluded that both her role and the teachers' roles changed often according to the needs at the time and required flexibility. Additionally, she and the teachers

\footnotetext{
${ }^{6}$ Socrates project was run in six countries; England, Italy, Greece, Finland, Spain and Sweden, and involved a survey in the first year of the quality of peer-peer and teacher-peer interactions and a study in the second year of teacher's beliefs and practices relating to relationships and cooperative learning.
} 
needed time to build collaborative relationships for there to be equality in their roles and participation and for teachers to feel empowered.

In the second study, Sigurdardottir and Puroila's (2018) CAR project was carried out in two Icelandic ECE centres over 2 years. The study was part of a larger project of action research in five Nordic countries. Sigurdardottir worked with one of the centres in Iceland and analysed her own self-narratives, four teachers' diaries, and recordings of focus groups to identify the role she, as the researcher, played through the CAR process. She identified three perspectives on the role; it sits in a third space of emotional ups and downs, it is somewhere between an insider and an outsider, and there is a need to manage the tensions and challenges in their relationship with teachers and between their differing expertise.

A study in Canada involved the analysis of 14 case studies from a large-scale, multi-year CAR project of university researchers and teachers investigating teacher-selected themes. Over 2 years, the study by Bruce et al. (2011) included six university researchers and 61 teachers over 14 sites. Teacher researchers focussed on collecting data related to their topic while university researchers gathered data to explore the value of CAR. Using final reports, journal entries, focus groups, field notes, questionnaires, and video from each site, they examined and compared the data with data from the other cases to identify what collaboration and collaborative relationships looked like in successful CAR. The identified outcomes from the research were similar to those of studies discussed previously. The CAR studies saw an increase in confidence and efficacy for teachers involved and a shift in their perspectives and practice. The university researchers learnt how to support teachers authentically and in turn validate their practice. Overall, the benefits of CAR were found to be a shared commitment and openness to each other through close and trusting relationships built over time and with shared interests. From the cross-case analysis and findings Bruce et al. (2011) developed the diagram (Figure 3.1) shown in Chapter 3, which is discussed further there and provided guidance for this CAR study.

The studies outlined in this section indicate the value of PLD to facilitate critical reflection and the exploration of alternative approaches for teachers to enrich their practice. Irrespective of whether it occurs through a PLD approach or an action research 
method such as CAR, it seems the role of a facilitator or researcher working alongside teachers is significant in aiding shifts in their practice.

\subsection{Science in ECE Internationally}

Internationally there is a growing number of studies investigating science in ECE. The international research can be categorised into two broad areas. Studies that investigated initial teacher education programmes, knowledge and competencies and the influence of this on the provision of science in ECE settings are discussed first. Secondly studies that explored what influences the occurrence of science in ECE are examined including studies that identify how environments and science resources afford scientific experiences and how teachers' pedagogical approaches facilitate science.

\subsubsection{Teachers and Their Science Learning}

Much research has explored how teachers' knowledge, expertise and training influenced how often and how they provided science experiences in their settings as well as the importance of teachers' knowledge of how to do science (e.g., Abd-El-Khalick et al., 1998; Kallery \& Psillos, 2001; Piasta et al., 2015). As Katz states in the foreword of Trundle and Saçkes's (2015) edited book, Research in Early Childhood Science Education, the research shows ECE teachers would "substantially improve the effectiveness of their science teaching" (p. vi) if their initial teacher education had given them a more thorough understanding of science and science education.

Research that investigated teachers' initial teacher education programmes, PLD and their perceptions of science and philosophies of practice in science learning, has indicated the value of explicit instruction in understanding the nature of science (NOS) and the practice of teaching science in ECE. The NOS is seen as "the epistemology of science, science as a way of knowing, or the values and beliefs inherent to the development of scientific knowledge" (Abd-El-Khalick et al., 1998, p. 418). These authors elaborate that it is also an understanding of how science knowledge is created and becomes accepted, and that it is not permanent but often challenged and changed.

Studies have shown that teachers' beliefs about teaching, children and curriculum influenced their practice of science teaching, and this then influenced their understanding of the NOS. Studies undertaken by Waters-Adam (2006) and Akerson et 
al. (2008) sought to increase teachers' understanding of the NOS and investigate how this affected their practice of teaching science with the provision of support through an action research study and during pre-service courses respectively. Through action research with four English early years teachers, Waters-Adam (2006) noted that the teachers gained confidence in teaching science when there was a correlation between their values about how to teach science, their understandings of the NOS, and their pedagogical approach in general. Similarly, Akerson et al (2008), in their survey and interviews of 14 preservice ECE teachers, found the student teachers' own cultural values had a significant impact on their understanding of the NOS. For example, if their own cultural values conflicted with what is important for teaching science this could then influence how they taught science in practice.

Research has shown PLD for teachers in both science knowledge and how to teach science influences an increased implementation of scientific learning opportunities in their practice. For example, an Australian study by Watters et al. (2001) found there was a positive effect for teachers from PLD covering scientific literacy and constructivism. These researchers explored the value of a PLD initiative to enhance ECE teachers' understandings of science concepts and how to teach science using a constructivist approach. Findings from an open-ended questionnaire of 192 teachers indicated the teachers believed science should be taught through a child-centred approach with investigative activities, and that their own knowledge of classroom strategies, learning in science and general understanding of science increased after the PLD. Watters et al. (2001) therefore argued that PLD results in teachers becoming more reflective on their practice as well as effective teachers of science.

Similarly, a Turkish study undertaken by Bulunuz (2012) investigated 94 preservice teachers' attitudes towards teaching science. Through questionaires at the beginning and end of a science methods course they found that specific instruction through the course showing teachers how to integrate science into playful activities improved both their attitudes and their understanding of science, and this translated to their practice. A more recent study in the USA by Piasta et al. (2015) provided 64 hours of PLD over 5 months in either maths or science to 23 teachers. They found that providing PLD in how to teach science or maths for ECE teachers improved the provision of learning opportunities in science, but not maths, for the children they taught. 
Research investigating ECE teachers' confidence with science and teaching science has identified that their attitude towards, their perceptions of science and their philosophy towards scientific learning affected how they fostered children's learning in science. For example, Kallery and Psillos (2001) investigated how Greek ECE teachers' knowledge of science affected their teaching of science in the classroom. They found the 103 teachers they studied had limited knowledge of or understanding of science concepts and this influenced the lack of, and even incorrect, scientific concepts in the activities they provided for children. This is consistent with more recent research on how teachers' lack of knowledge in teaching science and in particular their confidence in science affects their ability to explore science to any depth, whether they believed science was important to teach or not (Reinoso et al., 2019; Spektor-Levy et al., 2013; Torquati et al., 2013). For instance, the study by Spektor-Levy et al. (2013) explored how teachers' attitudes to science would influence how they engaged with children's scientific curiosity. A survey of 146 teachers found that while they thought science was important in ECE, most felt they did not have sufficient science knowledge to teach it well. SpektorLevy et al.'s (2013) findings suggest the need to encourage "teachers to engage children in scientific activities in a way that will nurture their natural curiosity" (p. 2226).

Additionally, some teachers have rated science as the least important area of content knowledge for children to experience and felt a lack of confidence in implementing these experiences (Torquati et al., 2013). More recently Reinoso et al. (2019) found the occurrence of science in ECE centres, as observed by 83 student teachers on their practicum, were $60 \%$ unintentional. The low recording of planned science activities, Reinoso et al. suggests, indicates teachers choosing not to plan activities that explore science concepts further because they do not feel confident enough or do not have the knowledge to do so.

An interesting contrast from an earlier study by Fleer (2009a) revealed that the teachers' philosophy of how children learn, more than their confidence, significantly contributed to their practice in teaching science. Fleer's (2009a) study highlighted a common factor in the other studies; that teachers' beliefs in how children learn in ECE influences their receptiveness to exploring and teaching science. Once teachers' attitude to science teaching shifted, their interest in and knowledge of science and scientific experiences seemed to increase, and this is then linked to their confidence in science. 


\subsubsection{Influences on the Occurrence of Science}

Other studies have explored what conditions within ECE environments are needed to foster scientific learning for children. Research has focussed on how much science learning is occurring in ECE settings and how much teaching of science happens. Studies indicate ECE teachers spend most of their time involved in non-science activities. For instance, the following two studies assessed the amount of scientific learning occurring using video. Tu (2006) videotaped ECE teachers in 20 classrooms of 13 ECE services in the USA. Using three checklist instruments developed for the study: science materials/environment checklist; science activities checklist; and a teacher classroom/sciencing form, they found teachers were engaged in activities mostly unrelated to science activities (86.8\%). Of these, 4.5\% were related to formal sciencing, and $8.8 \%$ were related to informal sciencing. More recently, in Ohio, Piasta et al. (2014) identified an average of 26 minutes (or $24.17 \%$ of the total instructional time) of science learning opportunities within 65 videotaped ECE environments. However, recordings showed the range could be anywhere from 0-102 minutes of science learning. This study used the Early Learning Math and Science (ELMS) coding scheme, designed for this project, to identify "the amounts and types of mathematics and science learning opportunities afforded" in the classrooms (p. 450). Interestingly this study was the initial phase of the PLD research mentioned earlier by Piasta et al. (2015) and teachers in this study went on to participate in specific math and science PLD, although they did not know what that would involve while the data was collected.

A study by Saçkes et al. (2011) analysed the frequency and duration of teachers' teaching science using data of 8,642 children's science achievement from the Early Childhood Longitudinal Study-Kindergarten (ECLS-K) cohort. The ECLS is an active longitudinal study in the USA undertaken by the National Center for Education Statistics (NCES). The ECLS-K is one of three cohorts, specifically the 1998-99 kindergarten class. This study collected data through direct assessment of children, parent interviews, questionnaires of teachers, special education teachers and school administrators and analysed school records and facilities. Using a sample of data that only included children in their first year at kindergarten and who remained there for the study, findings indicated the "majority of teachers reported that they teach science once or twice a week with a total of up to 60 minutes" (Saçkes et al., 2011, p. 230). 
Limited time with science experiences is also reflected in research investigating where children spent their time in free play based early childhood environments. Early et al. (2010) used data from two large-scale studies in the USA, observations in 652 classrooms across 11 states of 2061 children to observe how they spent their time over the day. They found they moved equally between free-play, teacher instructed activities and meals/routines. Overall children spent most of their time doing language/literacy, social studies, or art with the least amount in maths or science activities. Another study by Hanley et al. (2013) observed 20 children in one ECE centre, noting their movements between nine activity areas over three free-play periods. They recorded when children were in nine different activity areas as in-zone and calculated the whole class in-zone percentage for each. Their findings showed children were in the science area $11 \%$ of the time, one of three spaces where children spent the least amount of time.

Research exploring the factors that influence why and how often scientific learning occurs showed the facilities and scientific equipment available and teachers' knowledge and attitude towards science learning were significant. For example, Shaji and Indoshi (2008) found the majority (91.2\%) of ECE classes in Kenya were inadequately resourced with science resources to implement an effective scientific learning environment. Their study used three checklists designed for the investigation based on guidelines from the Kenya Institute of Education (KIE) and a science questionnaire of teachers. They found teachers were engaged in mostly unrelated science activities $85.7 \%$ of the time even though they reported a favourable attitude to the science curriculum. The main conclusion from this study indicated the "lack of adequate and appropriate conditions negatively influenced implementation of the science curriculum" (Shaji \& Indoshi, 2008, p. 398). Similarly, using the Kindergarten Teacher Questionnaire data from the ECLS-K dataset, of 3305 ECE teachers, Saçkes (2014) revealed how often ECE teachers teach science concepts was significantly influenced by the science courses they had attended, the availability of science resources and the teachers' perception of children's capacity to learn scientific concepts.

\section{Environments.}

There appears to be little published research investigating the relationship between centre environments and the affordance of scientific experiences. One qualitative study in Estonia did however explore how teachers create an environment for learning 
science (Timoštšuk, 2018). Data was collected via observational notes of activities and the environment/material check-list developed by Tu (2006) to collate the physical environment of 19 kindergartens. The study showed Estonian ECE centres provided science-rich environments which were well equipped and fostered science learning, with knowledgeable teacher mediation that followed children's interests.

Two additional studies by Inan et al. (2010) (discussed in section 2.5.2) and Rinke et al. (2013) also indirectly explored the association between the physical environment and opportunities for science experiences. Both investigated the influence of a centre's philosophy and the resulting culture or way teachers used the environment to develop and support young children's experiences of the natural world. Inan et al. (2010) indicated that a "Reggio Emilia-inspired preschool offered a science-rich context" (p. 1186). Their study analysed how a Reggio-inspired ECE centre facilitated scientific experiences for children. Inan et al. (2010) found that the Reggio-inspired environment created a culture that encouraged children to explore science concepts with hands-on materials and "where their understandings of science and their inquiry skills could be nourished" and socially constructed (p. 1205).

A further study by Rinke et al. (2013) investigated how inquiry science, the suggested framework for teaching and learning science in early childhood by the National Research Council (2000), could be put into practice within Montessori classrooms. The ethnographic study in four Montessori classrooms gathered data through observations over 10 months, along with semi-structured interviews and documentation to examine how classrooms fostered scientific learning. Rinke et al. (2013) found the culture and prepared environment of the Montessori classroom provided many opportunities for children to develop enduring interests, and to communicate about scientific topics. However, explanation or exploring an idea through evidence or deeper exploration required teacher direction which occurred only at an individual level, with only some teachers encouraging children to explain why they observed what they did.

\section{Science Resources.}

Literature investigating science resources in ECE was challenging to find as research measuring "classroom quality in regard to supports for science are not widely available" (Brenneman, 2011, p. 5). Brenneman suggested a need for further research using 
assessment tools that objectively measure the classroom equipment and how it is used to best support science learning. Most literature discusses the use of scientific resources as part of a science initiative or programme or alongside other areas such as teachers' pedagogical approaches, the science curriculum, science activities or time and space available in the centre for scientific experiences. For example research by Saçkes et al. (2011) exploring the impact of children's science experiences using data from the ECLSK study (see section 2.6.2), revealed when science resources were available, such as sand and water tables, children were more likely to initiate science experiences for themselves. Likewise, Saçkes (2014) examined how often teachers teach science concepts and what influences the frequency of teaching science and found the availability of science resources was a "statistically significant predictor of the frequency of teachers" teaching science (p. 179). As previously discussed in section 2.6.2, using data from the ECLS-K dataset of 3305 ECE teachers, Saçkes (2014) noted if teachers said they had a nature or science area in their centres they were more likely to teach science concepts.

\section{Pedagogical Practices.}

A large study by Cremin et al. (2015) exploring science and creativity in ECE across nine European countries identified the environment, resources and pedagogical practices together created opportunities for science. The project Creative Little Scientists was undertaken in 48 sites over 4 months across the countries involved. Data was collected through digital images, audio recordings and interviews with teachers and children. Their findings showed the value of sustained engagements with the outdoors, provision of a rich environment with diverse materials and resources. They observed that children's questioning and engagement was often prompted by teachers. However, they noted the potential to extend children's inquiries was often missed by teachers. Cremin et al. (2015) conclude that "in playful motivating and exploratory contexts, young children, often supported by their teacher, engage with resources, ask questions, collaborate and find and solve scientific problems" (p. 13).

Other influences on the occurrences of science learning in ECE settings were shown to include a country's cultural expectations of scientific learning and teaching and how this influenced pedagogical approaches towards science. For example, using qualitative data from video recordings and group discussions with up to 12 teachers, Sundberg et al. 
(2016) identified that within three Swedish ECE centres the curriculum, which emphasises care, play and following children's interests (educare), caused tensions and challenges for teachers' interpretation of how to shape their pedagogical activities with science content. The aim of the study was to examine, using Activity Theory (AT) as an analysis framework, how cultural factors might influence teachers' choice of science activities. Sundberg et al. (2016) found the emphasis on ensuring the activity met the educare culture meant the science learning became "fragmented and elusive" (p. 577). A comparative study by Hammer and He (2016) also noted a direct link between the teachers' culture and their teaching practice. Their qualitative study compared the way 13 teachers in a centre in China and six in a centre in Norway supported children's scientific learning. Using an ethnographic approach, they explored what cultural values and traditions might influence teachers' science practice by examining videotapes of the science activities and through semi-structured group interviews. Their findings highlighted the role of the teachers' pedagogical approach in facilitating science, and therefore argued that this should "be examined closely" (p. 462).

Hammer and He's (2016) study is similar to other research exploring practices to support scientific learning, which has shown the teacher's pedagogical approach significantly influences children's scientific learning. One USA study by Hong and Diamond (2012), for instance, examined the effectiveness of two different instructional pedagogies for teaching science concepts. The participants, 1044 and 5-year-old children were placed into 35 small groups and randomly assigned to an instructional approach. They were then involved in four 15-minute sessions exploring a science concept using either responsive teaching (RT), RT with explicit instruction (EI) or in the control group using neither RT nor EI. Children were tested pre and post the sessions. The combination of RT and EI was shown to be most effective with children learning more science concepts, vocabulary, and content specific skills than those taught through neither approach or through a RT approach alone (Hong \& Diamond, 2012).

An earlier study of two classes in an American ECE centre undertaken by Peterson and French (2008) investigated how teachers might support children's explanatory language during a 5-week colour mixing project. Using a science inquiry curriculum, they found when teachers engaged children in co-construction and as conversational partners in a scientific inquiry there was an increase in children's explanatory language. 
Peterson and French (2008) analysed video recordings and assessments of 47 children's explanatory language before and after the project and found the engagement of teachers alongside children in descriptive conversations and collaborative discussions positively influenced children's own explanatory language about colour mixing.

Similarly, research in Australia in two ECE centres, one rural with 24 children aged 4-5year-olds and an urban centre with 25 children of the same age range also found the role of the teacher was key. Fleer's (2009b) research, looking specifically at scientific concepts, sought to explore children's everyday and scientific thinking to understand how concept formation could be supported during play. The findings revealed that children's independent play with resources promoted comprehension at an everyday conceptual level only and showed that it is through focused teacher-child interactions of a scientific nature that children's understandings are moved beyond their everyday level to a scientific level of conceptual knowledge as identified by Vygotsky (1987). Likewise, a case study by Fleer et al. (2014) found "that a sciencing attitude of the teacher is likely to maximise the scientific learning opportunities of young children immeasurably" (p. 46). Fleer et al. (2014) examined what science opportunities were offered to 25 3-4-year-old children in each session and how teachers saw those affordances happening within the environment. They discovered that opportunities for scientific learning were enhanced using photographic documentation and through a science walk where a teacher was videoed as they considered how the environment of the ECE centre created scientific learning opportunities. This research highlighted the sciencing attitude of teachers, which meant they were more likely to think consciously about how to make science possible in the centre environment. Consequently, teachers and children were more likely to think beyond the everyday ideas that were obvious and consider the science concepts in the experience.

It therefore seems that the process of thinking about how to facilitate scientific enquiry and forming a shared understanding of the NOS teaching helps teachers feel more confident in their ability to facilitate meaningful scientific enquiries. This was highlighted in a study by McNerney and Hall (2016) whose action research project was undertaken in four early years classrooms in the UK, with four qualified teachers and six teaching assistants. The study found that during the process of developing a framework 
of enquiry for scientific learning with each other, participant teachers' confidence towards scientific teaching increased due to the shift from seeing themselves as having to be scientific experts, to promoting and developing children's scientific thinking. Additionally, another action research study in Denmark highlighted similar results. Broström (2015) and another university researcher worked alongside 12 ECE centres over 2 years to develop a science pedagogy within a play-oriented approach and explored what role teachers had in engaging children in scientific experiences. The research was based on a previous study by Broström et al. (2014) which identified that teachers perceived that children only learnt on their own or playing with other children. They did not see their role as teachers interacting with children as important in the children's learning. Building on the initial study Broström's (2015) action research identified the value of "active children in interaction with active preschool teachers" (p. 120). They noted the teachers' shift to realising the importance of their role in children's learning. Key practices emerged over the study such as teachers following and supporting children's wonder and inquiries, having shared engagement with children, asking productive questions and having their own science knowledge.

\subsubsection{The Influence of the Teacher}

The research has highlighted the role of teachers as key: their values, attitudes, and beliefs in how children learn in ECE is critical to their interest, confidence, and ability to engage with science and scientific experiences with children in their care. Their role has been previously argued by Nuttall (2005a), who stated that ECE is an "ongoing social construction" heavily influenced by the teachers' beliefs, values and theoretical influences (p. 20). The research examined has shown how initial teacher education and PLD in the NOS, and how to teach science, is effective in increasing the capability and confidence of teachers. This affects how they provide opportunities to investigate science experiences in their centres. Teachers' own beliefs and attitude to science and teaching science is also a significant influence on how much they gain from the PLD or initial training on science.

Research has also identified the value of a science rich environment with resources that provide opportunities for science experiences. Similarly, provoking science investigations in purposeful ways, such as through provocations, has also been highlighted in the studies discussed. Alongside this is the role of teachers. Their 
confidence, attitude and cultural beliefs have been noted as having a strong influence on how they afford scientific experiences for children. This is important because is the teacher's engagement alongside children in science experiences that shifts children's thinking beyond the everyday level to gaining new knowledge of scientific concepts. The influence of the teacher in realising the scientific affordances in the environment has been a key factor highlighted by the research.

\subsection{Science in NZ ECE}

Research exploring science in NZ ECE is limited. For this review the scope was broadened to include research carried out in the last 15 years. This section discusses the curriculum expectation for science in NZ ECE in the revised Te Whāriki (MOE, 2017). Studies of what influences the occurrence of science in NZ ECE are examined, including how the knowledge of teachers, their philosophy and pedagogical practices affects the availability of science experiences for children. Research investigating how to support teachers and their learning around science in their initial teacher education and while teaching is then discussed. NZ based research examining pedagogical practices that facilitate science in ECE such as funds of knowledge, working theories, relational pedagogy, sustained shared thinking and intentional teaching will be presented. Many of these studies have been referred to in the previous chapter.

\subsubsection{Influences on the Occurrence of Science}

The most recent research in NZ exploring science in ECE highlights findings similar to those indicated in the international research; that teachers' beliefs, confidence in and knowledge of science influence how much science occurs for children. In addition, the following studies suggest that what is in the environment only becomes visible when teachers' pedagogical practices connect children's experiences to the concepts being explored.

Hedges (2002), in her master's thesis, identified four elements to teachers' knowledge crucial to the inclusion of content knowledge in ECE: subject content; pedagogy and philosophy; knowledge of the learners; and of the context. In this case study, Hedges observed in one kindergarten as a participant-observer, examining teaching and learning interactions and capturing the beliefs of teachers, parents, and children through group and individual interviews. She spent 7 weeks in the centre, collecting 
data from curriculum planning and evaluation documentation and interviews of teachers, parents, and children prior and post an excursion to an Antarctic and aquarium experience. This meant the content discussed in her study was of a scientific nature. She discovered teachers supported children's learning in planned situations but not in spontaneous situations. In addition, in documentation used to support those practices the scientific content knowledge was near invisible (Hedges, 2002). Hedges and Cullen (2005) have further argued that in most play-based programmes teachers organise open-ended experiences, where the content knowledge tends to occur via discovery learning. Additionally, although teachers and parents believed content knowledge to be important, it was rarely seen in spontaneous teaching and learning interactions that formed most experiences for children in the study centre.

In an interpretive case study, Zhang and Birdsall (2016) investigated 20 teachers in two ECE centres using observations and interviews to explore how they provided for science learning. The centres used a play-based approach with minimum intervention, allowing children to explore independently. Zhang and Birdsall found the teachers' philosophical belief in a hands-off approach, and a lack of content knowledge, were the main obstacles to children learning science concepts and content. While teachers' use of funds of knowledge as a pedagogical approach meant they did access families and the community as a resource, documentation showed the links were not made to ensure scientific learning occurred for children in the setting. The lack of teachers' content and pedagogical knowledge in relation to science meant "the potential of affordances for science learning offered [were] not being realised" (p. 50).

A third study, PhD research by Backshall (2016) examined how children's science learning was enacted within a play-based ECE setting. Data was collected over 7 months via weekly observations, interviews with teachers, parents, and children and from teachers' documentation of children's learning pre and post the PLD sessions. Backshall examined how teachers' experience of professional leaning would affect their view of the "culture of science" (p. iii) and how children learn science. The PLD was two, 2-hour sessions focussed on improving teacher's knowledge of science and science education. The content was based on what teachers wanted to know and what children's interests the researcher had noticed. These sessions occurred half-way through the data collection process so the researcher could assess the influence the PLD might have had. 
Backshall's findings highlight the role of the teacher in using semiotic artefacts such as physical movement and interactions with the environment. Dialogue and science language, visual documentation such as posters and learning stories, books and natural events also provided opportunities to explore science concepts with children. Backshall found that when teachers were given a broader understanding of science knowledge through these professional learning sessions, they were more able to recognise and connect to children's interests. The significance of the PLD seemed to be key in this research and yet there is little discussion of the role the researcher played in facilitating this process.

Two recent reports by ERO have reviewed the factors that influence children's science experiences in 147 ECE centres across NZ (2021a) and provided guidance of good practice in science teaching and learning based on data from teachers, documents, and children in those centres (2021b). The initial report highlighted the variety of understanding of science and in teaching science across the centres. Using previous research on what influences successful science experiences in ECE, ERO (2021a) accessed centres in three areas: leadership; intentional teaching; and responsive curriculum. The findings show $9-10 \%$ of the centres demonstrated "almost all" of the identified rubric of good practice in these areas (pp. 11-18). In addition, the review revealed teachers had "limited opportunities to increase their knowledge and confidence to add complexity to children's learning in science" (p. 12). The companion report (ERO, 2021b) outlined how science could be supported, using 18 case studies exampling good practice for teachers. The common themes emerging from the case studies is the role of leaders in centres who are knowledgeable and enthusiastic about science, and an emphasis on teachers using strong relationships and intentional pedagogies to notice and build on children's motivation to explore science.

All studies indicated the important role of the teacher in enabling science through the centre environment. An expectation is therefore placed on teachers having the confidence and knowledge of science to support children's science experiences.

\subsubsection{NZ Teachers and Their Science Learning}

Research in NZ that explores teachers' confidence and knowledge of science is outlined next. The following three studies investigated either student or practising ECE teachers and their understandings of science. 
Two studies by Garbett (2003) and Heap (2007) assessed teachers' knowledge of science and found that it was limited and lacked depth. In Garbett's (2003) case study 57 first year ECE student teachers were questioned to ascertain their confidence and competence in applying science and other content knowledge in ECE settings. The students were asked to rank their confidence and competence in teaching these subjects in ECE. The science knowledge test was a 73-question multiple choice test, and students were asked to predict how well they did in the test. Between these two sets of data Garbett (2003) compared the students' actual versus perceived competence in science knowledge. The findings showed that the student teachers' science knowledge was limited, and they were also unaware of what they did not know and how this could influence their teaching of science in ECE settings. Similarly, the exploratory case study by Heap (2007) of 25 practising ECE and primary teachers found that after a 4-month long science course, the teachers' initial understandings of science, in particular their understandings of the NOS, shifted from very little knowledge to a more complex understanding.

Also exploring teachers' view of science but within the context of their practice, Edwards (2010) used a case study to investigate six teachers' views of how they supported children's scientific learning within one NZ ECE centre. With results similar to Garbett (2003), Edwards (2010) found the teachers' personal pedagogy of practice, their science knowledge and their understanding of the NOS were significant factors in how capable and confident they felt and therefore their effectiveness in supporting children's science experiences and learning. In addition, the findings indicated the value of a collaborative teaching team to support each other's abilities to foster children's scientific learning.

A common theme emerging from the above studies is that both student and practicing teachers lacked confidence in and knowledge of science or the NOS. Factors that supported them to learn more and bring this into their teaching were specific science learning, collaborative teaching teams, and reflection on their pedagogy of practice.

Research that explored how to influence teachers' science practice is limited in NZ. While Backshall's (2016) PhD study highlighted the value of PLD in influencing teachers' practice, only two other studies have explored professional learning for teachers. These two action research studies specific to science in ECE included the 
guidance of outside researchers and clearly indicate the influence this methodology has for teachers and their practice. Both Edwards (2010) and Backshall's (2016) studies highlighted the role of the teacher in supporting science through their intentional and fearless support of children's scientific interests.

From 2003 to 2009 the Centres of Innovation (COI) programme involved 20 ECE centres, with 16 completing their projects. Of those, one COI study investigated a centre's fearless approach to learning science (Bond et al., 2010; Meade, 2010). The study by Bond et al. (2010) involved teachers in an ECE centre and university researchers working together in an action research project to explore the philosophical approach of "fearlessness in science" within a rural, community owned ECE centre (Jordan \& Smorti, 2010, p. 89). This approach viewed children as capable and competent scientists, with their interests extended through in-depth investigations, supported by adults who developed a fearlessness towards their interests (Bond et al., 2010). The importance of teachers' ongoing extension of their own science knowledge to support children's developing expertise in and understanding of science concepts was emphasised in this study through the teacher-researchers documenting the science investigations that occurred (Jordan \& Smorti, 2010).

Similarly, the second action research study identified the importance of the teacher in facilitating scientific investigations. The study explored how to foster scientific enquiries in NZ ECE through a project carried out by the national museum, Te Papa, with three ECE centres (Browne \& Museum of New Zealand Te Papa Tongarewa (Browne \& Te Papa), 2016). This study produced the resource It's a Bugs Life. The findings identified ways teachers can use the MOE's five science capabilities: 1 . Gather and interpret data, 2. Use evidence, 3. Critique evidence, 4. Interpret representations and 5. Engage with science (MOE, 2014). The authors suggest using these capabilities to support children's science interests, with activities and pedagogical recommendations based around children's natural interest in insects. The study highlighted the value in focusing on the processes involved in scientific exploration to enable children and teachers to explore science content and new knowledge about insects through the science experiences the centres fostered in their outside environments (Browne \& Te Papa, 2016). The Browne and Te Papa (2016) resource clearly emphasises intentional 
teaching strategies such as asking questions and scaffolding to foster science exploration with young children in ECE.

These studies show the value of teachers being supported through reflection and that exploring pedagogical approaches enabled a change in teachers' practice and created effective learning opportunities for children in science. It is interesting that in both action research studies as discussed above (Bond et al., 2010; Browne \& Te Papa, 2016) there were researchers working with the teaching teams in the centres. However, other than the analysis done by Meade (2010) of the COI programme in general, what has not been examined is what their role involved, and how it influenced the action research process or even the change in teachers' practice.

Research in NZ has indicated that for teachers to increase the amount of time teaching science concepts in their centres, they need additional knowledge about science and how to teach science and need to view children as capable of learning science concepts. They also need a rich environment that supports science through the availability of diverse scientific resources. Studies of pedagogical practices that best support children's learning in ECE have been discussed, including the active role of teachers alongside children through sustained shared thinking, relational pedagogy and utilising children's funds of knowledge and working theories. Additionally, provocations, planned or spontaneous, can be a valuable practice to create thoughtful and meaningful environments or activities to foster science. In the revised Te Whāriki (MOE, 2017), there is an expectation for teachers to engage with content knowledge such as science. With the stronger sociocultural underpinnings of the curriculum, there is also an expectation for teachers' practices to be purposeful and intentional. Intentional teaching practices have been shown to actively engage teachers in children's interests and extend their thinking through conversations.

\subsection{Gaps in the Literature}

This review of literature has explored theoretical influences on and how content knowledge is included in ECE, the importance of PLD to shift teachers' practice and how the sociocultural approach influences pedagogical practices that support science in early childhood. Several conclusions can be drawn. First, that scientific learning within ECE appears limited and restricted by either the philosophy of the centre, the 
pedagogical practices used, the availability of resources and/or the confidence and attitude towards scientific learning of the teachers.

Second, that the teachers' philosophy, confidence in and understanding of the NOS plays a significant role in what way and how much teachers recognise and support children's interests and extend their conceptual learning in science. Those studies that involved increasing teachers' knowledge through specific science instruction and how to support science in their teaching practice found an increase in teachers' understandings and an improvement in the occurrence of scientific experiences in their centres. Research that had teachers reflect critically on their implementation of curriculum found this brought about shifts in their pedagogical practice.

Thirdly, the dominant pedagogical approach of development theory with independent discovery by children has been linked to a lack of scientific learning. Pedagogical approaches such as taking a fearless approach to science, accessing the communities' funds of knowledge, participatory learning theories or putting into practice a sociocultural-historical approach have been shown to have a positive influence on scientific learning for children. Identifying how teachers might put these strategies into their daily practice and how they may perhaps fit under the concept of intentional teaching to create opportunities for scientific experiences needs to be explored further. Finally, NZ research has identified a link between the lack of content knowledge within curriculum documents and consequently within the practice of curriculum. Some studies have strongly advocated for intentional teaching approaches to be a core component of teachers' practice, however none have occurred post the revised edition of Te Whäriki which outlined a clear expectation for teachers to "facilitate children's learning and development through thoughtful and intentional pedagogy" (MOE, 2017, p. 59). Nor do they explore intentional teaching strategies in relation to science. There is therefore a gap in our understanding of how to support teachers' confidence and attitude towards science learning, how they are implementing a curriculum expecting content knowledge to part of children's experiences, and how pedagogical approaches, such as intentional teaching strategies and provocations, can be executed within their settings therefore discovering how best to support young children's scientific learning in NZ. The following chapter explores the research design and methodologies used in this study. 


\section{Methodology}

\subsection{Chapter Overview}

The first section of this chapter explores the theoretical positioning of this research project within an interpretive paradigm. To answer the research questions, it was necessary to interpret and understand the phenomenon of scientific experiences in NZ ECE centres with those engaged in those experiences in their daily lives. The methods chosen, a survey and CAR, are justified. The reason for the choice of action research is discussed next, followed by an explanation of the design of the research and how data was collected and analysed. The role of the researcher became instrumental in this project and is explored more fully in chapter 7 , however what this role involved is initially outlined in this chapter. The chapter finishes by discussing the trustworthiness of the research process and the ethical issues involved.

\subsection{Research Paradigm}

Framed in a relativist ontology where the existence of multiple realities exist is acknowledged, this research was positioned in the social constructivist paradigm where what we know is constructed through the social meanings and interpretations of those living the experience (Braun \& Clarke, 2013; Denzin \& Lincoln, 2003). The research was therefore situated within an interpretive paradigm where my intention was to understand the meanings participants in the study brought to the phenomenon of scientific experiences in ECE. I wanted to examine the key influences that enabled scientific experiences in NZ ECE settings. Researching within an interpretive paradigm meant concentrating on how those involved in the study made sense of what the research was seeking to answer and developed knowledge from their and my interpretation of the phenomenon under investigation (Prasad, 2005).

When discussing research in educational contexts, McNiff and Whitehead (2011) identify three research paradigms: technical/rational, interpretive, and critical. A technical paradigm is a form of research which assumes there is objectivity from the researcher, that there is a problem identified and solutions are being sought which results in a hypothesis that can be generalised. An interpretive paradigm sees researchers observing and explaining what participants are doing in their natural 
setting, with participants also offering their own understanding of their practices alongside the researcher's interpretations. Critical theoretical research assumes social situations are controlled by participants and that they can change them. The structures of power and injustice influencing those situations and participants must be identified and changed. This research project sat within an interpretive paradigm and used a critical lens through which the researcher and participants analysed the situation they were in and reflected on the regulatory structures that influenced their centre's programmes.

Fleer and Robbins (2003) have argued that research in science education has been dominated by psychological constructivism which has focussed on the individual and does not account for the social and cultural contexts that surround young children when they learn. They contend that a sociocultural perspective in science education research provides a more inclusive way to capture children's thinking and learning around scientific concepts; mapping not just what children do, but their interactions with others and their environment. Therefore, this research took a sociocultural approach to capture the transformation of understanding around science of both teachers and children, how they interacted with their environment, each other and on and within their context such as curriculum, resources and their community (Fleer \& Robbins, 2003; Lemke, 2001).

In addition, Lemke (2001) argued that taking a sociocultural perspective of science education as a researcher requires a "skeptical (sic) and critical" lens (p. 297). He contends that science, and research in science, must be viewed as a socially constructed activity within a cultural framework. It is therefore appropriate to situate this research within an interpretive paradigm and explore the meanings of those within the context being studied (Denzin \& Lincoln, 2018). In addition, using a sociocultural lens to examine scientific experiences in ECE contexts requires the focus of the research to interpret the socially constructed nature of interactions between teachers, between teachers and children, between children and with their environments and the wider context of their centre (Kumar \& Whyte, 2018). This provides a wider view of how scientific experiences might be enabled and offers a way to investigate the role of the teachers specifically in a method that asks for their involvement to be crucial in answering the research questions (Fleer, 1993). 


\subsection{Research Questions}

My main research question was: What resources and practices influence scientific experiences for children in ECE centres?

This was addressed by the following three sub-questions:

1. How did the process of action research, including the researcher's role, influence the occurrence of scientific experiences?

2. How do teachers' pedagogical approaches enable children's scientific experiences?

3. What are the enablers/challenges to scientific experiences in ECE centres?

\subsection{Research Approaches}

Qualitative research does not have one distinct method of research, it is "a set of complex interpretive practices" (Denzin \& Lincoln, 2018, p. 13). Denzin and Lincoln (2018) contend that the qualitative researcher is a bricoleur, a term used to describe a "handywoman" who makes use of everything around them and explores reality aware of her and others' positions and how they may produce and interpret their contexts in a variety of ways (Kincheloe et al., 2018, p. 244). Denzin and Lincoln (2018) suggest that, within the interpretive paradigm, the researcher produces a bricolage, where the representations of the issue are pieced together and constructed over the course of the study from the various ways the issue is examined. Use of a case study allows the researcher to deeply focus on a phenomenon while also retaining the capacity to view the whole situation and all that it involves (Yin, 2012, 2018).

This research used a case study approach to investigate the issue of scientific experiences in NZ ECE centres. It was executed through two phases: firstly, a national survey and secondly a CAR project with teaching teams in six ECE centres. In this study the sources of evidence were collected via a survey and through the action research process using participant observation notes, audio recordings of focus groups and teachers' online journal entries. Additional data from video recordings, photos, and centre documentation such as learning stories were also used. 


\subsubsection{Case Study}

The definition of the term case study is disputed with various interpretations of what a case may be (Schwandt \& Gates, 2017; Yazan, 2015). Merriam (2010) claims that working within a constructivist and interpretive view where reality is socially constructed, and multiple interpretations are acknowledged, means case study research should be qualitative in nature. Therefore, using the definition by Merriam and Tisdell (2016) that a case study is "an in-depth description and analysis of a bounded system" is relevant for this research (p. 37). Similarly, Creswell (2012) suggests case study methodology allows for the in-depth investigation of a bounded system such as an issue, activity, or process. In addition, Stake (2006) identifies a case as a noun or an entity, not a function. He believes a "qualitative case study was developed to study the experience of real cases operating in real situations" (p. 3), and when the focus is on a phenomenon, it is the entities that illustrate or give the opportunity to examine the functioning of that issue.

Drawing on both Stake (2006) and Merriam and Tisdell (2016), this study viewed the case study as a bounded phenomenon to be investigated through real-life situations. Therefore, the context of this research was NZ ECE, with the phenomenon being scientific experiences for young children. The case was explored through the main research question: What resources and practices influence scientific experiences for children in ECE centres? The units of analysis were the six early childhood centres. A case study approach allowed for the investigation to explore the complexities of the relationships and interactions that unfolded around scientific experiences from within the real situation of an early childhood centre. Thus, this study examined the phenomenon through the detailed, in-depth data that was collected over time from several sources of information (Creswell \& Poth, 2018).

This study sought to explore the different ways opportunities for science experiences could be enabled in an ECE centre by using multiple sources of evidence gathered through different data collection methods. The nature of real-life contexts means there were many variables of interest. Therefore, as Stake (2006) states, it is important to present the variety of views from the ordinariness of places to better understand the phenomenon. To do this, action research provides a method that allows the researcher to be situated inside the context to be studied and capture the reality of all that 
influences the phenomenon. In this study researching inside an ECE centre alongside teachers was conducive to examining what influences the occurrence of scientific experiences.

\subsubsection{Action Research}

Action research has been described as a way for academics to "transform inquiry into praxis or action" (Denzin \& Lincoln, 2018, p. 27) in a socially responsible way through collaborative participation of all involved, and to co-create knowledge that is useful and looks to solve local and world problems. As a method, action research can take a variety of forms and be used in a range of settings, in education, health, or any type of workplace, or by an individual or a group (Cohen et al., 2017). Lewin (1997) argued that to understand and improve social situations research needed to be involved in the action of that social situation; to set a plan, action it, evaluate it, modify the plan, action it and evaluate again in order to access the results; a "spiral of steps each of which is composed of a circle of planning, action, and fact-finding about the result of the action" (p. 146). It is a cyclical process that "seeks to bring together action and reflection, theory and practice, in participation with others in the pursuit of practical solutions to issues of pressing concern to people" (Reason \& Bradbury, 2001, p. 1). It is the linking of research with action through a cyclical process that distinguishes action research from other methods of research. Also, the relationship between the researcher and those researched has varied over time, whether it was one person holding both roles as in the teacher as an action researcher or more recently to avoid credibility issues, held by two different people who work together, where "collaboration and participation is stressed" (Punch, 2014, p. 138).

The essence of action research is that it "involves several phases of thinking and doing to create change" (MacNaughton \& Hughes, 2008, p. 1). In educational reform, seminal texts from Stenhouse (1975) and Elliott (1991) maintain there must be active participation of teachers in the transformation process, with Elliott taking it further and identifying action research as a form of teacher PLD through reflective practice. As Elliott (1991) stated: “Action research integrates teaching and teacher development, curriculum development and evaluation, research and philosophical reflection, into a unified conception of a reflective educational practice" (p. 54). He believed the central aim of action research was to improve practice, not to produce knowledge. In contrast, 
McNiff and Whitehead (2011) reason that while exploring change in praxis, teachers are generating new knowledge about how and why they have improved their pedagogy and are creating new theories that can contribute to others learning and practice. They believe action research enables those exploring change to also create living theories that can be shared.

To explore what might enable scientific experiences in the ECE settings in my study I wanted teachers to be involved in the investigation and to gain from the research. As it was going to be their environments and their practices that may need to change, I wanted them to take ownership of the changes, be part of creating new knowledge and benefit from the improvements that would hopefully occur. Therefore, action research seemed to be the appropriate methodology for this study.

\section{Outsider Role in Action Research}

While most literature discusses action research as research where practitioners drive their own investigations (Elliott, 1991; Kemmis \& McTaggart, 2005; McNiff \& Whitehead, 2011), some identify the role of an outsider working with participants in a collaborative way as valuable for the research process. This can be either as an observer in the classroom alongside the teacher researcher (Stenhouse, 1975), as initiating researchers in co-operative inquiries with participants (Heron \& Reason, 2001), or as two separate roles of research and action done by separate people but where collaboration and connection between them is essential (Punch, 2014).

Discussion about research in education has explored the appropriateness of various methodologies, in particular the role of outside experts judging the practice of those within education (Erickson, 2018). This has led to a range of research models involving the practitioners themselves leading to the idea of the teacher as researcher where the exploration of educational practice becomes an organised inquiry into their profession (Goodfellow \& Hedges, 2007). With the intention of developing and accessing curriculum, Stenhouse advocated for a model of the teacher as researcher (Stenhouse, 1975). This was explored further by others who suggested action research enabled teachers to be actively engaged in researching their own practice (Goodfellow \& Hedges, 2007). Similarly, Heron and Reason (2001) claim that "good research is research conducted with people rather than on people" (p. 179, italics in original) and where the inquiry is cooperative and explores the transformation of practice as well as gaining an 
understanding of the problem. More recently Sigurdardottir and Puroila (2018) have identified CAR as being employed more in education because the evidence points to PLD for practitioners is linked to the facilitation of change in educational practice.

In this study, the approach of working collaboratively with participating teachers in the role of an outsider with insiders, where "outsiders initiate and conclude the research, and work in collaboration with insiders" (Herr \& Anderson, 2015, pp. 40-41), offered a way to enable teachers to be fully involved. I could also reflect with them and offer my knowledge as needed. This is similar to the definition outlined by Punch (2014) earlier where connection and collaboration between the separate roles is highlighted.

\section{Critical Reflection in Action Research}

Findings from action research occur in a variety of ways during the study but do involve reflection in some way. Yost et al. (2000) suggest that critical reflection helps teachers be critical thinkers and problem solvers, with action research providing the means for them to "link prior knowledge to new information, frame questions, and systematically find answers" (p. 44). In agreement, MacNaughton and Hughes (2008) stated "reflection and critical reflection 'in action' (in the moment) and 'on action' (after the moment) are core drivers of change in action research" (p. 97). They proposed that reflecting and thinking critically is asking participants to question and analyse their practice to better understand it. In addition, they contend that there are two approaches to critical reflection in action research, each has a different approach to what to question or analyse. MacNaughton and Hughes (2008) argued that those involved in action research for professional change use critical reflection through an interpretive lens, while those seeking social change draw on critical theory in their critical reflection process. Therefore, I drew from an interpretive paradigm in using critical reflection in this action research project.

Critical reflection is important when seeking a change in practice. The teachers in action research need to reflect and analyse their actions during and after the teaching experience (MacNaughton \& Hughes, 2008). Reason and Bradbury (2006) have argued that action research brings together reflection in and on action in collaboration with others to solve issues and create new knowledge in an area identified by those involved in the process. According to Meade $(2005,2006)$, effective ECE practice sees teachers engaging in reflection of what they have done and what could be done better and 
investigating and articulating their practice for children's benefit. This fits well with the action research cycle of observing, acting, planning, reflecting, acting, and returning to the cycle again. For example, using action research in the COI programme was effective in seeing a transformation of practice. This was mainly due to teachers investigating their own practice, working in a collaborative relationship with outside support, such as a PLD facilitator or university researcher, which encouraged critical thinking and helped question their previous assumptions (Gibbs \& Poskitt, 2009; Meade, 2009).

\subsubsection{CAR}

MacNaughton and Hughes (2008) state that there are two branches of action research, for social change and for professional change. "Action research for social change" is orientated towards emancipation and questions of fairness, justice, and inequalities (p. 39, italics in original). My intention was not to pursue social change in this study but a change in practice, or professional change. MacNaughton and Hughes (2008) identify CAR as a member of the branch of action research for professional change.

MacNaughton and Hughes (2008) provide an overview of action research for professional change within ECE, and my action research can be identified as CAR as it promoted "professional growth and learning in individuals and teams who can initiate change around an issue; and /or driving site-wide or system-wide change" (p. 44). According to Avgitidou (2009), using CAR in education as a form of PLD has increased and has evolved into a more formalised process. For this study I drew on the process documented by Bruce et al. (2011) through their multi-year, large-scale CAR project in Canada. Figure 3.1 below outlines the CAR cycle as identified through their project. 


\section{Collaborative Action Research}

\section{Collaboration}

Throughout collaborative action research activity, teachers frequently meet to set goals, and to plan and engage in related interventions, data collection, data analysis and report writing. The involvement of researchers and knowledgeable others can range from full membership in the team to a supporting role (e.g., providing resources, assisting with data collection and analysis strategies).

\section{Identifying the Problem}

- articulating the teacher/learning

issue for investigation

- gathering baseline data

- developing research question(s)

Goal Setting and Planning

- planning interventions that will improve teaching and learning - consulting current research and accessing human/print resources - setting timelines

\section{Implementing Plan of Action}

Data Collection and Analysis

- enacting the plan in the classroom, - observing, co-teaching, supporting

team members

- collecting evidence and reflecting

\section{Evaluating the Interventions}

- drawing conclusions from data

- summarizing findings

- writing and sharing reports

- asking new questions

Note. Reprinted from "Examining what we mean by collaboration in collaborative action research: A cross-case analysis," by C. Bruce, T. Flynn and S. Stagg-Peterson, 2011, Educational Action Research, 19(4), p.436. Copyright 2011 by C. Bruce, T. Flynn and S. Stagg-Peterson.

Similar to the process described in the figure above, this CAR study identified a problem, planned, and implemented an action plan in each centre alongside the teaching teams, and collaboratively evaluated the action plan. Constant data collection and critical analysis fuelled this process.

I wanted to understand where my CAR project sat within the educational research continuum. I used a framework created by Rearick and Feldman (1999), which they used to evaluate and acknowledge the complexities of action research studies. The framework was used as "a tool for the self-reflective analysis of [my] own practice of action research" (p. 347). 
Resembling the three research paradigms, technical/rational, interpretive and critical, outlined by McNiff and Whitehead (2011) earlier in section 3.2 of this chapter, Rearick and Feldman (1999) use the terms technical, practical, or emancipatory to describe the theoretical orientation of the action research study. In addition, Rearick and Feldman use two other dimensions: purpose and types of reflection. This helps identify where specific action research projects sit within the broader action research space. Using their framework, I was able to confirm that my study sat within the branch of action research MacNaughton and Hughes (2008) identify as action research for professional change. As MacNaughton and Hughes (2008) put it, the aim of action research is for professional change to initiate wiser practice through the generation of "new and deeper thinking about it" (p. 43). Thus, the foci for change is on issues or dilemmas identified by ECE teams and where they look to change their practice via the action research cycle with an outside facilitator to support their professional growth and learning

Using Rearick and Feldman's (1999) framework, shows the relationship of the different dimensions to one another within my action research space (see Figure 3.2). The primary foci of the action research project are in the centre of the shaded oval that represents the scope of my research project. 
Figure 3.2

\section{Classification of this CAR Study}

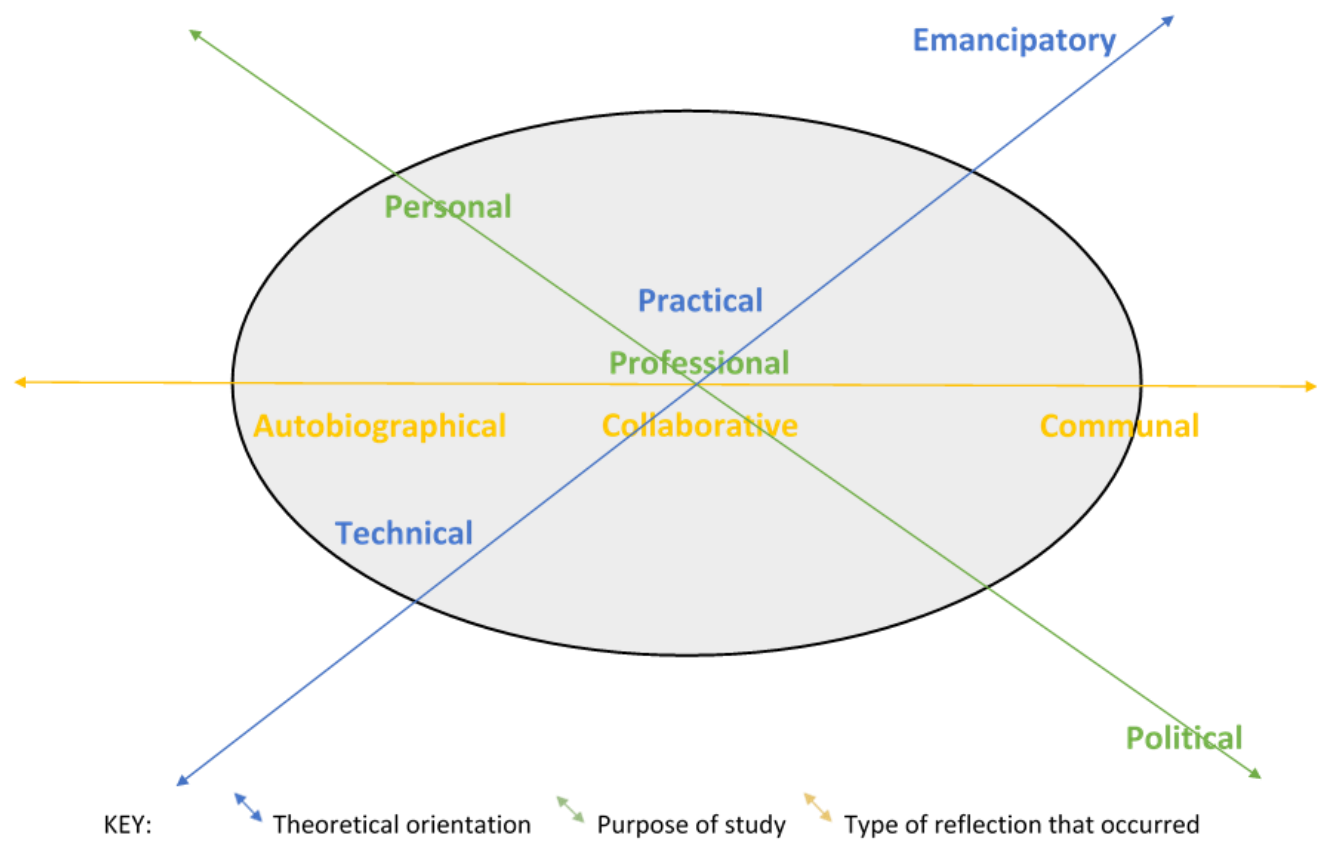

Note. Adapted from "Orientations, purposes and reflection: A framework for understanding action research," by M. Rearick and A. Feldman, 1999, Teaching and Teacher Education, 15(4), p.338. Copyright 1999 by M. Rearick and A. Feldman.

My CAR study therefore had a practical, interpretive theoretical orientation in that it looked to understand the interactions in each centre I worked with, between teachers, between teachers and children, between children and their connections with their centre environment and resources. The phenomenon of the study was science experiences in NZ ECE centres, and the problem was already identified by previous research to be a lack of scientific learning with young children. There was a technical theoretical orientation to the research in that the action research set out to find solutions to this problem.

The purpose of my action research project was to seek professional understanding of the phenomenon through the inclusion of the teachers' knowledge and reflections on their practice. The intention was to share the new knowledge to improve scientific experiences within ECE settings. Having teachers and researcher reflect on the development of their own knowledge and understandings meant the purpose was also personal. 
The type of reflection that occurred throughout the project was mainly collaborative. It was through collaborative discussions between the researcher and teachers and between the teachers themselves that identified the action plan, examination of the actions taken, identification of what modifications to make and evaluations of what had (or had not) enabled scientific experiences within their centre. It was autobiographical because the process of reflecting enabled teachers to understand and adjust their own practice throughout the project. This type of reflection was also seen in the way I constantly reflected throughout the research project on my role, how best to support the teaching teams and to interpret and find meaning in the experiences I was involved in. In addition, I identified communal reflection to acknowledge the questioning and critique of the wider policy requirements, regulations, and centre routines that the teachers found were a challenge to them enabling scientific experiences in their centres. The Rearick and Feldman (1999) framework confirmed that CAR, in looking for professional change, was appropriate for this study. This study used a practical, interpretive theoretical orientation to look for solutions to enabling scientific experiences for children in NZ ECE. It sought to investigate and enable professional and personal change through collaborative and individual critical reflection of participants' practice.

Using a CAR framework in this study provided an organised and purposeful process that offered opportunities for personal and group critical reflection and facilitated thoughtful and intentional action and considered change in practice. This approach to research and professional development is similar to professional learning communities (PLCs) that have been found to be useful in ECE because of the collaborative nature of the process (Thornton \& Cherrington, 2018). In addition, teams of teachers who know the children and their context well and who come together in a supportive environment ensures "effective teacher education and curriculum development" (Pedretti, 1996, p. 324). Research also indicates teachers gain more from action research when supported by a researcher or facilitator (Ponte et al., 2004). CAR is therefore well suited for use within teams of teachers in ECE centres.

CAR in each centre provided deep insight into the complexities of how scientific learning was or could be supported within an early childhood setting. CAR involved teachers within an ECE centre working together: reflecting, critiquing, and changing 
their practice regarding a phenomenon or question of interest (Kemmis \& McTaggart, 2005). Rather than situating this research as an outsider looking in, this research sought to change scientific teaching and learning practices within select ECE centres to improve pedagogical practices for fostering scientific experiences.

\subsection{Research Design}

Using a variety of data collection tools allows for a rich and in-depth description of the phenomenon, with interpretation and analysis of the experiences of the situation important to understanding the issue and answering the research question (Merriam, 2010; Stake, 2006). This study used a survey in phase one, and CAR for the second phase.

In Phase one of this case study, the survey gained quantitative data to provide a broad picture of the phenomenon, which helped inform the choice of CAR. According to Merriam (2010), using quantitative data helps provide a general picture of the research problem. A survey can gather material at a point in time to describe the nature of a phenomenon, and provide descriptive and explanatory information (Cohen et al., 2017). This survey sought to explore the issues further. It provided some quantitative as well as qualitative data on what NZ ECE teachers thought influenced the occurrence of scientific experiences in their centres. In Phase two the CAR generated qualitative data which had a greater role in addressing the research questions. This project was therefore a predominantly qualitative case study, with a quantitative component used to generate a richer understanding of the phenomenon or to answer part of the research question (Merriam \& Tisdell, 2016).

\subsubsection{Phase One: Survey}

The survey was developed via Qualtrics software and comprised a combination of yes/no answers, multiple choice, Likert questions on a seven-point scale (for example strongly agree, agree, somewhat agree, neither agree nor disagree, somewhat disagree, disagree, strongly disagree and extremely confident, moderately confident, slightly confident, neither confident nor unconfident, slightly unconfident, moderately unconfident, extremely unconfident) and open-ended questions (see Appendix A). The advantage of using an online survey is that it is a fast and simple way to collect data (Sue 
\& Ritter, 2007), and can provide access to a wider audience and generate a larger volume of representational data (Cohen et al., 2017).

After gaining ethical approval from VUW Human Ethics Committee, Approval number 24490 , the survey was piloted with a few early childhood teachers to check the flow and ensure the questions were clear and easily understood. Upon completion of the pilot questions were added to ask about the philosophical approach and age range of children in the centre. The revised survey was sent on 20th June 2017 to 3325 Education and Care centres and Kindergartens throughout NZ (see Table 3.1 below). Emails were sent directly to the publicly available addresses held in the MOE database as of May 2017. Two reminder emails were sent on 28 June and 3 July 2017 to encourage as many responses as possible. The subject heading of the email asked recipients "How does your centre encourage children to wonder about the world?" They were then invited to respond to a survey through an anonymous URL link provided in the email. I asked that the survey be forwarded to other teachers within the centre. Each response to the survey was counted as one respondent, so there could have been several respondents from one email sent to one centre.

Table 3.1

Number of Emails Sent and Responses Received

\begin{tabular}{|l|c|c|}
\hline & Emails sent & Responses \\
\hline Education and Care centres & 2673 & 91 \\
\hline Kindergartens & 652 & 238 \\
\hline Other & & 20 \\
\hline Not answered & & 29 \\
\hline Total & $\mathbf{3 3 2 5}$ & $\mathbf{3 7 8}$ \\
\hline
\end{tabular}

There was an 11\% response rate. Participants were asked to categorise their service as either an education and care service or a kindergarten. Twenty noted themselves as Other and 29 did not answer that question. The survey asked respondents for background information such as the age of children in their centre, qualifications of the teachers, additional details such as experience, beliefs, and attitudes about the pedagogy of ECE were sought through scales and self-completed questions. 
The quantitative data from the survey was analysed through Qualtrics, which provided graphs and tables showing numbers and percentages of how participants responded to each question. Qualitative data (open-ended answers) were examined and categorised to identify the various themes and patterns that emerged. These findings are outlined and discussed further in Chapter 4.

\subsubsection{Phase Two: CAR}

The centres involved in the action research phase of this research were purposefully selected from those who volunteered based on identified criteria (Cohen et al., 2017). The criteria being centres in the Wellington region (where the researcher resides), licensed teacher-led, with a minimum of $80 \%$ qualified teachers and catering for 3 to 5 year olds. I hoped for at least three centres, a kindergarten and two education and care centres; one being a Montessori centre. From the number of survey respondents who were interested in joining the study in Phase Two, seven centres from the Wellington region indicated they would like to be involved. An email discussion with each centre's representative outlined what involvement in the CAR would entail. This process finalised the participation of four of those centres; a large full-day kindergarten, a small centre for infants to 4-year-olds, a small centre for 3-4-year-olds and a Montessori centre for 3 to 6 years old.

Two more centres were included the following year. A teacher in another Montessori centre which catered for infants to 5-year-olds had completed the survey and wanted to be involved. The teacher emailed in August 2017 asking if their centre could be part of the CAR, and I agreed as they met the criteria. The other centre was a sessional kindergarten who had been introduced to the research project through their association. They also contacted me directly, in November 2017, asking if they could engage in the CAR study, which I agreed to. This provided a range of ECE centres to draw data from. While two were Montessori centres and are not identified in the findings for confidentiality reasons, their approach is discussed later. Pseudonyms were used for each of the six centres.

Three of the ECE centres, Kanuka, Matai and Whau, were able to start immediately. I had an initial meeting with each of the six CAR centres to discuss what the research would involve for them and what my role would be. 


\section{Timeline.}

Work with each centre was staggered over the next 12 weeks as outlined in the timeline, Figure 3.3 below.

Figure 3. 3

Timeline for The First Three CAR Centres: Kanuka, Matai and Whau

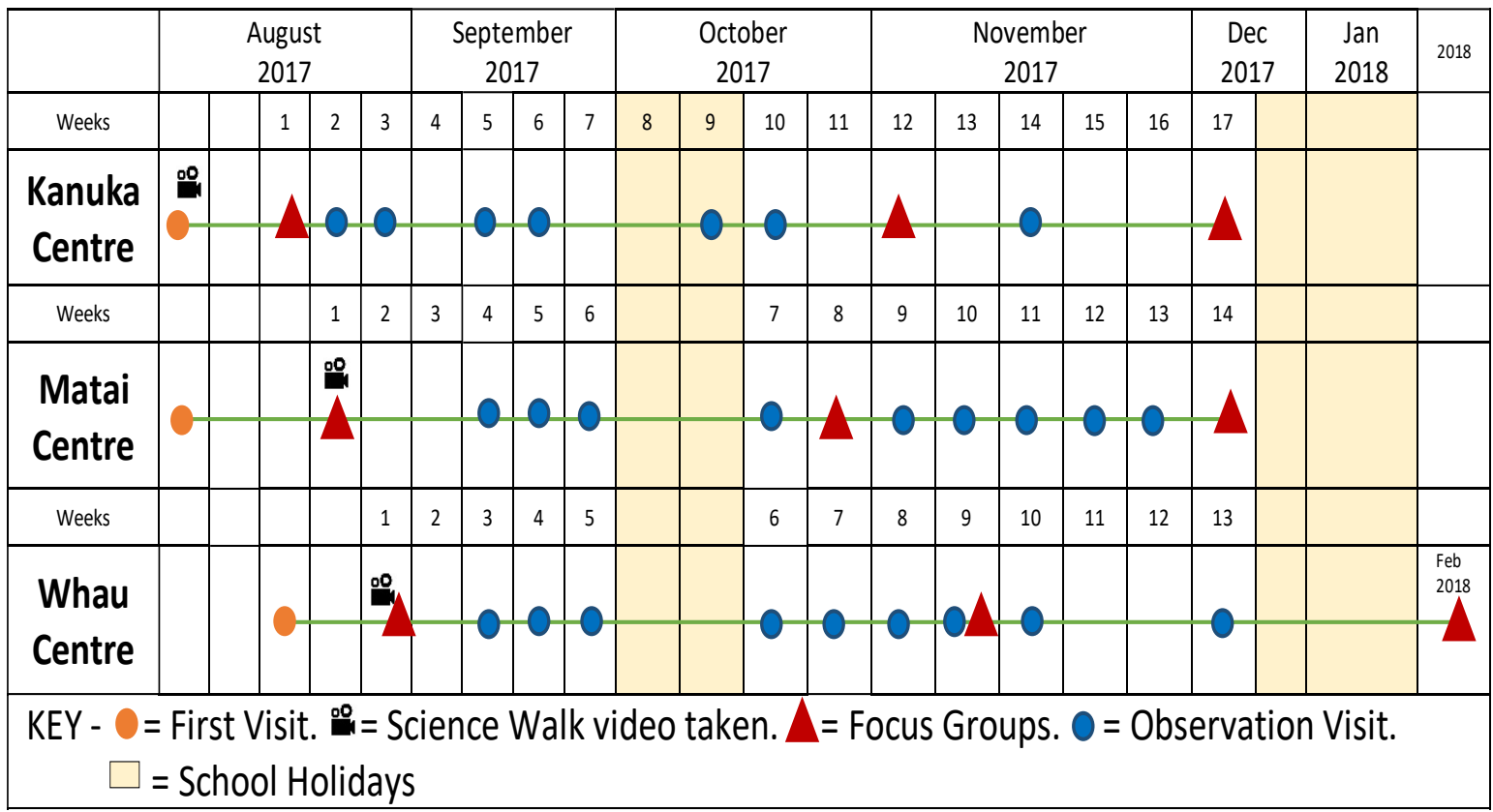

During this time the additional two centres, Mahoe and Kowhai, contacted me to be involved, I visited them at the end of 2017 and the beginning of 2018, and began our 12week CAR project together in February 2018. The fourth centre of the original four began their CAR cycle with me in March. Again, I staggered my visits and focus groups sessions with each centre over the 5-month period from March to June, so each centre had 12 weeks of engagement in the CAR process. The timeline for these three centres is illustrated in Figure 3.4 below. 
Figure 3. 4

Timeline for The Second Three CAR Centres: Mahoe, Kowhai and Ngaio

\begin{tabular}{|c|c|c|c|c|c|c|c|c|c|c|c|c|c|c|c|c|c|c|c|c|c|c|c|}
\hline & 2017 & $\begin{array}{c}\text { Jan } \\
2018 \\
\end{array}$ & & $\begin{array}{l}\text { ebru } \\
201\end{array}$ & & & & $\begin{array}{r}\mathrm{Ma} \\
20 \\
\end{array}$ & & & & $\begin{array}{l}\mathrm{Ap} \\
20\end{array}$ & & & & $\begin{array}{l}\mathrm{Ma} \\
201\end{array}$ & & & & & & & $\begin{array}{l}\text { Juy } \\
2018\end{array}$ \\
\hline Weeks & & 1 & 2 & 3 & 4 & 5 & 6 & 7 & 8 & 9 & 10 & 11 & & & 13 & 14 & 15 & & & & & & \\
\hline $\begin{array}{l}\text { Mahoe } \\
\text { Centre }\end{array}$ & $\begin{array}{l}\text { Nov } \\
\text { 2017 } \\
-\end{array}$ & $\stackrel{\circ}{\circ}$ & & & & & & & & 1 & & 0 & & & & & - & & & & & & \\
\hline Weeks & & & & 1 & 2 & 3 & 4 & 5 & 6 & 7 & 8 & 9 & 10 & 11 & 12 & 13 & 14 & 15 & & & & & \\
\hline $\begin{array}{l}\text { Kowhai } \\
\text { Centre }\end{array}$ & & & 음 & & & & 0 & & 0 & 0 & & 0 & $\triangle$ & 0 & 0 & & & & & & & & \\
\hline Weeks & & & & & & & & & & 1 & 2 & 3 & 4 & 5 & 7 & 8 & 9 & 10 & 11 & 12 & 13 & 14 & \\
\hline $\begin{array}{l}\text { Ngaio } \\
\text { Centre }\end{array}$ & $\begin{array}{l}\text { Aug } \\
2017 \\
0\end{array}$ & & & 00 & & & & & 1 & 0 & & & 0 & 0 & 0 & & & & J & 0 & 0 & & $\Delta$ \\
\hline KEY - & & & & & & & & & & & & & & & & & & & & & & sit. & \\
\hline
\end{tabular}

Teachers Involved in the CAR.

In four centres every member of the teaching team was involved in the CAR. Kanuka, Matai and Mahoe were smaller centres with two or three teachers while Kowhai had all five teachers involved from both their infant and preschool spaces. The other two centres, Whau and Ngaio were significantly larger with a bigger teaching team so only some of the teachers chose to be involved: five in each centre. All teachers involved in the CAR were qualified with at least a Diploma in Teaching (ECE), except one who held a 5-week certificate in the preschool Montessori curriculum. The years of teaching experience between the teachers ranged from 35 years to being in their first year of teaching.

\section{Data Collection Within CAR.}

Following the action research process identified by MacNaughton (2001) and Kemmis et al. (2014), the study began with the researcher and teachers from each centre meeting to discuss and agree on the research procedures, the expected timeframe, the agreed principles, expectations of each other, and the roles of the teachers and the researcher. 
As explained in section 3.4.2, action research involves gathering evidence to examine the influence of the changing practices. How that evidence is gathered can be done through a variety of methods (McNiff \& Whitehead, 2011) to provide a range of perspectives (McNiff \& Whitehead, 2010) and to allow for triangulation (Kemmis et al., 2014). The type of data collected is usually determined by the research problem and qualitative sources are seen to be more appropriate in action research (Mills, 2011). Mills (2011) suggests using three qualitative data collection techniques in action research: experiencing, enquiring, and examining. In this project the data collected sat under these techniques as outlined in Table 3.2 below.

Table 3. 2

Action Research Data Collection Techniques

\begin{tabular}{|c|c|c|}
\hline $\begin{array}{c}\text { Experiencing } \\
\text { (through observation and } \\
\text { field notes) }\end{array}$ & $\begin{array}{c}\text { Enquiring } \\
\text { (when the researcher } \\
\text { asks) }\end{array}$ & $\begin{array}{c}\text { Examining } \\
\text { (using and making } \\
\text { records) }\end{array}$ \\
\hline $\begin{array}{l}\text { participant } \\
\text { observations via } \\
\text { narratives, running } \\
\text { records and notes }\end{array}$ & $\begin{array}{ll}- & \text { focus groups } \\
- & \text { observation notes and } \\
& \text { discussion }\end{array}$ & $\begin{array}{ll}\text { - } & \text { learning stories } \\
\text { - } & \text { teachers' reflective } \\
& \text { journals } \\
\text { - } & \text { researcher's reflective } \\
& \text { journal } \\
\text { - } & \text { videos and photos }\end{array}$ \\
\hline
\end{tabular}

Note. Adapted from Action research: A guide for the teacher researcher (4th ed., p. 89) by G. Mills, 2011, Pearson. Copyright 2011 by Pearson.

The data collected during this study formed a portfolio of evidence for teachers and I to reflect on, evaluate, critique and to inform their action. MacNaughton (2001) argued that if the cycle of critical reflection is the motor of action research, then data and documentation is the fuel. She asserted a need for two levels of data; documentation of what happens when action occurs, and data gathered from the critical reflection of the first level data and the planning that follows. In this study my observation notes, photos and video and the learning stories written by teachers provided the first level of data. Critical reflection on the experiences and their teaching practice occurred through their reflection journals and responding to my observation notes, this delivered the second 
level of data. Further critique and reflection happened during the focus groups, which meant teachers could adjust their plans in the action research.

\section{Science Walk.}

After our initial discussion outlining what would be involved in participating in the CAR, I videoed some or all teachers walking around their centre to identify the science opportunities available for children in their centre. This method had been used in previous research looking at the perceived everyday science practices in an ECE centre in Australia (Fleer et al., 2014). I adjusted the method by videoing teachers outside of the session time, so they could walk through the centre without interruptions from children. In the same way as Fleer et al. (2014), the video captured the way teachers planned for formal science opportunities in their centre environment and how they had or might respond to "incidental moments with children as they asked questions or noticed phenomena" (p. 43).

The video was then shared on the online learning platform Moodle ${ }^{7}$ for teachers to view and reflect on before our first focus group. This data was then used at the beginning of the first focus group with each centre as a way for the researcher and teachers to collaboratively reflect on what enabled science experiences well and what areas could be explored further through the CAR process.

\section{Focus Groups}

I facilitated three focus groups with each centre's teaching team at the beginning, middle and end of the 12-week CAR cycle. This provided three formal meetings where I could focus discussions and capture interactions within the group, including the critical thoughts and reflections of teachers, and they could identify the challenges and successes of the study. As a data collection method, focus groups provide a useful means to record the thoughts and deliberations of a group of people gathered for a shared task (Cohen et al., 2017; Denscombe, 2014; McLachlan, 2005). A focus group collective conversation provided valuable insights through the opportunity for deliberate, democratic, and critical dialogue around enabling science experiences in their centre (Kamberelis \& Dimitriadis, 2008).

\footnotetext{
${ }^{7}$ An open source software package to create private websites to host online learning platforms or a course management system which in this situation was used to host the reflection journals and discussion forums for each centre.
} 
I created an agenda with questions to guide discussions prior to each centre's first focus group (see Appendix B). Rules and expectations of the research were discussed initially and guidelines for the focus groups were agreed to. Using my research questions and reflecting on the science walk video, discussion with teachers explored what they thought was enabling science to occur in their centre, what the challenges were and what areas they thought they could work on. Drawing on research such as Fleer (2009b), Hedges (2014) and McLaughlin and Cherrington (2018), I suggested areas they might want to explore such as curriculum resources, accessing funds of knowledge within their community, extending children's interests and working theories, using provocations and intentional teaching strategies like questioning. I also prompted them to consider their own scientific knowledge.

Each focus group was audio recorded and I kept hand-written notes. Transcribed scripts of the focus groups were sent to teachers to check for accuracy. With the first centre, Kanuka, I provided a brief action plan as a summary of the first focus group expecting the teachers to add to it to provide more depth. I tried a similar approach with the second and third centres, Matai and Whau. However, the teachers did not engage with the action plan as I thought they would, which indicated that I needed to produce a detailed action plan with specific areas for them to work on and more concepts for teachers to explore and critically reflect on. This occurred for the final three centres where I used the key ideas in my research questions: environment and resources; curriculum supports; and pedagogical approaches to frame the areas the teachers wanted to change. How my role changed during the CAR process is explored in more detail in Chapter 7.

I analysed data from teachers' journal entries, their learning stories, and my observations, the common themes and issues identified provided a structure to questions asked during the second and third focus groups. As argued by Merton and Kendall (1946), this allowed me to prepare an agenda or interview guide for the following focus groups, based on analysis of the action plan and the initial themes that had emerged, and present these to the teachers to discuss. Careful and responsive listening throughout the focus groups and while transcribing meant I was able to monitor their responses and be prepared to explore their implications in my following visits or the next focus group. 


\section{Online Interactions and Reflections.}

An online platform via Moodle was created to host the reflective journals for each teacher participant and my observation notes. My notes were a summary of my reflections, the conversations I had with teachers and my field notes taken during my visits, where in my role as a "privileged, active observer" (Mills, 2011, p. 75), I was able to observe teachers and children uninterrupted at times or be actively engaged with activities in the centre.

Teachers were encouraged to write journals as often as they could or after a specific instance or experience in science. Reflective journals are a valuable method for gathering data and examining teaching through critical self-reflection with the intention of prompting change (Phelps, 2005). Most of the teachers in this study used the opportunity to share insights and thoughts regarding their practice. Their online journals were only accessible by me, which according to Boud (2001) allows for a more critical analysis of their practice when free of the "scrutiny of others" (p. 15). Teachers were able to share learning stories about science experiences that had happened in their centre and I could share photos and videos from each visit with them. I also used Moodle to suggest articles and other resources to each teaching team.

The platform allowed for interaction between teachers and me. I replied to each reflection posted by teachers and this often started an online conversation between us. My responses needed to be gentle and flexible to the needs of teachers, providing encouragement and feedback as needed (Fenwick, 2001). In addition, some teachers responded to my observation notes and this often prompted an examination of their practice. I found my observation notes were a useful way to pose challenging questions and suggestions that could provoke teachers to explore other ways of approaching science in their centres.

\section{Research Hui.}

Two hui were organised over the research period for participating teachers from the six centres. Those involved gave permission through the ethics approval process to meet as a group. The aim of the research hui was to create a community of learning for those involved in the study and to capture data from discussions focussed on the research questions. Opportunities to share ideas and challenges was welcomed by teachers. The first one was held 13 November 2017 and involved three teachers from the first three 
centres and four teachers from two centres about to start. The second one on 20 September 2018 involved six teachers from all six centres. Various ice-breaking activities were used before teachers shared their research stories with the group. The final activity involved teachers using post-it notes to write their main thoughts, what had worked and what was challenging, and placed them under the research questions. This collaborative analysis captured a useful summary of the main themes across the study.

The research hui and the data produced was helpful in guiding the analysis of the other sources of data. It provided initial themes to use in condensing the data from the teachers' reflection journals, my observation notes, and the focus group transcriptions. This fits within the inductive process identified by Miles et al. (2014) where data collection feeds into data condensation, and emerging themes are identified, and colour coded. This process is outlined in Section 3.6.1.

\section{Documentation.}

Two centres gave me permission to view their learning stories on Storypark ${ }^{8}$, an online platform centres use to document and share children's development with their families. I was able to draw on learning stories teachers had shared that related to science specifically, and this provided another source of data demonstrating their plan in action. Photos of scientific experiences that occurred outside of my visiting times were also used (of those who gave consent) as illustrative data. Additional data was shared by teachers such as learning stories in PDF format on Moodle or via email and one team shared their individual reflections from their team review of science after being involved in this study.

\subsection{Data Analysis}

Analysis of the survey data was completed through Qualtrics as explained above. However, most of the data gathered in this study was qualitative. Qualitative data can be analysed through a variety of methods; either theory-led or data-driven. This study took a data-driven method by starting with the research questions as a framework for organisation of the data (MacNaughton et al., 2001) then followed a cyclical approach to

\footnotetext{
${ }^{8}$ An online software for documenting and sharing children's learning between early childhood centres and their families.
} 
the collection and analysis of data (Miles et al., 2014). This iterative cycle involves the researcher using an inductive process to discover patterns in the data, verifying these themes with further data, which then provide additional understandings which are fed back into the cycle (Mills et al., 2010). The process of verification and understanding can be influenced by the interpretation of literature on the phenomenon studied. The knowledge gained from the literature also provided an ability to reflect critically. MacNaughton and Hughes (2008) believe that to critically reflect, an interpretivist researcher needs to be able to draw on a range of ideas, make fair judgements and suggest suitable action for the situation.

\subsubsection{Inductive Approach}

Using the approach outlined by Miles et al. (2014), the process of data analysis in this study was inductive. As Figure 3.5 illustrates, this interactive cyclical approach sees data collection feeding into the process of data condensation, where I compared the statements from teachers in their reflective journals to those in focus group discussions, to my observations notes and those ideas identified in the research questions to help find some initial patterns.

Figure 3. 5

Components of Data Analysis: Interactive model

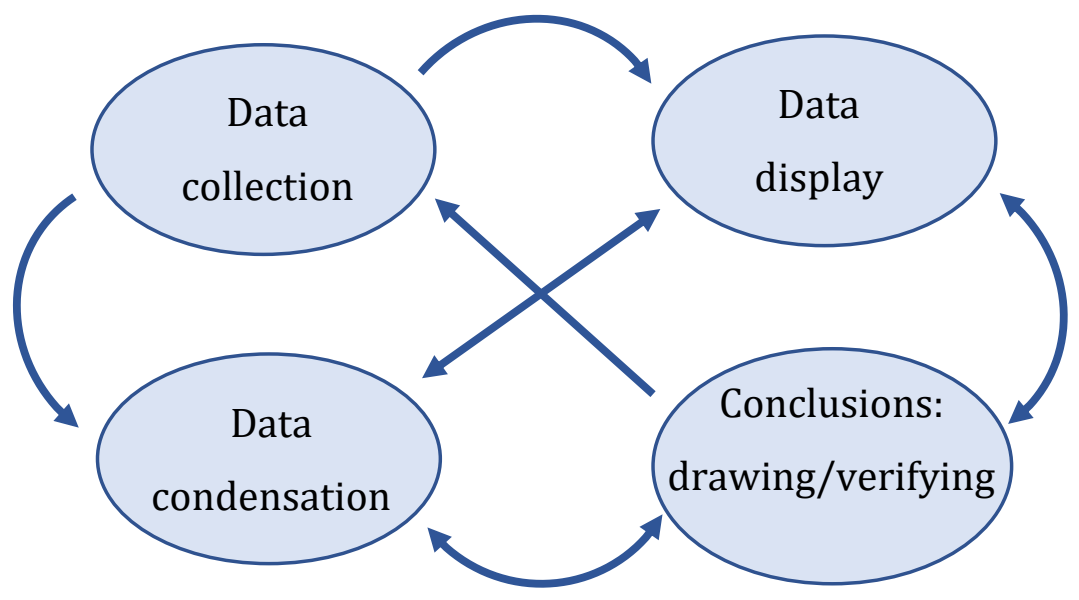

Note. Reprinted from Qualitative data analysis: A methods sourcebook (3 ed., p.14), by M. Miles, M. Huberman and J. Saldana, 2014. Sage. Copyright 2014 by Sage.

Colour coding these patterns in the data display (see Figure 3.6) helped clarify those early themes that were supported or adjusted as more data was collected. 
Figure 3.6

Codes for Qualitative Data

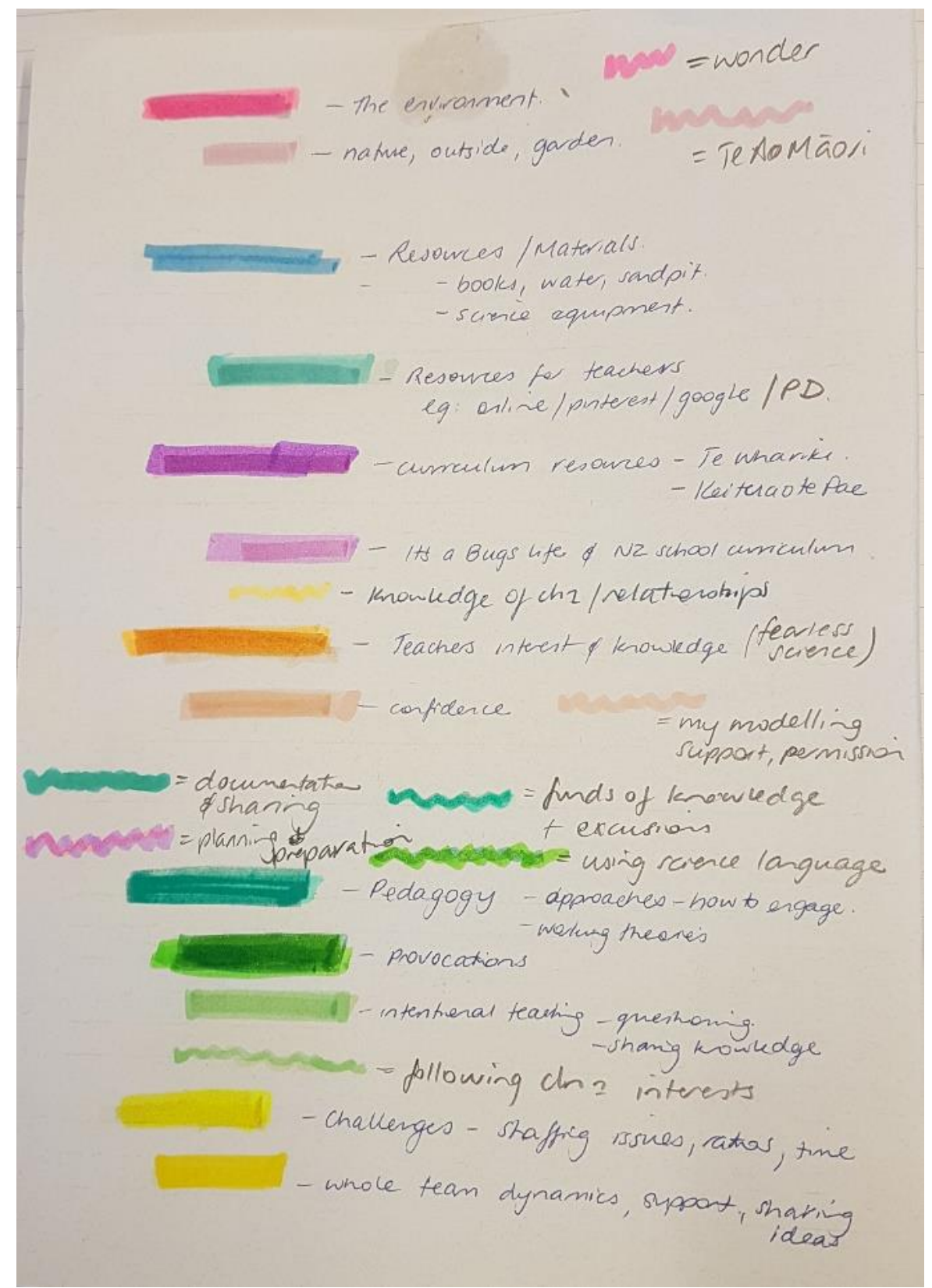

This organisation of the findings from each data source resulted in key themes emerging from each unit of analysis. I was then able to interpret these findings and draw conclusions from developing patterns (Miles et al., 2014). 


\subsubsection{Iterative Process}

An iterative process during data analysis provides flexibility and the ability to adapt the research design to accommodate new information found in the data (Mills et al., 2010). Emerging patterns from data sourced during the first three CAR centres highlighted the influence of my role and the value of certain pedagogical approaches for enabling science experiences. This meant I was able to adapt my engagement during the CAR process with the final three centres. For example, I asked additional questions in the focus groups and adjusted my support and suggestions to the teachers to focus more on the developing themes that had emerged from the data from the first three centres. I wanted to gain further data to explore these ideas, such as investigate the intentional teaching practices that teachers in the first three centres had found enabled more scientific experiences.

Analysis of qualitative data has been identified as an inductive process where the themes and patterns appear out of the data rather than having been identified prior to collecting the data (Patton, 1980). However, Srivastava and Hopwood (2009) contend that often it is not straightforward, arguing researchers are often driven by what they want to know from the data or by theoretical or ontological positions that skew how they view the data. To solve this, they have suggested an analysis framework that helps structure the iterative process of visiting and revisiting the data to spark insight and develop meaning, which in turn brings refined understandings. Srivastava and Hopwood (2009) developed three questions to provide "specific reference points to explicitly engage with the data analysis process"; "Q.1: What are the data telling me? ... Q.2: What is it I want to know? ... Q.3: What is the dialectical relationship between what the data are telling me and what I want to know?" (p. 78). Using this process helped illustrate how the shift in my involvement between the first three and the second three centres affected my analysis of the data; the questions of my data shifted from asking what it was telling me, to what I wanted to know.

This iterative method of data analysis allowed me to gather initial data, critically reflect on what the data was telling me that identified an emerging set of themes which could guide me for the next data collection as suggested by Grbich (2007). My epistemological stance is that reality is made with others and within the messiness of daily life. It is contextually influenced and an active process. It was therefore inevitable that my 
knowledge and experiences would influence the research process and how I would interpret and analyse the data (Sikes \& Potts, 2008). I also needed to be sensitive and responsive to any contrary findings and recognise the perspective I brought to the data analysis.

\subsubsection{Hermeneutic Approach}

My approach to data analysis was hermeneutic in that my understanding of the data was influenced by my interpretations of the literature about scientific learning in ECE. My examination of this literature helped me better understand the phenomenon under investigation. Throughout the study I returned to the literature often; either to find resources to give to teachers, to scaffold my own knowledge to better support teachers or to explore how my role was changing over time. There was constant movement between the literature, my previous understandings and the data emerging throughout the study. This process is referred to as the hermeneutic circle; "an iterative spiral of understanding" (Prasad, 2015, p. 34) where the parts can only be understood by looking at the whole, which in turn helps to clarify the parts. Prasad argued that to work in the hermeneutics tradition means using it as a methodology and appreciating the philosophical stance of the approach. From an epistemological perspective, my view fits within the hermeneutics position of Gadamer (1975) who argued that in the process of interpreting data the interpreter brings their own ideas and beliefs, or prejudices, to the activity. His position is that the interpreter must be aware of their prejudices "so that the text may present itself in all its newness and thus be able to assert its own truth against one's own fore-meanings" and so a dialogue occurs between the literature and the reader until understanding is achieved (p. 238).

I was therefore aware of the influence of my ideas and beliefs in how I interpreted the literature and how the discussions with teachers created shared understanding that in turn affected the suggestions, the questions or the additional literature I brought to the teaching team. Koch (1999, p. 32) identifies this as the "critical self-consciousness" of the researcher, an awareness of their background and how this might influence participants and the collection of data and sees this as a significant part of the hermeneutic circle. 


\subsubsection{Critical Lens}

The hermeneutic circle requires thinking about something to get to know it differently. This is an interpretivist process to data analysis; gradually getting to know something more deeply, looking at it in a variety of ways, or thinking critically about it (MacNaughton \& Hughes, 2008). Using a critical lens in the data collection process meant analysis of the various sources of data that occurred throughout the action research cycle (Kemmis et al., 2014). The first data collected during the science walk video was critically reflected on during the first focus group. The action plan was created from the discussions held during the first focus group and then implemented by the teachers. Evidence and documentation of the action plan in action was collected by observations, photos, video, teachers' reflection journals and learning stories written by teachers. This data was used to shape the focussed interview guidelines for the second focus group held after 6 weeks with the centre. The action plan was updated, and further data was collected during the final 6 weeks. This was added to the data from the first two focus groups and used to create the guiding framework for the final focus group questions and guide areas for discussion. Throughout this process there was continuous critical reflection and discussion, either as individuals or in collaborative conversations. This was all part of an iterative and inductive cycle of data collection, critical reflection and analysis, additional data collection and more analysis, to come to a deeper understanding and to consolidate meaning and provide explanations to the initial research questions (Grbich, 2007) and to also look to generate new knowledge (Corbin \& Strauss, 2008).

\subsubsection{Summary of how Data Sources Informed Research Questions}

The following diagram (see Figure 3.7) identifies how the range of data sources provided evidence that could be analysed for each research question. 
Figure 3. 7

How Data Sources Met Research Questions

\begin{tabular}{|c|c|c|c|c|c|c|c|c|c|}
\hline \multirow{2}{*}{\multicolumn{2}{|c|}{$\begin{array}{l}\text { Research } \\
\text { Questions }\end{array}$}} & Phase 1 & \multicolumn{7}{|c|}{ Phase 2} \\
\hline & & \multirow[t]{2}{*}{ 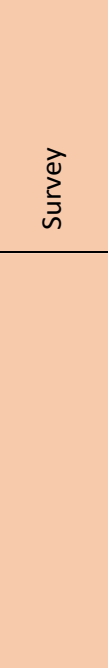 } & 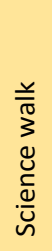 & 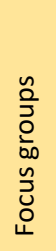 & 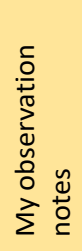 & 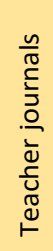 & $\begin{array}{l}\text { o } \\
0 \\
\frac{0}{0} \\
\frac{0}{0} \\
\frac{0}{0} \\
0 \\
\frac{0}{0} \\
\frac{0}{5}\end{array}$ & 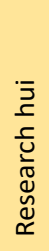 & 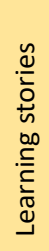 \\
\hline \multirow{3}{*}{ 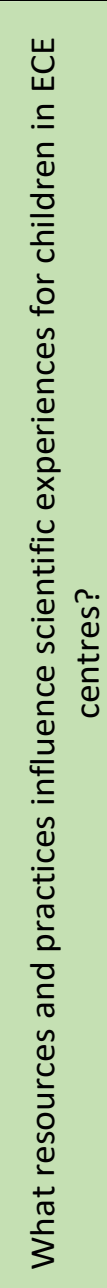 } & $\begin{array}{l}\text { How did the } \\
\text { process of action } \\
\text { research, } \\
\text { including the } \\
\text { researcher's role, } \\
\text { influence the } \\
\text { occurrence of } \\
\text { scientific } \\
\text { experiences? }\end{array}$ & & & V & 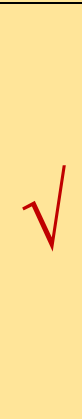 & V & & $V$ & \\
\hline & $\begin{array}{l}\text { How do } \\
\text { teachers' } \\
\text { pedagogical } \\
\text { approaches } \\
\text { enable children's } \\
\text { scientific } \\
\text { experiences? }\end{array}$ & $\sqrt{ }$ & $V$ & V & $V$ & V & V & $V$ & \\
\hline & $\begin{array}{l}\text { What are the } \\
\text { enablers/ } \\
\text { challenges to } \\
\text { scientific } \\
\text { learning in ECE } \\
\text { centres? }\end{array}$ & $\sqrt{ }$ & V & $V$ & V & $\sqrt{ }$ & V & & V \\
\hline
\end{tabular}

\subsection{Role of the Researcher}

My role shifted over the course of this study. I needed to continuously reflect on where my role was situated on the insider/outsider continuum and how my previous role as a university lecturer might generate a perception of expertise and power and therefore influence the CAR process (Herr \& Anderson, 2005). I explore this in more depth in chapter 7, however what I intended to do and what I did are outlined here. 
My contact with each of the six CAR centres began with an initial meeting where we talked through what the research would involve for them and what my role would be. For the first three centres I outlined that my role would involve videoing the science walk and facilitating focus groups at the beginning, middle, and end of the 12 weeks. After a plan of action was agreed to amongst the teachers that drew on the portfolio of evidence, literature, pedagogical and curriculum resources provided by me, I expected to leave the teaching team to implement the planned actions with regular monitoring, and then move on to begin the action research phase with the next centre. I intended to visit them during staff meetings to see how they were going, occasionally observe during sessions and take videos and photos of any occasions where science experiences were occurring. This approach was to give teachers control over the action research process. They were to identify and instigate their action plan, while my role was to observe, support and collect data.

However, after the first two session visits with the first centre, Kanuka, and reading a reflection from one teacher, I realised I needed to be more involved. As seen in the data collection timeline (see Figures 3.3 and 3.4), my increased visits to the centres happened about once a week while children were in session, which allowed me to observe, video and take photos of the science opportunities occurring in the daily practice of the centre. The informality of these visits allowed for casual conversations with teachers, opportunities to explore their ideas and discuss my feedback or observations from the previous week. Being there during session times also meant I engaged with children, modelled intentional teaching practices or explored alongside teachers as they investigated with children. These times together meant I was able to form a collaborative working relationship with the teachers, an outsider working with the insiders.

Working closely with teachers meant I needed to recognise the effect I could have on them and the situation and the effect others and the situation could have on me. Herr and Anderson (2015) argue it is important to define the position of the researcher at the outset of the research and understand that positions may shift through-out the research and be different for each centre. Herr and Anderson (2015) have identified six categories of the possible insider-outside roles within action research. Category 5 , Outsiders with insiders, best describes the collaborative relationship that developed 
between me and the teachers in this study. Herr \& Anderson (2015) outline this as where outsiders initiate and conclude the research, and work in collaboration with insiders.

I was also very aware of the various contextual influences on me as an outsider as identified by Herr and Anderson (2015), and the different roles I took during the research: such as interviewer, facilitator, expert, colleague, and observer. I examine this more in chapter 7.

\subsection{Trustworthiness and Authenticity}

Situating this study within a social constructivist paradigm means considering the study's worthiness by establishing its rigor or trustworthiness (Denzin \& Lincoln, 2018). In addition, as Lincoln and Guba (2013) have previously argued within a constructivist inquiry, authenticity is also relevant when using hermeneutic methods. In this study trustworthiness and authenticity are used to embrace the terms and encompass how I worked to meet credibility, transferability, dependability, and confirmability in this research (Elo et al., 2014; Lincoln \& Guba, 1985).

Qualitative research such as CAR is focussed on the socially constructed nature of reality and acknowledges the values that are involved in the research process. This means ensuring reliability can be challenging (Denzin \& Lincoln, 2011; MacNaughton, 2001). Therefore, within this ontological perspective where there is no essential truth, the approach to ensuring trustworthiness of the research findings and the knowledge created needs to be reimagined (MacNaughton, 2001). Lincoln (2001) has discussed the similarities between constructivist research and action research methods that are collaborative and participatory, and noted their shifting views on ethics and reliability criteria but that they both work on "honest and authentic relationships built on trust and caring" (p. 127). It is interesting to note the tension between the literature on action research which refers to the rigor and validity of action research studies (e.g., Herr \& Anderson, 2015; MacNaughton \& Hughes, 2008; Reason \& Bradbury, 2006) and the literature on qualitative research that refers to trustworthiness as the term to be used for assessing the reliability of qualitative studies (e.g., Amankwaa, 2016; Connelly, 2016; Denzin \& Lincoln, 2018). Within teacher and educational action research the discourse argues for trustworthiness (e.g., Mena \& Russell, 2017; Phillips \& Carr, 2009). Elo et al. 
(2014) contend that the trustworthiness of a study "depends on the availability of rich, appropriate and well-saturated data" (p. 8). Hence, they claim data collection, analysis and reporting needs to be thorough and clearly identified as appropriate to answer the research questions.

The trustworthiness of my research was strengthened by the rigorous approach I took to data collection and analysis. The process and findings of my research can therefore be seen to be trustworthy and authentic because of the comprehensive preparation, organisation and reporting of the content analysis involved in this study (Elo et al., 2014). Phillips and Carr (2009) also believe "transparency of process" in action research is important for teachers to ensure trustworthiness (p. 208). They state that data needs to be collected for a purpose, with multiple perspectives included and that change in practice occurs which ensures "results that matter" (p. 208). Exploration of data collection, analysis and reporting is therefore used to review the trustworthiness and authenticity of this study.

\subsubsection{Collaborative Analysis}

Data analysis during the CAR process provided further opportunities for demonstrating authenticity and trustworthiness. By providing transcripts of the focus groups, the action plan and observation notes from each visit to all participants to review, I sought to be as transparent as possible of the ideas and discussions occurring over the 12 weeks with each centre. I looked to emphasise moments teachers thought were important, which they noted in their reflection journals or I captured in mine. I drew on these to guide discussions during the following focus groups. I sought their input and perspectives on the data as one way to overcome my partiality dominating. This allowed for multiple perspectives of the phenomenon of scientific experiences in ECE, offering diversity, distanciation and critical reflection in data analysis (Cornish et al., 2014). In keeping with the post-structuralist approach to trustworthiness (or validity) as outlined by MacNaughton and Hughes (2008), I looked to "locate dynamic, multiple truths in specific local circumstances" (p. 129). I saw my relationship with the researcher participants, the teachers, as equitable and wanted their voices to be heard throughout the CAR process. This position of equality, openness and trust allowed for critical and collaborative analysis of data with the teachers and met the authenticity criteria outlined by Lincoln and Guba (2013). In addition, Sandburg and Wallo (2013) argue for 
researchers and participants working together towards mutual understanding and consensus means they believe the integration of the insider and outsider perspectives in joint analysis generates new knowledge with greater trustworthiness.

\subsubsection{Reporting}

Denzin and Lincoln (2011) claim capturing an objective reality in qualitative research is unlikely. Using multiple methods of data collection, triangulation and rich descriptions in this study provided through teachers' reflective journals, learning stories, my reflective journal and observation notes, enabled an in-depth understanding of the phenomenon of scientific experiences in ECE. Analysis was also able to highlight common understandings, interpretations and meanings of the issue and so provide thoroughness and rigour to the research (Denzin \& Lincoln, 2011).

More recently the assessment of rigour in completed research is seen to rely on the reviewer's ability to evaluate each dimension of the study (Morse, 2018). Lincoln and Guba (2013) have updated their criteria for trustworthiness to one of an authenticity criteria. As my study fits within a constructivist paradigm, using hermeneutic methodology, I used Lincoln and Guba's (2013) criteria to assess the authenticity and trustworthiness of my research. They suggest that the quality (rigour) of a study should be determined using the following principles: fairness, ontological, educative, catalytic, and tactical authenticity (pp. 70-71).

\subsection{Ethics}

The criteria for ethics in the social sciences has generally been based on several guidelines such as informed consent, do no harm, privacy and confidentiality, and nondeception (Denzin \& Lincoln, 2018). These are usually set by the institute the researcher works in, and I received ethical approval from the VUW Human Ethics Committee, for my study (Appendix C).

Following these guidelines, the respondents to the online survey gave consent through their completion and their responses were anonymous. All teachers participating in the CAR were given information sheets and letters (Appendix D) about the research, the methodological process and what would be required of their involvement. They were able to ask questions during initial meetings or via email and gave their informed consent by signing a consent form (Appendix E). The consent form outlined that 
pseudonyms would be used for the centres and teachers so they and anything said by them could not be identified. Their online journals and focus group data were kept confidential. Through the two research hui held over the research period participants became aware of each other and so consent for this was signed by those involved (Appendix F). The Participant information pamphlet is attached as Appendix G.

Parents in each centre were given an information letter and asked to give informed consent for their child/ren to be involved in the CAR, if visual images of their child could be used and if they wanted a summary of the findings from the research (Appendix $\mathrm{H}$ and I). Initials would be used for any children discussed in the study. Reflecting on the four axis of research participation with children devised by MacNaughton et al. (2006); “Axis 1- Children are assigned to an adult-initiated project, but informed ... Axis 2 Adults initiate projects and share decisions with children ... Axis 3 - Children are consulted and informed [and] Axis 4-Children initiate and direct research" (p. 171), I positioned my research between Axis 1 and 2 where children were included in an adultinitiated project but where children could choose to be involved or not. Each child thought capable of understanding were offered an agreement form to sign giving consent to be watched, be talked to, be photographed and videoed and information about them shared by teachers to me (Appendix J). If a parent or child chose not to be involved teachers and I ensured they were not included in any recordings or discussions as part of the research.

Nonetheless, as discussed by MacNaughton et al. (2006), there were challenges. The teachers and I viewed children as having rights in this research process, so we needed to support their choices and work around them. For example, when a child who did not have consent from their parents or who had not given consent joined a science activity, they could remain part of the experience, but their involvement was not intentionally recorded in any way. If, however they happened to be in any video, their image was blurred. This study was therefore conducted under the ethical principles of confidentiality, informed consent and the right of participant teachers, parents, and children to withdraw from the research at any stage.

MacNaughton and Hughes (2008) have provided specific ethical responsibilities for those involved in CAR, in particular the "ethical responsibility to share power with their co-researchers" (p. 84). They suggested ensuring there are clear directives to guide the 
collaborative relationship between the researcher and participants, a strategy to deal with disagreements and to ensure reciprocity so that trust is fostered. I made all efforts to be open and honest with teachers, offering them opportunities to review and change any transcripts, action plans and my version of the situation through my observation notes. I encouraged teachers to trust in their ability to change their practice and recognise there could be different understandings of events. I wanted to share ownership of this research project and so worked to empower teachers to trust themselves and "believe that they [could] create change" (MacNaughton \& Hughes, 2008, p. 86).

However, while meeting the ethical requirements of my university I was very aware of the lack of room for participants to take ownership of the research through this ethical model. For example, all centres wanted to let their communities know their teachers were involved in the research to show the value they placed on learning and teachers' PLD. Over the CAR several centres did this through their centre newsletter, or digital communications. This highlighted for me the value in exploring another ethical framework more suited to protecting the participants, rather than the institutes setting the ethical guidelines, as argued by Christians (2018). He calls for the principles of feminist communitarianism to provide an ethical structure for qualitative research like CAR where the power relationship between the researcher and participants is more equal. This ethical approach presumes there to be community values that are common to all involved; shared ideals of care, trust, and kindness (Denzin \& Lincoln, 2018).

The relationships that formed between the teachers and me during the research became firmly situated within a collaborative research model where we had mutual understandings of trust, care, and ownership. Having teachers share their involvement in the CAR with their community was beyond my control, and it did not feel right to restrict it. As argued by Denzin (2003), this type of research "makes the researcher responsible not to a removed discipline (or institution), but to those he or she studies" (p. 259). Similarly, for Christians (2018), the ethics of being places moral values in human existence where it needs to be seen in communal terms; seeing "human interactions that teach us the good in everyday life" (p. 76). This fits the ontological approach of this study, and the collaborative nature of this action research meant I was 
constantly assessing and working towards "honest and authentic relationships built on trust and caring" (Lincoln, 2001, p. 127).

\subsection{Chapter Summary}

This chapter has outlined the research methodology used in this study. Identifying the interpretive paradigm this study is situated in and the ontological lens used in this case study involving a survey and CAR has shown how I chose to investigate the phenomenon of scientific experiences in six NZ ECE centres. This research approach has been justified through discussions around the research design, data collection and data analysis as has my role in the study, how I worked in partnership with teacher participants and how our collaborative data analysis led to a way to view the trustworthiness of this study. Being involved in a mainly qualitative research study like this is rewarding in many ways but also raises unsettling dilemmas, such as those examined around ethics. The impact of this methodology and my role is explored further in later chapters, including other influences enabling scientific experiences for young children. The following three chapters present the findings from both phases of this study. 


\section{Scientific Experiences for Young Children in NZ}

\subsection{Chapter Overview}

This chapter outlines findings from the first phase of this research project, a national survey of teachers in kindergartens and education and care centres in NZ. The purpose of this anonymous online survey was to provide an overview of what scientific learning was happening in ECE centres. The survey was designed to gain information about what teachers think about science in ECE and how well they believe they support scientific experiences in their centre.

The survey provided quantitative data, which is presented through graphs and tables, and qualitative data from text answers. The text replies have been collated, with content falling into the areas within the research questions: possible enablers in the environment; resources; the teacher; their pedagogical approaches; and the challenges to scientific learning occurring. The full survey is included as Appendix A.

\subsection{The Intention of the Survey}

In this survey a broad sample of teachers' perception of science and scientific learning for children in NZ ECE was gained. The survey was designed to address the main research question; What resources and practices influence scientific experiences for children in ECE centres? Questions asked for information about the centre: the type of service, the philosophical, religious, or cultural approach, the ages of the children, and the respondent's role in the centre. Questions then asked the respondents' views of science in ECE, how often they thought opportunities for science occurred in their centre and what was helpful in supporting science to occur.

The survey was sent out over a week in mid-June 2017, with a follow up email 2 weeks later. The response rate was 11\%; a total of 378 responses.

\subsection{Survey Findings}

The following section presents quantitative and qualitative data from the survey. Not all of the 378 survey respondents answered each question, so there were some differences in total responses for each. 


\subsubsection{Quantitative Data}

Quantitative data from the survey provided information on the type of service the respondent worked in, the position held in the centre and their qualification, whether the centre belonged to any organisations or had a philosophy they followed.

Respondents identified which type of service they worked in which is shown in Table 4.1.

Table 4. 1

Service Type

\begin{tabular}{|l|r|r|}
\hline Type of Service & $\%$ & Count \\
\hline Kindergarten & $26 \%$ & 91 \\
\hline Full day education and care & $63 \%$ & 221 \\
\hline Sessional education and care & $5 \%$ & 17 \\
\hline Other & $6 \%$ & 20 \\
\hline Total & $100 \%$ & 349 \\
\hline
\end{tabular}

Respondents were asked if their centre identified with any organisation or philosophical approach. This information in Table 4.2 allowed the researcher to link philosophical approaches with specific answers to later questions.

Table 4. 2

Identified Approach

\begin{tabular}{|l|r|}
\hline Approach & $\%$ \\
\hline Ethnic or cultural (most identified themselves as Māori, Samoan, or & $19 \%$ \\
Pasifika) & $13 \%$ \\
\hline Montessori & $13 \%$ \\
Reggio Emilia & $10 \%$ \\
Resources for Educarers (RIE) & $9 \%$ \\
Religious (most identified themselves as Christian) & $2 \%$ \\
Rudolf Steiner & $34 \%$ \\
\hline Other* & \\
\hline
\end{tabular}

Note. ${ }^{*}$ Other includes: RIE, Reggio, Forest or nature, attachment or place based, or a mix of some of the above. 
The age range of the children in the centres was also captured. Results indicated $65 \%$ of the respondents worked in centres which catered for children 2 to 5 years old. Many of the respondents were Centre Managers (36\%), while 26\% identified themselves as teachers or educators. Of the 333 who replied to a question about qualifications the majority were qualified in some way as shown in Table 4.3.

Table 4. 3

Qualifications

\begin{tabular}{|l|r|}
\hline Qualification & $\%$ \\
\hline BTchg (ECE) & $33 \%$ \\
\hline BTchg (Primary) & $6 \%$ \\
\hline Diploma of Teaching (ECE) & $30 \%$ \\
\hline Montessori Teaching Diploma & $5 \%$ \\
\hline NZ Steiner Teaching Diploma (EC) & $2 \%$ \\
\hline Other* (please specify) & $24 \%$ \\
\hline Total & $100 \%$ \\
\hline
\end{tabular}

Note. *Other includes: Graduate Diploma in Teaching, Master's degree, Kindergarten Diploma, and various education or teaching diplomas or degrees.

\subsubsection{Qualitative Data}

This section presents the qualitative data from questions which sought to explore the respondents' views of science in ECE, how often they thought opportunities for science occurred in their centre, and what they believed was helpful to support science to happen. Their answers were provided in text form or via a Likert scale. Graphs have been used to show data from Likert questions. Findings are presented under each of the survey questions asked. Where respondents answered two questions similarly, the answers have been presented together. For two of the questions, which provided the largest source of data, the findings fall under the areas identified in the project's research questions; the possible enablers in the environment such as resources, how the teacher enables science through the pedagogical approaches they use, and the possible challenges to scientific learning occurring.

Qualitative data from the respondents' text answers provided has been summarised or direct quotes have been used. All respondents who identified themselves as a teacher held one or more of the qualifications listed in Table 4.3. Information such as the type of 
centre they worked in, whether it was full day or a sessional service, and the role they held in the centre has been identified. The following abbreviations shown in Table 4.4 are used when presenting the respondents direct quotes.

Table 4. 4

Abbreviations

\begin{tabular}{|l|r|}
\hline Title & Abbreviation \\
\hline Teacher & $\mathrm{T}$ \\
\hline Head Teacher & $\mathrm{HT}$ \\
\hline Centre Manager (or Supervisor) & $\mathrm{CM}$ \\
\hline Owner & $\mathrm{O}$ \\
\hline Full day service & $\mathrm{FD}$ \\
\hline Sessional service & $\mathrm{S}$ \\
\hline Education and care centre & $\mathrm{EC}$ \\
\hline Montessori & $\mathrm{M}$ \\
\hline Kindergarten & $\mathrm{K}$ \\
\hline
\end{tabular}

\section{Last Formal Science Study.}

In addition to their teaching qualification, respondents were asked when they last studied science formally. Of the 337 responses there were 401 choices from the options provided: many years ago at high school, year 11 or $5^{\text {th }}$ form, year 12 or $6^{\text {th }}$ form, year 13 or $7^{\text {th }}$ form, undergraduate level at university, post graduate level or during teacher training. Some respondents chose 2 or more options (see Figure 4.1). Due to a limitation with the formatting of the question, the data cannot identify if those who indicated undergraduate or post-graduate science education did so before or after their initial teacher training. In addition, of those who chose only during teacher training, the data does not show when they last formally studied science, if at all. 
Figure 4. 1

Last Formal Science Study

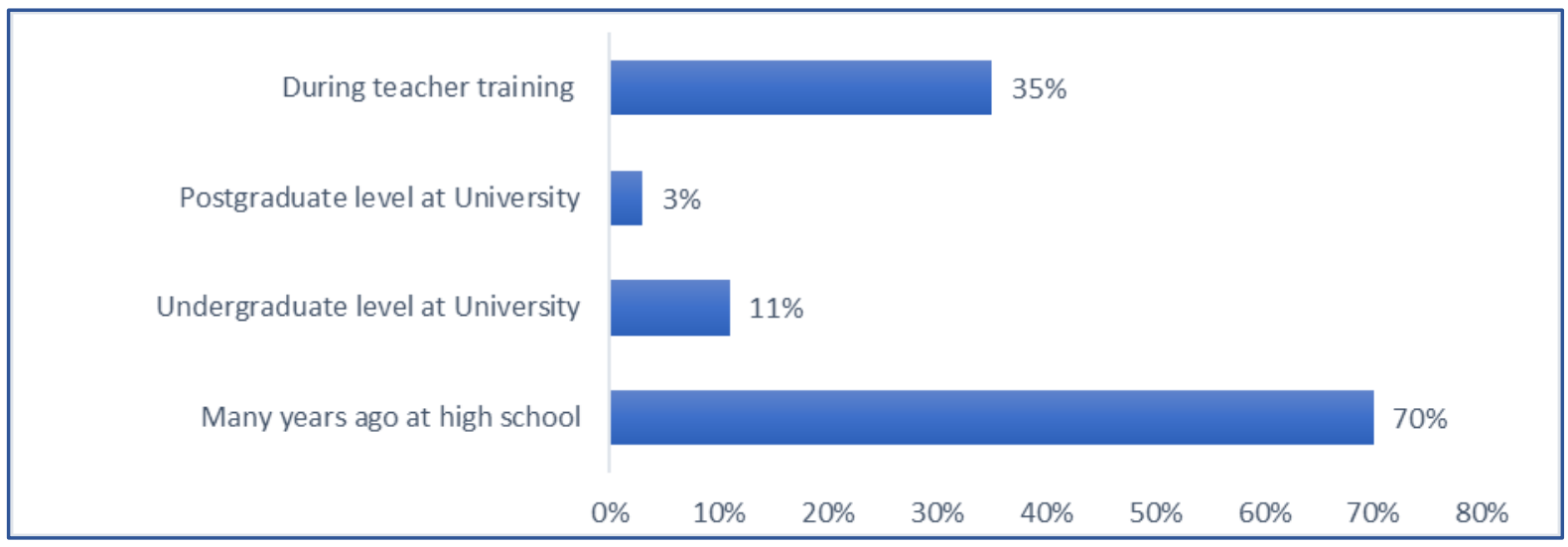

Confidence to Support Science Learning.

Respondents were asked how confident they felt supporting children's scientific learning, and why. Of the 266 responses to this question, just over half (53\%) chose moderately confident. The participants who felt extremely confident had studied science at year 13, at an undergraduate or post graduate level at university, or during their initial teacher education, or both. They explained they felt confident due to their level of science knowledge and/or because they enjoyed science:

My initial teacher education, my experience with young children and my love of science in nature.

Because I love science.

$(C M, S, E C)$

In contrast, $56 \%$ of the respondents who identified as slightly confident, slightly unconfident or neither confident nor unconfident (53 out of 266 responses), indicated that the last time they studied science formally was many years ago at high school, or up to year 12 . They felt their lack of confidence and knowledge affected their ability to support children's' scientific learning:

I need more skills about science.

I am not that confident in my own knowledge about science concepts so tend to shy away from teaching it as I don't always know the answer. $(T, F D, E C)$

For example, one participant who chose the least confident option on the Likert scale, moderately unconfident, had studied science formally many years ago in high school 
and felt a "lack of knowledge" (HT,FD,EC) affected their ability to support science learning with children.

\section{Importance of Teaching Science.}

Respondents were asked to indicate their support for the statement "Teaching science is important in ECE". This was to capture the overall view of science as a subject or area of learning within ECE. Nearly all, 96\%, indicated that they agreed or strongly agreed with this statement (see Figure 4.2).

Figure 4. 2

Importance of Teaching Science

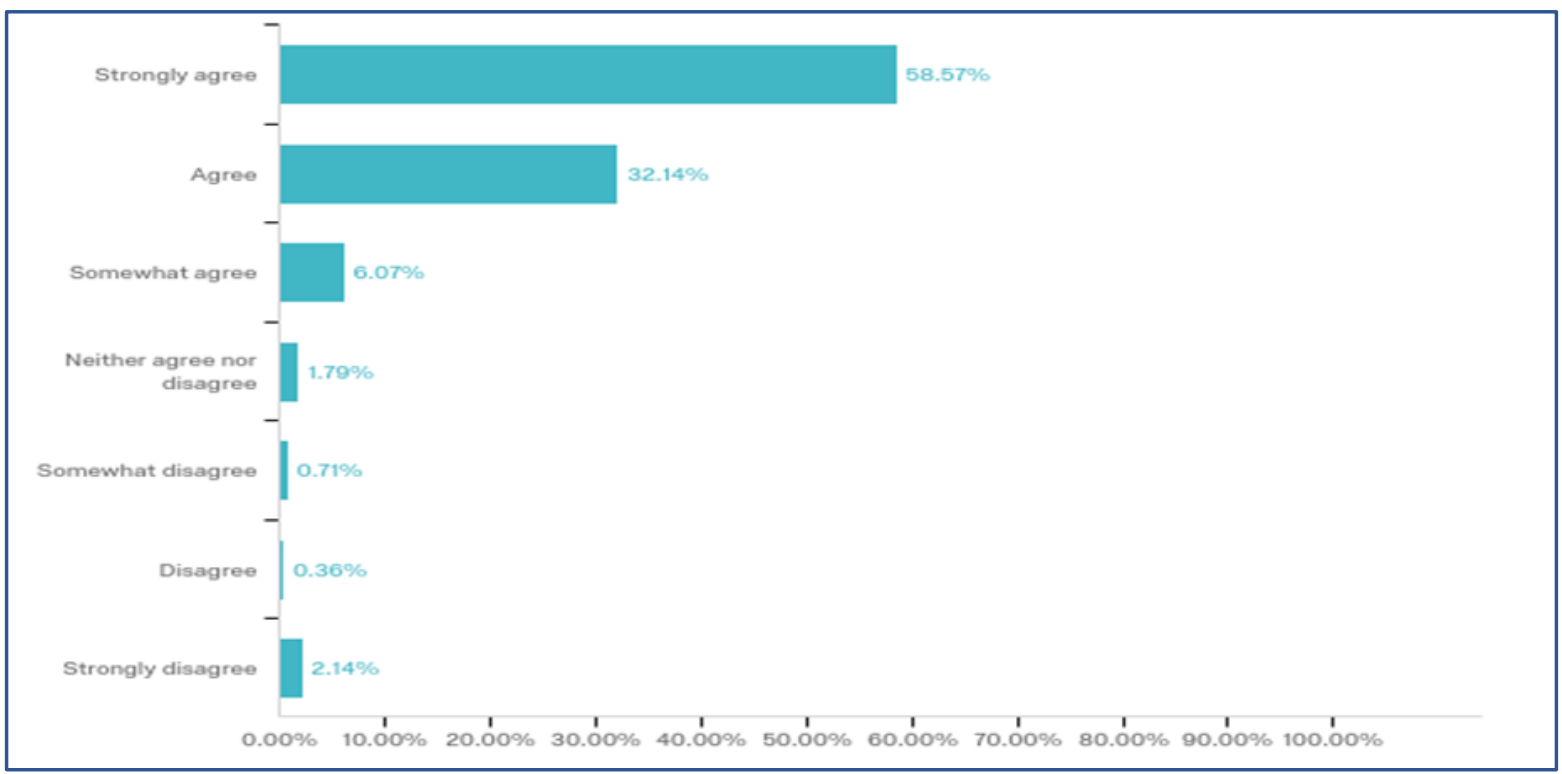

The respondents who provided written answers on why science was important, indicated this was due to one or more of the following ideas which emerged in the text answers to questions later in the survey. Respondents felt science supported the development of children's working theories:

Developing working theories about their environment, history and the living world around them.

Many science concepts inform children's working theories about the world around them. Having exposure to science helps them to create and recreate working theories about how this world works. 
Or that science allowed children to make connections, make sense of and gain an understanding of their world:

Gain an understanding of how and why things are the way they are.

Science helps us understand the world around us and how it works, makes connections between mathematical concepts and technological processes.

$(C M, F D, E C)$

About $20 \%$ of respondents felt science fostered curiosity in children and encouraged them to wonder about their world and how it worked:

Because it fosters curiosity and a sense of wonder; making connections with the natural and physical world.

It teaches children to be curious about their world.

Respondents also believed science was important because it is all around us and part of our everyday activities:

Science is part of children's everyday life.

$(C M, F D, E C)$

Furthermore, some felt children are naturally scientists anyway:

Young children ARE scientists.

$(C M, F D, E C)$

The Practice of Science in ECE Centres.

Respondents were asked to explain how they saw science happening in practice at their centre. The 269 responses to this question indicated they saw opportunities occurring through children discovering scientific concepts while exploring and involved in childdriven free-play. They felt science happened naturally through activities outside; in the sandpit, using water in the sandpit or on its own or gardening, while $26 \%$ believed science occurred through the involvement of water in science activities:

Outdoor activities such as, sandpit, water, painting, nature walk to observe the beauty of nature in finding snails, slugs, flowers, butterfly, different plants.

$(C M, F D, E C)$

Respondents believed science happened indoors when children were baking, involved in messy play, doing art, discussing hygiene, playing with blocks or through reading stories. 
Through learning experiences such as; preparation of baking/cooking, water play, sand, sensory - playdough, gloop etc, construction/deconstruction, blocks, carpentry, small animals, painting, collage \& science experiments - volcanoes, lava lamps, floating \& sinking concepts.

$(H T / C M, F D, E C)$

Responses on how science opportunities arose mentioned exploration, discovering, and asking questions. Respondents said curiosity and wonder were dispositions that children showed when exploring science. They saw children's development and testing of their working theories as another way for science to happen.

Written replies on the role of the teacher said science was enabled by the provision of resources planned and placed purposefully to support scientific experiences and materials that encouraged exploration and experimentation. Respondents felt noticing these moments and recognising them as teachable moments meant they could support scientific learning by asking questions and using scientific language when conversing and co-constructing knowledge with the children.

Teachers' interactions through quality questions, careful listening and coconstructing their learning also important to promote science.

$(C M, S, M)$

Purposeful placing of resources, planned science activities, and experimentation.

The responses also explored the pedagogical approaches teachers used to support science. Some felt free and uninterrupted play would do this, while others considered teacher-led and planned experiences with intentional resourcing would do so. Other responses mentioned provocations to stimulate science experiences.

Science is not taught formally, it is explored freely and child directed.

As teachers we provide provocations through, the environment, resources, and our language.

When asked how they saw science happening in their centres some respondents (28\%) mentioned experiments, in particular using baking soda and vinegar to create a reaction to simulate lava flowing out of a volcano. For example:

The famous vinegar / baking soda volcano in the sandpit. 
We also perform science experiments in the classroom and children are amazed to see them.

Opportunities for Scientific Learning.

Of the 274 respondents who replied to this question, 209 (76\%) felt science occurred everyday through the children's daily activities. They felt science was in, or potentially in, everything the children did and everywhere within the centre.

The idea of science happening everywhere and everyday was reinforced by respondents' responses to how often they thought opportunities for scientific learning happened in their centre. They could choose either daily, 4-6 times a week, 2-3 times a week, once a week or never. The results indicated many of the respondents saw science happening daily. As shown in Figure 4.3.

\section{Figure 4.3}

Opportunities for Science Learning

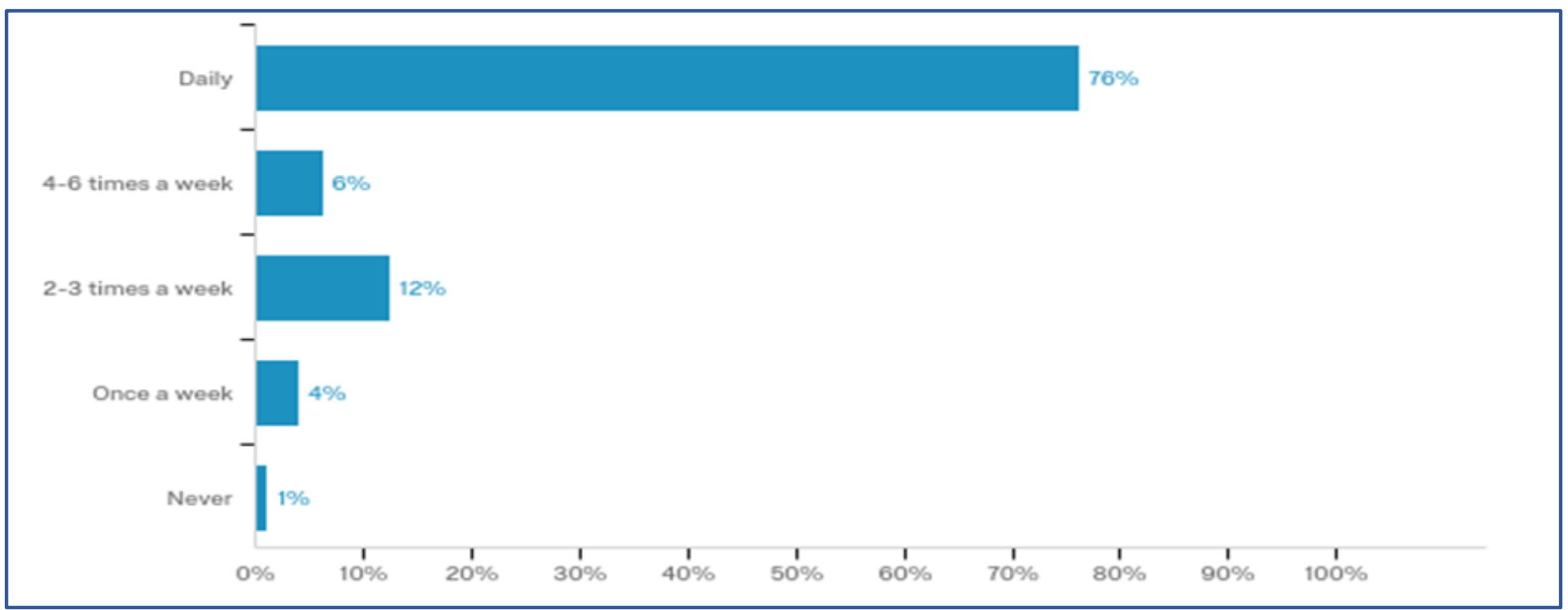

If the respondents specified daily, 4-6 times a week or 2-3 times a week they were then asked:

What factors support this scientific learning to happen so often?

Examples were provided for the respondents to consider, such as the service's environment, the resources available, the teacher's interests, or the teaching team's pedagogical approaches. There were 251 responses to this question. Respondents were also requested to answer: What else do you think, or have you found to be helpful to support scientific learning with children? A total of 204 responses were received. 


\section{Factors That Support Scientific Learning With Children.}

The two questions provided differently phrased answers but indicated similar ideas. These ideas fell into the three areas identified by the research questions: the enablers such as environment and resources, the teacher, and pedagogies used. The following section structures the findings to these two questions under three of the original research questions.

How Does the Curriculum, the Environment and/or Materials Help Support

\section{Scientific Learning?}

Respondents were asked how they thought the curriculum and/or the environment supported science in their centres. Many respondents noted the environment and the resources provided in the centre were the most significant influences on how scientific experiences were enabled in their centres.

\section{The Environment.}

Respondents (about 58\%) identified the environment as an important factor to support children's scientific learning either as a prepared or intentionally arranged space where science experiences are facilitated or as a natural space for children to explore and discover. Many respondents saw science occurring outside and when engaging with the natural world. If their outside space was large, it was often mentioned as a key area for science to happen. Outside activities were also mentioned as a way for science to occur or to be supported such as gardening, composting, worm-farm, finding insects, riding bikes, caring for animals, going for walks, in the sandpit, and using water:

We have spacious grounds where children can explore the natural environment. $(C M, F D, E C)$

Children make discoveries throughout the day with engaging and exploring the outdoor environment. For example, finding bugs to study, experiencing with their senses, mud, earth, natural elements, nature, rain on their face, wind in their hair, planting and watering plants.

The respondents identified the importance of the environment inside, arranging spaces intentionally to support scientific engagement:

The environment is provocative and inspiring ensuring time and space to query, listen and consider. 
The environment supports children's scientific learning inside the kindergarten rooms and outside in the garden.

We have intentionally worked to create an inside and outside environment which supports natural curiosity and links to nature and which is accessible to the children and inspires them to be curious.

$(C M, F D E C)$

Resources.

Resources were not mentioned (about 48\%) as often as the environment. Where they were mentioned, it was as specific science equipment, such as magnifying glasses, scales, binoculars, magnets, and compasses. Responses suggest specific science materials were set out for children to explore, to introduce or support their scientific inquiries and to extend their interests.

Other resources that were identified as important for facilitating science were books, use of the internet, and open-ended resources:

We have many resources on hand to extend science activities including many references books.

We use the internet to discover more about creatures and extend learning in any field the children are interested in.

When asked what they found helpful, or thought would be, respondents often mentioned resources for themselves or their team. Teaching guides, research articles, exemplars, online science websites or Facebook pages. The search engine Google, as well as YouTube and Pinterest were often mentioned as useful ways to find information or to provide ideas for science related activities.

\section{The Support or Learning Needed for Teachers.}

The survey explored what support or knowledge the respondents thought the teachers might need to foster science. The role of the teacher was highlighted as a key influence for science experiences to occur. The interest the teacher had in science was often mentioned. Teachers who are passionate about the subject and had an enthusiasm to learn more. 
The teachers are EVERYTHING in scientific learning. You can have all the best resources but until a teacher takes an interest there will be very little scientific learning.

$(C M, F D, E C)$

A teacher who is knowledgeable / enthusiastic about science!

Science is my passion so I bring it out in pretty much everything I do.

$T, F D, E C)$

They thought it was important to support scientific learning by teachers' showing their interest through a sense of wonder in the world around them and doing so alongside children. It was noted that teachers who loved science and showed awe and wonder in the world around them created the same attitude in children which afforded opportunities for investigations and interest in scientific experiences.

Respondents noted that this was sometimes left to one particular teacher in the centre:

One of our teachers is specifically interested in the world of science and she takes the lead within our centre in regards to this.

One of our teaching team has a particular passion for science so is always researching appropriate activities.

Specific knowledge in science was identified by respondents as important for teachers to ignite passion and interest in science in children. For some respondents it was important to have an understanding and knowledge of science within the early childhood context; knowing how to recognise science and scientific learning in young children and then knowing how to respond to their interests to support scientific explorations:

Teachers' knowledge and understanding about what science is and how it looks in ECE. $(C M, F D, E C)$

Most importantly is the teachers recognising that many of the experiences we do daily have an element of science involved - using a science lens.

\section{How do Teachers' Pedagogical Approaches Enable Children's Scientific Experiences?}

The identification of teachers' roles in supporting children's scientific experiences was inextricably linked to the pedagogical strategies they used. The pedagogical approach of 
the centre was often identified by respondents as an influence on scientific learning occurring in their centre, either through the way children engaged in science or the teaching strategies used. Some respondents suggested that allowing children to explore their environment and the resources available through free play meant science experiences occurred:

Our kindergarten philosophy allows children to be free to play - investigating and exploring throughout the day in natural ways. Children are encouraged to problem solve and be creative with their ideas and theories independently.

Our free play philosophy that supports children's interest in science. It is the opportunities to explore in uninterrupted ways that support science.

$(C M, F D, E C)$

Some respondents saw the role of the teacher as more intentional in supporting scientific experiences through the teaching strategies. They mentioned teachers helped bring scientific learning into everyday activities when they were responsive to children's interests and used specific teaching strategies like asking questions:

All the best science occurs through exploration and discovery, it is more meaningful when it is child led and teachers can scaffold and extend developed interests.

$(C M, F D, E C)$

Teachers respond, support, and extend on the children's natural curiosity about the world them.

Respondents explored how teachers might respond to children's interests, providing examples of what they were already doing in their answers to the question: What factors support scientific learning to happen so often? Or what they think might be helpful to support children's scientific learning in their answers to the question: What else do you think, or have you found to be helpful to support scientific learning with children? The pedagogical strategies outlined in their responses involved being interested and encouraging curiosity with the children, asking questions, and responding to children's questions. Other strategies mentioned were learning alongside children, such as co-constructing knowledge together, provoking or facilitating experiences to either prompt or extend children's scientific interests, and supporting the children's working theories about why and how the world works. 
Specific strategies used by teachers that were seen as important in initiating and supporting scientific experiences for children were provocations and intentional teaching strategies. These included planning, providing resources and provocations, researching for themselves or with children, sharing ideas and knowledge through conversations and experiences and asking and responding to questions.

We have a natural area for the children to explore, we have a range of resources available throughout the centre for the children, we set up provocations around science related opportunities, we encourage science thinking through experience and conversations, we have a science related theme incorporated into our transition to school programme.

$(C M, F D, E C)$

Responding to children's curiosity and strengthening this learning through noticing children's interests, responding to these through discussion, looking closely, sharing ideas to deepen understanding, supporting children to be inquisitive and ask questions about what is happening around them.

$(H T, F D, E C)$

Some respondents said another way to include science experiences in their programme was to take children out of the centre environment, either going on nature walks, to the beach or to museums.

We have our nature-based programme where groups of children go out twice a week so science is often a focus on these excursions.

We take children on extended visits to University and to a nature reserve weekly.

$(H T, F D, E C)$

Access to parents/family and science experts' funds of knowledge was identified as helpful to support scientific interests. Family involvement was highlighted; either through the family being interested or participating in science experiences or coming into the centre to share their knowledge. Respondents noted the value in building relationships with the local science community, and having experts visiting to share their knowledge with teachers and children.

The Infrequent Occurrence of Science in ECE Centres.

Findings from the survey provided insights into the sub-question: What are the enablers/challenges to scientific experiences in ECE centres? When asked how often science learning occurred, if respondents felt science occurred only once a week or 
never in their centre, they were then asked why they thought scientific learning occurred so infrequently. In a small number of text answers (12) the respondents thought teachers' lack of knowledge, understanding, confidence and interest in science was the main influence on science occurring so infrequently in their centres.

The concerns above were confirmed in the challenges identified through text responses to the questions; what factors support scientific learning to happen so often? and; what else do you think, or have you found to be helpful to support scientific learning with children? Teachers who were not interested in science or felt they lacked the knowledge or confidence to explore science with children meant science was not happening as much as it could.

I feel like if I had more experience and knowledge about science I would be able to implement it more in the curriculum more confidently.

I think it is really all about teachers' knowledge and confidence in this area. Many teachers think that they "don't know how to do science" but that's because I think they have a narrow, knowledge-based view of science, they are not thinking about the scientific dispositions that they could be encouraging.

Other challenges were structural issues such as regulations around outings from the centre, staffing, and staff-to-children ratios. A key challenge was teachers not having enough time. Time was viewed as important to enable teachers to observe children, respond to their interests and situations in the moment, to document and then follow up on these experiences with further activities.

The reality is we are stretched much of the time and do not get enough time to document or sit and listen to a child's ideas.

Having limited resources to support and prompt children's interests was also a challenge for some respondents. The limitation of resources was identified as either a lack of funding to buy them or resources not being respected by the children thereby not lasting long enough for them to be revisited.

\section{Supports Helpful for Scientific Experiences in ECE Centres.}

The respondents were asked to use a slider to indicate which of the following supported scientific learning: 
- Curriculum resources about science

- Science areas in the centre environment

- Science materials/resources for the children

- Teacher PLD

The results showed most respondents felt teacher PLD would be extremely or very helpful (76\%), a similar number felt the same for curriculum resources about science and science materials/resources for children (73 and 72\%) (see Figure 4.4).

Figure 4. 4

Supports Helpful to Scientific Learning in ECE Centres

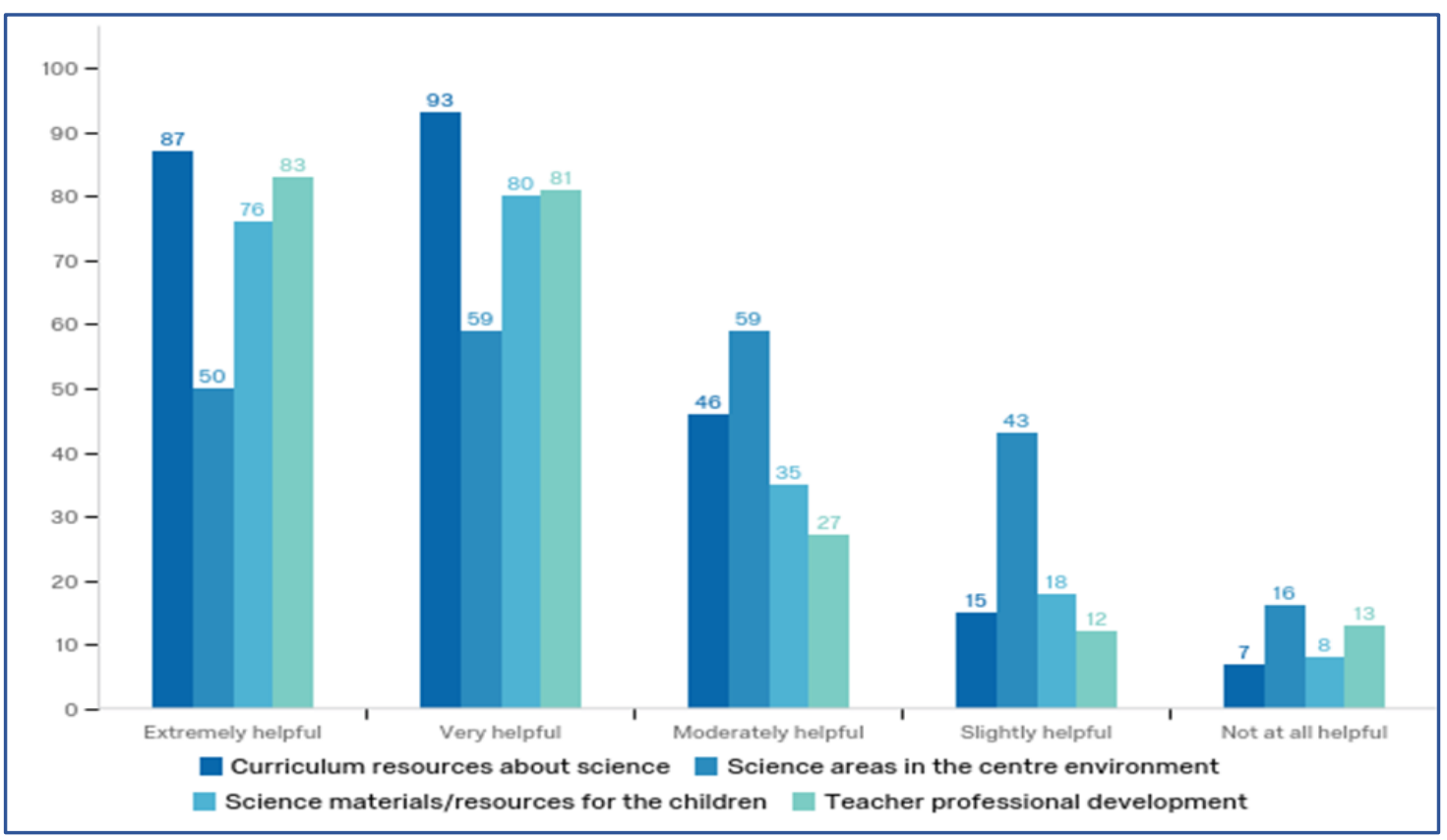

This is reinforced by the high number of times PLD was suggested as helpful to support scientific learning with children in the text answers to question 6.1: What else do you think or have you found to be helpful to support scientific learning with children? Suggestions for PLD included it being situated in their centre and having the whole team involved. Respondents thought PLD should explore what science might look like in ECE and therefore how to recognise when it is happening and the possible pedagogical strategies to respond and extend learning in a scientific way.

Professional development is a big one. Helping teachers recognise that science is all around us and our language with children can help encourage them to notice, questions, explore and develop scientific thinking. 
The 203 respondents who rated teacher PLD as either extremely helpful, very helpful, moderately helpful, or slightly helpful were then asked what sort of professional development would be useful. Of the nine responses given two asked for advice on how to incorporate a te ao Māori ${ }^{9}$ view in scientific experiences, one requested examples of best practice and one mentioned a strong mentoring programme. The main thread running through the answers was asking for guidance on how to engage children with science and how best to support their learning.

\section{Visibility of te ao Māori in Science Experiences.}

Findings from the text answers to this question indicated a positive response to the idea of te ao Māori within science experiences in their centres. The respondents saw te ao Māori being made visible through their use of te reo, exploration of tikanga such as myths and stories and the centre's commitment to bi-cultural practices. There was a strong emphasis on the children's connection to and respect of their environment by being guardians of their world.

Developing the children's awareness of guardianship of the land, respecting all living things and how we can protect and develop the environment for the future while acknowledging the past.

Some respondents felt they were unsure about the relationship between te ao Māori and science experiences, or that they incorporated te ao Māori in a limited way or not at all. Two noted the possible conflict between te ao Māori and science ideas.

This is a tricky one, in fact I've just done an assignment on atua Māori which made me realise how tricky it is to combine the two. Atua and science has two completely different approaches to nature and outdoors.

This is an interesting question as we had a sorting activity that classified objects between living and non-living - using the scientific basis for this the classification is different when using Te ao Māori. Is a mountain a living thing? The scientific analysis would say it is non-living but culturally Maori see the whenua as a living entity.

\footnotetext{
9 Te Ao Māori - a term to encompass the commonly understood perspectives of the Māori culture.
} 


\subsection{Chapter summary}

The survey responses provided a snapshot of perceptions of what science experiences might look like within NZ ECE contexts. The findings indicated the respondents believed children experience science in free play, child-led environments, with interested and knowledgeable teachers who look to provide intentional resources or activities that prompt or support explorations of scientific concepts. The range of influences of scientific learning for children in ECE centres were identified as the environment, the resources in the centre, the role of the teacher and the pedagogical strategies they used. Having an environment with opportunities to engage with the natural world were perceived by survey respondents as enabling of scientific experiences to occur, as were materials that had a scientific purpose such as magnifying glasses. Provocations or resources set up to prompt science inquiries were identified as helpful in bringing about science investigations with children.

The teachers' role was highlighted often, not just through the need for them to be confident and knowledgeable about science, but also so they understood how science could be for young children and what they could do to support and extend those interests. The respondents viewed their pedagogical approaches as important. They believed if they noticed when science was occurring, recognised what could be explored further, questioned and discussed with the children as they investigated and extended their working theories, and also engaged in the process as an interested and knowledgeable other, scientific learning would be supported well.

The data from the survey provided a snapshot of the scientific landscape in NZ ECE and indicated areas for further investigation; how teachers support scientific learning through the prompts they use and/or through their teaching practice. Many of the respondents indicated it would be beneficial to hold PLD with their whole team, exploring the possible environmental adaptations and pedagogical strategies they could put into action in their own centre. This reinforced the value of phase two of this research project as it signalled that action research projects within ECE centres would be an appropriate option. The findings from the CAR with the first three centres involved in this study are presented in the next chapter. 


\section{CAR with Kanuka, Matai and Whau Centres}

\subsection{Chapter Overview}

This chapter outlines findings from the first three centres involved in the CAR process. For each centre the same format was followed. I videoed the teachers showing me the scientific affordances they thought were in their centre. This science walk was reflected on during the first focus group and prompted discussion about the strengths and weaknesses in relation to scientific opportunities in their centre. At one of our first meetings, usually at the first focus group, we would agree on our group guidelines and my role throughout the research. I prepared an action plan for each centre, drawing on teacher's ideas and intentions shared in the first focus group. This provided a framework for teachers to return to, reflect on, and revisit throughout the 12-week CAR project. The action plan was different for each centre and reflected the areas they thought would enable science experiences in their centre. Findings from the science walk, first focus group, and action plan are outlined for each centre. The findings from the mid-research and final focus groups, the individual reflections from each teacher, observation notes I took from each of my visits, and my own additional reflections are then presented under each of the areas identified in the centre's action plan. The challenges identified throughout the CAR are also discussed. Table 5.1 below presents the abbreviations used for each data source.

Table 5. 1

Abbreviations of Data Sources

\begin{tabular}{|l|l|}
\hline Source of data & Abbreviation \\
\hline First focus group & FG1 \\
\hline Mid-research focus group & FG2 \\
\hline Final focus group & FG3 \\
\hline Reflection & R \\
\hline Observation note & ON \\
\hline Additional reflections & AR \\
\hline
\end{tabular}




\subsection{Kanuka Centre}

Kanuka is a full day education and care centre that operates under an umbrella organisation. It is licensed for 30 children, including up to 4 aged under 2 , and is open from $8 \mathrm{am}$ to $5 \mathrm{pm}$. Average attendance is about 20 children whose ethnicities are mostly of Maori and Pacific Island. The local school has an MOE Decile 1 rating; indicating it is in a low socioeconomic community.

The centre employed three qualified fulltime teachers; Kelly, Emily, and Alison, who was the Head Teacher. Each teacher had 4 hours non-contact time a week, which they took when the number of children attending allowed for one teacher to be in the office. Alison took her additional 10 hours management time in the same way. A cook prepared the children's lunches each day.

Alison's teaching practice incorporated respectful practice and the idea of Ako ${ }^{10}$. She felt she was an intentional teacher who liked "to 'jump on' teachable moments as much as is practicable". She was also "confident in [her] understanding of basic scientific concepts, and [doesn't] believe in 'dumbing it down' for children" (Alison,R1)

Kelly mainly worked with infants and toddlers before joining Kanuka Centre a year before the start of the research. Her pedagogy was influenced by respectful practice, and since working with older children she has explored the idea of intentional teaching more deeply. However, she felt her confidence in science was low.

At college Science was never really my thing, so I never pursued anything relating to science outside of college. I think that the fact that I never really enjoyed it has contributed to my lack of confidence in regards to "Teaching" science with young children.

(Kelly,R1)

Emily was a new teacher, and this was her first fulltime position. She studied chemistry at university and really enjoyed exploring science with children during her ECE initial teacher education. She reflected that she "still love[s] science but [tends] to second guess [herself] which holds [her] back from trying new things or trying to introduce new concepts" (Emily,R1).

\footnotetext{
${ }^{10}$ Describes a teaching and learning relationship, where the educator and student are learning from each other.
} 


\subsubsection{The Science Walk}

My first visit to the centre was to meet the teaching team and video them doing a science walk. Alison volunteered to talk and walk through the centre describing the areas she thought supported scientific learning. For example, inside she noted the art area was a space for children to experience different media, and the kitchen was used for baking that involved experiencing heat sources and chemical reactions. Other resources in the centre that Alison felt supported science experiences were the construction materials; exploring balance, ramps, trajectory and speed, the plastic animals which were set out as a provocation for the children to explore, and the books as a great source of information and to prompt interest in their world. She mentioned the nappy changing area was a place for the children to explore ideas around anatomy. Outside, Alison pointed out areas such as a raised garden bed which they planned to plant with vegetables, the water trough, and the sandpit. She noted the climbing equipment provided experiences of physics such as forces, trajectory, and speed through for example raising the slide to a steeper angle which resulted in children noting that they moved much faster down the slide. The natural environment around the centre was viewed by Alison as a source for discussion, for instance noticing the local bird life, the seasons, and the changing weather.

\subsubsection{First Focus Group - Reflections on the Science Walk}

For the first focus group, held in the second week, I prepared initial questions to help frame our discussion. We watched the science walk video and reflected on what Alison had identified. The teachers all felt there were plenty of opportunities for science especially once you viewed the environment through a science lens. They also defined what scientific experiences looked like for them:

For me science falls into the three main strands; biology, chemistry and physics and there are heaps of strands that come off those. That would be my view of scientific learning and at this stage it is encouraging that thought.

(Alison,FG1)

You see I'm nervous about it. I don't know if I do look at things from a scientific perspective apart from baking, water, light... so I probably need to have a deeper understanding. I want to have a deep understanding of ways I can jump on it. 
I think for me ... it's more the why, the how, the way of thinking. 'Okay this just happened, why did it happen?' ... it's the open-ended questions and getting critical thinking going.

(Emily,FG1)

The teachers identified the strengths in their programme, encouraging children to think and explore, especially through messy play. They saw room to improve by identifying the knowledge around experiences, such as "discussing the gloop and why it does that" (Kelly,FG1). They wanted anything they did around science to "fit within our regular programme planning. So thinking about children's interests" was important (Alison,FG1). This meant discussing the areas of interest shown by the children, including transportation, dinosaurs, water and going to the hospital. We then explored how they could support these interests and extend on them with the children. We identified the action plan the teachers wanted to achieve over the CAR period.

\subsubsection{Action Plan}

I summarised the ideas explored during the focus group and an action plan was developed, as shown in Table 5.2 below. Teachers identified the areas they wanted to focus on, incorporating my ideas and suggestions. Providing resources that explored children's areas of interest such as construction materials, dinosaur books and access to water was identified as the key approach. Other ways to support children's scientific experiences was through provocations to extend knowledge, use of funds of knowledge through family engagement and arranging the environment to facilitate specific interests, such as creating a hospital corner.

Table 5. 2

Kanuka Action Plan

\begin{tabular}{|l|l|}
\hline Areas to action & How \\
\hline $\begin{array}{l}\text { Pedagogical } \\
\text { approaches }\end{array}$ & $\begin{array}{l}\text { Explore use of Intentional teaching - open-ended questions, } \\
\text { critical thinking, a sense of wonder, support developing working } \\
\text { theories. }\end{array}$ \\
\cline { 2 - 2 } & Explore drawing on funds of knowledge from the community. \\
\cline { 2 - 2 } & Explore use of provocations. \\
\cline { 2 - 2 } & Explore curriculum documents. \\
\hline
\end{tabular}




\begin{tabular}{|c|c|}
\hline Resourcing & $\begin{array}{l}\text { Areas of focus identified and to be explore further: } \\
\text { - Transportation - finding photos and books about trucks etc, } \\
\text { more Mobilo with pictures of how to make trucks and } \\
\text { bulldozers, dress ups such as high-vis jackets and construction } \\
\text { hats, also drawing on families who have access to trucks to } \\
\text { possibly visit the centre or asking the local fire brigade to visit } \\
\text { with a fire engine. } \\
\text { - Dinosaurs - books to support and extend children's knowledge. } \\
\text { - Water play - hoses, syphons, pumps, explore the water cycle. } \\
\text { - Hospital play - books, dress ups, stethoscopes. }\end{array}$ \\
\hline \multirow[t]{2}{*}{ Environment } & Create a hospital corner. \\
\hline & Extend materials with the water trough outside. \\
\hline Planning & $\begin{array}{l}\text { Explore science ideas within regular planning, using a science } \\
\text { lens. }\end{array}$ \\
\hline
\end{tabular}

\subsubsection{Action Plan Process}

With the action plan in place, the teachers explored the ways they could enable science in their centre over the CAR period. My 7 visits occurred during the morning and meant I was available to work with the children, to discuss ideas with teachers, and to also provide feedback via observation notes which I later shared on Moodle. The teachers reflected on their practice via their online journals and during the mid-research and final focus groups. The mid-research focus group provided an opportunity to check in with how teachers thought the action plan was going for them, what was working well to enable scientific learning and perhaps what additional factors they had found were influencing science experiences for the children in their centre.

The last 6 weeks of the CAR was carried out during November and December 2017. Prior to the last focus group, I provided guiding questions which were drawn from the mid-research focus group transcription and from observations and discussions during my visits. I wanted them to reflect on their action plan and identify the enablers they thought had helped support scientific learning in Kanuka. I used my research questions to help guide our discussions. 
Over the CAR period the teachers and I referred to their action plan foci and my research questions to guide the focus groups. My observation notes and their reflections responded to the action plan and to other enablers and challenges that came up during the CAR. The findings from the focus groups, teachers' reflections and my observation notes are presented under each of the areas identified in Kanuka's action plan. The challenges to enabling science are also discussed.

\subsubsection{Pedagogical Approaches}

The teachers at Kanuka were interested to explore their pedagogical approaches during the CAR. They wanted to use practices such as asking questions to encourage a sense of wonder amongst the children. They were already confident in their respectful practice with children and this research offered a way for them to add more intentional teaching strategies to their repertoire.

\section{Questioning and Supporting Working Theories.}

Teachers' reflection on their pedagogical approaches were often prompted by my visits to Kanuka during the day. In particular, Kelly's reflection on my first visit highlighted the value of my time spent there during the sessions; specifically, my engagement with children and role modelling more intentional teaching practices. I therefore tried to visit the centre weekly, but this was not always possible, so my total number of visits over the 12 weeks was seven.

It was a sunny day when I first visited and there were several children outside. My observation notes record what was going on; I noted one boy matching some plastic dinosaurs with the dinosaurs in a book and a few children building with the Duplo inside. Outside some children were jumping in and across a puddle beside the sandpit. I engaged in questions and discussion about the puddle and asked what will happen to it. "It will be gone by lunchtime" says one child and I ask how, "the sun does it" says another child. We then discussed how the sun dries up the water. After this incident Kelly and I briefly discussed what happened, my approach with the children and the scientific experience that occurred. (ON1).

The thinking Kelly had done around questioning and encouraging children's interests was visible in her reflection on the experience she had with them around ice. Her feelings emphasised how valuable this incident has been for her. 
This was such an awesome experience and it highlighted how easy "Science" can be, children are curious by nature, so questions are an everyday occurrence. It is my role as a teacher to ensure that I am supporting these children to answer their questions to the best of my ability.

(Kelly,R1)

Kelly noted the intentional teaching practices she used such as "co-constructing, challenging and identifying" and making time to "make findings with the children and reflect on these".

After my second visit I observed several experiences happening over the session and reflected on how questions and teachers sharing knowledge would have fitted into these moments. For some activities children's experience was at a very physical and sensorial level, so discussing the scientific concepts occurring within their play felt incongruous. That seemed to prompt Alison to think about it. She set up a "mud" activity using sand, shaving foam and water. The texture proved popular with several children exploring its viscosity. As the water separated from the "mud" Alison discussed what was happening with the children and explained to them how due to gravity the water was flowing down the sides to the centre of the trough.

This experience got me thinking about how I could incorporate more 'sciencey' explanations and conversations into regular everyday experiences here that I wouldn't have thought to have offered opportunities for scientific thought.

(Alison, R2)

During the mid-research focus group questioning was identified as a pedagogical approach that had been effective for the teaching team in facilitating science experiences.

I thought the questioning, [and] the more we are involved ... asking questions has meant the children are more engaged in it and it keeps it going ... So the questioning has been good.

(Kelly,FG2)

Yeah that's what I'm trying to do - is asking them lots of open [ended] questions and get them to think about things.

(Emily,FG2) 
Figure 5. 1

Photos and Explanations of Science Explorations into Puddles, Air, and Ice (Own Image)

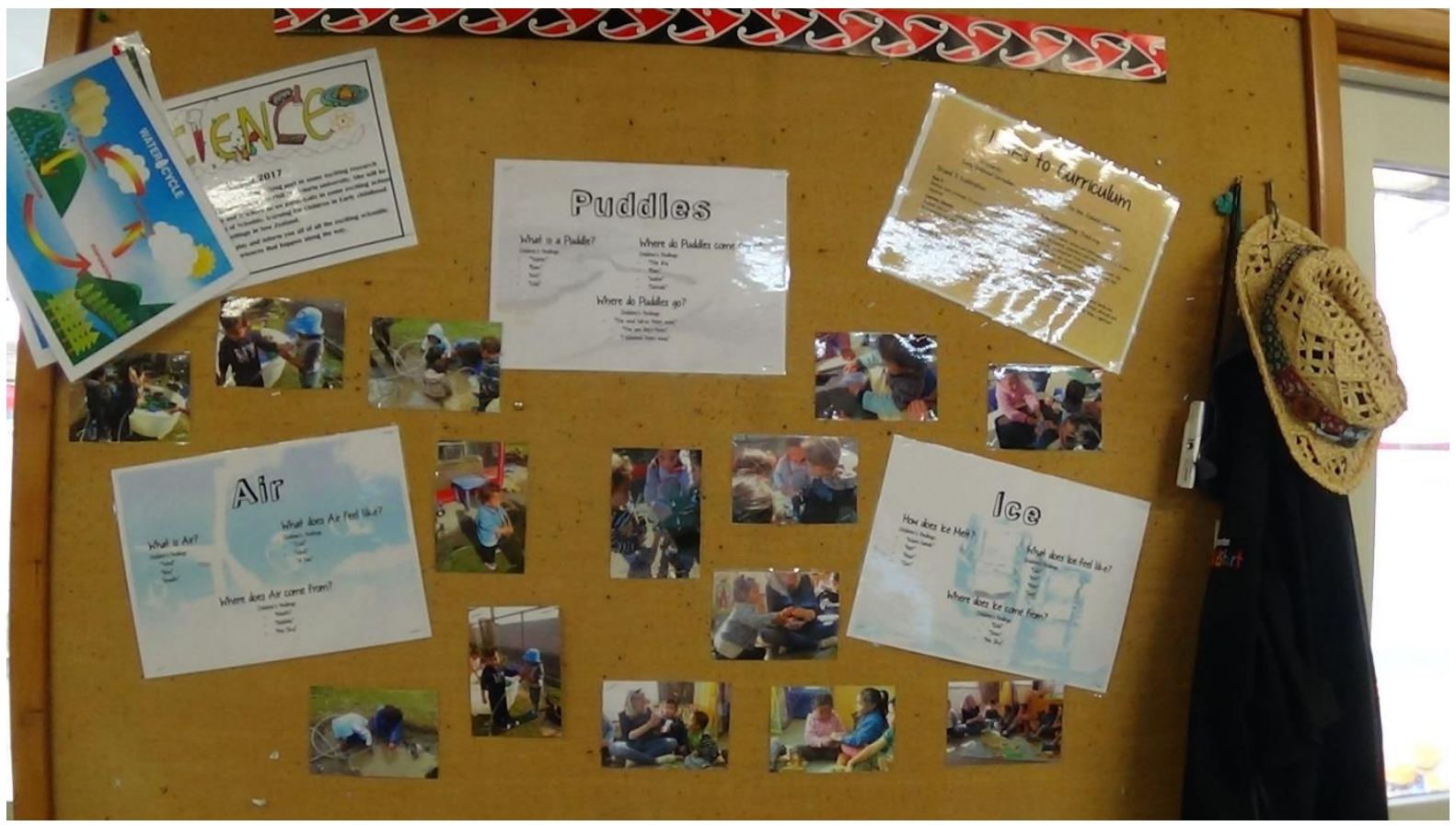

During the following visits I noticed the documentation on the wall showing the ice exploration with Kelly (see Figure 5.1). Water was an ongoing theme in the centre, the children enjoyed exploring it in several ways. The leaking gutter outside produced a constant drip when it rained, and dressed in their Kanuka Centre provided raincoats, the children loved to stand under it and experience the drips on their head as shown in Figure 5.2.

Figure 5. 2

A Toddler Enjoys the Drips (Own Image)
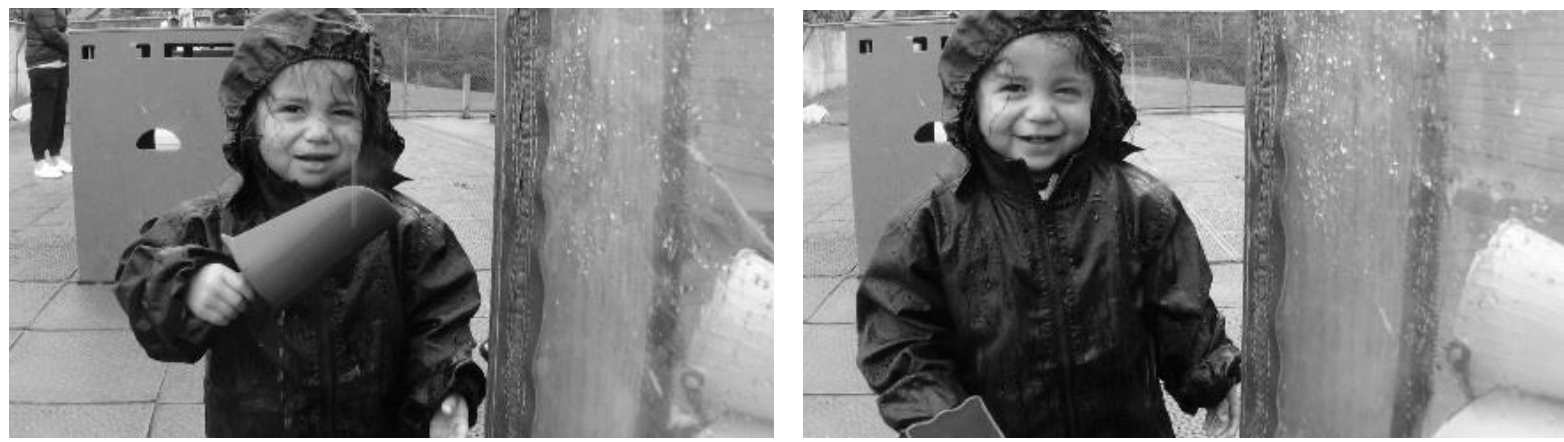

An exploration of wind and air was provoked through the introduction of some hoses. I videoed Kelly as she explored the force of air through the hose with N. Kelly and I 
discussed how the concept of air is difficult to explain as it cannot be seen. We explored other possible ways to investigate these ideas. A few weeks later Kelly set up an activity with dishwashing liquid and straws to extend this interest further. The children enjoyed the experience and explored making bubbles with the straws. Kelly revisited their previous discussions about air and wind and found this event helped show the effect of air in a more visual way.

We talked about wind being "Moving Air", we also discussed how the air from our lungs is creating the bubbles as we blow through the straws. It was also really cool to see some of the children make connections between the experience we engaged in a few weeks previously with the hoses and a puddle.

(Kelly,R3)

\section{Provocations.}

The teachers found provocations were a valuable pedagogical tool to initiate and extend science experiences and were explored by teachers throughout the CAR period. Activities such as bubble blowing were useful to provoke and extend children's interests. I noted the provocations created by teachers through arrangements on tables; such as plastic animals with pictures were set out to illustrate the habitats animals might live in or objects, pictures and books were laid out to support the gardening activity occurring outside. This involved a flower planted in a glass vase to show the roots growing and photos of children gardening.

However, teachers reflected that keeping the provocations relevant for all ages in the centre was challenging. The older children explored the concepts and revisited prior learning, but the toddlers seemed to just like taking the photos off the wall and wandering away with them. However, as a mechanism for promoting a sense of inquiry amongst children, provocations were seen as valuable, either as an arrangement of objects, pictures, and books on a table (for example to support the vegetable garden) or as an activity set up to investigate a specific scientific concept (such as the blowing bubbles activity to continue exploring air and wind). The teachers felt the provocations kept them on task and focusing on an area of interest. While they all agreed a provocation could end up going in a variety of tangents, Kelly hoped that if they persisted there could be a shift in the culture of the centre towards children being more inquiring and interested to explore knowledge to a deeper level. 


\section{Funds of Knowledge.}

While the teachers had hoped to involve families more in their exploration of science interests, this proved more difficult than they expected. They had wanted to extend the interest in transportation by bringing in trucks as provocations, but Alison explained the families seemed to struggle to see the value of their visit, especially if they had work or a delivery run to complete.

One success had been through teachers' knowledge of children and their families. Making connections with gardening knowledge within their centre's community had also proved useful to add to the experience.

This is a good opportunity for sciencey things but if I think about funds of knowledge; $N$ is a gardener at home and he's more than happy to share his knowledge and then his Mum was showing us the photos. That was cool. Because I knew that they had a garden with herbs and veggies and stuff ... he's got flowers as well.

(Alison,FG2)

\section{Intentional Teaching.}

During the mid-research focus group, the teaching team noted that they had found the idea of intentional teaching useful. Initially working out what this might mean for them and how it would manifest in their practice involved reflection and discussions during my visits. For Kelly it was quite a shift for her practice, as she was concerned with the experiences being teacher-led, but then realised her involvement was not leading the learning. Rather she was encouraging and steering the experience so children gained more from it.

I think I have made the connection between ... child-led and teacher-led. But I feel like if you don't stay on top of it as a teacher then it's just lost and that's where intentional teaching is quite important and not, like if ... we don't keep revisiting and encouraging them to revisit then it can just go and all that learning is missed.

(Kelly,FG2)

When asked in the last focus group what the main shift in their practice had been to enable scientific learning to occur the teachers identified pedagogical approaches. As a team they noted these prior to the focus group.

We've got something here that we prepared earlier: 
- Co-constructing and working alongside the children was also as useful as questioning.

- Questioning is a useful starting point but adapting to children's needs and interests are also important so use of a range of strategies is best.

- $\quad$ So intentional teaching strategies, where questioning is one of them, coconstructing, and scaffolding.

(Alison,FG3)

How these intentional teaching strategies were demonstrated seemed to differ for the teachers, often reflecting their personal philosophy of teaching and their confidence with science knowledge. Emily and Kelly both wanted to identify the science in whatever was happening with children. This involved recognising when something scientific was occurring, mentioning it to children and asking them questions, so they too made connections to the science taking place. Alison saw the value of her science content knowledge and drawing on it when the opportunities arose and "tailoring [her] response to get them thinking in a different way" (FG3).

The teachers felt being involved in the CAR had been particularly valuable in generating the shift towards intentional teaching. Alison felt it had encouraged them to find answers to questions posed by themselves and the children. Kelly thought she had become more purposeful in her planning and thinking about what to provide for children. They had explored how more intentional teaching strategies could fit into their pedagogical philosophy, such as finding the balance between teacher-led and childinterest-led practices. There were many discussions and reflections throughout the CAR process about their role as teachers; what did being a teacher mean?

- Did it involve setting up the environment for the children to investigate alone?

- Did it mean they were to follow children's interests only or could they bring in other ideas too?

- And could they lead investigations and share knowledge with the children?

In the final focus group all teachers felt their role as teachers meant they were there to teach. As Kelly argued:

I'm a teacher. And I'm all about them following their interests, but then I need to look at that in depth so I can teach them and then be purposeful in everything that I am providing to them. 
The idea of the teachers' role in opening doors to knowledge and new ideas resonated for the Kanuka teaching team. They all agreed that it was valid and valuable for them to introduce new experiences and share their knowledge with children, noting that if they as teachers do not, who does? They were very aware of how important it was for them to be involved in experiences alongside children, especially when being demanded elsewhere often meant children moved onto something else. For Kelly the CAR had helped her find that a more intentional teaching role worked for her; she had discovered the value of encouraging children's interests and taking a lead to facilitate deeper thinking or to introduce new ideas. She also knew when to step back and let children work it out themselves or when to share what she knew.

\section{Curriculum Documents.}

At the first focus group we discussed available curriculum resources. I provided a link to the NZ Curriculum: Science (MOE, 2007) and It's a Bugs Life (Browne \& Te Papa, 2016). Only Kelly had looked at the resources. She thought It's a Bugs Life looked like it would be an "awesome" resource but was too large to print. They discussed printing it as a resource for them to share, and Alison offered to do it through the centre.

By the final focus group, the teachers had used both documents and had found them useful. The documents helped identify what science could be and provided ideas to support science experiences through processes such as hypothesising and asking questions and taking ideas further.

\subsubsection{Environment and Resourcing}

My observations indicated that changes in the environment came about through the provocations teachers put out and the setting up of the vegetable garden. Children engaged in the project during the process of weeding the planter box, filling it with new soil and planting the seeds and seedlings. The teachers purchased watering cans to water the garden only, however making sure children knew this proved to be frustrating. While teachers had been firm about the appropriate use of the watering cans, children damaged them through continued use in the sandpit.

The teachers identified the value of resourcing in their own internal evaluation; they were planning an inventory of what the centre had already and what to add to it. Alison was keen on having a collection of basic resources, a list identifying what these could be 
used for. They had recognised, in the mid-research focus group, the value of having a variety of books available for children that covered scientific areas often explored by them, such as insects and the body. Emily noted that the anatomy book had been well used.

We've been pointing out veins and the nervous system and stuff, and talking about how it works...

(Emily,FG3)

However, teachers struggled with the lack of respect for the resources in the centre. Kelly had stated in the second focus group that having unlimited resourcing was ideal but in the last focus group she noted just having resources that were not broken or used inappropriately by children would be good. She talked about the children's lack of respect for the books. Both she and Emily felt frustrated by the way the books were often stood on or ripped by children but taking them away was not an option.

\subsubsection{Planning}

Alison said their focus on science and reflecting on their practice had a positive effect in other areas of their programme. They all felt working as a team proved helpful, especially being able to draw on each other's knowledge. For Kelly, this meant feeling more confident about tackling scientific concepts with children because she was able to draw on Alison's knowledge if needed.

Overall, for all three teachers, feeling more confident about science was shown in their fearless approach. They were more open to explore concepts and objects that they did not know about or feel comfortable with. Emily was also working on her science knowledge. Using Google to access information and co-constructing knowledge alongside children was working well for her. But she felt her lack of confidence remained an issue.

\subsubsection{Challenges}

While teachers identified the struggle with appropriate use of books and resources by children was one of the challenges to enabling scientific experiences, the main challenge was structural; the teacher-to-child ratios within the centre. This was highlighted when discussing their exploration of pedagogical approaches such as co-construction which required uninterrupted time between teachers and a child or a small group of children. 
The teachers agreed that this was particularly difficult for them even when meeting the MOE teacher-to-child ratios.

The teachers thought that their centre did not have many children each day but that the diverse range of needs within the group was acutely demanding. Alison noted that the high proportion of children with learning needs and behavioural issues placed additional demands on teachers throughout the day. The necessity to respond to children's social and behavioural needs meant engaging in sustained shared conversations with children was limited. This seemed to be reflected in children's lack of interest in exploring scientific concepts to any great depth. Once interrupted the teachers found going back to investigating that interest with the child was difficult if not impossible. Alison provided a clear picture of their daily struggle.

We are the number one resource here but you can be sitting with a child having a really cool in-depth conversation but little 'Johnny' over here has whacked little 'Tamati' and well unfortunately you need to deal with that. Or someone is away changing a nappy, the other teacher is outside, or another teacher is with another group of children, and you're the closest so have to [respond to it]... that resourcing is not going to be sorted anytime soon.

(Alison,FG3)

For Kelly the range of ages and needs of the children in Kanuka centre meant her time and attention was often demanded in a variety of ways.

I find it quite hard as well, with the diverse needs of our children, that it is really tricky ... I'm trying to be a bit more intentional in my teaching and following up a bit more but I do find it very hard here because something would have happened and you get lost and then you try to come back and you can't come back.

(Kelly,FG2)

All the teachers needed to manage the interests of the toddlers alongside those of the older children, for example the garden outside had involved a significant effort from all teachers to maintain. Children thoroughly enjoyed watering the garden, however ensuring the plants stayed in the garden was challenging.

These demands meant teachers felt it was often difficult to engage children in sustained conversations about science. The teachers were interested and wanted to share and discuss it further, but children were often uninterested and moved onto something else. 
For example, during an activity involving coloured ice the children enjoyed watching the ice melt and the colours mixing but Kelly wondered what learning children had gained from the experience. She thought perhaps it was the questions she asked, while Emily thought it relied on the interest children had in finding out about what was happening. All teachers agreed experiences could be hit or miss and they found it hard when they started explaining something with enthusiasm only to find children had wandered away or lost interest.

We discussed how to create a culture of inquiry in the centre, much like their focus on respectful practice had created a culture of kindness and care. I suggested teachers could continue to be more intentional about sharing and co-constructing knowledge with children. While children were not engaging in sustained conversations to the degree that they wanted, they might begin to do so. Kelly suggested revisiting experiences might help, so they planned to use documentation of the learning experiences further. The issue of the photos being taken away by the toddlers was raised. A possible solution would be to ring-bind the laminated photos into small books which could be carried around but easily found and replaced back on the table. All agreed in the value of intentional teaching and questioning. This would continue with a focus on creating a shift in the centre towards a culture of inquiry within the children.

By the end of the CAR period teachers were confident that the shift in their practice had meant enabling more science experiences to occur. In general, their confidence to support scientific experiences with children and their ability to recognise when science was happening. For Kelly, my visits and the focus groups had fostered her confidence to support scientific experiences with children. My role modelling had encouraged her to reflect on her practice and she saw the value in focusing on curriculum areas to help define what learning was occurring and then intentionally plan what resourcing or support she could give children to extend their interests. She felt her noticing, recognising, and responding to children's learning was more purposeful.

\subsubsection{Summary}

Overall, for teachers at Kanuka the main enablers of scientific learning for children were using intentional pedagogical strategies such as questioning, co-constructing, scaffolding, and sharing of knowledge. Provocations to introduce or extend interests and experiences were also a valuable strategy. The CAR experience had a significant 
influence, keeping teachers' focus on science, helping them to remain conscious of the possible science opportunities that could occur during the daily experiences with children. For one teacher, Kelly, my visits had been instrumental in helping her reflect and explore her role as a teacher.

The challenges of the diverse range of ages and needs of the children in the centre and teacher-to-child ratios meant putting the intentional teaching strategies into practice was challenging. The last focus group indicated a sense of frustration amongst the teachers. They wanted to explore ideas and experiences with children to a greater depth and to engage in sustained shared learning alongside children but the demands of the younger age group, and the social and behavioural needs of some children often disrupted these opportunities. The teachers were still hopeful that a commitment to provocations and intentional teaching would slowly create a culture of inquiry within the centre, with children wanting to investigate ideas and concepts alongside and independent of teachers.

\subsection{Matai Centre}

Matai is a full-day education and care centre situated on the grounds of a school. The local primary school has a rating of decile 10 indicating the local suburb is a high socioeconomic area. The centre is licenced for 30 over two-year-olds, with 15 attending each day; all 3.5 to 5 -years-old. The centre is open from $8.15 \mathrm{am}$ to $3.30 \mathrm{pm}$. Most children attend all 5 days, some 3 or 4 days only.

There were two qualified teachers at Matai. Sam, and Anabelle - who had been Head teacher for 4 years. For Anabelle, involvement in this research project offered an opportunity to explore her science practice more deeply.

My teaching approach is to be quite intentional about children's learning, but still to mainly follow their interests. Exploring how to teach science better is exciting as I love children's interest in science but want the science I do to be integrated into the programme, not just pyrotechnics.

(Anabelle,R1)

Sam was a qualified ECE teacher with a degree in Education and Māori. She spoke and was passionate about te reo Māori. For Sam doing the science walk video and reading an article I provided helped her view the science potential in their centre. 
I am very glad I read the research paper 'Science learning affordances in preschool environments' as this really helped me to see the classroom for what it could be and not what it is to me, which is how I see it every day. Looking around our classroom with ... a more 'science' focused lens helped me to realize more of the potential of our space.

$(\operatorname{Sam}, \mathrm{R} 1)$

Anabelle and Sam each had 3 hours a week non-contact time. Additionally, Anabelle had 2.5 hours admin release while Sam had 1.5 hours. For 3 hours each day, a teaching assistant released Sam and Anabelle for their lunch breaks.

\subsubsection{The Science Walk}

I met with Anabelle and Sam at Matai to record the science walk after the children had left. They showed me where science experiences were supported in their centre environment. We started inside in the construction area, where Anabelle noted the blocks were a material children could explore balance and gravity with. Sam indicated the books, also in this area, were an obvious source of science via their non-fiction collection. In this space Matai has a large range of equipment; a wooden spaceship, Imagine blocks for large scale building, Duplo, Lego, plastic animals, and a train track. Sam noted the world map on the wall often raised conversations and questions about geography and the earth, as did children's National Geographic magazines. Also, the solar powered windmills and reflection balls hanging in the window raised discussions about the sun, light, and reflections.

The classroom had a nature table that the centre's families could donate objects from the natural environment, and a magnifying glass meant children could explore the specimens in more detail. In addition, Matai followed Letterland ${ }^{11}$ and focussed on a letter each week which meant children were asked to bring in something that started with that letter. Anabelle thought children's contributions were often interesting and started discussions about scientific concepts such as the on/off electrical switch for " 0 " week. Sam noted resources that explored specific science ideas such as the magnetic equipment, nuts and bolts and box construction in the art area. Both Sam and Anabelle mentioned children mixing colours when using paints and when blending different coloured playdough.

\footnotetext{
11 A phonemic awareness programme.
} 
A weekly excursion was to take their recycling bin to the school's big recycling bin. Anabelle identified other weekly activities which provided science experiences such as cooking on a Wednesday and making playdough each Monday.

Sam thought the dress ups and dramatic play equipment provided plenty of opportunities for children to explore science concepts through their play, either in the kitchen or the hospital play area. Both teachers had observed very detailed medical dramatic play around birthing babies and hospital visits originating from children's own experiences at hospitals or the arrival of younger siblings.

Outside, Anabelle and Sam identified the carpentry table, the sandpit, and the water trough as areas where science had occurred. The raised garden had peas growing in it and children had watered and harvested those over the previous months. Anabelle felt the large range of outside equipment such as ladders, swings, pulleys, and bikes encouraged science experiences in gravity and balance. They also had swan plants and gardens which allowed for finding and investigating insects.

Sam commented that the weather was a strong initiator of outside discussions about science, along with trees growing in the outside space. She stated that the cherry blossom tree on the grounds of the neighbouring school was often noticed by children and was a great indicator of seasons through its blossoms and loss of leaves. Anabelle felt the application of sunblock each day and earthquake drills meant children were exposed to scientific ideas around sun, sunburn, and earthquakes. The abundance of native birds in the local neighbourhood also meant children were exposed to conversations about the local birds.

\subsubsection{First Focus Group - Reflections on the Science Walk}

My initial guiding questions helped structure our first focus group, we agreed on our group guidelines, watched the science walk, and reflected on the areas they thought they did well.

I think we talk a lot about the environment and the weather. I think that's something we often talk about, it's usually from observations from the children. It is raining, it's sunny, there's a rainbow.

(Sam,FG1) 
And plants and insects. Birds, they are very interested in, so we tend to follow-up and help them find out more about them and get the answers. Yes I think we're strong on the natural environment.

(Anabelle,FG1)

The nature table was well used with regular contributions of "dead butterflies and all sorts of things, pinecones, leaves" (Anabelle). Anything that came into the centre for the nature table was respected and well looked after. If anything sparked an interest in a child, they felt they responded well.

Following children's interests drove Matai's curriculum as they had an inquiry-based programme. For instance, after a large insect landed on their window children's interest in finding out what it was extended into a larger exploration of insects. The following conversation between Sam and Anabelle illustrated this.

Sam - That's how we get most of what we expand on. From a group of children bringing in something or enquiring about something and then everyone else gets on board, and then we think oh we've got something we can follow up on. Anabelle - So the insect inquiry was based on multiple times the children were observing insects and interested in them and talking about them.

For Sam and Anabelle this was an area of their pedagogy they felt confident in: following children's interests, co-constructing knowledge with them and discovering new knowledge. They used Google if they were unable to answer children's questions, felt confident about learning alongside children and enjoyed gaining new knowledge for themselves.

We explored the areas they wanted to work on. Anabelle wanted to explore science in a more integrated way. She wanted to avoid random science experiments and have children discover science concepts through the inquiry they were working on. I suggested provocations as a tool that could bring in other aspects of science that might be missing in the programme. Anabelle was not so sure. Her experience of provocations had been through an International Baccalaureate programme, where the provocations were very teacher-led and she felt more comfortable with their programme predominately following children's interests. I explained the Reggio Emilia idea of provocations where they can introduce teachers' interests but also link to children's interests to extend them further or more deeply. The provocation could also introduce a 
new idea that could then go in several directions based on where children's interests went. Sam and Anabelle were enthusiastic about this concept of provocations and wanted to explore it further.

Anabelle - That's interesting because one thing we've talked about is if you just follow children's interests there is a limit to what you can do. Like you might want to teach them about recycling and the environment but they are not going to come up with that themselves.

Sam - Because they have limited knowledge. They can't ask questions if they don't know about it.

Both Anabelle and Sam agreed to include provocations as part of their action plan and to discuss it further during their next staff meeting. Sam wanted to explore how they could introduce scientific concepts and be more intentional in encouraging children to explore scientifically. Anabelle agreed and wanted to examine the idea of sparking an inquiry into physics or chemistry through a provocation.

The children have been interested in under the sea, the creatures, but also on top of the sea the ships and boats so maybe we could consider doing a provocation to lead into that. It is still their interest, but we could consider doing the physics of floating and boats, there is an awful lot in that.

(Anabelle,FG1)

I introduced the NZ Curriculum: Science (MOE, 2007) and It's a Bugs Life (Browne \& Te Papa, 2016) as resources Anabelle and Sam could draw on to help them in their planning. They were keen to use the scientific process outlined in It's a Bugs Life, and the introduction of scientific language especially.

This led to a discussion about how to share this newly gained knowledge at their centre, particularly as the scientific process identified by It's a Bugs Life indicated the importance of sharing findings during or after scientific experiences. I noticed they used their wall spaces to display the centre's current inquiry, so asked if this was where findings were shared.

Yes. And in the learning stories too that go to the parents. But we do tend to make displays and put findings up. We did that with the insects' inquiry; we put up the questions that the children generated and then the answers that we found out along the way.

(Anabelle,FG1) 
The opportunity for children to share their findings or new knowledge was also deliberated. Anabelle felt children had plenty of opportunities to discuss their understandings during mat times, where they listened to each other and shared ideas in a group situation. She could see the advantage of formalising or structuring the sharing of ideas during mat time and wanted to work towards that.

\subsubsection{Action Plan}

Following the focus group, I prepared an action plan, shown in Figure 5.3, based on a summary of the areas they wanted to focus on.

Table 5. 3

Matai Action Plan

\begin{tabular}{|c|c|}
\hline Areas to action & How \\
\hline \multirow[t]{3}{*}{$\begin{array}{l}\text { Pedagogical } \\
\text { Approaches }\end{array}$} & $\begin{array}{l}\text { Focus on planning - updating planning template to include } \\
\text { science. } \\
\text { To identify possible science experiences in children's interests or } \\
\text { inquiries. } \\
\text { Planning discussion with a science lens. }\end{array}$ \\
\hline & $\begin{array}{l}\text { Explore use of provocations - identifying gaps in programme and } \\
\text { using provocations to bring in science areas to investigate. }\end{array}$ \\
\hline & $\begin{array}{l}\text { Explore use of funds of knowledge - drawing on knowledge within } \\
\text { the parent community. } \\
\text { Also using the school or wider community resources to support } \\
\text { inquiries. }\end{array}$ \\
\hline \multirow[t]{2}{*}{ Resourcing } & $\begin{array}{l}\text { Use the library - use of books from own, school, or local } \\
\text { community library. }\end{array}$ \\
\hline & Possibly use the light box, the bones or the new Bebot ${ }^{12}$. \\
\hline Environment & Make some areas overtly science-based. \\
\hline
\end{tabular}

12 A programmable mobile floor robot. 


\subsubsection{Action Plan Process}

Anabelle, Sam, and I discussed my intention to join them at staff meetings. However, we decided that my role would be like a critical friend who could provide an objective overview of their programme and give suggestions and feedback regarding their practice by visiting during sessions. We agreed Monday mornings from 11 am would provide time to observe and be with children during their free-play time and then mat time run by Anabelle prior to lunch. They were keen to have time to work through what they wanted to do in their staff meetings, so my first session visit was 2 weeks later. Over the CAR period I visited Matai 10 times.

In the mid-research focus group the Matai teachers reflected on their action plan, how well they had been going and any adjustments they wanted to make. We decided to switch my visits to Tuesdays from 11 am so I could observe Sam taking mat times.

Our last focus group was scheduled in the second to last week of their year. I provided guiding questions drawn from the mid-research focus group data, my observation notes and their reflections in Moodle. The teachers reflected on what elements of their action plan worked well and what additional aspects from the research they thought had enabled science to occur. The findings from the final two focus groups, the teachers' reflections and my notes are presented under the areas in Matai's action plan as well as the challenges experienced.

\subsubsection{Pedagogical Approaches}

Annabelle and Sam were experienced teachers who were confident about their programme. They both looked for PLD opportunities, consequently this study provided a chance to review their practice and how they were fostering science in their centre. Resourcing and their environment were already strong areas for them so they thought they could enable more scientific inquiry by exploring their pedagogical approaches.

\section{Planning.}

Anabelle and Sam wanted to specify science in their planning. They found their planning template was useful, with Sam observing that they already had a space in their template for science. Anabelle agreed. 
Yes because we have done a lot of science topics this year. A previous term we also did body parts, and the term before we did insects, and then last term we did Space. We have done a lot of science topics.

(Anabelle,FG2)

They felt their approach to planning around science had become more intentional.

Sam - I think we're trying to make science intentional rather than just random. Before we were like 'oh that fits into science let's put it in there,' as opposed to going ... What specific scientificy things can we do in this inquiry to enhance this inquiry?

Anabelle - And How. Because you have been leading us through the scientific process of how to go through a science inquiry.

\section{Provocations.}

Both Anabelle and Sam thought provocations had been particularly valuable at instigating and extending investigations into specific areas of interest.

There is always that core group of children whose interest it is, but then you've got to sort of rope the others in. So I think the provocation does that really well. It just gets them all on board and excited. Children are just interested in general and if you get something, wham, they're like 'I wanna do this'. So I think that's really good.

Over the first 6 weeks, I had observed Anabelle running a mat time where children discussed their boat building activity and recalled the materials and shapes they discovered were best for floating. Anabelle asked them to remember their findings and to then hypothesise about what they wanted to test next.

Since we started working with Sola this term, I find that I am much more aware of all the science openings that occur and take the time to follow through by asking leading questions.

I have started to help the children to formulate a hypothesis and make predictions. They look a little confused by these terms so far, but I am sure they will soon become second nature to them. They are coming up with interesting questions for us to research.

(Anabelle,R1) 
One of my visits coincided with an exploration of what makes a boat float in the water trough that had been moved onto the deck. There were a few children with boats in various shapes and sizes, and they were testing if they floated. The children were asked to give predictions about whether their boat would float. They discussed with me the construction of their boat, identifying the key factors teachers had discussed with them; if it was flat, had sides, or if it had air inside. There was much experimentation which involved adding sides to wooden boats and wrapping cellotape around cardboard boxes to stop water getting inside. I wondered if visiting the schools rowing boats might be a useful provocation to extend children's thinking and suggested documenting their thinking through pictures would be valuable too.

Sam was keen to introduce te ao Māori into any investigation going on in the centre.

As we were looking at boats and floating and sinking, I decided to look into the Māori legend of Māui ${ }^{13}$ fishing up the North Island. ... We decided to draw pictures of Māui's waka14. There was a lot of discussion at the table around the shape and how the sides needed to be high so the water can't get in. I reminded the children about what helps a boat to float. We talked about how much air is in the boat. Most of the children made really high sides on their boats so there was a lot of air.

$(\operatorname{Sam}, \mathrm{R} 2)$

Figure 5. 3

Children's Pictures of Māui's Waka (Own Image)

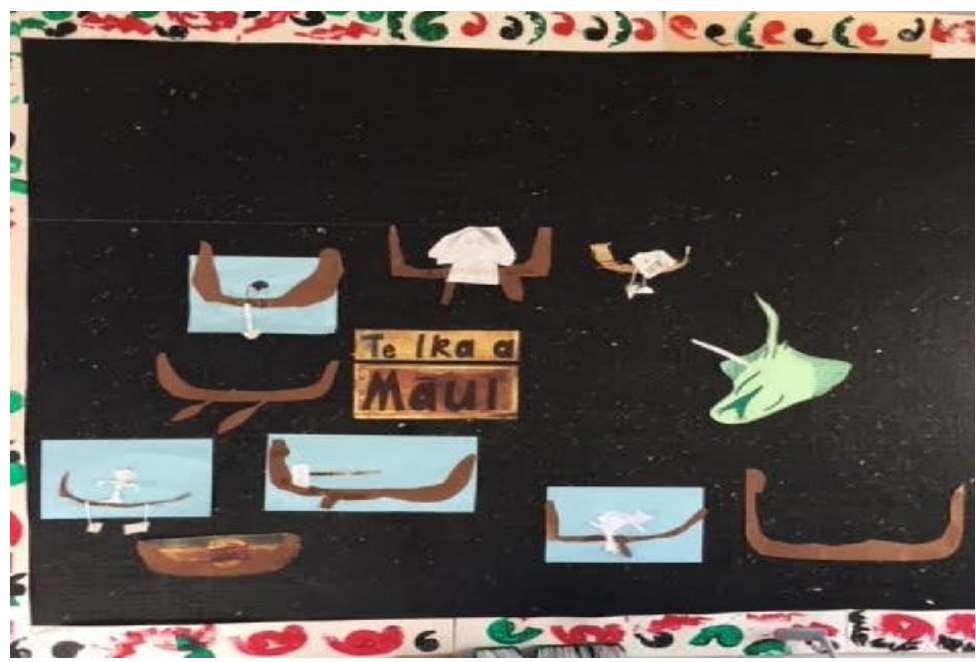

13 Māui - a Māori demi-God.

${ }^{14}$ A waka is a Māori canoe. 
The documentation on the wall (see Figure 5.3) showed how children thoughtfully explored the shape of the waka. In addition, Sam took a small group of children to visit the school's rowing boats, as shown in Figure 5.4. The school's sports coordinator explained how the boats worked and they got to look inside one. Back at the centre Sam also showed them the video of Waka Ama ${ }^{15}$ and Olympic rowing to see how the boats looked and functioned in the water.

Figure 5. 4

Children Visit the Rowing Boats (Own Image)

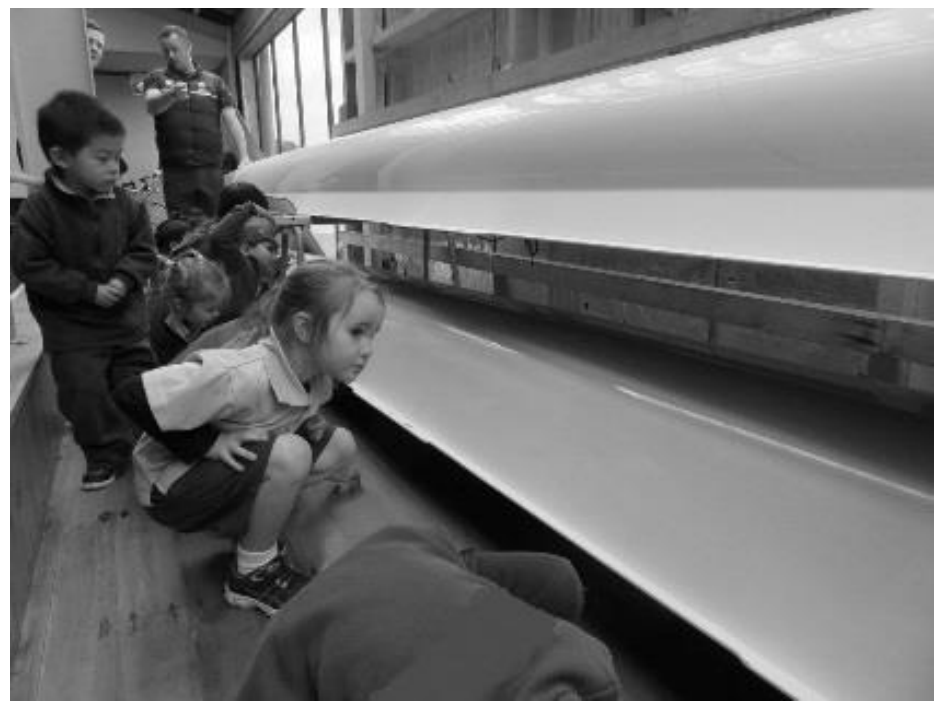

The inquiry into floating and boats was explored further when I visited during a mat time run by Anabelle, where she carried out a floating experiment with the group. Using three plastic bottles that were full, half-full and empty she asked children to predict if they thought they would each float or sink when put in a big bowl of water. The children's predictions were close to what happened and thus the group was able to hypothesise that "Things with air inside float in water" (ON3)

Other provocations occurred in less obvious ways, such as the introduction of CDs into the centre. Anabelle and the children had noticed the CDs hanging in the school's vegetable garden were making rainbows. She asked the families to donate old CDs and left them and some mirrors outside for children to investigate making rainbows. On

15 A waka racing competition. 
another day children noticed when watering the garden how the spray made rainbows in the sunshine. Anabelle followed up this investigation at mat time.

I reminded them about making rainbows with the CD outside and trying to make them with the mirrors. They talked about how the mirrors had made reflections but not rainbows. I asked why this was but they didn't know. I told them that CDs had very small grooves going around in circles, so small they couldn't see or feel them. These broke up the light into different colours in the same way as the water spray from the hose did. I introduced the word refraction and contrasted it with reflections.

(Anabelle,R7)

\section{Questioning, Discussion and Using Scientific Language.}

Anabelle reflected during the last focus group that the introduction of CDs was another example of her growing confidence to explore science concepts with children through questions and discussions, and by bringing in science language. There were other science experiences that occurred during my visits over the CAR period such as finding the name of a dinosaur and an experience with one child throwing a plastic lid off the climbing frame and getting very excited about its ability to fly. This child had very little English and while Anabelle could understand a little of his first language it was not enough to have a deep conversation with him about his thinking. This incident raised, for both Anabelle and I, the importance of having language to shape and illustrate thought. In this situation we were unfortunately unable to work out what concepts, science or otherwise, this child was exploring.

During the last two focus groups Anabelle and Sam thought the main shift in their pedagogical practice was using more scientific terms and scientific process language, such as predict, hypothesis and findings. This was connected to them engaging in discussions and using open ended questions that enabled deeper exploration of scientific concepts. They both felt they were doing this more.

Moving the conversations on and taking them deeper and that's a skill that gets better and better and that's what I'd like to keep working on. I think we are getting really good now at seeing the opportunities for science and in a wider way than we did before.

(Anabelle,FG2) 
Sam agreed, and noted in the last focus group the value of sustained conversations in "helping move [children] on and inspire them and helping them to get to the next step" (Sam,FG3)

The teachers' confidence with science was evident in the mat times they instigated. At the last focus group Anabelle reflected how she had researched the physics behind balancing a bike while riding. She had discovered this was rather complicated. After a brief discussion with me she brought a bike inside and during mat time explored with the children how to balance it. Anabelle realised that she did not need to go into the actual physics of it. Asking questions helped children develop working theories identifying the difficulty of balancing the bike when it was not moving and how it was much easier when the bike was moving.

It is the difficulty of [explaining] complex things, and physics seems to be particularly complex, [putting it] across in a simple way but you don't need to in many ways because often it's the experience. And they remember the experiences, so that increased my confidence a lot.

(Anabelle,FG3)

I observed Sam taking a mat time prior to their trip to the show Under the Sea. She had noted what children already knew about the sea so asked them what they wanted to find out about the animals that lived under the sea. There were many questions to investigate and decided they could find out by looking at a movie, a book or do research.

\section{Funds of Knowledge.}

Another pedagogical approach they hoped to explore further was accessing the funds of knowledge within their families or wider communities. They felt they had not done this so well, but I reminded them that using the resources available through the school was accessing other funds of knowledge. They agreed that they used the wider school often, they took children to look at the rowing boats and saw the skeleton in the science lab when they were investigating the body. The school library was also available whenever they needed it.

The nature table was also a way for the families to contribute to the centre and they often gave gifts of a scientific nature. Sam recalled the value of documenting so decided to take a photo of each child with their object. They planned to create a book so the children could revisit the nature table contributions. 


\section{Curriculum Documents.}

Anabelle found It's a Bugs Life (Browne \& Te Papa, 2016) very useful. She printed and laminated pages that provided scaffolding techniques and questions that could be used with children. The NZ curriculum: Science (MOE, 2007) had also been useful. Anabelle liked that it gave them guidance of what they could explore with children. They also used Google or YouTube videos to explore inquiries. I suggested other search engines such as DuckDuckGo, SweetSearch and using their attached school's access to tki.org.nz to use Kidsinfo and Britannica Primary to find appropriate and advertising free information.

\subsubsection{Environment and Resourcing}

For Anabelle, the intention of this research process was to explore how to incorporate science into their programme in more authentic ways rather than through random experiments. In a reply to one of her reflections I suggested the idea of an Insect Basket, a resource I had seen in another centre. This included a basket with an insect catcher, magnifying glass, and insect identification book. Both Sam and Anabelle liked the idea and instigated an Insect Basket for outside.

We really liked Sola's idea of having a basket for use outside with magnifying glasses, bug catchers, and Andrew Crowe's book which we have. Sarah is going to buy some new large magnifying glasses over the holidays.

(Anabelle,R2)

Anabelle recalled how bringing the Insect Basket outside had created an interest in finding insects. Once one was found children looked at it closely, identified it in the book and discussed its needs and where it might live. They considered the Insect Basket had been successful at enabling science and would keep it available and add to it to keep it relevant with equipment like a clipboard, paper, and pen. They had also added a second basket to hold the CDs and mirrors for children to continue to explore rainbows, reflections, and refraction of light.

The teachers discussed how bringing the water trough up onto the deck had brought about interest and engagement in boat building activities.

Sam - The thing that I loved for our kids was when we put the water trough inside. That was huge for them, was something that we don't do and it really got them into the whole floating and sinking thing - that was a great starting point wasn't it? 
Anabelle - That's true. Yes.

Sam argued that having it available all the time meant "through trial and error that's what [the children] were using to find their answers" (FG2).

\subsubsection{Challenges}

There were a few challenges identified by Sam and Anabelle, such as having the water trough available. To ensure children did not become completely saturated either Sam or Anabelle remained at the trough. This meant they could have conversations with children as they explored. They saw this shift to more intentional teaching as hugely valuable. Sam raised the challenge that being in just one place meant possibly missing opportunities elsewhere.

As she outlined in the last focus group:

Sometimes you feel like you are answering this question for one or two children and yet there might be chaos out there. Because there is only two of us, one inside and one outside, sometimes it is hard. And some experiments or experiences might get broken up because you have to run off to do something and come back [to it].

(Sam,FG3)

Similarly, Anabelle felt guilty that she had missed an opportunity to follow up on a child's question or interest because of the other demands on her time during the day.

\subsubsection{Summary}

Anabelle and Sam believed the key changes that occurred over the CAR period that enabled scientific learning for children were the pedagogical approaches they actioned. Planning around children's interests was already part of their programme, but they found having science identified in their paperwork meant they were more intentional about the science experiences they chose for children. This led to using provocations in a more purposeful way to prompt scientific experiences or extend children's interests. Anabelle believed feeling confident towards science and having an inquiring mind was important. Both teachers showed this in their engagement with children during science explorations. Asking questions, discussing their ideas, and sharing their knowledge all meant children's interests were taken to a much deeper level. Also sharing what they knew via mat times was helpful for both teachers and children. Using this time to 
explore concepts in more depth, using scientific language and working through a scientific process, for instance predicting, hypothesising, and concluding, meant children gained knowledge or extended their own working theories about scientific concepts in a more focussed way. Both teachers found the NZ curriculum: Science (MOE, 2007) and It's a Bugs Life (Browne \& Te Papa, 2016) valuable in supporting them do this.

Using provocations as a pedagogical tool meant adding resources and changing the environment purposefully. Both teachers felt this had been an exciting shift for them and the children. Overall, they felt more confident about introducing and fostering scientific inquiries in their programme and supporting them through intentional teaching practices.

\subsection{Whau Centre}

Whau centre is a large full-day education and care centre situated in a school. It is licenced for 120 children over 2 , and there are 90 children divided into four classes with a mixed-age range of 3, 4 and 5-year-olds. Two classes, Tahi and Rua, were involved in the CAR project. The children attend the centre from $8.45 \mathrm{am}$ until $3 \mathrm{pm}$, with some attending before and/or after school care which means the centre is open from 8 am to $6 \mathrm{pm}$. The children attend all 5 days, but a few 3 and 4-year-olds finish after lunch at $1 \mathrm{pm}$ on some days. The school has a Decile 8 rating so caters to families within a wide range of socioeconomic backgrounds.

In the Tahi class there were two qualified teachers, Kim, the Head teacher, and Mandy. Tracey was the Head teacher of Rua class, while Izzy was the other teacher. Another teacher, Betty, oversaw the outside environment at the centre. Mandy, Izzy, and Betty had one afternoon a week as non-contact time. Kim and Tracey were paid a salary so used their time after 3pm for administrative work.

Both Kim and Tracey were comfortable with science. Kim had a very science focussed family hence it was a part of her daily life and she was confident about bringing more science into her classroom. Tracey enjoyed science, although she was not that confident in her knowledge of science concepts. She was excited to be involved in the CAR to explore how to fit more science into her teaching. 
My personal philosophy of practice is letting children make their own discoveries through getting their hands and bodies involved in what they are doing. I enjoy watching them experiment and try, again as they rarely judge themselves poorly if something doesn't work out the way they had planned. Another aspect of my philosophy is letting children learn from each other rather than always expecting it from a teacher.

(Tracey,R2)

Betty was passionate about science, particularly through nature and gardening. She enjoyed sharing this with children. Similarly, Mandy was also confident with science and believed she had a good understanding of science for this age group. Izzy, on the other hand, did not enjoy science, a consequence of a bad experience at school and subsequently tended to avoid it if she could. She was apprehensive about the CAR project.

\subsubsection{The Science Walk}

After our initial meeting to discuss the CAR project I returned to video the science walk with all teachers. Kim and Mandy walked me around their Tahi class, Tracey and Izzy walked me through their class, Rua, and the two Head teachers Kim and Tracey did the outdoor science walk.

The two classes, Tahi and Rua were arranged differently but had similar materials available to children. Each class had an animal to care for, an axolotl in Tahi and a turtle in Rua. All teachers saw animals as a source for scientific discussion and information around biology and caring for an animal. The plants around the class were identified in a similar way. Rua's spider plant was being used as a propagation activity.

The teachers identified the resources they believed supported scientific inquiries. They noticed similar activities such as the food preparation and baking areas which introduced changes in state (chemistry), different types of food and discussions around nutrition. Activities were laid out in each class which teachers believed introduced and supported a variety of science concepts including polishing tarnish off metals, flower arranging, pouring liquids, sink and float, magnets and sewing. They also noted the classroom construction materials, which supported exploration of balance, gravity, weight, dimensions, and other engineering concepts. There were specific science materials available to children such as puzzles showing the different parts of the flower, 
a tree, various animals, cards introducing classification of animals and trays showing land and water formations, for example how a lake or island are formed. In Tahi class, Kim identified the electric jug and iron, used for making cups of tea and ironing the tea towels, as equipment that introduced concepts about electricity and heat. Tracey thought the mat and cards with yoga poses in Rua class was a source of scientific ideas around children's body and anatomy.

Outside, Tracey and Kim showed me around the sandpit and gardens. The large garden area had been arranged to provide a variety of activities that supported children caring, harvesting, and exploring the plants. Children were involved in the overall care of the garden and learnt about the purpose for the plants, for instance which flowers were for picking, to provide food or to re-condition the soil. There was a weta house, a hutch for the rabbit, and a worm farm. Inside the garage there were activities set up for the children. The teachers identified which ones they felt supported science, for example, felting wool, sewing lavender bags, cutting up food for the worms, making a slug trap, planting seeds, and bug hunting. There was also a carpentry table, balls and a catapult board, a variety of books, and climbing equipment. Both Kim and Tracey agreed that the outside environment offered more opportunities for children to explore nature and discuss ideas around insects, animals, the weather, and the seasons.

\subsubsection{First Focus Group - Reflections on the Science Walk}

The three science walk videos were loaded onto Moodle for each teacher to view independently prior to the meeting. I provided guiding questions via email and on Moodle. The videos raised some questions for teachers about the breadth of science. Mandy had not realised the body mechanics that children had to explore and learn while in the classroom, including balancing the materials on a tray as they walked. She thought it was hard to differentiate between maths and science concepts. Tracey wondered if anthropology could be considered a science because she felt children explored human relations in the centre. Izzy wondered if sewing was science, but most thought it was technology. The teachers agreed that science could include sewing and anthropology as they were concepts children were exploring that required gaining new knowledge, understanding through conversations, and developing theories around how things work. 
The teachers identified areas in their practice they wanted to improve. Kim wanted to follow up on children's interests by being more intentional in her practice, such as planning, using provocations to start conversations and allowing additional time for discussions. Mandy wanted more discussions with children and to introduce extra scientific vocabulary. Tracey and Izzy thought they supported children's theorising and hypothesising well although Tracey wondered if their philosophical approach constrained the amount of scaffolding they did with children.

I'm not sure if we are supposed to be describing the concepts, so like if someone continually builds [a] tower upside down and it keeps falling I don't ever say the reason it's falling is because of gravity or balance. I might just say 'try it another way' and let them continue theorising but I'm never giving any backbone to the science that is happening.

Tracey considered the possibility that this was due to her lack of confidence with those science concepts. For Izzy her confidence to do science was the main area she wanted to work on.

Betty felt the philosophy had placed "constraints around what we are meant to be doing" (FG1). She did not think she was able to bring in new materials or provocations although the other teachers felt she could follow individual children's interests through conversations and resources. I suggested she explore It's a Bugs Life (Browne \& Te Papa, 2016) for ideas around the science capabilities she could be supporting through investigations and discussions with children.

\subsubsection{Action Plan}

An action plan for each class and the outside area in Whau (see Table 5.4) was created from the discussions and intentions identified during the first focus group. 
Table 5. 4

Whau Action Plan

\begin{tabular}{|l|l|l|}
\hline Areas to action & How & Who \\
\hline Pedagogical & $\begin{array}{l}\text { Follow-up children's interests through planning, } \\
\text { identifying the next step and what to do to support } \\
\text { further learning. }\end{array}$ & Tahi \\
\cline { 2 - 2 } & $\begin{array}{l}\text { Plan using group time to introduce science inquiries. } \\
\text { Bring in in-depth discussions and introduce scientific } \\
\text { vocabulary. }\end{array}$ & \\
\cline { 2 - 3 } & $\begin{array}{l}\text { Explore engaging with and alongside children to support } \\
\text { their working theories. }\end{array}$ & Rua \\
\cline { 2 - 3 } & $\begin{array}{l}\text { Bring in new knowledge through co-construction and } \\
\text { scaffolding. }\end{array}$ & \\
\cline { 2 - 3 } & $\begin{array}{l}\text { Follow up children's interests through conversations } \\
\text { and introduce new materials. }\end{array}$ & Outside \\
\hline Resourcing & $\begin{array}{l}\text { Bring in new materials through provocations - via } \\
\text { teachers or children. }\end{array}$ & All \\
\hline
\end{tabular}

\subsubsection{Action Plan Process}

We discussed my role during the CAR process at our first meeting. The teachers were happy for me to engage with children, observe and video moments of science investigation as they occurred. From these visits I made observation notes on where I saw science happening or where it could be enabled. I also used these notes to raise any questions about what I saw or to challenge teachers to think about other ways of bringing science into their practice. After the first focus group, the teachers discussed their action plan within their teaching teams over the following two weeks. In addition, they posted their bios on Moodle. My first of 9 visits, each Wednesday through to December, followed.

The mid-research focus group was set for the beginning of November. The final week of the 12-week research period fell in the last week of the term, due to various reasons we did not meet for this until February the following year. 
I provided guiding questions for both focus groups which drew on their action plan, my observations, their reflections, and my research questions. The teachers provided reflections via their online journal and often discussed ideas during my visits. The findings from these sources of data are presented under headings which have combined the actions each of the teaching teams wanted to work on. The challenges identified throughout this CAR are also discussed.

\subsubsection{Pedagogical Approaches}

Whau had a philosophy that guided the teacher's pedagogy, so exploring ideas of intentional teaching needed to be done in a way that was appropriate for, and supported, the centre's approach. All teachers were strong advocates of their philosophy but were open to critique and investigating how they could best foster scientific experiences. The teaching strategies including following up children's interest, having deeper conversations with them, supporting their working theories, introducing new knowledge through co-construction and scaffolding, all fit within the concept of intentional teaching. This term is therefore used to encompass the findings relating to these practices.

\section{Intentional Teaching.}

Kim wanted to follow up on children's interests and explore ways to extend their learning through these. At the mid-research focus group, she reflected that she was doing this more, especially with one child who had a strong interest in insects. Kim felt this meant "he [felt] a greater sense of belonging [because] his interests [were] picked up more" (FG2). Overall, Kim thought she responded to children's questions when previously she would have left them. Mandy agreed that thinking about science was more obvious in their interactions with children.

[We] have agreed to take turns planning and leading the groups, having a week each so that we can follow through on ideas, interests, and themes. This will allow us to introduce an area of interest (from tamariki whenever possible), explore it through literature, experiments, conversation, hypothesising etc, rather than just having a conversation about something and leaving it there - which is something that I felt I was doing. 
Mandy wanted to bring in more science through her daily exchanges with children. She noted that intentional teaching practices was a way to do this.

I will be aiming to do more 'intentional teaching' and responding to comments and interests which can be harder to do 'on the fly' and in this environment. I liked one of the suggestions in 'Bug's Life' which was not to 'dumb it down' to children. A good reminder.

(Mandy,R3)

Tracey found it harder than she expected to be intentional in her interactions with children. She was aware the philosophy of the centre meant they often left children to explore on their own.

One thing that has struck me ... is that we often don't help. We allow for hypothesising but we don't go the extra distance to get the resources for children.

(Tracey,R3)

Tracey could see the value in questioning, theorising and co-constructing with children and had begun to do so but was still working out how to participate without taking over. She also wanted to avoid the inquiry taking over the culture of the whole class. Further discussions with me during my visits and reflections on this occurred throughout the research process so by the last focus group Tracey thought this had been a significant shift in her practice. She felt more confident to be involved in conversations with children, to ask questions and engage in their discussions and inquiries and coconstructing new knowledge with them.

Co-construction was also an area Izzy tried to incorporate into her practice. Firstly, by noticing and responding to the science opportunities when they came up and then working alongside children to explore what was happening. This shift happened slowly over the research period, but by the end she reflected that these moments were happening more often.

Now I will take the time to pause and think for a moment and many times I picked up a conversation that [involved] science. ... I also learned to be brave about 'science'. It is truly not my cup of tea but I try to approach the matter with an open mind. 
In the outside space I observed children frequently exploring the garden in groups and hunting for insects together. I would join them to find out what they were investigating, and our conversations and discoveries were often rich with new scientific learnings. While I did observe teachers with children in the garden or reading a book with them, I did not often notice them joining children in conversations about what they were doing. I posed the following question on Moodle.

When I am there, there is plenty of discussion with the children about what they have found and often the discussion explores other aspects of their and my knowledge. And the research is clear that it is these conversations that are so valuable for children's knowledge growth. My question is are these questions happening when I am not there?

Betty responded that having the centre observed from a fresh perspective was helpful and appreciated my feedback. She agreed that there were many more discussions about science occurring during my visits but felt the philosophy of the centre was "very particular about protecting children's individual focus and minimising interruption, but this aspect can also place restrictions on interaction and conversations" (R2). She thought another restriction was not having enough time to engage in spontaneous conversations with children.

Inside the centre I observed children occupied with resources that were scientific in nature, yet opportunities to explore what they were learning from them were missed. For example, on one occasion two children were exploring the transport cards and when asked they explained to me how the activity worked. I then inquired about the actual pictures on the cards and there was some confusion. This prompted me to ask the teachers via Moodle if the lack of conversations with children when they were involved in activities meant the knowledge that could be gained from the resources was lost? Kim replied that being involved in the research had helped her see the value of these conversations and consequently they were occurring more often. But she was "conscious of finding the balance between respecting the importance of independent work and enriching their knowledge by having a conversation about it; questioning and allowing them to question their own working theories" (R5). 


\subsubsection{Environment and Resourcing}

While provocations were explored as a pedagogical approach by both Kanuka and Matai, Whau teachers used provocations as a way of bringing other resources into the centre environment. This allowed changes to the environment or resources to fit within the philosophical approach of the centre.

\section{Provocations.}

Kim considered scientific conversations could be encouraged during the daily group times. The teachers used this time to follow up on something that had happened or to introduce a new topic. The Liquid or Solid book was a good example of this. Kim found the book and on each page was a picture of an object with the words "liquid or solid?". As Kim read the book with children, they shared whether they thought the object was a liquid or a solid and why. It created a lot of discussion and the book remained a source for insightful conversations between children. For Kim this was a useful way to bring provocations into the centre.

In Kim's class the provocations had mainly come in via one particular child, who had a strong interest in insects and later became an expert guiding other children with his knowledge.

A lot of ours did come from $R$ - it wasn't us bringing in heaps of things. Because $R$ would bring in books, or the huhu ${ }^{16}$ grubs ... and we used them as provocations for the class.

(Kim,FG3)

Recognising the value of provocations was something Kim and Mandy began to do more over the research period. For example, as shown in Figure 5.5, a child brought in capsicum seeds and wanted to see how to grow them. Kim helped her create an experiment to find out which environment grows capsicums best, in a hothouse with soil and water, outside with soil and water or just in water. The child hypothesised that the seeds in the hothouse would grow first.

\footnotetext{
${ }^{16}$ Huhu grubs are the larvae of the huhu beetle, a large beetle native to NZ.
} 
Figure 5.5

Experimenting with Capsicum Seeds (Own Image)

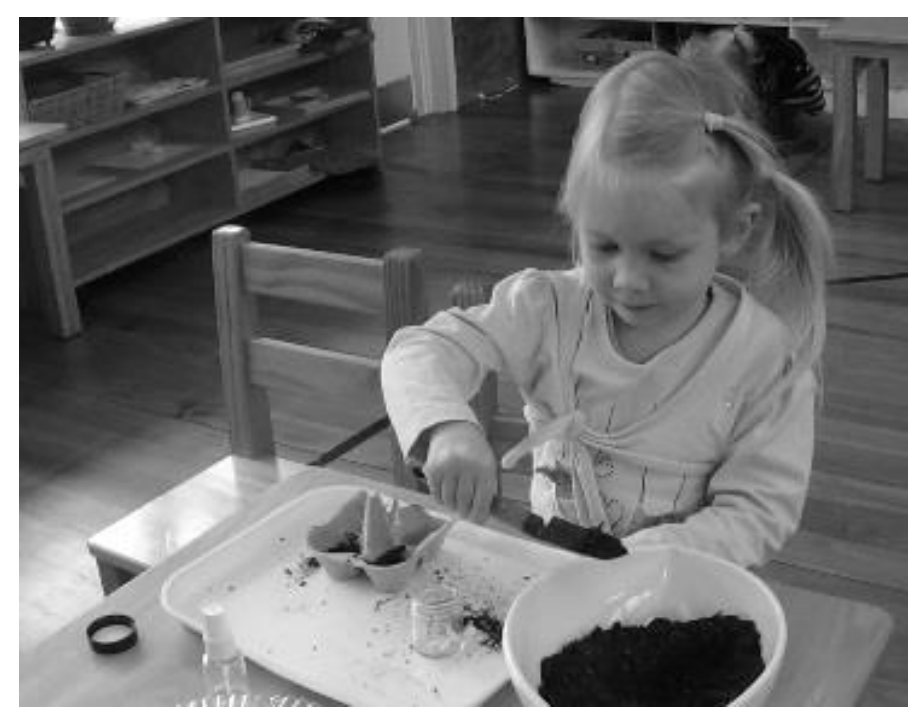

I called provocations that occurred without planning happenstance provocations (explored further in section 8.4) and discussed their value with the teachers. A good example was when the centre experienced a spontaneous heavy downpour of rain. Children from all classes rushed outside to experience the rain and the resulting puddles (see Figure 5.6). I could sense the teachers' unease. Kim reflected that she too could see that it did not look like "productive work" but children were thoroughly enjoying themselves.

I think that this was the biggest learning of the day for me! Once I had gotten over that, there were many scientific conversations to be had - many of which are actually there most rainy days I have realised. Talking to L and V about the sticks and water flow was interesting, especially hearing their working theories about what was happening.

$(\operatorname{Kim}, R 4)$ 
Figure 5.6

Experiencing Puddles Outside (Own Image).

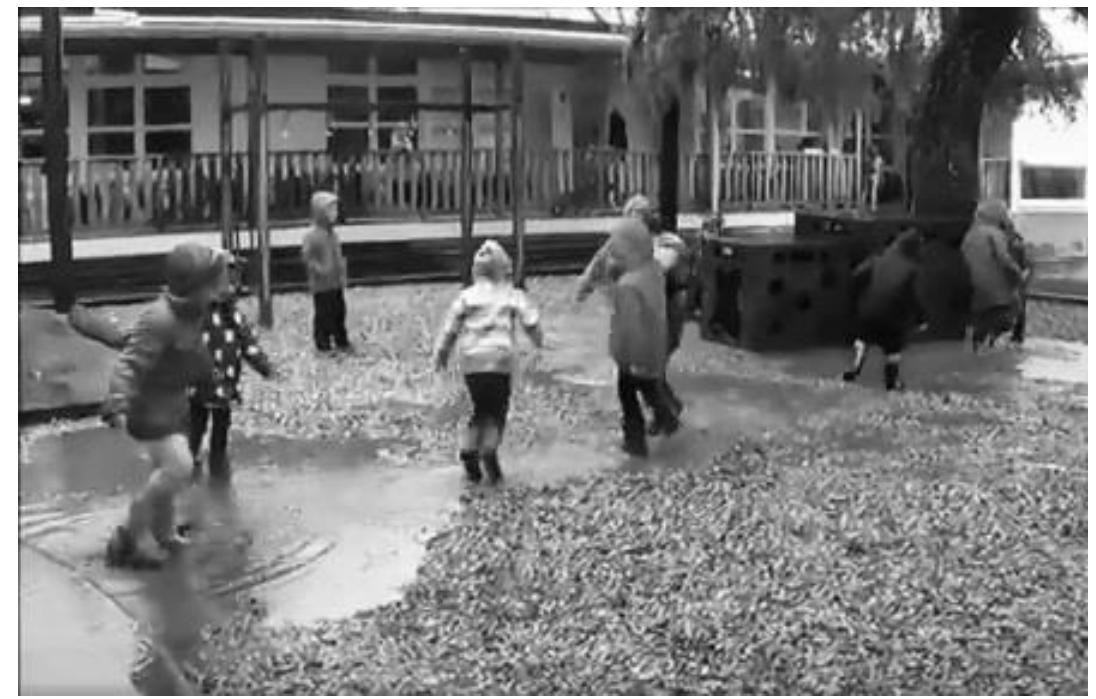

Tracey too had a similar experience when she cleaned out the turtle's tank while children were there. Their interest and questions during the process reinforced for her the value of sharing and co-constructing knowledge with children. It also indicated how taking advantage of happenings that are out-of-the-ordinary created opportunities for learning.

This experience was a lot of fun for all of us and I found myself far more receptive to the spontaneous whole group discussion than I might have been before partaking in the science study. I think that my focus on allowing co-construction of knowledge and information passing has been very influential in my teaching practice.

(Tracey, R5)

She nonetheless reflected during their last focus group that perhaps they were more receptive to exploring different pedagogies because they were experienced teachers.

Like I wouldn't say a first-year teacher ... would be so receptive. I know I wouldn't have been.

(Tracey,FG3)

\section{Resources.}

The resourcing of Whau was identified by teachers as a strength during the science walk. I noticed the variety of resources and activities available for children to use during my first visit, especially in the outside space. For example, children were able to plant seeds, sew material bags filled with lavender from the garden, create felt balls from 
pieces of wool, or use the insect catcher to catch an insect and identify it through the insect book readily available. These were all presented on trays ready for children to access whenever they wanted. I commented how these resources could support and initiate science inquiry and asked how important teachers thought this was. Again, Betty responded in her reflection.

I believe that resourcing a learning environment with provocations and equipment is vital for encouraging children's scientific explorations: without specific scientific resources, [such as a bug-catcher] spontaneous explorations are still possible, but unlikely to become part of a centre's daily culture. We only become intrigued by those things we are exposed to - if opportunities for specific exploration just aren't there, children become much less likely to have their interest sparked or sustained.

(Betty,R2,own emphasis)

Betty felt the opportunities to provide spontaneous provocations were limited, particularly as the resources provided had to be purposeful with clear objectives identified.

I find this makes resourcing the environment more difficult and restricts the learning opportunities which tamariki are exposed to each day. ... I feel there are simply more ways to 'do science'.

$($ Betty,R2)

\subsubsection{Curriculum Documents}

When discussed during the focus groups, It's a Bugs Life (Browne \& Te Papa, 2016) was found to be helpful by Mandy, Izzy and Tracey. Mandy saw the Code of Conduct for how to handle insects as especially useful for the Insect Hunting activity outside. The NZ Curriculum: Science (MOE, 2007) was looked at briefly by the teachers but as Kim identified they had a curriculum to guide their programme already.

It was interesting to read but I don't feel the need to take that curriculum any further because what we are doing is meeting a lot of those objectives already.

(Kim,FG3)

\subsubsection{Challenges}

Observations during my visits identified the lack of challenge in the outside space for the older children and the teachers also noted that older children did not engage in outside activities. This had been an ongoing issue for the centre. I suggested they 
investigate ideas around a nature or place-based programme and examine the concept of regular walks into the local bush to a wilderness space. I connected them to another centre in Wellington who did something similar and left it with the teachers to see if they could put it into Whau's programme.

For Tracey, who had been involved in something similar in her previous centre, this was an exciting prospect.

The idea of the nature-based programming has been very exciting for me. Kim and I have met with K in Wellington and we are figuring out what we need to do to get a weekly nature walk off the ground. I think this will be doable by term 1 next year and the benefits will be far reaching. This is an idea that has come from being in this research study, so we are very lucky to have participated!

The teachers recognised the need to create more opportunities for constructive investigations in the outside area, especially during the insect hunting activity. For example, I often observed children wandering outside with no obvious purpose, who immediately responded to my engagement and questions. There were two elements the teachers wanted to attend to here; adding variety to the outside environment so there were more places to hunt for insects, and a shift in teachers practice towards a more interactive approach with children when outside. Tracey brought in some river rocks and placed them around the garden to create spaces for insects to live and encourage children to observe the insects in their habitat rather than catching them. The change in practice for the outside teachers was a little more complicated.

I feel a little bit like I'm using my clout as an HT when actually I'm not maybe respecting their kaupapa, so I agree outdoors has so many affordances but at the same time I sometimes feel awkward just stepping all over [what is happening outside].

(Tracey,FG3)

After the CAR at Whau I was invited back during the following year to join Tracey, a student from the school's Year 13 class, and the group of eight 5-year-old children from Rua class for their walk into the local bush. It took 20 minutes to walk into the clearing they use as their wild space. There was a creek, space to build shelters, and a variety of areas to explore. They stayed for about an hour. Tracey discussed the value in these expeditions; mainly the challenges it presented for children, the discussions that come 
up, the skills they gained and the new knowledge, scientific or otherwise, that they acquired each time. With a group of 5-year-olds from each of the four classes going each week it meant they could only visit once every 4 weeks, but Tracey felt they would gain even more if it were to happen more often.

\subsubsection{Summary}

There were some significant changes for the teachers at Whau, most related to their pedagogical practices. They felt that my visit each week was a useful reminder and being involved for 12 weeks helped the changes become part of their practice. One major change for Kim and Mandy was the increase in conversations with children and discussions about their scientific interests which had led to more science occurring. Tracey agreed with them and identified that I gave them permission to engage with children more, to stop and have a conversation and to add their knowledge to the discussion too. This shift to more intentional teaching practices differed a little to the centre's emphasis on children working independently, but Kim felt as oral language was such a core part of their philosophy it was just a matter of having conversations at the right time and place and finding the balance of when to interrupt or to join in.

Tracey, too, had added intentional teaching practices to her repertoire such as coconstructing knowledge with the children, discussing ideas and joining their conversations. She saw the value in provocations to introduce new ideas and concepts children might not have access to at home and wanted to continue to work on adding them to her daily practice. Izzy had discovered she was brave with science and could recognise and take opportunities for science investigations alongside children, but mostly she enjoyed the chance to learn off the other teachers through the focus groups. Additions to their resources and environment were few, other than as provocations or minor additions such as extra rocks in the garden or a poster on the wall. However, the biggest change was moving children out of the centre environment. The teachers saw the value of weekly bush walks for the 5-year-olds and were working towards increasing their frequency.

\subsection{Chapter Summary}

For all three centres my involvement was key in enabling more science to occur. Either via my role-modelling or just my questioning and presence meant it remained a focus 
for them. This influence manifested itself through teachers' planning and having science at the forefront of their thoughts, so they found they recognised scientific experiences more readily and responded to them in more purposeful ways. The teachers all felt there had been a shift in their pedagogy especially their use of intentional teaching practices such as questioning, co-constructing, and sharing knowledge. They embraced the more meaningful and deliberate engagement in scientific explorations and knowledge they had with children, which in turn meant they felt more confident to inquire and learn about scientific concepts themselves.

Provocations had also created a mechanism to introduce and extend scientific occurrences in their centres. For Matai, provocations had been an easy addition to their programme and the teachers thought it had enabled them to extend children's interests or introduce new knowledge more effectively. Teachers at Whau used provocations in a more subtle way to fit their centre's philosophy, however, embracing happenstance provocations or those brought in by children proved to be valuable for scientific explorations. Kanuka found provocations useful but problematic when accommodating the diverse range of ages, needs and abilities of their children. The following chapter presents the findings from the second group of three centres involved in this CAR study. 


\section{CAR with Mahoe, Kowhai and Ngaio Centres}

\subsection{Chapter Overview}

This chapter outlines the findings from the second three centres involved in the CAR process. After reflecting on my role with the previous centres I realised the influence of my role in the research process, so my involvement with these three centres changed. I spent more time with them, offered additional suggestions and provided specific feedback during my visits and at the focus groups. Teachers in each centre responded positively to my engagement, using the ideas, articles, or advice to affect their action research goals and practice to various degrees.

The CAR process followed for these three centres was the same format as explained in the previous chapter for Kanuka, Matai and Whau. This chapter therefore outlines the findings from the science walk, the action plan and the focus groups for Mahoe, Kowhai and Ngaio.

\subsection{Mahoe Centre}

Mahoe is a sessional kindergarten, operating under a regional association, licenced for 50 children aged 2-years and older. Each session has a maximum group size of 30 children. The sessions on Monday, Tuesday and Thursday catered for an older age group (4-5 years) and were from $8.30 \mathrm{am}$ to $2.30 \mathrm{pm}$. The younger children, attended on Wednesday and Fridays, which finished earlier at $12.45 \mathrm{pm}$. During the CAR period the session hours increased, consequently the session times went through to $2.30 \mathrm{pm}$ each day. The centre is situated in a culturally diverse community beside a local primary school with a decile rating of 10 , indicating a high socioeconomic area.

There were three qualified teachers working at Mahoe centre, Sharon, the Head teacher, Cynthia, and Alyssa and all were involved in the research. There was also an administrator who worked in the office for 15 hours per week and she covered the teachers when they had their lunch break. All teachers had non-contact time each day after 2:30pm.

Sharon believed every child has potential and that it was her role as a teacher to foster this. For Cynthia learning through play was most important and children should direct 
their own learning. Alyssa enjoyed learning alongside children. They all felt confident about science and had been involved in various science PLD sessions but were interested to use the CAR to review how they approached science in their setting.

\subsubsection{The Science Walk}

My first visit to Mahoe in November 2017 provided an opportunity to outline what was involved for the teachers and the role I would play over the research period. We met again in January 2018 to record the science walk. All three teachers walked me through their centre identifying the areas they thought afforded scientific opportunities.

We began inside by the kai ${ }^{17}$ table area. One teacher always sat with children while they had morning tea or lunch. The teachers felt this provided many opportunities to discuss the science of food such as healthy eating, the seasons and growing food. They also used this space for cooking and making playdough. The centre had a Light Table which was used in a variety of ways to explore magnetism, light and exploring two-or threedimensional shapes. Alyssa noted the art area as a place for children to explore science through mixing colours and problem solving.

A wall of photos was set up to show science experiences. The teachers thought this provided opportunities to discuss scientific concepts with children as well as parents. An area free of tables and chairs was used for musical activities. Sharon saw opportunities to explore science through music by children experiencing movement of their bodies and considering energy and force by playing with scarves, the parachute, and balls. The book area was identified as a place for science related conversations and information gathering. In their block play area, teachers pointed out a table they used for displaying science related materials such as shells and plastic insects. The basket of plastic animals and dinosaurs were often included in the block play so offered chances for discussions about their different habitats. Cynthia felt the building blocks gave the children experiences with gravity, balancing and other physics concepts.

Outside the centre, Alyssa saw the climbing equipment as a place for children to explore physics through their own body movements through using the slide and ramps. Also, the bikes, scooter boards, and balls meant children could experience speed, trajectory, and forces. There was a covered area with more tables with materials such as marble

\footnotetext{
17 Food or to eat.
} 
runs and mechanical Lego. The teachers noted the water trough and sand pit as places for further exploration of science ideas. The raised gardens were well looked after by children and were full of ripening strawberries.

\subsubsection{First Focus Group - Reflections on the Science Walk}

I prepared initial questions to help frame the first focus group. Reflecting on the science walk video Cynthia felt they could have mentioned a few more areas supporting science. Sharon thought having the activities out ready for the session would have helped them remember more. Alyssa also noted there was often a cross-over with mathematics.

We could have added this and that, so much more, and in several places we mixed up science with maths but then it overlaps because we hardly focus on one single

thing, it's everything.

(Alyssa,FG1)

However, they believed they provided for basic science opportunities. Alyssa thought they talked about science when the opportunities came up, discussing science ideas in a simple way to try to explain what was happening.

[When children are playing with science materials this] give us an opportunity to think and talk about what it is in a very simple way to explain. With a 3-year-old we wouldn't say it is magnetism but yes they stick together so you try to explore things in a very simple way.

(Alyssa,FG1)

Sharon agreed, and considered the role of the teacher was most important in these opportunities. How the teacher drew the child's attention to the science occurring in an activity meant children were able to gain new knowledge or notice and think about what was happening. It is "the role of the teacher to bring that science lens in" (Sharon,FG1). Cynthia and Alyssa thought another way to help children identify the science in situations was by teachers noticing, recognising what was happening and asking questions.

The teachers had previously been involved in science PLD sessions. They discussed the complexities these had raised in considering the teaching practices they used to support children's science experiences, such as when to use science language, when to bring in facts and how to support children's developing working theories without hijacking their ideas. 
Cynthia - there is that interesting balance though... the balance of giving children the answers and the language as opposed to don't give them the answers and try and let them theorise about what it is, even if it's completely wrong ...

Alyssa - you don't have to give them the answer. And that's quite important at this age.

Cynthia - yeah [but] how long do you let them go with their theory before you provide the answer... it is quite a challenge I think.

The teachers could see value in exploring their pedagogy through the CAR and developing their own knowledge and understanding so they felt more confident when supporting science exploration with children.

All teachers thought their centre environment was effective, as was the way they brought in materials to prompt science, such as experiments. They did want to ensure the equipment they set up was purposeful and connected to children's interests in a way that could advance their learning.

\subsubsection{Action Plan}

The areas the Mahoe teachers wanted to focus on, incorporating my suggestions, are summarised in their action plan outlined in Table 6.1 below.

Table 6. 1

Mahoe Action Plan

\begin{tabular}{|l|l|}
\hline Areas to action & How \\
\hline Environment & Make research books more readily available. \\
\cline { 2 - 2 } and resources & $\begin{array}{l}\text { Set out science related materials and resources - such as a science } \\
\text { table. }\end{array}$ \\
\cline { 2 - 2 } $\begin{array}{l}\text { Explore weather as a focus, thinking about possible next steps. } \\
\text { approaches }\end{array}$ & $\begin{array}{l}\text { Explore intentional teaching - preparing the environment and } \\
\text { materials to support children's interests. }\end{array}$ \\
\cline { 2 - 2 } & $\begin{array}{l}\text { Develop their own knowledge to confidently work with children } \\
\text { around their interests. }\end{array}$ \\
\cline { 2 - 2 } & Use scientific language. \\
\cline { 2 - 2 } & Ask questions to foster wonder and awe. \\
\hline
\end{tabular}




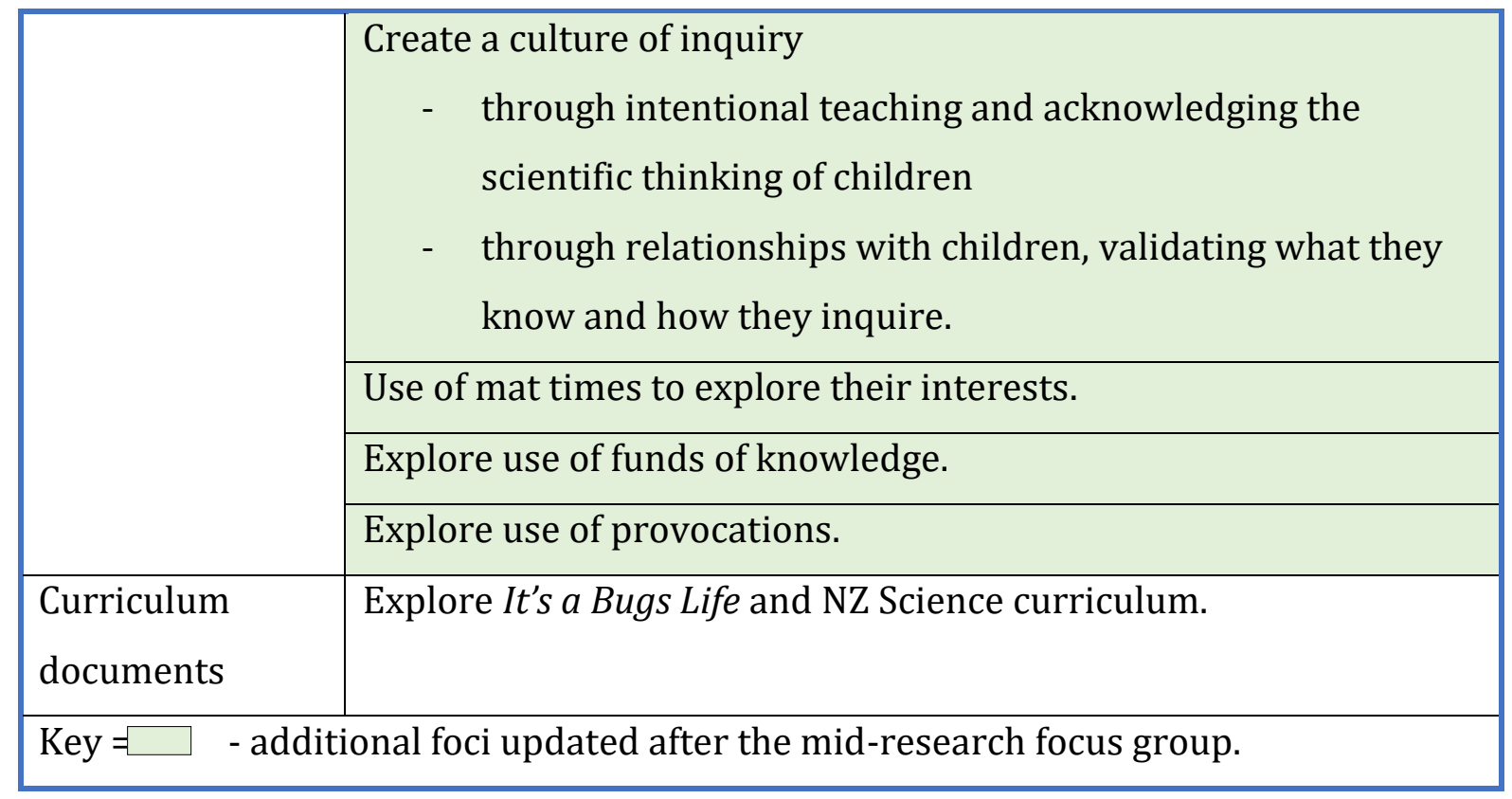

\subsubsection{Action Plan Process}

Sharon, Cynthia, and Alyssa worked through their action plan over the next 14 weeks. My first visit of 11 visits took place on a Monday morning, when older children were attending as the teachers thought this would be the best time for me to observe and engage with children. My observations were posted onto Moodle to give feedback and ideas for teachers to consider. The mid-research focus group was a chance to reflect as a group on how they thought they were working through the action plan, identify any areas they or I thought could be explored further or add to their action plan. I adjusted their action plan at this point to acknowledge the additional areas they wanted to work on for the last half of the CAR project. The final focus group presented an opportunity for teachers to reflect on the impact of being part of the CAR and what they thought had enabled science in their centre. Findings from both the focus groups, teachers' reflections and my observations are presented under the areas identified in the action plan.

\subsubsection{Environment and Resourcing}

The teachers wanted to focus on the resources they put out for children each day, arranging a specific science table and offering more science related books and materials. However, after a few weeks Alyssa noted that they did not need a table just for science as every table could be science. They began bringing science into what they were doing with children and providing books and resources as they needed them. During one of 
my visits a child observed a spider outside. After this incident I suggested a basket of books, an insect catcher and magnifying glasses as had been introduced by Matai. The Mahoe teachers created a similar basket of insect related material which was placed outside during favourable weather days (see Figure 6.1). Sharon reflected that this had been a valuable change.

Having that basket outside was good. And ... we have set up a little area and put some of those research books there ... we've put the chair there, and they look through all the books and talking to one another about what they are seeing.

(Sharon,FG3)

Figure 6. 1

Using the Insect Basket to Identify a Slater (Own Image)

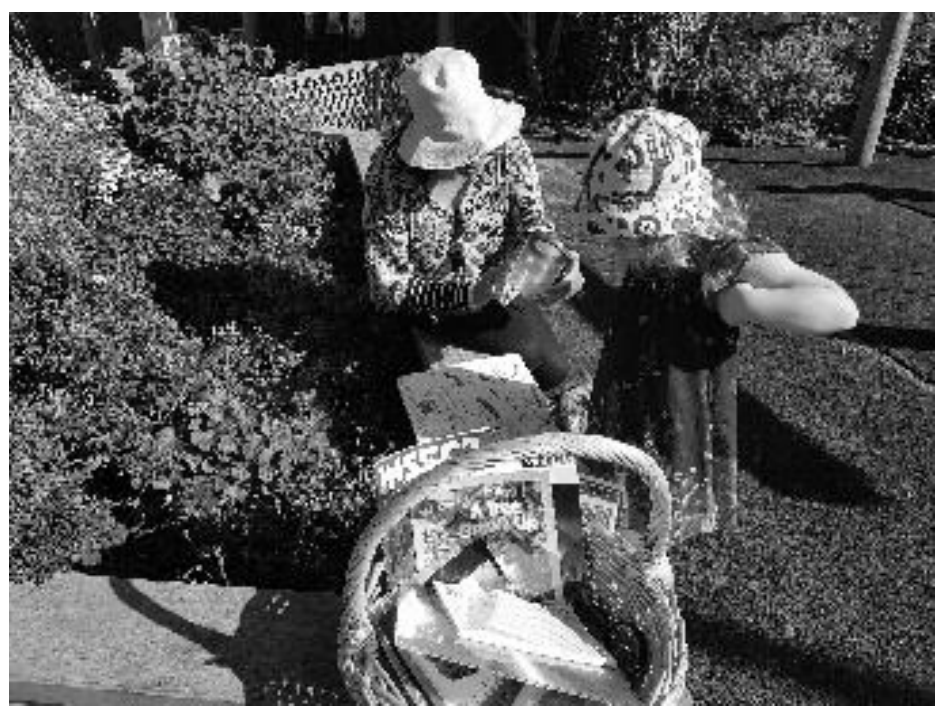

Cynthia remarked that the non-fiction books they put by the couch outside, rather than the usual story books, had been well used. For example, when a hedgehog visited the centre the book about them was especially popular.

During my visits I noticed various activities set up by teachers to promote scientific inquiry such as a cornflour and water mix in the water tray outside (ON1), the ice, salt, and red coloured water with small droppers in the water tray (ON2) and an oil and coloured water activity (ON3). Each activity had been set up by a teacher and when I arrived children were busy exploring them. A teacher was with them at the activity, asking questions and noticing what was happening. Inside there were other activities set up on tables. 
During my fifth visit I noticed one table with insects set in resin, plastic insects, and a book about insects, but there were no children exploring this resource, so I sat there. Within minutes two boys joined me and we investigated the insects together, identifying them in the book and discussing what they were. I reflected in my observation notes that my time sitting at the table was child led and involved sustained discussion between the children and myself. I believed this sat comfortably within the intentional teaching framework outlined by Te Whāriki (MOE, 2017) and I asked how teachers felt about this idea.

Do we value the role of the teacher or the importance of meaningful engagement with children? Intentional teaching adds complexity to their play and further develops their understanding.

(Sharon, reply to ON5)

Sharon, Cynthia, and Alyssa often discussed their role as teachers during the research and wondered whether they were valued enough for their part in facilitating science exploration with children.

\subsubsection{Pedagogical Approaches}

The teachers explored their practice in relation to enabling more science experiences in their centre. Strategies such as intentional teaching, provocations and use of funds of knowledge were some of the approaches they explored.

\section{Intentional Teaching.}

The link between the provision of resources and how they are used by children, especially when a teacher is involved was explored often by the Mahoe teachers. Pedagogical approaches such as intentional teaching were discussed during the midresearch focus group.

Alyssa - Providing the activities ... and then sitting with them ... so being there and talking about it, yes it is providing the stuff and then being there with it to support the learning to happen ...

Sharon -... If a teacher is not intentionally going in there and engaging with them, are they learning?

Alyssa reflected on this specifically in one of her reflections on Moodle. 
I think the learning environment and materials provided for children with an intention of some specific learning, in this case it was science, plays a vital role. It provides opportunities for teachers to discuss specific topics. I reflected on it later on and thought how everyday play slowly developed into scientific learning. If a science resource and my intentional teaching was not there it would not [have] happened. Teachers' role of providing materials and then involving themselves with children is really helpful and supports scientific learning.

During an earlier visit I had noted the value in introducing scientific language and sharing knowledge during interactions with children. Cynthia reflected on this as she had put out the catapult foot boards with tennis balls and the equipment was being used by children. As shown in Figure 6.2, one boy, J, experimented with how hard he stomped on the board and the resulting height the ball was lifted. Cynthia discussed with him what he thought was happening. I was observing and joined the discussion.

Sola [explained] to J how the force of his foot transferred along the board and into the ball, making it go higher and fly further. She asked provoking questions to support J to think about how to try and work out the amount of force required to lift the ball high enough to catch it.

I realised how we can make the most of these scientific teachable moments and support the children to take their thinking and working theories to the next level through our language and sharing of knowledge. We have the knowledge, and it was a great reminder of how I can put this into practice.

(Cynthia,R1)

Figure 6.2

Using the Catapult Board to Explore Force (Own Image)
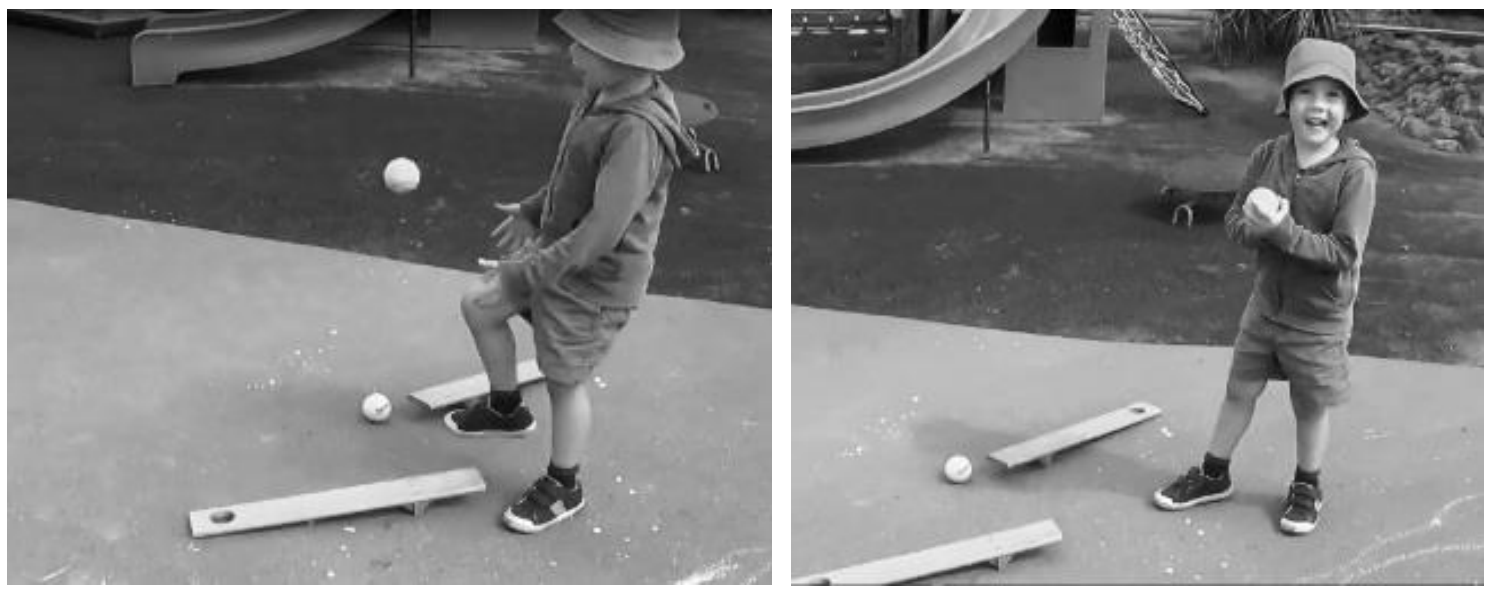
Using scientific language with children was a key enabler for the Mahoe teachers. There were a number of situations where scientific terms were used. For example, when a dead weta was found by one child he put it in the garden to watch it decompose. In an exploration of clouds, teachers used an experiment to investigate condensation and evaporation. The oil and coloured water activity prompted a discussion between Sharon and Alyssa about the words that described what was happening.

We discussed what was actually happening and were we using the right language. We used words like repel, extract (when $R$ was trying to remove the oil), molecules, particles, expanding and mixing.

(Sharon, R2)

For Cynthia it was also knowing that introducing scientific language was an acceptable pedagogical tool to use, "that you have the confidence to think actually this is appropriate and this is fine and if they don't get it straight away, they will get it and there is no reason why we can't use that language." (FG3). Having the confidence to use scientific language resulted in teachers using more.

\section{Provocations.}

Using language when introducing provocations was also found to be important, especially being prepared with knowledge around the science that the provocation might initiate. Cynthia's knowledge and confidence meant she took advantage of provocations and recognised the science in the opportunities that came up.

I guess you use any opportunity, it's like today when the boys were out making the volcanoes in the sand pit ... the fact that there is a volcano happening right now, you can ask if they have seen it or know about it... it sort of builds on or taking any opportunity you can to introduce a new idea.

(Cynthia,FG3)

Sharon thought provocations were utilising the teachable moments that came up during the day, often these came about through weather, visits from animals or something brought in by a child or family. I identified these to them as happenstance provocations. Provocations had not been on Mahoe's action plan but during the mid-research focus group the teachers reflected on an instance where a family loaned the centre a metal detector and how this had created a large investigation into where you could find metal (see Figure 6.3). Teachers could see the value in provocations, how these incidences had enabled science through bringing in new ideas, facilitating conversations and sharing of 
ideas amongst children. They decided to add provocations to their action plan and work towards making them happen more often in their centre.

Figure 6. 3

Exploring with a Metal Detector (Own Image)

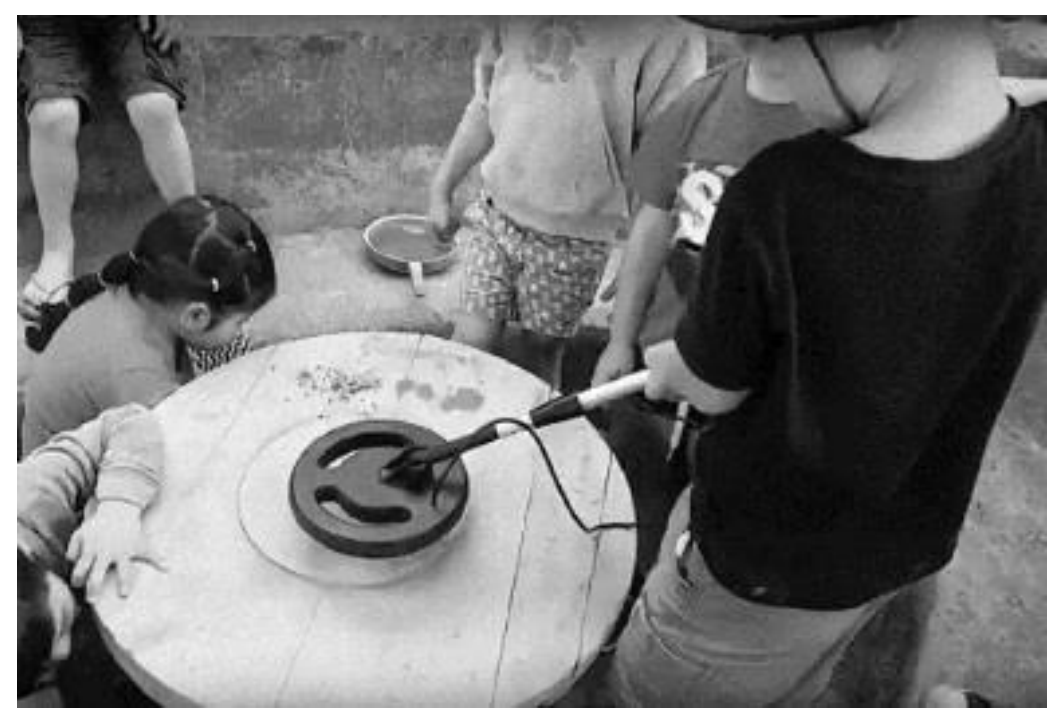

One happenstance provocation that created a significant amount of discussion and learning for children and teachers was a hedgehog residing in the centre's top garden. Cynthia reflected on the value of the hedgehog provocation, whenever it came out of its burrow there would be a small crowd of children observing it and discussing what it might need.

Each time we see the hedgehog we seem to talk about different aspects of what an animal needs to thrive and survive. Today it was the burrow and protection. When Sola visited they talked about what hedgehogs might eat. Another day when it was raining quite hard, one of the children was concerned about the hedgehog's hole getting flooded.

Finding animals in our environment provides such great provocation for discussion and a chance to encourage children to share their existing knowledge and for teachers to introduce new knowledge in an authentic and meaningful way.

(Cynthia,R3)

\section{Mat Times.}

Using mat times was another way to introduce and explore new ideas with children. Sharon reflected on a discussion she had with children at mat time about the stormy 
weather and high winds they had been having. She felt her role was to provoke thinking by asking questions. However, during the mid-research focus group, she observed that mat-times were only valuable if focused on something specific "rather than having them every single day for the sake of having them. There has to be a focus and a reason" (FG2). Cynthia saw them as an opportunity to find out what the children were interested in as the discussion could go in several different directions depending on the children's interests. Teachers agreed that the number of children and their capability to engage in a group was key to the success of mat times. So, they stopped holding mat times with new or younger children in the session. Sharon noted "we are constantly adjusting what we are doing to fit the needs of the group at the time and the children" (FG3).

\section{A Culture of Inquiry.}

Provocations, mat times, and intentional teaching were used by teachers to create a culture of inquiry in their centre. This was something teachers wanted to foster so identified these in their action plan mid-way through the CAR. In the final focus group, they reflected on examples where children's actions had changed, such as being more respectful of the insects they found, noticing spiders' webs and finding out what sort of spider lived there rather than pulling them down as they had done previously. For one child, A, this had been a significant shift and Sharon noted how he had started sharing his new knowledge of spiders with the younger group.

Whereas he is the junior in this session, he is one of the older ones in the other. So we are seeing the tuakana/teina ${ }^{18}$ [relationships happening]... and he's got some mana by doing it too.

(Sharon,FG3)

This was just one example of children sharing their knowledge with each other, and teachers observing how this had developed into a strong attitude towards investigation within children.

Another factor that contributed to the overall shift for children was teachers' growth in their awareness of science. Sharon thought they were identifying science in what they were doing more, and this meant supporting children in ways that encouraged them to ask questions, inquire and engage in more in-depth learning. They all felt my presence

\footnotetext{
18 Describes the teaching/learning relationship that can occur between an older or more experienced (tuakana) person and a younger (teina) person, often children.
} 
and involvement during the sessions had provoked them and kept it relevant for them. They also identified the increase in reflection and conversations about science amongst themselves as a team had meant they were more able to support the various science investigations in the centre as they happened.

Because we have shared what is going on [in the centre], it doesn't matter which teacher it is, we all have that shared understanding, that knowledge of what's been going on. So when either of us are out there we can actually revisit with all of them.

(Sharon,FG3)

Moreover, Sharon felt this shift in their pedagogy towards "talking to children about wondering and the more open-ended questions" was transferring over into other areas of the curriculum. (FG2)

\section{Funds of Knowledge.}

During the mid-research focus group, teachers were enthusiastic about the contribution of families in their centre, for example the metal detector and the mothers who helped with cooking pakora for their Holi ${ }^{19}$ celebration. However, on reflection Sharon felt drawing on their community for additional funds of knowledge to enable more science had not been so successful.

They either don't want to or don't value it ... I think in general, it's always hard to get that information [or] that input from our parents. I don't think they do value it or they don't have that time or energy to put in.

(Sharon, FG3)

Nevertheless, they all thought their knowledge of the families and their relationships with children were vital to their ability to engage and support the children's scientific interests.

\subsubsection{Curriculum Documents}

The curriculum documents It's a Bugs Life (Browne \& Te Papa, 2016) and the NZ Curriculum: Science (MOE, 2007) had been identified in the action plan as a way to support how children learn scientifically through the pedagogy teachers use and to

\footnotetext{
${ }^{19}$ A Hindu festival, known as "festival of spring", "festival of colours", or "festival of love" and signifies the triumph of good over evil.
} 
provide ideas of what sort of science they could examine with children. By the end of the research It's a Bugs Life had been printed and put in a folder to refer to as needed.

\subsubsection{Challenges}

When discussing the challenges to enable science experiences, teachers found the main issue was being interrupted, preventing sustained conversations with children. Sharon wondered if a lower teacher-to-child ratio would help.

They don't have to have us hovering there every second but if you want to add that complexity and extend their learning it would be good to be there. I don't know whether ... an extra teacher would make a difference?

(Sharon,FG2)

The lack of an extra teacher during the younger age group session was mentioned by Alyssa in one of her reflections. Due to the children needing more help with toileting, even nappy changing, and requiring emotional support, monitoring at the kai table due to allergies and help with their social skills, it was difficult for teachers "to sit down with a child and build on his knowledge. Though kaiako ${ }^{20}$ know what and where are the learning opportunities and how they could be supported and built on, still, they are unable to do it most of times in this session. It is very frustrating" (Alyssa,R3).

Alyssa noted that respect for the equipment was an issue such as keeping materials intact or magnifying glasses from being scratched. For Sharon the key was their abilities as teachers to adapt to the needs of the group.

\subsubsection{Summary}

Teachers found being engaged in the CAR had challenged them and kept them focussed on science. It had created change that became their usual practice, especially a shift in their pedagogical approaches. They identified they were noticing, recognising, and responding to science opportunities and extending these to work toward deeper understanding and new knowledge alongside children. This incorporation of intentional teaching strategies had highlighted the importance of their role as teachers. They all felt this was perhaps not as valued by parents or society as it should be.

Teachers' confidence, engagement, and relationships with children resulted in meaningful and sustained teaching practices which they felt enabled science

\footnotetext{
${ }^{20}$ A teacher or instructor who works reciprocally.
} 
opportunities occurring in their centre. This had affected a significant change in the culture amongst children at Mahoe, one where inquiry and acquiring new knowledge was part of their normal discourse.

The concept of provocations influenced the way teachers set up activities; thinking about the science concepts they could introduce or extend on, based on children's interests. They recognised the value in responding in a more purposeful way to the happenstance provocations that happened during the daily life of the centre.

\subsection{Kowhai Centre}

Kowhai is a full day education and care centre licenced for 26 children each day, 10 of whom can be under 2-years-old. The group size each day is 35 children. It is separated into two spaces; the Tamariki room, which is for up to 163,4 and 5-year-olds, and the Pēpe area where the numbers and ages of the children depends on which day they attend. Usually there are no more than eight babies under 2-years-old each day to make up the licencing number. The centre is open from $8 \mathrm{am}$ to $5.15 \mathrm{pm}$. The closest school has a decile rating of 9 indicating most of the families from the surrounding area have high socioeconomic incomes.

The Head Teacher of the Tamariki space, Liz, contacted me to be involved in the research. She attended the first meeting, the science walk and the first focus group, however she left the centre for another job a week later. During the mid-research focus group all the other teachers admitted that they were worried about participating in the research.

There were five teachers involved in the CAR at Kowhai. Three taught in the Pēpe space, Andrea, Helen, and Steph. In the Tamariki area Jackie became the main teacher after Liz left, and a few relievers taught alongside her over the CAR period. Lauren, the Centre Manager, taught as needed or when teachers took their non-contact time or lunch breaks. Each teacher had two hours non-contact time a week.

Andrea and Steph were experienced teachers. Helen had just qualified overseas before heading to NZ, teaching at Kowhai was her first full-time position. Jackie was also a teacher new to NZ. Lauren provided overall guidance of the programme in the centre. 


\subsubsection{The Science Walk}

I recorded the video of the science walk during our first meeting. In this meeting we first discussed the expectations of being part of the CAR and what my role would look like, then Liz, Jackie, Andrea, and Helen walked me around the centre. Starting outside Liz described this area as a space for children to explore and experience science through the weather, finding insects, noticing planes or the moon in the sky, sweeping up the leaves, and planting in the garden. Jackie and Andrea also discussed children exploring scientific concepts such as gravity and force through the movement of their bodies including jumping, spinning, and swinging. Andrea and Helen noted that the water trough was an activity the younger children loved and through exploring water they experienced various science concepts.

An enclosed deck was used by the Tamariki children and some of the older Pēpe children to explore art materials. Liz stated the collage art activity introduced science ideas about structures and shapes. Jackie said the area had been used to work through various projects of the Tamariki children. They had recently sorted through rubbish and plastic in sand collected from a local beach. Liz thought sustainability, which is a focus of the centre, laid the foundation for all the other sciences - knowing how to care for the earth. Moving inside the teachers identified the areas they thought enabled science, starting in the kitchen where they talked about food preparation activities, cooking, washing up and polishing. In the Tamariki space Liz and Jackie distinguished resources such as matching cards, puzzles and manipulative activities that introduced science concepts, for example parts of an animal or plant, biology, types of clouds, gardening, and mechanical ideas like light, electricity, and magnetism.

At the front of the centre was another outside area where teachers had recently set up a garden. As children helped prepare and plant the garden, they had discussed what plants need to survive. There was also a carpentry bench and sandpit, both were seen to foster science exploration.

Back inside Andrea and Helen walked us through the Pēpe space and discussed what areas they thought promoted science exploration for the younger children. They had a pet fish that was often noticed and fed by children, and which provided chances to talk about the needs of fish. Teachers felt most of the materials afforded opportunities for children to make sense of their world. They had a mirror for children to explore their 
bodies, trolleys, and balls for them to investigate pushing, pulling, and rolling and baskets of materials to introduce scientific vocabulary.

\subsubsection{First Focus Group - Reflections on the Science Walk}

The science walk video was loaded onto Moodle for teachers to watch prior to the first focus group, which meant Lauren was able to watch it too. I provided questions to frame our discussion. Jackie was the first to comment they had thought afterwards that there were so many things they could have said. Liz considered the materials they had available supported science well and Lauren felt following children's interests was a strength in their programme, although the busyness of the day could be a challenge to this. She believed their focus on the environment meant children gained a strong understanding of sustainability. Cooking and baking had been a regular part of their day and Liz thought it allowed for plenty of opportunities to explore changes in state and ideas around chemistry.

Lauren, Liz, and Jackie all mentioned that children spent quite a bit of time outside, which allowed for plenty of scientific learning opportunities, but they wanted these experiences to have more purpose. They thought gardening and a worm farm had potential for more meaningful experiences for children as well as introducing pulleys and levers into the sandpit and bringing in more resources for the carpentry area.

Andrea and Lauren believed children in the Pēpe area explored science through their senses. Andrea said the science walk had reminded her how excited the younger children were about nature and she could see the value in responding to what they were discovering, especially when they were outside.

Because with their language developing they want to chat ... and they are noticing everything and they are not at all inhibited about their excitement about things, everything is terribly exciting ... they would actually love you to sit and be chatting or reading or looking with them all the time, so it does start then doesn't it.

(Andrea,FG1)

This prompted a discussion about conversations and the importance of language in developing science concepts for young children. Both Liz and Lauren thought they did not encourage conversations in the Tamariki space as much as they could because the emphasis was on children using the resources. They had started a regular mat time in 
the morning so wondered about using that time to explore children's interests.

Pedagogical approaches such as asking questions, conversations, and provocations were also discussed. I suggested using It's a Bugs life to provide a scientific process that the teachers could use to support children's inquiries (Browne \& Te Papa, 2016). Also, the Achievement objectives for Level 1 and 2 of the NZ Curriculum: Science (MOE, 2007) could give a framework of the scientific ideas they could be covering in their centre.

\subsubsection{Action Plan}

After the first focus group I summarised the discussions and identified the areas they wanted to work on over the CAR period as shown in Table 6.2.

Table 6. 2

Kowhai Action Plan

\begin{tabular}{|c|c|c|}
\hline Areas to action & How & Who \\
\hline \multirow[t]{5}{*}{$\begin{array}{l}\text { Pedagogical } \\
\text { approaches }\end{array}$} & $\begin{array}{l}\text { Explore use of Intentional teaching, } \\
\text { - Planning, preparing environment, materials, and } \\
\text { own knowledge to support children's interests, } \\
\text { - Use questions and conversations to foster } \\
\text { children's inquiries and working theories, } \\
\text { - Explore co-construction, using an iPad or books to } \\
\text { explore new knowledge together. }\end{array}$ & \multirow[t]{4}{*}{$\begin{array}{l}\text { Tamariki } \\
\text { area }\end{array}$} \\
\hline & $\begin{array}{l}\text { Explore use of provocations - teacher-planned or } \\
\text { happenstance/children introduced. }\end{array}$ & \\
\hline & Explore use of funds of knowledge. & \\
\hline & Documenting children's learning to revisit later. & \\
\hline & Use of questions to prompt wonder and inquiry. & $\begin{array}{l}\text { Pēpe } \\
\text { area }\end{array}$ \\
\hline \multirow[t]{3}{*}{ Resourcing } & Have a set of science resources readily available. & \multirow{2}{*}{$\begin{array}{l}\text { Tamariki } \\
\text { area }\end{array}$} \\
\hline & $\begin{array}{l}\text { Planning around areas of interest to include how to } \\
\text { support and extend learning through materials. }\end{array}$ & \\
\hline & Bring in materials to stimulate scientific exploration. & $\begin{array}{l}\text { Pēpe } \\
\text { area }\end{array}$ \\
\hline
\end{tabular}




\begin{tabular}{|l|l|l|}
\hline $\begin{array}{l}\text { Curriculum } \\
\text { documents }\end{array}$ & $\begin{array}{l}\text { Explore It's a Bugs Life, specifically the five science } \\
\text { capabilities. }\end{array}$ & $\begin{array}{l}\text { Tamariki } \\
\text { area }\end{array}$ \\
& NZ Science Curriculum for Level 1 and 2 expectations. & \\
\cline { 2 - 3 } & Explore "Small Science" journal article. & $\begin{array}{l}\text { Pēpe } \\
\text { area }\end{array}$ \\
\hline Key $=\square$ - additional foci updated after the mid-research focus group. & \\
\hline
\end{tabular}

\subsubsection{Action Plan Process}

At our first meeting we discussed my role during the action research. They were happy for me to engage with children during my visits and to video or photograph any moments of science I saw occurring. I was able to comment and give feedback via Moodle on how science was being or could be enabled in their centre. Teachers were expected to reflect on the research process and my observations via their Moodle posts. After the first focus group I visited Kowhai 10 times on Tuesday mornings.

The mid-research and final focus groups were held during the fortnightly staff meetings. I provided questions for each focus group to guide our discussions through their action plan. After their reflections and my suggestions during the mid-research focus group we updated the action plan. The final focus group was an opportunity to reflect on what they thought had enabled science in their centre and what they had gained from the CAR. The findings from the focus groups, my observations, and teachers' reflections are presented under the areas of focus identified in the action plan.

\subsubsection{Pedagogical Approaches}

During the first focus group Liz and Lauren identified how teachers responded to children's interests as an area they wanted to explore more. They hoped the CAR would help them reflect on pedagogical approaches that could fit within the centre's philosophy and bring about more scientific experiences for children in authentic and meaningful ways.

\section{Intentional Teaching.}

In the Tamariki area, Lauren and Jackie wanted to plan the ways they encouraged children's interests. Introducing resources to support areas of focus was discussed at the first focus group and Lauren explained that she would like "things on a tray ready to 
go" (FG1) to work with a small group but it was as struggle having the time to prepare the resources. We then discussed how responding to children's interests did not have to happen through pre-prepared materials on the shelf. Working alongside children questioning and co-constructing knowledge through books and the iPad could be more effective. Lauren reflected on this when she shared a conversation she had with two younger boys while preparing morning tea:

I have been consciously trying to bring questions into my conversations with children more and more. Taking time to be aware of everything as a learning opportunity, trying to tread the line between hijacking children's independent work/play and laying the path for further learning.

(Lauren, R2)

\section{Provocations.}

Teachers introduced the Māori story of Kupe and Te Wheke as a theme for the term. Children showed great interest in Te Wheke (the octopus). On one of my visits a group of children made octopi from balloons and attached strips of paper with circles drawn on them. The children told me these were the legs for the octopus and the circles were the tentacles. I was not sure this was correct information and researched it myself and discovered that octopi have six arms, and two legs with suckers all the way along. During my visit the following week Lauren organised a provocation to extend the children's interest in octopi. The other teacher Jackie showed children, during mat time, a dead squid, as shown in Figure 6.4. Children felt and discussed it. We searched the correct terms and discovered that a squid has eight arms, and two tentacles which have suckers at the end only. Reflecting on this Jackie recalled that she was not prepared well enough to make the most of the experience.

I should have looked up about octopus and squid... because there were so many differences ... [the children asked so many questions] ... and you want those sorts of questions... but then you also need to find the answers ... so this is what I definitely noticed that if I'm to give a presentation I definitely need to prepare myself much better.

(Jackie,FG2) 
Figure 6. 4

Children Investigating a Squid (Own Image).

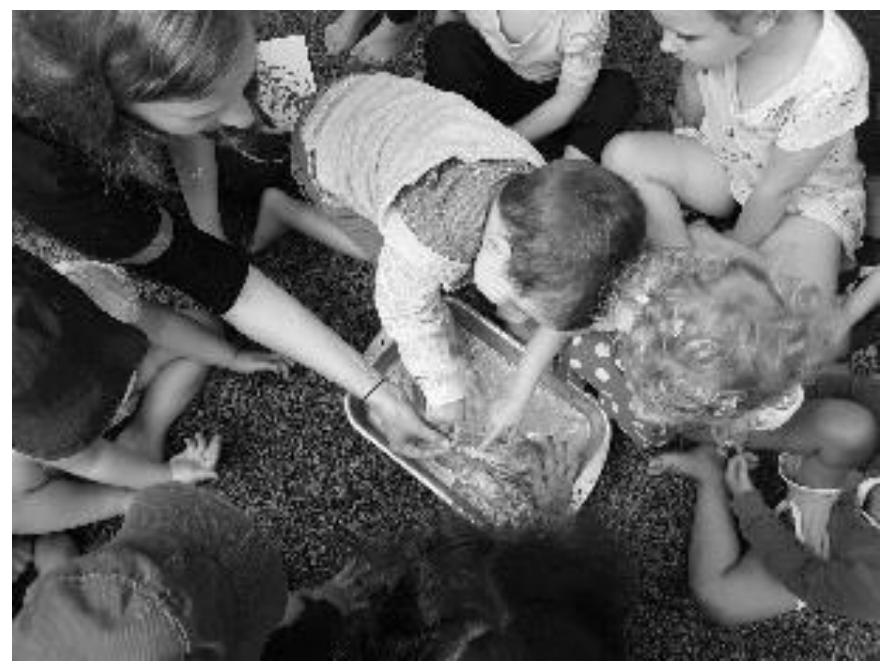

The ocean remained an interest when a child brought in a clam and they created an experiment to see if it would poke out its tongue to get the salt (see Figure 6.5). More discussions about the sea and the beach happened during the cleaning of the centre's fish tank. I noted the number of questions and discussions that occurred during this experience, and how Jackie's knowledge of the children helped her prompt their recollection of encounters they had had outside of the centre.

Figure 6. 4

Clam Experiment (Own Image).

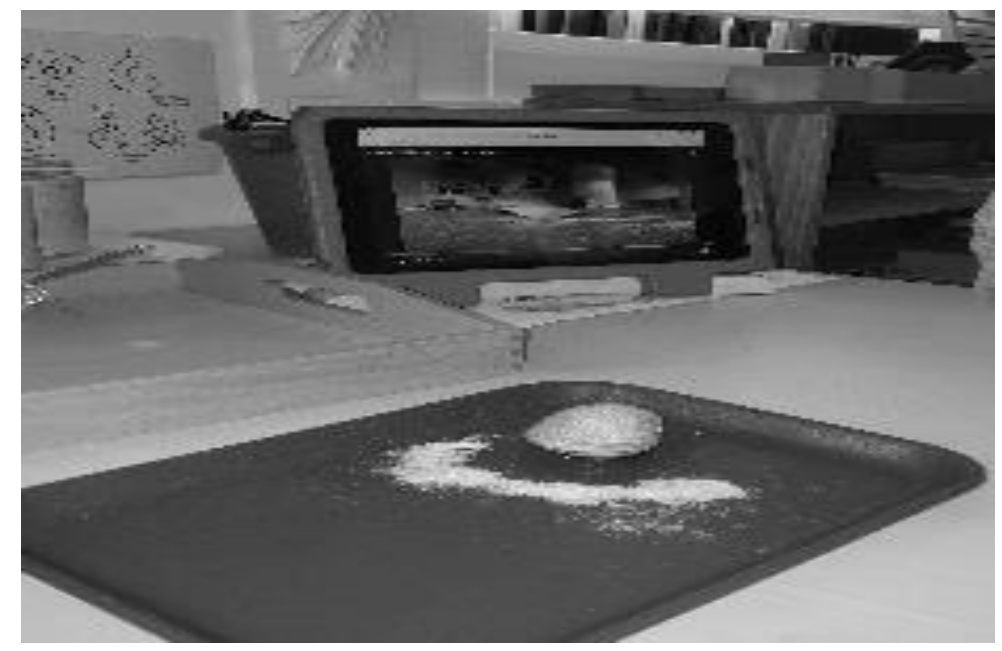

Experiments became a significant focus in the centre. Jackie brought in a book of experiments, which prompted one child to instigate a number amongst a few children in the Tamariki space. In the Pēpe room Steph ran an experiment with a few 2-year-olds 
away from the rest of the group. It involved baking soda, vinegar and food colouring to show the fizzing reaction that occurs between these ingredients. There was much excitement during the experiment and exclamations about the different colours. I wondered if the discussion could have focussed on the bubbling that was happening, as this was what children noticed most. Using it as a "provocation for language around what was happening - even introducing some more complicated language like reaction, gas, or sodium and acid creates a chemical reaction, simple but through your language an explanation can be given" (ON5).

Steph carried out another experiment with the same group of children a week later. She used the same ingredients in a model of a volcano. This time her discussion with the children was centred around using scientific language.

"What is happening to the volcano?" I asked the children. "Bubbles" said L. "It's coming out" he added. I explained to the children about the volcano eruption. The bubbles flowing are like lava coming out of the volcano and it's very hot. (Steph,R2)

\section{Questioning.}

Another provocation was introduced to children by Andrea. Coloured ice cubes with glitter were put into the water trough, which generated questions and discussions about the cubes melting, and how they melt (see Figure 6.6). This led to how to make more ice and Andrea took three toddlers inside to make some.

Figure 6.6

Exploring Ice (Own Image).
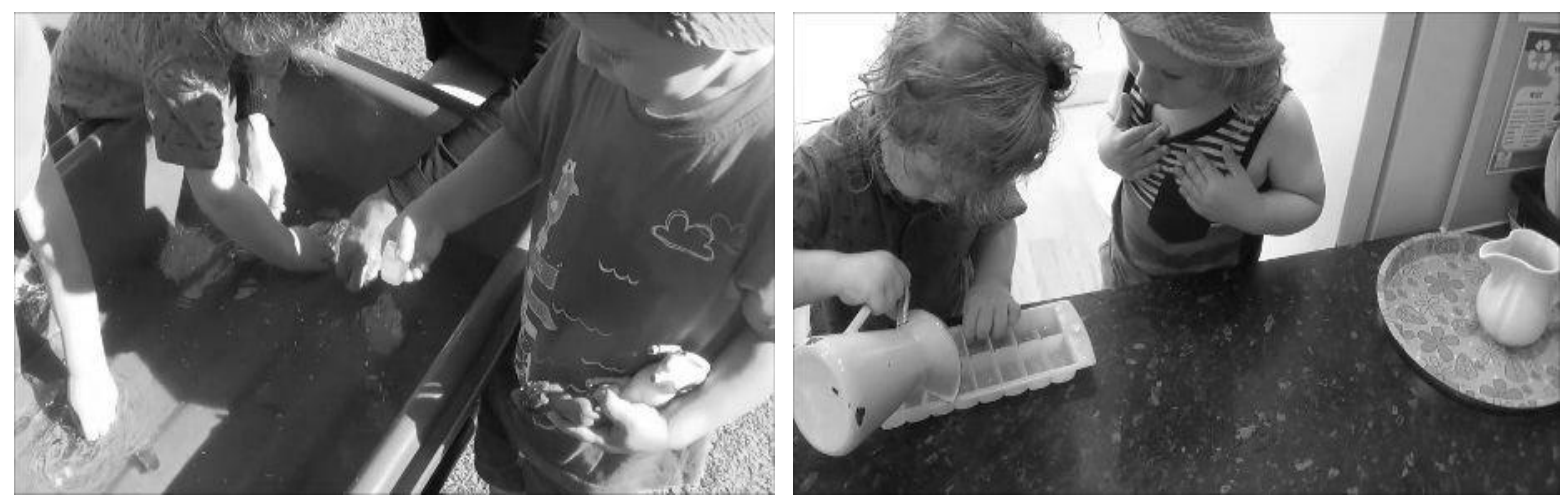
The power of these experiences, the conversations and language that occurred was reflected on by teachers during both focus groups. They were especially aware of the value of asking questions and wondered aloud how to foster inquiry and acquisition of new language.

By asking questions children ... because they are naturally inquisitive ... will also inquire about things, it becomes a habit to inquire about things; what is that, why is that, what happened, so it is good to ask questions of the children so they think.

(Steph,FG2)

Using 'I wonder' and 'what's that noise? ... We had it today with a huge tui up in the tree, I feel as if the children are also looking for things more themselves now. Because I think they too are getting into the 'oh what's that noise?'! (Andrea,FG3) Helen believed she had gained confidence in asking questions and extending discussions by exploring new ideas and supporting children's working theories.

I was horrific with questions... I never knew what to ask them, but L and I were lying on the ground and looking at the sky, and he started pointing that he could see orange, so we talked about autumn and the leaves ... I've felt a lot more confident ... because I think its dragged out their thinking as well. Like I will ask 'what do you think of this', it's like they are thinking because of my questions.

(Helen,FG3)

Seeing my interactions with children was valuable for Jackie, giving her an idea of how to bring about conversations with children to explore what they were finding out.

\section{Documentation.}

During the mid-research focus group Jackie talked about the role of documentation to help extend children's thinking when exploring scientific experiences, for example children had drawn pictures of the clam and labelled the different parts. She wanted to explore this as a way for children to revisit their previous learning and investigate concepts in more depth.

Helen utilised this idea when revisiting previous learning with a group of 2-year-olds in the Pēpe area prior to introducing an ice painting provocation. She thought this had been very helpful for her and children. 
Because there was such a big gap between the last ice experiment and the ice experiment that I was doing. I think it was so important to go back and let them see what they were doing before and see how can we develop this.

(Helen,FG3)

\section{Funds of Knowledge.}

Jackie and Andrea mentioned asking interested parents via Storypark if they wanted to share their areas of interest or expertise with children. They thought they had not had a huge response but then recognised the French mothers had come in to sing with the children, several families were involved in celebrating Greek Easter and one mother had shared pictures of her daughter doing science experiments at home. They were also waiting on a mother who was a doctor to come in and share her knowledge of the human body. Because the centre's focus had moved towards looking at nutrition, the human body and movement, they were also planning a visit from Plunket ${ }^{21}$.

I observed the value of the connections teachers had with their families and how this was evident in the conversations they had with children. This indicated teachers had strong relationships with and knowledge of the children.

\subsubsection{Environment and Resourcing}

The Kowhai teachers introduced resources to support areas of interest, such as plants for the gardening or ingredients or equipment for experiments. Almost daily, resources came into the centre as a provocation, for example the book of experiments, the squid, the clam, and the ice cubes in the water trough.

\subsubsection{Curriculum Documents}

When we discussed the curriculum documents I had offered, teachers recalled how Lauren had printed a page from It's a Bugs Life (Browne \& Te Papa, 2016) and put it up around the centre. The page outlined the five science capabilities that can be supported by working with children in a scientific way, for example gathering and interpreting data and critiquing evidence. Jackie mentioned in the mid-research focus group that this had helped her know what to focus on and how to keep it going. I suggested she might find the article by Hedges and Cooper (2018) about relational play-based learning and

\footnotetext{
${ }^{21}$ Plunket provides health and wellbeing services for children under five in NZ.
} 
intentional teaching helpful in guiding her teaching approaches when fostering children's inquiries.

Another article I introduced during the mid-research focus group was about science for infants and toddlers; the Sikder and Fleer (2014) article referred to small science to highlight the everyday nature of scientific concepts for this age group. The teachers in the Pēpe area found this very helpful as they had been struggling to shift their ideas about science from doing experiments to noticing and responding to the science occurring in children's everyday activities. Helen felt this helped her see science as not just experiments and to notice how many experiences they did with children without realising they were scientific. Both Andrea and Steph agreed their focus shifted to seeing scientific concepts in the simple activities like playdough that younger children were doing each day, and through their questions and conversations with children these ideas could be explored further.

\subsubsection{Challenges}

The first challenge identified by the teaching team, which came up several times throughout the CAR, was raised by Lauren and Liz during the first focus group. They thought the configuration of their building, the age range and the resulting demands of the extra duties required to keep the centre running meant no teacher was available to stay with a child or group of children to continue an investigation or even sustain a conversation about science.

If you've got someone preparing tea and the dishwasher is an endless mission throughout the day, so that is a teacher who is not working with the children and ... then there's the nappies so those things get in the way of having someone available to just go and work with the children.

The busyness of the centre and the relievers coming in and out of the centre was a constant factor that impacted on teachers' time with children, however their commitment to enabling science meant I rarely noted a lack of science occurring during the days I visited. Nonetheless, having just 2 hours a week non-contact time was a significant challenge for the teachers. They each wanted more time to explore how to encourage science investigations in Kowhai, either through resources, preparing 
materials and the environment or just finding out more so their own knowledge better supported children's explorations.

Teachers saw it was valuable to have the time to connect, share and support each other. Jackie noticed the support that was happening amongst the teachers in the Pēpe area and she missed that for herself.

We need to have staff meetings just for [Tamariki] and then just for [Pēpe] because we really need to come together and talk about it. Having staff meetings altogether is so difficult.

(Jackie,FG2)

Andrea noted how they could support each other throughout the session.

If somebody wants to do something ... you can ask others to help ... we can ask each other and we can take ourselves away for a little bit with one or two children. Again it doesn't always happen but it is there through the week and it is really important.

(Andrea,FG3)

Nevertheless, having time to "prepare, time to even reflect on things", as Lauren noted, was missing for all of them (FG3). They recognised the value in having time to stop and consider how they fostered science as a team and that this would help ensure continuity in the experiences they offered.

\subsubsection{Summary}

The Pēpe teachers identified that a shift in their awareness of science in the everyday experiences children were having meant more science occurred. Also, the conversations and questions encouraged wonder and inquiry amongst children. Helen, Andrea, and Steph felt they stood back too much and involvement in the CAR helped them see value in intentional teaching practices. They all noted a shift in their pedagogy towards using provocations and getting involved alongside children, asking questions, exploring with them, and introducing new ideas.

Jackie, in the Tamariki space, felt my presence and role modelling had helped her see that science was already in the activities available to children and that she did not need to constantly bring in experiments. She understood she could enable science to happen through conversations with children about their interests and extend them through questions. Jackie was very aware of the importance of being prepared with her own 
knowledge so she could make the most of provocations with children, to help them explore and gain more from the experience.

\subsection{Ngaio Centre}

Ngaio is a full-day kindergarten located on the site of a school. It operates under a regional association and is licensed for 45 children, ten of which are under 2-years-old. They had between 43-45 children each day with only 5-7 under 2-year-olds at a time. The school has a Decile rating of 9 which indicates the area has a high proportion of families with a high socio-economic background.

There were 10 qualified teaching staff; five full-time and five part time who worked full shifts part of the week. There was also a full-time teaching assistant and an administrator who worked 12 hours a week. All teachers had the equivalent of 2 hours non-contact for each 8-hour day they worked, which meant about 2 hours a day for most of them.

Five teachers were involved in the action research project: Kathryn, Margaret, Regan, Ruby and Stella. Regan worked full-time, while Margaret and Kathryn were part-time teachers in the older area of the centre, the Wana space. Stella and Ruby were also part time and spent most of their hours working in the under-two space. While the Kano area was a designated space for babies and toddlers, they could move into the older area if they chose to. There was fluidity in where teachers worked too.

All teachers were excited to be exploring science and indicated a strong understanding of what science could be when we discussed the areas they wanted to focus on. Ruby and Kathryn discussed their outside natural environments as the biggest influence on science happening in their centre.

Ruby - our natural environment I think is our biggest influence ... it's like a resource ... our backyard space, and we have access to a stream or access to a community garden, so environmentally rich resources. That would be the biggest science teaching that I do.

Kathryn -yes and I think it's the most readily accessible for the children, the level of noticing that goes on when they are in the wild space in particular, they are often looking for bugs, or thinking about habitat or noticing weather patterns or whatever. Outside for me is when I notice most of the science. 
Margaret agreed, and felt they were already doing science in other areas too but perhaps not recognising it as such.

There's a lot of hidden science in what children do that we may not [recognise], that I think if we put on our science lens we can focus on a bit more.

(Margaret,FG1)

Working with the younger children meant Ruby saw science in all of the sensory learning that they did; "like they are touching something and it is hard, or smooth or rough that is all science stuff, isn't it? And I think we do it all the time with our very young children because they are learning with all of their senses." (FG1). The role of the teacher was, for Regan, integral to science being enabled. How teachers viewed children's learning, what they focussed on as the child interacted with the environment was pivotal to whether science was noticed or not.

Bringing up those conversation about, you know, the viscosity of something, or how the water is eroding away the sand. It really shows how teachers are a very important resource and so once you put on that science lens then you are able to access science forever, so the best resource is the teacher.

(Regan,FG1)

Stella, as a new teacher, was interested to see through the CAR what could be considered science and how to be aware of it happening.

\subsubsection{The Science Walk}

My initial meeting was with Kathryn and the Head teacher of the centre, Cathy. We discussed the expectations of teachers and my role during the research. It was decided to delay the CAR until the following year to avoid other work the centre was involved in. Six months later I visited to film the science walk. Kathryn and Margaret took me through the centre and identified the areas they thought afforded science experiences for children.

We started outside Ngaio centre at their entrance way. Kathryn noted the school tennis courts nearby where children could explore physics by riding scooters and bikes. She pointed out the pot plants which children cared for.

We then walked through to one of their two outside spaces, the wild space, so named because of the unstructured character of the area. There were trees that had been 
pruned to provide climbing structures, long grass, overgrown gardens and areas with rotting wood and vegetation. Kathryn and Margaret both felt this space provided many opportunities for science. Children were able to interact with nature in a variety of ways, finding and documenting insects and investigating the variety of flowers and fauna. There was also a worm farm and compost bins which Kathryn saw as a chance to understand the cycle of organic material. They had a water pump which children could use and there were also plans to introduce a vegetable garden to provide a purposeful activity for the water usage. Nearby was a stream which children could hear but only occasionally visit because the requirement for a 1:2 adult-to-child ratio made an outing prohibitive.

Kathryn and Margaret then walked through to the other outside space. This area had a deck with a pebble pit and sand pit. They had had a pulley over the pebble pit but problems with it swinging and hitting heads meant it was no longer used. Margaret noted that the sand pit was a great area for science, with children exploring the interaction between sand and water. They had a large variety of equipment as well, such as guttering and tubes for children to play with. Margaret commented that the exploration was varied due to the different levels of competency in their mixed-age setting. Around the edge of the artificial grass were large rocks and plants which the children climbed over and onto. According to both Margaret and Kathryn these and the climbing frames afforded opportunities for discussions about physics, using language such as momentum, gravity, velocity, and centrifugal force. Kathryn felt the weather was a key enabler of science through the many conversations about the wind, the clouds, putting on hats and sunscreen, and coats and gumboots for playing in the rain.

Inside Kathryn noted the shelf with nonfiction books, which were kept separate to the story books and were well used by children. She also mentioned the nature table but felt this was not used as purposefully as it could be. The kai table was a place where both teachers saw science conversations happening, such as discussions about healthy eating and digestion. For one child this had led to a fascination with the human body so a reference book with complex illustrations of the human body was brought into the centre and became a well-used resource. Margaret pointed out that cooking in the kitchen provided opportunities to discuss science ideas. In the staff room the teachers remarked on the science in the technology available to children, photocopying, iPads, 
and computers. The maps on the wall and the pet fish were commented on as sources of science discussions.

Margaret showed me the pictures on the wall documenting visits to the community gardens which were within walking distance to the centre. There children could experience science through the gardens, chickens, ducks, and eels in the stream.

\subsubsection{First Focus Group - Reflections on the Science Walk}

The first focus group was when I met with all teachers who wanted to be involved in the research. The science walk video had been put onto Moodle so they could view it prior to the focus group. I posted questions to Moodle to guide our discussions. We began by identifying the areas they thought enabled science in their centre.

Ruby proposed that the centre's outside natural environment was their biggest influence for science. Margaret and Kathryn agreed, with Kathryn suggesting that the area they called the wild space was where she noticed the most science happening. It was easily accessed by children and offered opportunities to investigate insects and experience changes in weather. Margaret suggested there was other areas of science that were not easily recognised.

I think there are other science that we may not be recognising readily as science, like the way they swing on the rings, and all the physical stuff, and the way they throw a ball and watch trajectory, and gravity and effect.

(Margaret,FG1)

Inside the centre Kathryn and Regan thought the availability of science resources to foster science was important. Their shelf of non-fiction books was a "kind of a reference book library" (Regan, FG1). Kathryn suggested the resources brought into the centre via provocations could enable scientific experiences. She saw this as part of more intentional teaching; bringing in scientific language, responding to children's interests and extending their learning through the materials introduced or activities set up. She thought teachers could extend and support children's scientific explorations by encouraging observation, questioning and conversations. Ruby saw the value in responding to the teachable moments, using questioning to encourage children's wonder and inquiry. Regan thought scientific language was particularly valuable. They all wanted to focus more on these areas of their pedagogy: intentional teaching, 
provocations, and using scientific language. The teachers wondered about identifying some areas that children were interested in to focus on over the action research period.

Resourcing the centre in ways that were more specific to science was also seen as helpful. Margaret offered to set up science kits that offered children magnifying glasses, jars to hold insects and pens and paper to document their finds. Kathryn thought posters of the lifecycles occurring in the compost and worm farms would be good. Extra materials for children to explore in the water trough were suggested by Regan, and Ruby suggested finding a rain gauge and wind monitor. All teachers proposed buying more reference books. Ruby felt her own knowledge needed to be extended, through articles about science teaching and just science in general. I therefore suggested It's $a$ Bugs Life (Browne \& Te Papa, 2016) and the NZ Curriculum: Science (MOE, 2007) to provide ways to support science. Margaret noted that she had already started a folder of readings and information that all teachers could look through. She suggested it be added to and they could also support each other with their own knowledge if needed.

\subsubsection{Action Plan}

I summarised the focus group discussion and identified the areas the teachers wanted to emphasise during the CAR as noted in Table 6.3.

Table 6. 3

Ngaio Action Plan

\begin{tabular}{|c|c|}
\hline Areas to action & How \\
\hline \multirow[t]{4}{*}{ Pedagogical approaches } & Explore use of scientific language. \\
\hline & $\begin{array}{l}\text { Explore Intentional teaching, } \\
\text { - through co-constructing knowledge with children } \\
\text { - noticing children's interests } \\
\text { - extending interests with conversations and questioning, } \\
\text { and sharing knowledge } \\
\text { - planning to support these with resources. }\end{array}$ \\
\hline & $\begin{array}{l}\text { Explore use of provocations } \\
\text { - Kano area - addition of resources and provocations to } \\
\text { bring in science. }\end{array}$ \\
\hline & Identify areas of focus. \\
\hline
\end{tabular}




\begin{tabular}{|l|l|}
\hline Environment/resourcing & Introduce science kits (Margaret). \\
\cline { 2 - 2 } & $\begin{array}{l}\text { Introduce composting/worm farm lifecycle resources } \\
\text { (Kathryn). }\end{array}$ \\
\cline { 2 - 2 } & Explore materials for the water trough (Regan). \\
\cline { 2 - 2 } & Bring in a weather and rain gauge (Ruby). \\
\cline { 2 - 2 } Teacher supports & Bring in more reference books (All). \\
\cline { 2 - 2 } & Wild space - use more often through gardening etc. \\
\hline & Extend own knowledge. \\
\cline { 2 - 2 } & Pool knowledge of the teaching team. \\
\cline { 2 - 2 } & Use a team notebook to support continuity of interests. \\
\hline Curriculum documents & Explore It's a Bugs Life and NZ Curriculum: Science. \\
\hline Key = - additional foci updated after the mid-research focus group. \\
\hline
\end{tabular}

\subsubsection{Action Plan Process}

My first visit to Ngaio was during the week following the first focus group. We decided that my visits would alternate between Mondays and Thursdays, as the five teachers involved worked different days. I visited on 12 days over the CAR period and spent time observing and videoing, engaging with children, and discussing ideas with teachers. My observation notes were shared on Moodle as were the occasional video. Teachers reflected often on their practice through their online journal and responded to my observations notes many times. This meant conversations about their practice occurred both during and between my visits. In addition, they shared their learning stories with me via Storypark.

The mid-research focus group offered an opportunity to revisit the action plan, update it and identify the areas they thought were enabling science. Our final focus group occurred a month after the CAR had finished on their teachers' only day. They shared the changes to the programme initiated by the research.

The findings from both focus groups, teachers' reflections, and my notes are presented below under the key areas identified in their action plan. 


\subsubsection{Pedagogical Approaches}

All teachers at Ngaio wanted to explore their pedagogical approaches to create and support more science experiences for children. Reflecting on their practice happened often through their journals, conversations when I visited or during the focus groups indicating a strong culture of reflective practice in the centre.

\section{Using Scientific Language.}

Teachers thought increasing their scientific language would help identify science for themselves and for children. Stella reflected that she was not using scientific language as intentionally as she would like to. However, the teaching team felt she did use language often when describing what she was doing with children during the many experiences in nature she provided for them. She did nonetheless recognise during the last focus group that through the project she began "feeling okay to use some language to make some connections to specific science concepts" (Stella,FG3). Regan gained confidence as well in using scientific language during activities with children, particularly as she became more intentional in preparing for these experiences.

As I increase my content knowledge and understanding and vocabulary around these scientific concepts I feel more confident when talking about them with tamariki.

Later she realised the value of language when working with younger children after introducing a dead bumble bee into the Kano space (see Figure 6.7).

One of our goals was to increase our use of descriptive science language and I began to realize how this is a huge part of our practice with infants and toddler, and in this way we are laying foundations for science learning later in life. This change in my thinking led to some lovely observations of a dead bumble bee. I noticed how much focused observation some of our infants and toddlers have. I also spoke the same way as I would with the older children describing the things I was noticing, naming the parts of the bee's body - and not in a watered-down version. 
Figure 6. 7

Examining a Bumble Bee with the iPad (Own Image)

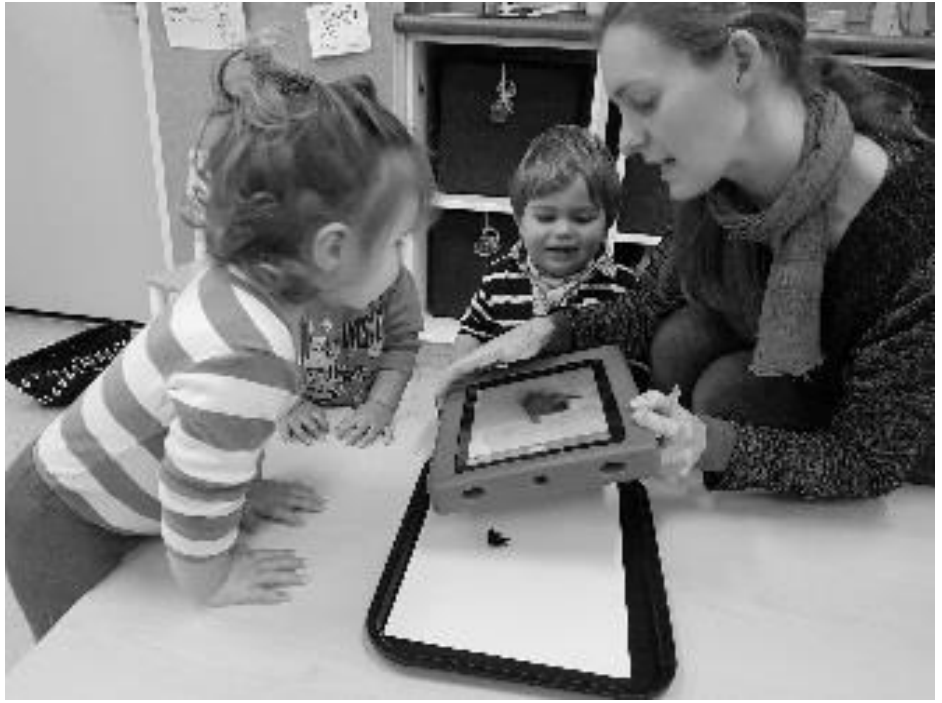

During both focus groups the teachers all commented on how their use of scientific language had increased and given them confidence, as they did not feel so "silly about it" according to Margaret (FG3). Kathryn observed that it seemed to also influence the children.

Our language with the children must have changed over the course of the research action project, as I have heard several children describe themselves as scientists. I have also heard children say they are 'doing' science.

(Kathryn,R8)

\section{Intentional Teaching.}

A key driver for teachers was reflecting on how they teach, and how they foster the child's view of themselves as learners or scientists. Discussing what they thought about teaching and being a teacher was a significant part of our conversations. Margaret identified this process as a shift for her.

I'm thinking about ways I can feed, or encourage that curiosity about the natural world, and so I guess that has been a shift in the way of looking at how to teach, in a way, I guess I'm looking at the child as a scientist and thinking how do I feed this scientist part of her nature.

(Margaret,FG3)

Intentional teaching practices such as questioning, co-construction, sharing knowledge, documenting, revisiting and being prepared were all investigated by teachers to find the approach that best fitted their teaching style. Regan identified revisiting children's 
learning and having them share their knowledge through regular hui (when the children came together on the mat in a large group) to possibly foster their view of themselves as scientists.

I want to bring back to children, through documentation and through them sharing and revisiting it, their sense of themselves as a learner, of themselves as a scientist, because I'm seeing them as scientists and I see myself as a scientist, but I don't know if they see themselves as a scientist.

(Regan,FG2)

Reflecting on her hui about Matariki ${ }^{22}$, Regan felt there was a view that the teacher needed to be an expert and therefore she was expected to be that when taking a large group of children. However, she wanted to be a teacher who co-constructed knowledge and questioned alongside children. She therefore admitted it had taken courage to put herself out there and to be a teacher who was a learner too. At the end of the CAR Regan felt the hui she had led had been successful and had "influenced [the children's] view of themselves as learners and their understanding of what science encompasses" (FG3). At the teachers only day the team agreed they should hold hui more regularly on set days. Ruby believed revisiting their pedagogy had helped her return to co-constructing with children to explore new ideas and experiences. She wanted to avoid "launching into the facts" (R4). In her journal she considered two separate situations with one child, T. Firstly, when she had been more intentional in sharing knowledge and answering her questions, which in turn had meant T was able to be the expert and share her new knowledge with other children. In another situation she had given space and time for the child to observe, wonder and pose her own theories, but the conversation finished after Ruby responded to the child with "what do you think?" She therefore wondered if giving her an answer might have seen the discussion continue. Ruby reflected that she was still finding the balance between "exploring children's thinking and providing them with some answers to their questions" (R6).

\section{Provocations.}

Kathryn had been excited to explore intentional teaching further. This involved bringing in activities and identifying the learning that could come out of them. However, she felt

\footnotetext{
${ }^{22}$ Matariki is the Māori name for the Pleiades star cluster. It is a mid-winter celebration in NZ for the Māori New Year, a time for crop harvesting and planting.
} 
she had been "forcing things" (FG2). By the mid-research point she had observed the value in noticing and following children's interests and providing a provocation that could then extend the learning around that interest.

Bringing in some provocations to extend an existing interest, is what I'm finding really valuable at the moment ... extend it or giving another opportunity for the same thing to happen, or else expanding it a little bit by bringing in a book about it or something else that will support that learning, cement it and revisit it. So provocations is something I'm really big on.

(Kathryn,FG2)

In her journal Kathryn reflected on the provocations she introduced over the CAR. Some raised challenges, others grew into significant inquiries for children. An example was the bird's nest she found and put out on a table with photos of nests made by tui, waxeye, fantail and pukeko ${ }^{23}$. She had expected children to perhaps compare and explore the various habitats of birds (see Figure 6.8). Children however noticed the bits of plastic and paper in the nest, some pieces clearly from the centre, and proceeded to clean up the outside area.

Figure 6.8

Bird Nest Provocation (Own Image)

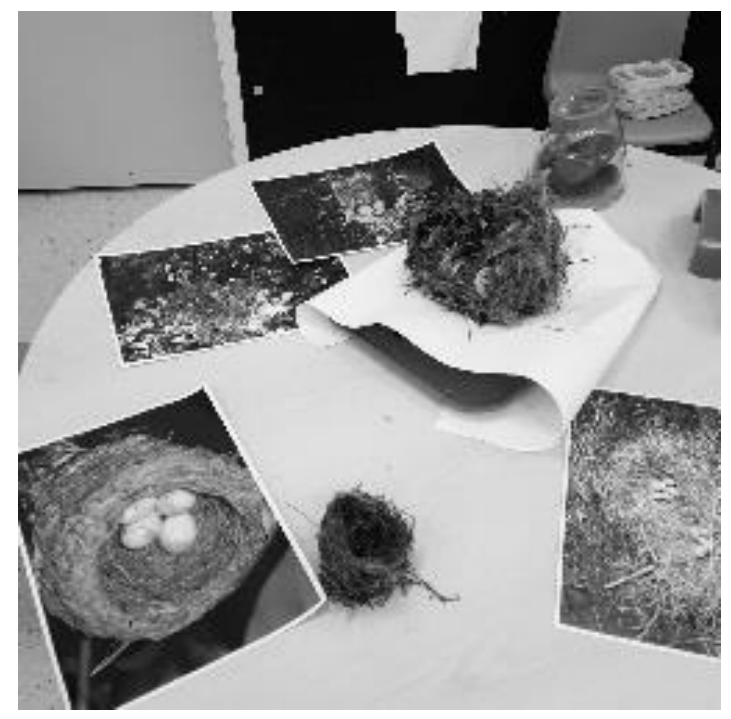

This then led to further investigations of plastic and rubbish with one child B especially interested. With more provocations from Kathryn and further discussions, she helped B

${ }^{23}$ Native birds of NZ. 
plan a clean-up of the local beach with a class from the primary school. This investigation and learning brought Kathryn to the following conclusion during the last focus group:

I've come to accept that sometimes it is ok to lead children's thinking a little bit and provoke and help them to make connections to prior knowledge that don't come in that moment, so with $B$ she had the marine thing going on in her head and the plastic and ... showing her the two things together, helped ... connections to be made. And ... maybe three months ago I would have felt like that's not my place to force that to happen. I don't feel like I did force it to happen, but it's okay to prompt those connections.

(Kathryn,FG3)

Kathryn's reflection led to a discussion amongst teachers about their role, the vital part they played in bringing provocations alive for children. As I had noted in my observations at Mahoe, at Ngaio the activities set up on tables were explored to a deeper level when teachers were present. Regan reflected on this after setting up a table with a provocation of leaves changing colours that did not go anywhere at all.

Unfortunately it was a flop. This was because I couldn't sit with the activity, so me being the intentional teacher was the aspect of this activity that would either make it work or not. I was not there to engage the 'I wonder' thinking and so in isolation, the resources I displayed did not capture children's interests.

(Regan, R2)

Kathryn likewise reflected on an experience where she and some children were exploring, through drawing with charcoal, the death of their goldfish. She needed to leave the table and asked a reliever to sit with the children and continue the experience. However, a few minutes later the table was empty. As Kathryn noted, it was not just the teacher being there but a teacher who had knowledge of the children and was "able to offer the right level of information for them to remain engaged" (R7).

Margaret acknowledged she now saw provocations differently. She saw the value in setting up provocations with a purpose in mind, and going with whatever happens, but she was also keen to explore what was already happening and using it provocatively. Within the Kano area Ruby had worked in a similar way; she had used a child's interest in a book about wind and the ribbon she was holding to begin an exploration of blowing and seeing how the ribbon moved. This experience and further discussion during the 
mid-research focus group highlighted for Ruby how bringing in resources and provocations for younger children was a way to create science opportunities. She planned to focus on that more for the remaining weeks of the research.

\section{Role of the Teacher.}

The teachers' role was not an identified action point for the Ngaio teachers. However, it was mentioned often in my observations, their journals and during the focus groups particularly when they reflected on pedagogical approaches. For example, both Stella and Ruby felt their role was to provide space and experiences to provoke wondering and theory building with children. This fitted with their approach when working with younger children with limited or no language skills.

Regan and Kathryn thought introducing provocations highlighted that their role was to create opportunities for learning. They discussed this in the last focus group:

Kathryn - [Providing provocations] has made me really aware of how if we have the teacher resource staying there, sitting there being available, it completely changes the way that the objects that are providing the provocation are used by the children.

Regan - yes they interact with it differently if the teacher is not there. Kathryn - yes and it can go for longer, and I think the learning is so much deeper if you can sit with it ... the teacher resource is so important.

Kathryn felt the research had helped her identify her role as a teacher more clearly.

[This research has] clarified the importance of my role as a teacher and that it's okay to steer learning by my language and what I provide, and through the environment as well. ... I feel like a stronger advocate for what I believe as being the optimum conditions for a child to learn in.

(Kathryn,FG3)

\section{Role of the Teaching Team.}

All teachers mentioned at some point during the focus groups that having science discussions within their group had supported them. For Margaret it was feeling like she was not working in isolation. Having others interested in science alongside her fuelled her passion for science. Stella enjoyed the opportunity to continually touch base as a group. Kathryn felt the conversations about science, being "all on the same page" (FG3) and being passionate together, had translated into their practice. Regan agreed it had 
meant they were able to support each other practically, taking over routines and responsibilities if one of them was involved in a sustained inquiry with a child. For Ruby, the support of the team had been very affirming when she was away, as the team had implemented her goal of implementing provocations to the Kano area through another team member buying science board books, and Stella and Regan exploring insects with the younger children.

As Kathryn identified in the last focus group the goal was to "keep being such a cohesive group [so] our confidence will grow because our support is there, and we are just going to get more science confident" (FG3).

\subsubsection{Environment and Resourcing}

In the first two focus groups each teacher identified the resources they would introduce to enable science in the centre. Margaret wanted to create science kits, which were introduced during the first few weeks and while they were being used, magnifying glasses were the most popular with children. I observed that they were being used in several ways not associated with their primary purpose. I asked if they had been introduced with some guidelines on how they were to be used and if they had a specific place to be returned to. During the mid-research focus group Kathryn mentioned the magnifying glasses now had a place to live and were still being used often and returned (see Figure 6.9). Regan noted that she had often reminded children how to use them purposefully through role modelling how to hold them and look through them.

\section{Figure 6. 9}

Space for the Magnifying Glasses (Own Image)

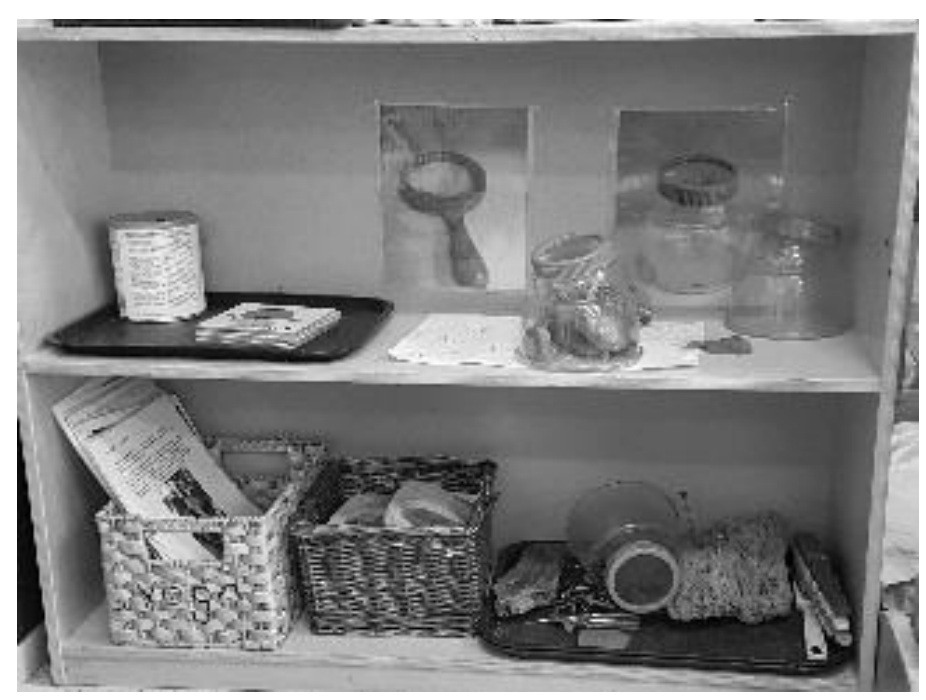


The water trough, and exploring sinking and floating, was hindered by a tummy bug in the centre which meant no water play for several weeks. The idea of a weather gauge did not come about as Ruby was away for a few weeks. The life cycle posters for the compost and worm farm were another action point that did not eventuate over the research cycle. Other more pressing activities occurred in the wild space such as planting for Matariki. This focus brought about another addition to the action plan: using the wild space more (see Figure 6.10).

Figure 6. 10

Children in the Wild Space (Own Image)

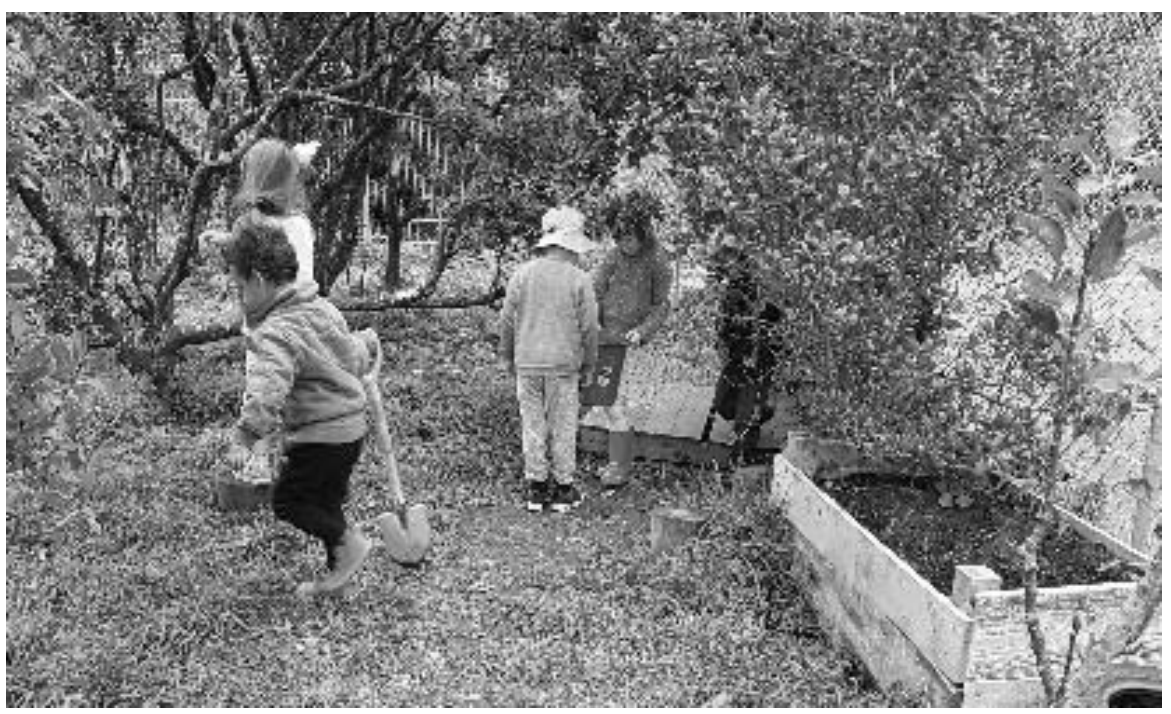

Science experiences in the wild space arose in ways related to the teacher's strengths. For example, Stella was passionate about gardening and being outside so she would often work purposefully digging, planting or just sitting and observing nature with a few children, especially toddlers alongside her. The value of what Stella did with children was appreciated by the rest of the teaching team and the role she played in introducing science experiences to children was commented on by Kathryn and Regan.

Regan - One of the things that comes naturally for you is the being outside and being involved in the real work, so even if you don't feel like you are doing it intentionally for science you are intentionally sharing your passion with the children through that.

Kathryn - opening doors for them... every day you are opening doors for them through what you do with them. 
Resources specific to science were raised by teachers as key to enabling science. In one situation, not having a book about leaves readily accessible had emphasised for Regan the value they added and how they assisted her as a teacher. Having a book available could support the discussions she had with children. For her the "environment [was] the third teacher!" (R3).

I love co-constructing, and supporting working theories, but I often feel uncertain about my own knowledge. I like having those reference books as a back-up, to validate what I know or help me to learn alongside the tamariki.

(Regan, R3)

Kathryn had used a microscope with children to explore more details of insects and wanted to do this more often. She reflected on one such success looking at seed pods with one child. However, at another time looking at a dead stick insect proved more challenging. Finding the time to set it up, having a teacher available and showing children how to use it before they gave up in frustration meant it was rarely used. Kathryn and I then discussed using a phone or iPad camera to zoom in on objects to show detail, after I did this with a couple of children looking at the wings of a butterfly.

Using ICT was raised by Kathryn during the last focus group. She felt that her more mindful use of ICT was a change. Using it to explore information with children or even as a provocation, such as a video of a Rube Goldberg 24 machine prompted much experimentation with wooden blocks, bamboo sticks and a golf ball.

\subsubsection{Curriculum Documents}

The curriculum documents I thought would be useful, It's a Bugs Life (Browne \& Te Papa, 2016) and the NZ Curriculum: Science (MOE, 2007) were provided for teachers on Moodle as I did with the other centres. Some of the teachers read through It's a Bugs Life and reflected during the final focus group that some of the ideas would have been helpful for them. Regan suggested workshopping the document as a group would have been more helpful for her, others agreed and as a team they planned to use it to reconnect as a group over science in the future. Stella did note that the reading about Small Science by Sikder and Fleer (2014) had been very useful for her.

${ }^{24}$ A chain reaction-type machine designed to perform a simple task in a complicated way. 


\subsubsection{Challenges}

For the teaching team the main challenge was the range of ages of children in their setting. The routines required to meet the needs of children often took them away from being engaged with them for any length of time. The following discussion outlined their frustrations.

Regan - one person has to be at the kai table and one person is toileting and one person is on [the sleep room and] we have a particular child with extreme challenging behaviours...

Kathryn - so you've always got to be visible so you've got to place yourself somewhere where you can respond if you need to respond.

Ruby - and also in this environment there are always relievers in.

Kathryn - yes they took our release teacher away from us which is crazy.

Ruby - ... and I think it's a challenge that I work with Kathryn one day, and Stella one day.

Kathryn - and we see each other once a month at team meetings.

Ruby - and I'm [in Kano] and they are [in Wana], there are lots of challenges in terms of us being a team.

I noticed the team's struggle to have sustained conversations with children, especially with older children who might want to explore something in more depth. Kathryn felt validated that my observations had confirmed her concerns. They were keen to find a way to better meet the needs of their older children. The challenge was discussed during their teachers' only day and the whole teaching team decided to put aside a room for older children to set up as a space for uninterrupted, more engaged exploration.

I think the shift has [identified], and this is with your support too because your observations reflected how we've been feeling about not being able to extend those older children, ... solutions or ways in which we can provide extended and noninterrupted time with our older children ... [and also be] able to extend everybody's learning.

(Regan,FG3)

\subsubsection{Summary}

The CAR created changes for the teachers at Ngaio. They created a separate space in their environment for more sustained and engaged learning with older children, away 
from the disruptions and demands of the larger centre environment. A shift in their pedagogical practices towards more intentional teaching strategies and provocations was seen by teachers to enable further science explorations with children. This resulted in teachers feeling more confident in doing science, using scientific terms, being passionate about science and sharing their science knowledge. Feeling more comfortable about their role as a teacher with knowledge and open to learning and coconstructing alongside children, meant the shared wondering and inquiry created a culture where children saw themselves as scientists too. The strength of this passion and engagement flowed over to children showing agency and wanting to create change.

The shared interest in science amongst teachers showed in their discussions and support of each other. They planned to continue this newfound practice, confidence and passion gained from their involvement in the research.

\subsection{Research Hui}

Following the first Research Hui in November 2017, and once my involvement in the last three centres finished, a second hui was held in September 2018. The number of teachers who attended was enough to facilitate a worthwhile discussion and provide a broader view of the factors that enabled or challenged the occurrence of scientific experiences across their centres. The role these hui played in producing data for the study is outlined in section 3.5.2 in Chapter 3.

The two research hui offered an opportunity for teachers from each centre to share their experiences of being involved in the CAR study. It also allowed for us to collaborate on data analysis and clarify the emerging themes. Teachers identified the key enablers and challengers by placing notes on the blackboard under the research questions. Several themes from their experiences became visible. Figure 6.11 below is a snapshot of some of the data gathered. 
Figure 6. 11

Collected Data from Research Hui 2.

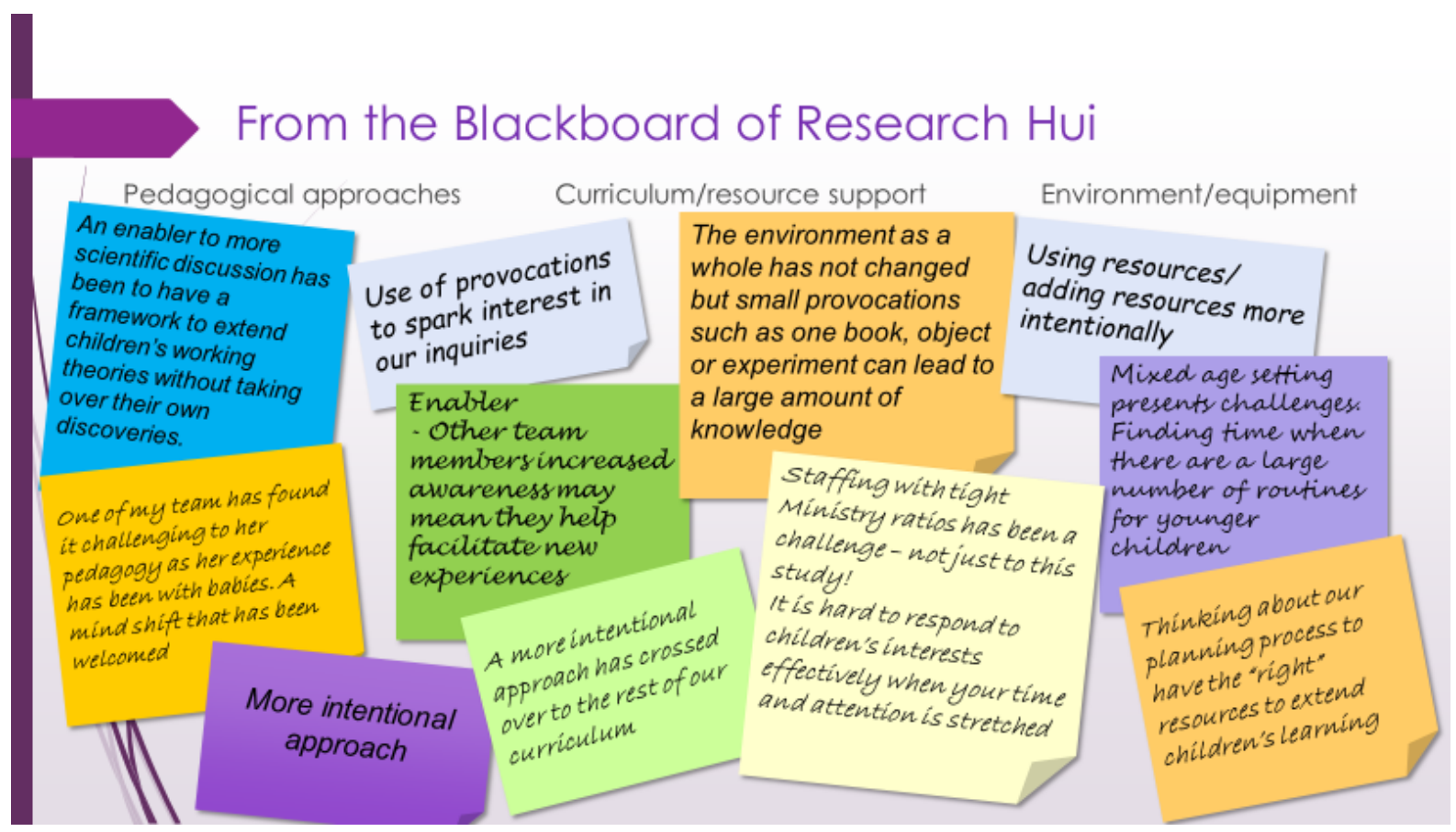

Teachers valued the chance to share their experiences with others outside their immediate teaching team. The experience validated their role as participants and learners in the CAR process and emphasised the changes that had occurred in their practice, especially their shift to more intentional teaching practices. They appreciated the opportunity to share similar challenges and support each other with various strategies to use to mitigate those difficulties.

\subsection{Chapter Summary}

The CAR study influenced all three centres. The teachers all found my involvement and being kept on task and focussed on science encouraged them to reflect on their pedagogy, change their practices and become more aware of science in everyday activities. Seeing their engagement with children through a science lens helped them realise their interest in science and in turn increased their confidence in recognising, responding to, and doing more science with children.

At Mahoe and Kowhai this had resulted in teachers using more intentional teaching practices, such as questioning and having more engaged conversations with children. This led to more inquiry and investigation amongst children. Intentional teaching 
practices were also seen by teachers in Ngaio as fundamental to enabling science, but they had reflected in depth about how that pedagogy might manifest in their own individual practice and with different aged children. It had also highlighted their struggle meeting the needs of all children in their mixed-aged setting, especially having sustained conversations with older children. Creating a separate space for the older children came out of being involved in the research. Provocations were used by all teachers to introduce or extend science experiences for children. In Ngaio and Mahoe teachers saw their role as significant in making science valuable and meaningful for children.

The value of having a teaching team who could meet often and offer each other support regularly was evident through this research. Its absence was highlighted in Kowhai through the lack of time they had to share as a teaching team, and its importance was appreciated by teachers in both Mahoe and Ngaio. Mahoe teachers valued the time they had to share how they could respond to science interests amongst children. For the Ngaio teachers, working with others also passionate about science increased their motivation to create and engage in further scientific exploration.

All these findings were confirmed and clarified during the research hui. Teachers from all six centres were able to share their findings and found the key enablers and challenges in their centre were very similar to those found in other centres. The next three chapters discuss those findings, with reference to relevant literature and each chapter seeks to answer the three research sub-questions. The following chapter discusses CAR and the researcher's role. 


\section{CAR and the Researcher's Role}

\subsection{Chapter Overview}

The key findings from this study have been outlined in Chapters 4, 5 and 6. The main research question: What resources and practices influence scientific experiences for children in ECE centres? was investigated by capturing the views of teachers via a survey and by exploring their practices through CAR.

This chapter addresses sub-question 1: How did the process of CAR, including the researcher's involvement, influence the occurrence of scientific experiences? and is in two parts. The first part explores how being involved in the CAR influenced the occurrence of scientific experiences in the participating centres. The process of CAR is outlined and how the time involved resulted in significant changes for some centres and shifts in practice for all teachers. It is difficult to examine the process of the CAR without discussing the role I played in it. The second part therefore examines this and how my involvement was multi-faceted. My role as a critical friend and the elements of that role are discussed and analysed in relation to the effect this had on teachers' scientific practice.

Additionally, this chapter examines the pedagogical approaches teachers explored during the CAR and how influential they were in enabling scientific experiences in their centres. The centres' environment and any changes that occurred are addressed, as is the role of the teachers individually and as a team. How these factors affected the occurrence of science in their centres is then presented.

\subsection{The Impact of CAR on Scientific Experiences}

This study's CAR methodology was used to explore what fosters science experiences through the daily experiences in an ECE centre. In seeking to answer the first subquestion this section presents an analysis of the teaching team's involvement in the CAR process and how they enabled scientific experiences in their centres. I begin by discussing the value of CAR in exploring change in practice, the time involved and the collaborative and empowering nature of this study. Following this, the effect the process had for teachers involved is examined. Quotes are used in this section to illustrate 
teachers' experience of participating in the CAR as this was not discussed in the findings chapters.

\subsubsection{The Value of CAR}

When asked to consider the value of being involved in the CAR teachers in this study, all reflected on how the process had helped them focus on science and explore other ways to enable scientific experiences in their centre. How they did this is discussed in the next chapter but the involvement in the study facilitated those changes and brought greater understanding of how to make scientific experiences happen.

Throughout the whole 12 weeks I found my understanding of science within the Pēpe room is far less complicated than I had originally thought ... there are a lot of scientific things we do in our room without even realising.

(Helen,Kowhai,R4)

Would I have done that if I hadn't had ... this science [research]? [It] is really working for me. Having this project and having this science lens.

(Ruby,Ngaio,FG2)

The action research it influences, it is a springboard, it starts things happening.

(Regan,Ngaio,FG3)

Involvement in the CAR process empowered teachers to reflect on and be challenged about their practice. According to Rust (2006) being part of a CAR study can be "a very powerful catalyst for the improvement of practice as well as professional development" (p. 95). The intention of CAR when working within the professional change branch of the action research family is "to generate wiser practice by generating new and deeper thinking about it" (MacNaughton \& Hughes, 2008, p. 43). As suggested by Somekh (2005), this study found the CAR process generated knowledge from the actions teachers engaged in, equity existed within the teaching teams and with the researcher, so agency and ownership of the research process and the initiatives were a key element of this study.

\subsubsection{The Process of CAR}

This research used the CAR framework outlined by Bruce et al. (2011) to guide the process with each centre. This is discussed in Chapter 3, Section 3.4.3 and used here to analyse the progression each centre worked through. According to Bruce et al. (2011) 
the decision-making power of teachers is the most influential aspect for team success in CAR. It was important that it encouraged teachers to identify the problem and possible solutions in their centres and therefore take ownership of the action plan. Collaboration between the teaching teams and myself during the CAR process varied between each centre and altered over the time we spent together. Teachers' engagement with the action plan and identifying solutions increased over the course of this study in each centre. Following Bruce et al.'s (2011) CAR framework teachers in this study identified the solutions together, reflected on the action plan, discussed ideas with me and amongst themselves and reviewed the pedagogies or changes to the environment they had made. They then gained confidence, asked questions, and proposed new changes or ideas themselves.

The CAR enabled and empowered teachers by supporting them to remain focussed on science. They met regularly to reflect on their action plan, on the problems and successes in how they supported science in their centres and to identify areas they wanted to work on further.

These meetings and also the conversations we've had, it's like being able to continue to touch base ... to bring it back, bring it back ... something to focus on and if you focus on it and then it will build and grow.

Comparable to research using CAR in other settings (see, for example, Avgitidou, 2009), this study found teachers' confidence grew throughout the project. They learnt more science content, became more confident to engage with science and so explored scientific experiences with children even more.

I'm feeling confident about taking these concepts and using it in just an everyday context.

(Margaret,Ngaio,FG3)

Teachers' confidence in their science knowledge was reflected in their use of scientific language and exploring science alongside children through the co-construction of knowledge.

I feel a lot more confident stopping and asking follow up questions.

(Tracey,Whau,FG3) 
This increase in confidence is similar to an action research project by Broström (2015) which found that the ECE teachers involved engaged in and enjoyed shared science activities with children. This in turn meant teachers "saw themselves in a new role: A professional preschool teacher with academic (science) knowledge, who influences children's (science) learning" (p. 118).

The value of the collaborative nature of the CAR process became evident through teachers working together and supporting one another over the research.

I have to say the change for me is not working in isolation, having the support of you guys has been huge ... and having discussions and a focus and actually having to write reflections.

(Margaret,Ngaio,FG3)

Teachers valued the opportunity to work together with the same focus and provide each other with encouragement, feedback, and critique. Other research has indicated the significance of the teaching team supporting each other in CAR; showing that it facilitates opportunities for learning for participants (Bruce et al., 2011) and enhances teachers own science knowledge (Goodnough, 2003; Jordan, 2010).

\subsubsection{Time Involved in the CAR}

The plan for this study was to work with each centre for at least 12 weeks, with the expectation that the action plan would have time to be identified, implemented, reviewed, adjusted, and implemented again. This also means understanding teachers' views and challenges because I had spent time in their centres. As identified by Bruce et al. (2011), spending time in the centres meant researchers "learn how to support teacher researchers authentically and directly" (p. 444). They argued that building trust between teachers and the researcher and therefore commitment through those close relationships, was an important contributor to a CAR project's success.

Teachers in this CAR study voiced an appreciation for the time the research gave them to focus on science.

I think 12 weeks was really helpful, keeping it at the forefront of your mind.

(Kim,Whau,FG3) 
Teachers felt the time involved meant the changes in their practice had become habits and how they enabled scientific experiences during the CAR had become part of their daily practice. They were hopeful that this would remain the case.

Sharon - it is quite a long time so having that period of time it becomes ...

Alyssa - ... it becomes a habit.

(Mahoe,FG3)

And you have been coming long enough that we have actually been able to start forming new habits.

(Anabelle,Matai,FG3)

The shift in teachers' practice came about because of the opportunity they had to try out new approaches, to see intentional teaching being modelled and to reflect on the successes that had occurred because of their engagement alongside children in scientific experiences. Having time to discuss these ideas as a teaching team was valuable. Coming together in more formal ways facilitated deeper and more critical reflection of their practice. The CAR projects analysed by Bruce et al. (2011) also attributed teachers' growth in pedagogical knowledge due to the time they had to work together to plan and reflect on the implementation of their action plan.

\subsubsection{Changes Prompted by CAR}

In two centres, Whau and Ngaio, the time involved in the CAR allowed me to see significant challenges to the provision of scientific experiences for the older children in their programmes. As a critical friend, I was able to use this time to fully understand the centre's way of doing things and view their practices as an outsider. As both Costa and Kallick (1993) and Stieha (2014) argued, a critical friend takes time to examine and critique the context and offer an outsider's perspective. At Whau my observation of the lack of challenge for older children in the outside area resulted in teachers initiating a once-a-week bush walk after the CAR project. It was still happening at the centre when this thesis was completed three years later.

My observations at Ngaio identified a challenge that teachers had already noticed. Older children were often missing out on sustained conversations or investigations with teachers, or were interrupted, which meant opportunities for deeper scientific thinking and extending children's science interests were being lost. 
Kathryn - You know the frustration was there, but I couldn't put my finger on exactly what it was until you get that kind of different perspective, and now that we have created change out of it, it is even better.

Regan - We can see a thing but it is so much more validated when an outsider sees it as well.

(Ngaio,FG3)

This prompted a discussion with the larger teaching group and the decision to put aside an area of the centre for older children only; a space where they could explore scientific concepts to a greater depth away from younger children. An email with a learning story arrived from Kathryn a few months after the CAR had finished, in which she commented:

I wanted to share a story that shows how well the new space for the older children is going. I'm so pleased with how it is working out and the children are chuffed.

Thanks for being a catalyst for this positive change.

(Kathryn,Email)

These are just two examples of changes that the CAR process enabled. There were many other aspects to teachers' practices that transformed over the study, as did adjustments to their environments and resources. As MacNaughton and Hughes (2008) put it, CAR is a research process looking for innovation, improvement of practice and to generate new knowledge. Furthermore, it is also often implemented over a long period of time to enable the researcher and participants to form robust collaborative relationships and to see the research cycle generate new ideas and transform practice (Sigurdardottir \& Puroila, 2018).

\subsubsection{Summary}

This section identified the value of CAR in this study and how the process empowered teachers to critically reflect on their practice and explore different pedagogical approaches. The time involved enabled teachers to collaborate as a team with a common focus on science. Their openness to me working alongside them and building a trusting relationship allowed me to understand their context and support them in meaningful ways. These factors all contributed to a shift in teachers' practice and changes to their programmes that facilitated more scientific experiences in their centres. 


\subsection{My Role in the CAR Research}

This section outlines the role I took in this study and how this shifted over the course of the research process. Aspects of my role are analysed using reflections from teachers and an exploration of the influence it had on their scientific practice. Quotes from teachers participating in the CAR are used to illustrate this aspect of the research which has not been discussed previously. Collaboration is a key element of CAR and therefore how that was enabled through this study is reviewed, as is the collaborative analysis of the study's data. The section concludes by considering the concept of a critical friend which was a useful way to examine my role in the CAR. This is explored using the four components: facilitator, supporter, challenger, and teacher, identified by Goodnough (2003) to highlight the multi-faceted aspect of my role in this study. Finally, a diagram is presented to show how I, as a critical friend, and the teachers contributed throughout the CAR process in this study.

\subsubsection{Shifting Roles}

At the beginning of this study I expected teachers to drive the process themselves. However, it became clear it was necessary for me to guide the CAR process and keep teachers focussed on the actions they wanted to establish. One teacher's statement articulated what many of the teachers voiced:

It is good having someone like yourself come in and just push us a little bit.

(Sharon,Mahoe,FG3)

Reflecting on my role it was clear that the relationships I had with teachers differed in each context and changed during the CAR process. Goodnough (2003) stated that the working relationships of outsiders with insiders in action research can differ depending on the context. Herr and Anderson (2015) have debated the various ways researchers can work on, for or with participants, which helped identify my role as an "outsider [working] in collaboration with insiders" (pp. 40-41). They argue that the nuances of whether the researcher is inside or outside the research context, what position they might hold, and their position of power must be considered throughout the study. I was, therefore, constantly reflecting on how my previous lecturing role at the university or my involvement in the Montessori ECE community might influence teachers' perception of me and the power I held. Additionally, Somekh (2005) believes the role the 
researcher takes shifts to ensure as much support and autonomy as needed which can result in a variety of partnerships.

This was certainly the case for me; however much my role differed in each context, my central aim was for collaboration with the teachers involved. MacNaughton and Hughes (2008) drew on Kemmis and McTaggart (1988) and others when they stated that it is only action research if it is collaborative, and it needs to be for practitioners to avoid reinforcing "what they think already, rather than generate new knowledge" (p. 51).

\subsubsection{Building Relationships}

Each teaching team in the six CAR centres were already busy with their daily teaching and administration so I was very aware that I was asking them to do extra work to be involved in my research study. With that in mind I found I needed to encourage and support teachers throughout the project. This is similar to the experiences of other researchers in CAR studies, where the collaboration between the researcher and teachers is often a balancing act of leading, encouraging and empowering (e.g., Platteel et al., 2010; Postholm \& Skrøvset, 2013; Sigurdardottir \& Puroila, 2018). Nonetheless, my involvement was welcomed by teachers as the following dialogue shows.

Sharon - I think having you in the sessions, engaging in those conversations and actually doing it,

Alyssa - it is more real for us, and more relevant.

(Mahoe,FG2)

At the first meeting with each centre, I explained the intention and process of the CAR and tried to convey an expectation that teachers would be active participants in exploring the enablers of scientific experiences in their centres. However, in outlining my hopes for the research I reflected that I may have been indicating the areas for them to explore. This was noted by Pedretti (1996) who mentions being worried she too was "guiding [the action research group] in a certain direction" (pp. 310-311). I wanted to avoid this but also realised the need to establish a clear outline of how the study would progress. I found I needed to guide the research study for it to run smoothly and be completed but likewise I had to gain their trust and engagement so our working relationship could develop beyond teachers seeing me as the outside expert with all the answers, as suggested by Sigurdardottir and Puroila (2018). Analysis of CAR studies by 
Bruce et al. (2011) found the researcher had an advisory role in the beginning to help refine the study's intentions.

In this CAR study the difficulties of the group members not knowing each other was avoided as each centre's teachers all knew each other well and already had strong working relationships. Others have discussed the complexities of the researcher's role (e.g., Postholm \& Skrøvset, 2013; Sigurdardottir \& Puroila, 2018) and others have explored the difficulties within collaborative relationships in educational action research (Platteel et al., 2010). Also, in three of the centres all or a couple of the teachers already knew me, and this was helpful in facilitating my engagement with the teaching teams. Sigurdardottir and Puroila (2018) identify a third space where collaboration between the researcher and participants sits, where the researcher is neither an outsider nor an insider. In this study, while I aimed for an equal relationship with teachers, because the research area was determined by me, I owned the data, and teachers' busyness and desire for guidance meant the collaborative nature of the study fitted the description of a clinical partnership as outlined by Wagner (1997). He identified the researcher as "the agent of inquiry, and practitioners are the people whose work is the focus of analysis and reform" (p. 15).

\subsubsection{Collaboration}

To fully explore what resources and practices teachers may use to facilitate science experiences for children in their centres I worked alongside them in their settings. As discussed in Chapter 3, Section 3.4.3, using the Rearick and Feldman (1999) framework, this study explored a practical theoretical orientation, with the purpose being professional understanding. The collaborative reflection that occurred involved teachers and me examining changes that could enable scientific experiences in their centre. Using CAR as the vehicle for practitioners' research, teachers and I were looking for professional change, recognising its ability to improve practice and provide deeper understandings as suggested by Goodfellow and Hedges (2007) (see Chapter 2, Section 2.4). As argued by Mills (2011), the results of action research are persuasive and influential for teachers because they develop "solutions to their own problems" (p. 11). And it is a "powerful and empowering way" to bring about change (Wells, 2009, p. 59).

Finding the balance between giving advice, asking questions, and providing support was key to my ability to foster an environment of collaboration with each teaching team. My 
role therefore varied, and it was in the process of exploring and collaborating with teachers that I constructed my role throughout the CAR (Sigurdardottir \& Puroila, 2018).

Gaining teachers' trust was key to facilitating a collaborative working relationship during the CAR with each centre. With the Mahoe teachers I noted in my reflective journal that we had not met before, so I needed to work harder to gain their trust. I realised they knew little about me and my background. As I had done with previous centres, I suggested we each post a bio on Moodle about ourselves and what we wanted to gain from the study. Following this our relationship grew stronger and their interest in my observations increased and consequently their openness to critically reflect and welcome suggestions from me. This was discussed in our second focus group.

Sharon - Having you here to provoke us ...

Alyssa - ... that has been really awesome for us.

(Mahoe,FG2)

I needed to constantly reflect and negotiate my relationship with teachers. How my position as an outsider might influence the nature of teachers' involvement was continuously being reviewed. I found the teachers wanted me to be more involved than I had initially planned. This was like Platteel's CAR where participants wanted her to become more involved as an "academic critical friend" (Platteel et al., 2010, p. 438). For this study I needed to ensure my positioning did not reinforce teachers' inclination to undervalue their own knowledge or place themselves in the knowledge quadrant of "We don't know. They know" (Herr \& Anderson, 2015, p. 50).

Encouraging teachers to feel their input was valued was important in fostering their ongoing engagement in the project as well as developing their abilities to critically reflect on their own practice and look for ways to improve it. I offered encouragement and often acknowledged their courage at extending themselves through the online reflection journals or when we chatted during my visits. Teachers at Ngaio noticed this in particular:

Stella - I think you have been really helpful with that, you have been a great sounding board.

Regan - and you feel safe.

Margaret - and a gentle pressure.

(Ngaio,FG3) 
My role therefore was a fluid one; shifting to meet the changing needs of teaching teams. While I had intended to spend 12 weeks working with each centre and thought that my role would be a facilitation and monitoring one through the focus groups and an occasional visit for their staff meetings, I soon discovered my involvement would be more complex. I found I moved between various roles and sometimes I "assumed several roles simultaneously" (Goodnough, 2003, p. 48).

I realised at the beginning of my time with the first centre, Kanuka, that I needed to visit them during the centre's session times. I wanted to see teachers working in their centre and as a team to understand how they worked together and with children. Swaffield (2007) and Hedges (2010a) have both argued that visiting the centre is vital for the researcher, so they get to know the programme and become a familiar face. It was through these visits I moved into the role of a teacher at times by role modelling intentional teaching pedagogy with children through science experiences, or I took on the role of a supporter when giving teachers positive feedback about their practice or as a challenger when "asking pertinent and provocative questions" (Swaffield, 2007, p. 209).

\subsubsection{Analysis and Reflection on Teachers' Practice}

Over the CAR project, I collected significant data from my visits. My observation notes were a combination of direct observations of what was happening and reflections on when I took on the role as a teacher alongside other teachers in the centre. Being a participant observer is an "interactive experience and relatively unstructured" (Guest et al., 2013, p. 79). Therefore, the times I was involved in the action of the centre or when I sat and observed, was in response to whatever was happening. This process allowed me to fully capture what was occurring in the centre during my visits. I could see and experience how the environment, resources and teachers enabled (or not) children to explore science concepts. I was able to experience the challenges that existed for teachers and I could understand and relate to teachers' reflections because I knew the children they were talking about or the routines they were discussing (Guest et al., 2013).

This meant the analysis of teachers' practice, and what enabled and restricted scientific experiences to occur was done by both teachers and me during the focus groups and through their reflection journals or responses to my observation notes. There was also a 
collaborative element to the data analysis throughout the CAR project. Bruce et al. (2011) identified the value of university researchers in their CAR project as they were able to share their expertise throughout the study often by not giving teachers the answer but by working alongside them in finding solutions or offering resources.

During my visits I was positioned within the daily life of the centre, which meant I could be involved in the practice and could suggest changes. But as I was also seen as a visitor, I did not become part of the system. This concept of the researcher being a virtual participant in interactive research such as CAR means the changes can continue once the researcher has moved on. This distance permits the researcher to maintain a critical view of the practice, to "support, stir up and steer" if necessary (Sandberg \& Wallo, 2013, p. 200). This approach is supported by Stieha (2014) who argues that the critical friend role allows for researchers to find a balance between their closeness to the context, the participants and therefore the data and having an important outsider view of the investigation.

Therefore, the value in the various ways I participated in the CAR process meant I was able to collect data from a range of perspectives and the collaborative nature of the study enabled analysis of the data to happen alongside teachers during the focus groups and the research hui. We were able to analyse the data such as my observations or their reflections initially through online discussions, again as a group during the focus groups and at another level in the Research Hui (see Chapter 6, Section 6.5). As the research hui involved teachers from several centres participating in the CAR, we were able to identify emerging themes from their experiences which aided the analysis of other data. In addition, the first research hui helped clarify the role I played with the first three centres and influenced how I supported the teaching teams over the CAR process in the following three centres.

\subsection{Being a Critical Friend}

Throughout this study the influence of my role became apparent and therefore it was necessary to acknowledge that and identify how my role could be defined. The concept of a critical friend corresponds well with how my role was situated in this study. Analysing her role as a researcher from a university in an action research project, Goodnough (2003) likened the role to that of a critical friend. Costa and Kallick (1993) 
earlier identified a critical friend as "a trusted person who asks provocative questions, provides data to be examined through another lens, and offers a critique of a person's work as a friend" (p. 50). To do this, the critical friend is expected to take time to understand the context of where that person is situated, know their goals and advocate for their success. Hedges (2010a) sought to be a critical friend in her PhD study from the beginning, and found it was a key reason why teachers wanted to be involved. Her intention was to spend time understanding the context and teachers' practices before introducing professional learning through collaborative discussion and critical analysis of the teachers' practice. As previously outlined in Chapter 2, Section 2.4, Goodnough (2003) identified four roles within the multi-faceted position of critical friend that helped foster collaborative relationships with the participants in her study: facilitator, supporter, challenger, and teacher. Using this framework, it is possible to see how my role in this CAR study was as a critical friend.

\subsubsection{Facilitator}

Facilitation was essentially my main role, as my organisation was evident throughout the research period. I contacted the centres, organised dates to meet, provided and collected ethics consent forms from teachers and parents. I videoed the science walk and facilitated the three focus groups with each centre. This task involved creating an initial guideline for the first focus group that prompted teachers to reflect on the science walk and how they enabled scientific experiences in their centre. I asked them what areas of science they thought they did well and what areas they wanted to work on. I also shared recent research and suggested possible foci they could explore. From this I generated the action plan that the centre would work through over the CAR project.

The administrative elements of my role in the CAR were significant; they ranged from setting up the Moodle site, to monitoring their journals regularly and replying to each post with positive feedback and critique if required, to moderating, recording, and transcribing the focus groups. As the facilitator of the focus groups, I worked to enable a relaxed atmosphere to encourage open and honest discussion. As teaching teams knew each other well already, I did not need to work hard to facilitate this, although interestingly each team had its own character and way of engaging which represented the collegial nature of their working relationships. The centres whose programmes allowed for teachers to meet often were able to draw on regular conversations with 
each other to feed into the reflection process, whereas the teams who had limited time together often used the focus group time to catch up on what had been happening. Here my role as a conduit of knowledge was quite important as I was able to share information about science experiences between children and teachers. As identified by McLachlan (2005) the tasks performed by the moderator or facilitator of the focus group are many with the intention of ensuring all participants feel comfortable and able to express their opinions openly.

In addition, I found I was often keeping teachers focussed on the research and ensuring the project maintained momentum. This was especially important because of the hectic nature of teachers' day-to-day running of the centre. Sharon, from Mahoe, articulated what many of the teachers noted throughout the study.

There are a lot of demands on our time, and our energy and our focus.

I therefore needed to remind all teaching participants to post reflection journals each time I saw them. Some teachers found the process valuable and posted many entries, some did not post any. At Kanuka, the first centre, I worked with, I noted after the first focus group that they asked me to give them deadline dates to post their reflections. This highlighted how my role as facilitator was integral to keeping the CAR study on track and teachers on task. As Mandy, from Whau, said.

You coming in each week, that's been a reminder.

This supports Thornton and Yoong (2011), who also noted in their study the teachers needed constant reminders and encouragement to contribute to their online journal.

\subsubsection{Supporter}

My role as supporter of the teachers was key to having them begin and continue being involved in the study. For many, my support of them through my comments online and when I visited helped keep them engaged in the process and encouraged their critical reflection of their practice. Positive affirmation of teachers was fundamental to their continued engagement in the CAR process as has been the case in other action research studies (Bruce et al., 2011; Sigurdardottir \& Puroila, 2018). For example, Regan at Ngaio posted a significant reflection about what being a teacher meant to her and how her growing confidence had helped her tackle a hui with children in a different way. My response needed to reflect this: 
What an AWESOME reflection Regan - I love it!

Such a powerful illustration of reflective practice and how taking a moment to explore your strengths and weaknesses and where you want your practice to go and be means such growth for you as an ece teacher. Beautiful, thank you.

(My response to Regan,R6)

I found my regular visits during session times allowed me to casually chat with teachers about their teaching pedagogy, elements of their action plan or provide advice, and this time also meant we could share information about each other at a personal level. This meant the friend part of critical friend was able to develop over the time I worked with teachers and it helped build the trusting relationship needed to allow them to be open and honest and accept questions and critique of their practice. As suggested by Thornton and Yoong (2011), taking time to know teachers and providing support all contributes to building trusting relationships. Trust is vital for teachers to feel safe enough for there to be critique of their practice without them feeling like "their competence is being questioned" (Postholm \& Skrøvset, 2013, p. 516). Not only did the sharing of information enable me to know teachers better and understand their approach to science and teaching science, but it meant they got to know more about me. Some teachers already knew me through my previous roles, which meant I came to the research with a professional reputation which, if favourable, can facilitate a relationship of trust (Swaffield, 2007). I hoped this was the case for me. However, Swaffield (2007) notes that a high professional reputation can also be an obstacle unless the critical friend works hard to equalise the relationship, ensuring the perception of power of the critical friend does not get in the way of a genuine open relationship. Having my visits occur as much as once a week meant I was able to regularly see teachers and facilitate both my professional credibility and develop enduring friendships with them.

As discussed in Chapter 3, Section 3.9, it was necessary to consider the possible ethical challenges that could eventuate during the study. Working closely with teachers and as an outsider working within their space, I needed to ensure free and open dialogue continued between us all. Setting clear expectations with the teaching teams during our first meeting was, as Minkler (2004) argued, a good way of setting "formal and informal ground rules" that "help prevent or successfully resolve difficult issues as they arise" (p. 694). 
Similar to Hedges's (2010a) role as a critical friend in her study, I often provided ideas and resources for teachers. Each centre was provided with academic articles which explored the areas teachers wanted to focus on, such as It's a Bugs Life (Browne \& Te Papa, 2016). I also shared instances of where I had seen science experiences being enabled in other centres and provided articles in response to ideas raised by teachers themselves, as my reply to Alyssa from Mahoe showed:

Nice reflection - it sounds like an interesting game - I look forward to seeing it. Yes, finding the link between the resource and your involvement is key.

I have found a recent article which explores these ideas some more and have put it in the 'articles of interest' folder. You might find it interesting. (-)

(My response to Alyssa,R1)

\subsubsection{Challenger}

Alongside fostering a supportive and trusting relationship with teachers, at times I found my role shifted into that of a challenger. While each of the teachers held their own beliefs and values regarding their practice and science (as did I), by being part of the CAR they had shown an interest in exploring how they could bring more science into their centre and their practice - so they were open to ideas and suggestions from me. I did need to be mindful in how I provided those suggestions as did Thornton in her role as a blended action learning facilitator. Thornton and Yoong (2011) used the term "trusted inquisitor" (p. 137), to describe the balance of providing empathy and support to enable a trusting relationship while challenging teachers to inspire reflection and learning.

My connections with teachers were therefore more often ones of encouragement and support, so when I did challenge it was done to foster critical reflection of their own practice. I either responded to their reflections with questions or offered critique in my observation notes. For example, I had noted in my observation notes after a visit to Whau the wide range of resources they provided to inspire scientific investigations but wondered if the emphasis on independence and children working on their own meant opportunities to have conversations with them about the science they were doing was missing. I shared the article by Zhang and Birdsall (2016) which showed that the handsoff play pedagogy of the centre in their research resulted in a lack of scientifically meaningful interactions with children. I also discussed Fleer's (2009b) research which 
argued the importance of teachers engaging with children and their explorations to ensure conversations occurred. Both articles point out how important conversations with children are to facilitate meaningful scientific interactions and how they are required for their knowledge to shift from everyday concepts to science concepts. This issue came up during the focus groups too and we discussed my challenge to their practice of leaving children to engage with science materials on their own without guidance or conversations with teachers. Each of the teachers reflected on how they had therefore worked to find the balance between respecting children's concentration and independence and extending their learning through having conversations with them. By the end of the study they were seeing the value in having more conversations and as Kim noted:

It has become part of what we do now. That we stop and have those conversations a lot more.

At Matai, Anabelle reflected in her Teaching Portfolio the value of working with me and the role my feedback had in encouraging her and her colleague's critical reflection.

Sola has been systematically giving us feedback to support us to read, think and critically reflect on our practice in order to refine our science teaching techniques.

(Anabelle,AR2)

My weekly visits to the centres allowed me to observe teachers in practice and participate in discussions held during the focus groups. Like Avgitidou (2009), my role as a facilitator of the focus groups changed as the collaborative nature of the project meant I became more involved in the centres. I participated in discussions, made suggestions, and raised different perspectives for teachers to consider. Here my role as a critical friend was significant, using discussions to facilitate, support, and challenge teachers. As Andrea at Kowhai noted:

You pointed out to us things that we didn't think were as important as they were.

Or as useful as they are. Or that those things are there.

\subsubsection{Teacher}

My unexpected role as a teacher in this CAR study meant working with children alongside teachers in the centres. With the first centre, Kanuka, I decided to visit during the session with children to observe how it was run and to get to know teachers. 
Kanuka was a busy centre and I found myself participating with children outside. It was a lovely day, and some children and I discussed a puddle drying up over the morning. Then I engaged with children jumping off the playground. Kelly noticed these exchanges and reflected on it later.

After a visit from Sola on Tuesday and watching her interact and engage with our children through an experience with "Puddles" and "Jumping" I began to reflect on the crucial role that a teacher plays in extending scientific knowledge ... Sola provided some great examples on her visit of ways to look at simple everyday occurrences that happen at our centre through a "scientific lens". So, with this newfound knowledge and confidence I began to look for more opportunities at our centre for scientific learning to occur.

(Kelly,Kanuka,R1)

From this reflection and following conversations with Kelly I realised the value in rolemodelling intentional teaching practices while I was in the centres. Kelly noted that it was the way I asked children questions she found useful:

You have kept me on my toes to be more intentional in my teaching. And it has been cool watching you when you come in and listening to you talk to the children, it has made me think about how I do ask questions to the children. (Kelly,Kanuka,FG3)

At Mahoe centre, my interaction with a boy and a catapult foot board illustrated the value in asking questions and sharing knowledge to help extend the child's scientific knowledge. By discussing with him how the height of the ball coming off the catapult foot board was created by how much force he used when stamping his foot on the board, Cynthia, who was observing, was able to see how she could share knowledge without hijacking children's own working theories, a concern of hers we had discussed during another visit.

I realised how we can make the most of these scientific teachable moments and support the children to take their thinking and working theories to the next level through our language and sharing of knowledge. We have the knowledge and it was a great reminder of how I can put this into practice. $\quad$ (Cynthia,Mahoe,R1)

My relationship and the roles I took not only differed over the project but also between each of the six centres. How much I was involved as a teacher working with children depended on the centre's philosophy of practice and my relationship with teachers. Like 
Sigurdardottir in her CAR study, I found I was "neither as an insider or an outsider but rather as a little bit of both" and therefore my participation alongside teachers and children did not have any defined rules (Sigurdardottir \& Puroila, 2018, p. 8). In previous CAR research projects, the role of the academic researcher or outsider has been described as multi-faceted but usually did not involve practising alongside teachers (Bruce et al., 2011; Platteel et al., 2010; Postholm \& Skrøvset, 2013). It seems however that the role cannot be fully pre-planned, that it is constructed throughout the project in collaboration between the researcher and participants (Sigurdardottir \& Puroila, 2018).

Thorpe (2015) used action research to investigate assessment of group music composing with three secondary teachers in their schools. She found she needed to shift her researching role from an observer in her pilot study to a practitioner inside the action of the main research settings. This meant she sometimes taught the classes with the teacher participants observing and together they reflected on aspects of her practice that the teacher could include in their own teaching repertoire. When reflecting on how my own role as an outsider researcher had morphed into being part of the action inside, I was able to draw on Thorpe's research to acknowledge the value in this.

Wow! Kelly's reflection is amazing and really highlights the value in me being in the centre. I really enjoyed being with the children, so I am keen to continue this. I think if this is what the teachers gain from it then it is worth me doing so. Also, I think [Thorpe] taught in her action research-so I can do this too - I think?

The value in my being able to teach alongside teachers in their centre allowed them to observe and reflect on other ways of being a teacher, which I believe gave them permission to transform their own practice. Anning and Edwards's (2006) action research found teachers' learning was enhanced by the "modelling of strategies with children by more expert practitioners" (p. 146). Similarly Bruce et al.'s (2011) analysis of CAR projects found the implementation of the action plans or interventions sometimes involved the researcher being part of the classroom action as a co-teacher, and through this process they were able to support teachers "authentically and directly" (p. 444). These collaborative relationships also saw teachers being more open to trying 
new teaching strategies and they also reflected on the experience as being more transformative for them.

\subsubsection{A Multi-faceted Role}

My role as a critical friend working alongside each teaching team involved in this CAR study was varied, dynamic and multi-faceted. I found myself moving between the roles often and holding two or more at one time. As the facilitator I was required to manage teachers throughout the process. In the role of challenger I needed to observe and critique, which required making a judgement of their practice. In these two roles I held more power than the teachers. As a supporter and a teacher, I saw myself as, and worked to be, equal to teachers so our relationship was more collaborative in nature when in these roles. Critically reflecting on my roles throughout and after the CAR study meant I was able to foster a collaborative relationship with each of the teaching teams. This is comparable to Goodnough (2003) who found "assuming a multiplicity of roles ... by shifting roles to meet changing circumstances and needs, and by assuming several roles simultaneously" meant she was able to encourage collaboration within the action research group and thereby provide the best possible support to her participants (p. 48). The diagram, Figure 7.1, below illustrates the relationships I had with the teaching team in the various roles within my position as critical friend.

Figure 7.1

The Role of a Critical Friend in CAR

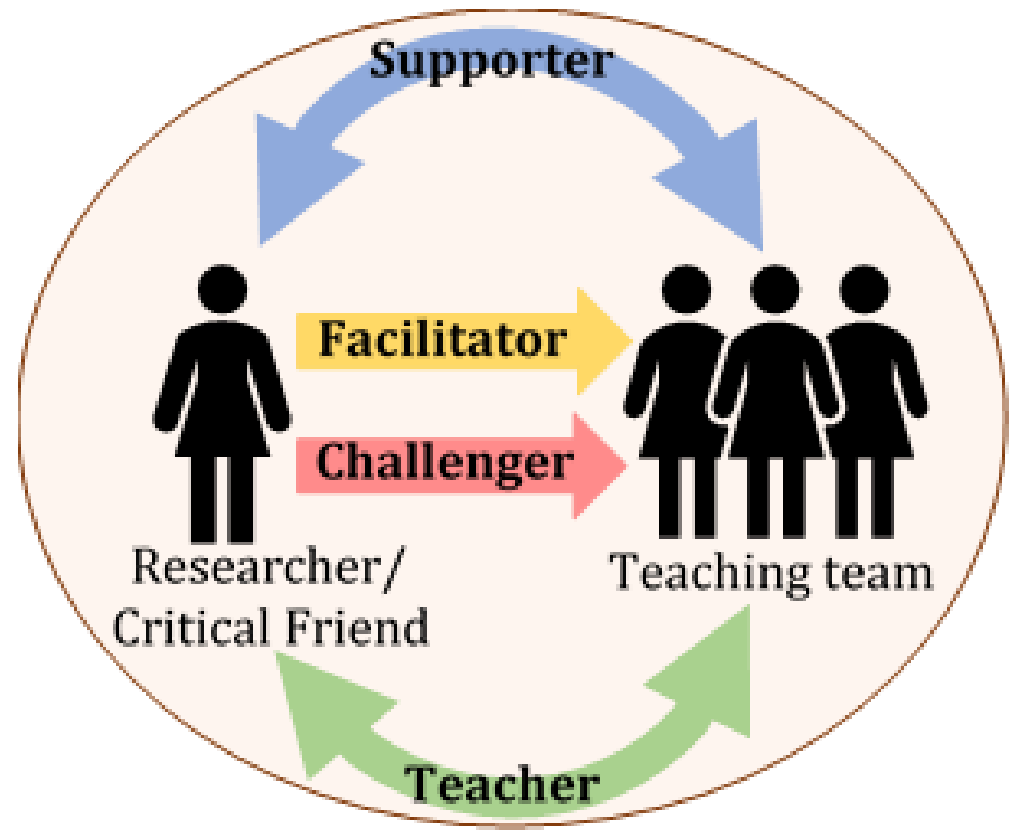


The colours in the diagram reflect the nature of the various relationships I had with teachers in the CAR phase of this study. As a facilitator of the study, I needed to motivate and maintain the study's momentum, and this is reflected in the yellow arrow. The red arrow represents the questioning, confrontation and courage of teachers and me in presenting and accepting the challenges to their practice over the CAR. The green double arrow flows in both directions to show how my position of power was equal to teachers and reflects the active nature of my role where I often found myself teaching or engaging with children alongside teachers. The blue arrow also flows both ways to represents the equal and strong relationships we had with each other. I needed their support and they needed mine.

The essence of CAR is collaboration; working together to promote professional learning through reflection of teachers' practice. Being sensitive and respectful of where and who I was with helped build strong relationships based on trust with all teachers involved in this study. As identified by Goodnough (2003), my role as a critical friend was to facilitate the process, support teachers, challenge their practice, and work alongside them. It required me to move often between these roles or be in more than one simultaneously as the context or situation required.

\subsection{CAR with a critical friend}

Throughout the process of CAR in this study my involvement as a critical friend, and that of the teachers varied according to the different phases of the project. Figure 7.2 below outlines my contribution, how the teachers contributed and where we worked together. 
Figure 7. 2

\section{CAR with a critical friend}

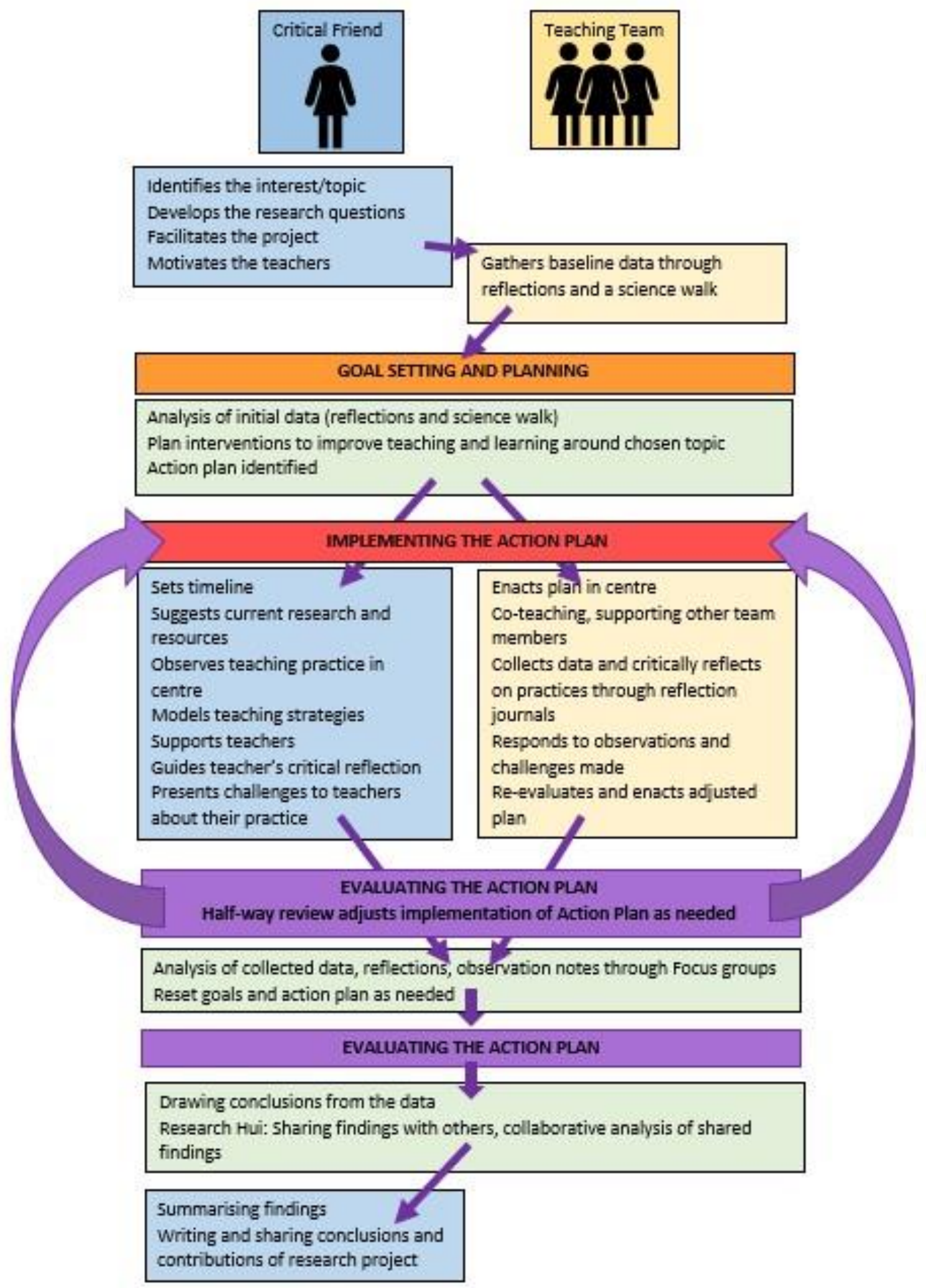




\subsection{Chapter Summary}

This chapter has outlined how the CAR process and my role as a critical friend influenced the shift in teachers' practice and therefore enabled scientific experiences in their centres. Literature focused on CAR for professional change was discussed and its role in facilitating learning, improvement in practice, PLD and the generation of new knowledge was highlighted. This study found CAR to be valuable in similar ways. The collaborative nature of this research gave teachers ownership of the process and fostered their confidence to critically explore their practice and be open to suggestions and challenges from me. My position in the CAR study used the four elements of a critical friend: a facilitator, supporter, challenger, and teacher. The multi-faceted role I had as a trusted critical friend in the CAR process highlighted the value of my role. Being part of a collaborative team critically reflecting on their practice, my support and the time I spent in the centres lead to some significant shifts in pedagogical practice for many of the teachers involved and changes in programmes for a couple of centres. The pedagogical approaches used by teachers to enable science are discussed in the next chapter. 


\section{Pedagogical Approaches that Enabled Scientific}

\section{Experiences}

\subsection{Chapter Overview}

This chapter addresses the second sub-question: How do teachers' pedagogical approaches enable children's scientific experiences? Findings from the survey and the CAR regarding teachers' pedagogical approaches are examined in this chapter with reference to relevant literature. The following discussion highlights how teachers' pedagogical approaches enable scientific experiences to occur for children in their centres. Analysing these findings using a sociocultural theoretical lens means viewing teaching and learning, and in particular science teaching and learning, as a social act embedded in the everyday experiences that occur in an ECE centre (Vygotsky, 1978). This chapter discusses the intentional teaching strategies used; questioning, planning, the relationships with and knowledge teachers had of children, and using funds of knowledge, group time and documentation. As well, provocations, the centre environment, and the role of the teacher and the teaching team are discussed as part of enabling scientific experiences in the centres in this research.

\subsection{Supporting Scientific Experiences}

Through the survey initially and more specifically through the methodology of CAR this study investigated the ways teachers could facilitate and encourage scientific experiences. The qualitative data from the study's survey revealed a wide range of opinions regarding how science was supported in respondents' centres. The teachers' role was identified as important for promoting and supporting science experiences to occur; either through the scientific knowledge teachers had, the resources provided, the environment teachers created or the pedagogical approach of the centre. Responses related to pedagogical approaches were divided. Some respondents felt their centre facilitated science experiences through a self-choice play approach for children within a richly resourced environment. Other respondents stated teacher-led incidents such as experiments created opportunities for science. Another range of responses identified intentional teaching strategies were mechanisms for supporting science, such as asking 
questions, noticing, and responding to teachable moments, and co-constructing knowledge with children.

Using provocations to facilitate science was mentioned by survey respondents. Interestingly when asked what sort of PLD they thought would be most useful, out of four options given (specific science knowledge, science activities ideas, pedagogical approaches to support scientific learning, or other) the highest percentage, $43 \%$, chose pedagogical approaches. That result supported using CAR in this research to explore how to enable science in ECE centres. How this process provoked change was discussed in the previous chapter, and it is understood to be an effective methodology to instigate change in practice (Goodfellow \& Hedges, 2007; MacNaughton \& Hughes, 2008). Consequently, during this study many of the teaching teams chose to focus on exploring changes in practice.

Through the process of CAR, teachers refocused on viewing science in the everyday activities in the centre which allowed them to identify and respond to scientific moments. Across the centres teachers drew on their own understandings of science, from Te Whāriki (MOE, 2017) and from the NZ Curriculum: Science (MOE, 2007) to create their own definitions. Teachers thought scientific experiences to be those where children are making sense of their world, investigating, and understanding how the natural and physical world works, developing their working theories, and exploring new ideas about themselves, others, and their environment. This helped teachers to recognise science in children's everyday activities and see opportunities in children's interests for exploring scientific concepts. The broad definition meant teachers moved beyond setting up experiments or making a volcano in the sandpit to seeing science opportunities in boat building, ball throwing, ice melting, and so forth. This highlighted the need for teachers to identify children's interests and think insightfully about how best to support them. Areljung (2019) argues this shift to pedagogies that support science in everyday practice, rather than occasional experiments, is welcomed by teachers.

\subsection{Pedagogical Approaches}

Exploring how pedagogical approaches might support scientific experiences was a key consideration of this research project. The action plans of each centre highlighted 
pedagogy as an area of critical reflection for teachers, drawing on previous research, as outlined in Chapter 2, which indicated teacher confidence and pedagogies within a sociocultural framework are key factors to enable science in ECE. Areas all centres identified in their action plans were exploring how they could bring about more intentional teaching practices, such as questioning, having sustained conversations with children, using more scientific language, accessing funds of knowledge within their wider communities, and using provocations. Having teachers actively participating in their own professional learning and being motivated to make their own changes in practice has been suggested as a way to ensure successful transformation in science opportunities (Watters et al., 2001).

\subsubsection{Intentional Teaching Practices}

The pedagogical approaches teachers chose to explore during the CAR included questioning children's actions to help reveal their thoughts and working theories. They nurtured relationships with children to encourage inquiry and sustained conversations, noticed and created opportunities to extend their interests and documented their thinking. These strategies have been identified as intentional teaching practices (McLaughlin \& Cherrington, 2018).

Just prior to this study's CAR, the 2017 version of Te Whāriki (MOE, 2017) was released and all centres were working through the revised edition and how they might interpret it in their centre. The teachers' role was emphasised more than in the previous version, with a section specific on the role of the teacher or kaiako in early childhood centres, which was clearly inviting "teachers to view their role as active, and embrace a thoughtful and intentional pedagogy" (McLaughlin \& Cherrington, 2018, p. 33). There was now an expectation that teachers incorporate domain knowledge into their centre's curriculum (MOE, 2017). All teachers within this study were interested in how they might do this and what intentional teaching might look like within their centre.

This study found the shift to being more intentional in how teachers responded to children's interests was key in enabling children's scientific experiences. Through the CAR process, teachers were able to explore how best to do this within the philosophy of their centre, or through their own approach as teachers. For many, the key was finding a balance, avoiding experiences that were too teacher-led and where children's thinking 
became hijacked, rather offering their knowledge in a way that encouraged and directed the experience to enhance children's learning. These findings build on the research of Edwards and Cutter-Mackenzie (2011) who suggested that to best support children's learning in ECE play-based programmes, children's competencies and previous knowledge needs to be recognised. They recommended a teachers' role should be to actively connect children's experiences to “concept and content-based ideas" (p. 52), and realise the importance in teachers planning for children to engage with content knowledge.

\subsubsection{Questioning, Sustained Conversations and Using Scientific Language}

Data from the CAR revealed that teachers found noticing children's interests and asking open-ended questions a particularly useful way to encourage their interest and foster sustained conversations around science with children. This supports earlier research by Cremin et al. (2015), which found when teachers voiced the questions implied through the children's explorations, further inquiry through reflection and discussion was encouraged. An emphasis on science in this CAR study meant teachers became more aware of science opportunities in children's play and of exploration of the centre's environment. Teachers more often noticed and responded to children's science interests or facilitated another experience that could extend that interest. Backshall's (2016) study also revealed that once teachers had been shown how to notice science in children's play through PLD sessions, they had a greater understanding of science and therefore the ability to notice opportunities or "potential for science learning within children's emerging interests" (p. 186).

This research showed the value in teachers using intentional teaching strategies such as asking open-ended questions or joining children's conversations as they were then able to find out what children already knew and what they were thinking. These discussions often revealed the working theories of children. Through their questions and even adding to the conversations, teachers could explore these theories to a greater depth. Questioning what children were doing and thinking has been identified in previous research by Siry (2013) as a way for teachers to support children's investigations and help clarify their perceptions of science experiences. In this study, extending children's thinking by sharing their own knowledge with children was something teachers were hesitant to do, with some concerned that they might hijack children's working theories 
if they did. I used the term opening doors to highlight the value in teachers introducing children to new knowledge, my argument being that if that knowledge or an experience to explore that knowledge was not available to children through their home background then teachers had an obligation to make it available to children in their centre. If teachers did not, then who would? As argued by Siraj-Blatchford (2008), effective ECE involves sustained shared thinking which includes both the teacher and child contributing to and extending the thinking.

Through discussions, teachers discovered they used more scientific language in conversations with children than they had before the CAR. Over the CAR process they found they became more confident to use scientific terms and concepts, and realised it was appropriate to do so. The shift in using more scientific descriptive language was also reflected in noticing and acknowledging the science related processes that were occurring during children's investigations. This supports Church and Bateman (2019) who have argued for the importance of teachers following and extending children's thinking through conversations. In doing so they found that children show they can understand complex concepts such as time and temperature. They state that it is therefore "entirely appropriate for teachers to lead discussions and ask the questions" (p. 278).

This CAR study showed that teachers' sustained conversations using rich science language resulted in science being more visible in the daily life of the centre and emphasised the capability and understanding of young children with science concepts such as evaporation, decomposition and force. This resembles the findings in Backshall's (2016) research where teachers took the science language they were using with children and made it more visible through the documentation of children's experiences. Additionally, recent research by ERO (2021a, 2021b) reinforces the findings of this study by concluding that teachers' deliberately responding to children's interests, planning science opportunities, including science language and supporting children's working theories with intentional practices creates more opportunities for science learning.

As the CAR process progressed, teachers' planning and thinking about what science they could explore with children expanded. The science lens of this CAR study empowered 
teachers to enable science experiences through a provocation, a piece of scientific equipment, or by bringing in resources in response to a child's interest. The success they found in the experiences where they were prepared with science knowledge and shared it with children, encouraged teachers to explore science further. In line with previous research (Bulunuz, 2012; Piasta et al., 2015; Waters-Adams, 2006), the additional science experiences teachers had encouraged them to do more. Furthermore, in this study teachers' confidence in science meant they were more open to finding out information alongside children. They found they verbalised their thinking more, such as wondered out loud with children; I wonder what that is? or I wonder what would happen if...?

By discussing scientific concepts more often, teachers in this study found children became more able to shape and illustrate their thoughts through everyday language and scientific language. Similarly, Fleer (2009b) has argued that while children's exploration of rich play-based environments promotes everyday conceptual learning, without focused teacher-child interactions around scientific concepts, children's learning does not shift beyond everyday knowledge to scientific ideas.

Teachers found this shift to purposeful explorations around scientific concepts created a culture of inquiry in their centres. The findings from this study clearly indicate this shift through evidence such as teachers noticing children identifying themselves as scientists and children sharing their new knowledge with others and using science terms when doing so. This is like research by Patrick et al. (2009) which found meaningful and sustained involvement in science activities significantly affected children's beliefs about their competence in science and their liking of science. This study therefore reinforced the contention from Fleer and Pramling (2015) that teachers' engagement in science learning alongside children constructs and facilitates their curiosity.

\subsubsection{Planning}

All teachers in the CAR study saw the focus on science as a chance to be more purposeful in their planning and thinking about how best to support children's scientific experiences. Epstein (2014) argues that intentional teaching is "planful, thoughtful, and purposeful" (p.1) and that teachers use their knowledge to plan experiences for children as well as respond to opportunities where children's interest could be extended. Some 
teachers in the CAR made a concerted effort to prepare themselves with further science knowledge to support equipment or experiences they introduced to the centre, or in preparation for the possible directions children's thinking or questions could go. The importance of teachers' own content knowledge to best support children's learning has been argued by many (e.g., Hedges, 2002; Hedges \& Cullen, 2005; Shulman, 1986) and specifically in relation to scientific knowledge (Kallery \& Psillos, 2001; Trundle \& Saçkes, 2015).

For some centres, their programme involved set inquiries for children to explore, therefore as part of their staff meeting and to ensure science was more visible in their planning, they discussed the content and possible funds of knowledge available to support the science investigations they planned. Not only did they think about what they could explore with the children but also how they would investigate it scientifically. Using It's a Bugs Life (Browne \& Te Papa, 2016) some teachers often referred to the science capabilities and science processes highlighted in the document (see pp. 23-24), and used terms such as hypothesis, observe, test, find evidence and share findings throughout their discussions with children. The value of scientific processes in experiences for children is argued by some as vital, for example Eshach and Fried (2005) and French (2004) state that science is a natural part of children finding out about their world and making sense of those experiences. Moreover, some claim that identifying the processes involved in scientific inquiry is just as important as learning the content of science (Browne \& Te Papa, 2016; Epstein, 2007). This study indicated that teachers found using scientific processes to support children's investigations was valuable.

\subsubsection{Relationships With and Knowledge of Children}

Teachers' knowledge of and relationships with children in each of the centres in this study allowed them to make connections to children's previous experiences either in the centre or with their families. The relationships between teachers and children were pivotal in how teachers interacted with children during science experiences as they knew how best to support children's thinking. According to Epstein (2014), effective teachers can identify when and how to support children, recognising when to share knowledge to add depth to an investigation or provide "direct assistance ... to prevent frustration" (p. 24). 
Having strong relationships with children enabled teachers to better support their scientific interests. Because teachers knew the children well, they were able to respond appropriately; explore alongside them and co-construct knowledge together or share their knowledge to help children explore their science interests in a deeper way. In this study teachers often referred to their knowledge of children and how that influenced the pedagogical practices they used with them. The relationships ECE teachers have with children and their families is seen to be "foundational to their practice" (Cherrington, 2011, p. 209). The emphasis on relationships as core to teachers' pedagogy fits within the definition of relational pedagogy outlined by Papatheodorou and Moyles (2008), where the respectful relationship between teacher and child sees the learner as an active contributor to the learning. Research in NZ has identified the importance of strong relationships between children and teachers (Brennan, 2007; Dalli et al., 2009) and how this impacts their learning and teaching in ECE (Carr et al., 2008; Cherrington, 2011) and in particular with science (Bond et al., 2010). This was also the case in this research.

The interactions between teachers and children exploring scientific concepts in this study have similarities to interactions discussed in Fleer's (2009b) research. In this study teachers sought additional knowledge from parents and families, to know more about children's funds of knowledge, which helped them explore their interests further. Fleer (2009b) argued the teachers' knowledge of children in her study helped them ask questions to promote conversations and introduce scientific concepts to bring together children's observational and scientific knowledge. She contends that the learning environment therefore developed complexive thinking ${ }^{25}$ amongst the children as it "allowed for the interlacing of everyday concepts that the child was exploring with scientific concepts gained at home and in the centre" (p. 299). It could be argued the approach taken by teachers in Fleer's research was replicated in this study through the intentional teaching practices and relational pedagogy teachers used to identify, follow, and extend children's interests.

25 "Complexive thinking ... occurs when children begin to link concepts in relation to knowledge outside their practical experience." (Fleer, 2009, p. 290). 


\subsubsection{Funds of Knowledge Within the Community}

As discussed, teachers in the CAR noted that knowing children well helped them better engage with and support their interests. Additionally, teachers found using documentation to share children's science investigations with families and the wider community was valuable in making those connections. Teachers were able to articulate how valuable knowing children well was to them making links between children's experiences and their interests and ideas. This study reinforced funds of knowledge as a pedagogical tool to add to their kete ${ }^{26}$ of intentional teaching strategies. Teachers were able to identify where children's interests had originated or find connections to people with expertise within the parent or wider community. This provided a way for teachers to access broader science knowledge and bring science knowledge and experiences into the centre. Other ways for families to support children's interests or the centre's investigations was through the nature table or sharing photos or incidents that had happened outside of the centre via Storypark. For some centres they were also able to access resources through their local community such as a school library, facilities, a local stream, or community garden.

Teachers found the focus on science over the course of this research meant they were more attuned to recognising where children's interests came from, and they made concerted efforts to connect to the funds of knowledge amongst their centre community. Perhaps the emphasis on scientific interests helped teachers in this study highlight and respond to children's interests in more focused ways, which is in contrast to the findings of Hedges (2007) where teachers' engagement was described as "piecemeal" and of a "somewhat serendipitous nature" (p. 261).

This study found the more connections teachers made to access and understand the funds of knowledge within their centres' families and wider community, the better able they were to acknowledge and support children's interests in their centre. They reflected that, most importantly, knowing their community well meant they knew their children well. This correlates to research by Hedges et al. (2011) who found teachers needed to engage more with families and communities outside the centre environment. They argued using a funds of knowledge approach to understand children's interests

\footnotetext{
${ }^{26}$ A basket.
} 
helped teachers better support children's explorations within the centre. Teachers in this study found connecting with children's interests, knowing where and how those interests had been inspired, provided valuable opportunities for scientific investigations. This supports Hedges's (2010b) argument for teachers to use funds of knowledge to recognise and use children's interests to co-construct curriculum.

\subsubsection{Group Times}

During this CAR study all but one centre used group times or hui to explore children's interests, to introduce new ideas, capture what children already knew and/or to discuss a planned investigation in the centre. Group times are opportunities to prompt dialogue and support collaboration (Cremin et al., 2015). The findings of this research indicate that planned regular hui with all children together or a spontaneous small group experience facilitated by teachers generated questions and discussion in response to a provocation or a science-related occurrence in the centre. This supports Leggett and Ford's (2013) study which found that teachers often used group sessions to meet "the requirements of intentional teaching" (p. 46).

Group times were valuable mechanisms for teachers to revisit children's learning, help them share their thinking with the wider group and to facilitate children's thinking in a scientific way. This approach included using the idea of scientific processes to guide the discussions, for example talking with children about the evidence (what they had found out), their hypothesis (what they thought would happen), and their conclusions (what they discovered). The value of this sort of dialogue in science learning as a way for children to share, develop and consolidate their thinking has been recognised by Cremin et al. (2015) as one of the seven effective pedagogical tools which was identified in two literature reviews of science and creativity research in ECE.

\subsubsection{Documentation}

Teachers in this CAR study found documentation not only captured children's emerging working theories and the scientific processes they engaged in but also supported their intentional teaching practices. Using various forms of documentation such as posters and photos on the centre walls, and through Storypark, teachers found their focus stayed on science and made the experiences, seen through a science lens, more visible. Teachers found they could use documentation to revisit previous science experiences 
with children, or to share with the child's family and other teachers so they too could support and extend children's interests. This approach to assessment is seen as a valuable way to make visible children's learning as well as highlighting opportunities for further learning (Carr, 2014). This study therefore builds on other research which shows documentation of science experiences in ECE centres was an important mechanism to capture children's learning (Siry, 2013) and prompts children to revisit what they have experienced (Bond et al., 2010; Epstein, 2014).

\subsection{Provocations}

In this study, the term provocations was used to describe all activities that were set up by teachers with the intention of fostering a science experience. As discussed in Chapter 2, Section 2.5.2, provocations are a pedagogical approach usually associated with Reggio Emilia settings but have become a strategy used in ECE more widely to extend children's interests and even introduce new ideas to investigate.

The concept of provocations was understood by teachers in this study to mean setting up experiences or arranging materials in a more thoughtful and planned way. They found provocations were a significant factor in enabling science in their programmes. It meant they initiated new scientific investigations or extended children's scientific interests in more authentic ways. To do so they considered and prepared themselves for where children's investigations might go. Teachers being well prepared with subject knowledge builds on Hedges's (2005) research who saw it as vital for them to make the most of experiences and to help children "restructure their existing ideas to take account of new ... information" (p. 15).

Not only were provocations used in a planned way, but teachers also found the CAR process helped them see opportunities for scientific experiences that occurred in an unexpected way. In this study teachers and I used the term happenstance provocations to identify incidents where sciencing occurred as a result of something unplanned. Capturing these moments through intentional teaching strategies such as questioning, wondering aloud themselves and through conversations with children was an authentic and meaningful way for teachers to enable science to occur in their centre. This finding resembles research by Inan et al. (2010) which found teachers used planned and "serendipitous events" (p. 1196) such as a change in the weather or finding an insect as 
occasions for science experiences. In addition, this also builds on Fleer et al.'s (2014) research identifying the sciencing attitude of the teacher as key to maximising the scientific opportunities offered through incidental science events.

The value of the teachers' role in both planned and happenstance provocations became apparent over the CAR project. In planned provocations, it was teachers' presence that facilitated the introduction of scientific concepts or enabled further scientific investigations and therefore supported children's thinking and explorations. This was also the case for happenstance provocations as teachers' ability to capture children's interests in what was happening allowed scientific investigations to develop. This finding is in line with Fleer's (2009b) research which found the role of the teacher as mediator was central in bringing together everyday experiences and scientific concepts for young children. An example of such an approach is found within Reggio Emilia centres where "teachers organise environments rich in possibilities and provocations" to invite children to explore ideas and to question and inquire (Edwards, 2002, p. 8). There is an expectation that the teacher will be available alongside the provocation, to scaffold, explore or provide help as needed for children (Edwards, 2002; Stegelin, 2003).

Teachers in this study became more mindful of the resources they brought into the centre and viewing them as provocations meant considering how they could support the resulting explorations. Intentionally, teachers began using resources in a way that provoked, supported, or extended children's interests through thoughtful and planned presentations or activities. Teachers reflected often on how being present to answer and ask open-ended questions of children meant the potential for science experiences with the resources they had set up could be fully realised. With the focus on science, teachers also reflected often on how best to support children's scientific interests whether that was through their pedagogical approaches, the resources they provided or the way they set up the centre environment. Like the research of Inan et al. (2010) the facilitation of science in the centres involved in this study occurred through a strong relationship between a rich, thoughtfully arranged environment and resources oriented towards science investigations and teachers who noticed, recognised, and responded to the science opportunities that came about throughout the day. 


\subsection{The Centre Environment}

Exploring how the environment could best support science was another key consideration in this study. Overall, the qualitative data from the survey responses suggested the centre environment was a key factor that enabled science to occur in their service. Just over half of the respondents (58\%) identified the environment as an important factor in supporting children's scientific experiences, either as an arranged space to facilitate science experiences or a natural space where children could explore and discover. The outside activities such as gardening, finding insects, the sandpit, or water play were identified as ways for science to happen. Inside, respondents noted the environment was intentionally arranged to facilitate science experiences for children.

In contrast, teachers in the CAR study found that while aspects of their centre environment or changes they made were effective in introducing or supporting science investigations, it was their engagement alongside children that took the science experiences to a deeper level. While children did seem to engage with science activities on their own in this study, the findings indicate that the teachers' role was vital in noticing children's science interests and supporting them to explore further. Through intentional teaching strategies, teachers were able to make the science experiences available in the environment become opportunities for children to explore science concepts and acquire new knowledge. Other research has revealed similar findings. Tu's (2006) research identified that children did not show an interest in a science concept on their own as "no incidental sciencing was observed" (p. 250), it was through formal or planned experiences by a teacher that science occurred. Likewise, Fleer (2009b) found that "teacher beliefs about materially rich environment as the main site for learning, promotes learning, but mostly at an everyday conceptual level and not at a scientific conceptual level” (p. 294). It was the mediation of the teacher who took children's "mostly repetitive, random and not conceptually connected" play to "higher levels of thinking" (p. 294). Research by Nayfeld et al. (2011) supports this view through their findings that children "seldom spontaneously engaged in activities in the science area" (p. 982) suggesting that children did not engage in science on their own. In this study children showed an interest in science activities, especially if presented through a provocation, but it was teachers' engagement alongside children that took the interest further and offered deeper scientific learning. 
The findings from the two participating Montessori centres in this study were like the other centres involved. There were however differences regarding the focus on these centre's environments and resourcing. Within the Montessori approach there is an emphasis on the prepared environment; a considered space with resources laid out for the children to access independently (Lillard, 1996). Therefore, the Montessori centres in this study provided a wide range of scientific materials and areas for children to independently explore. As this approach also emphasises independence and cooperation amongst children, I observed many situations where children explored scientific experiences together such as insect hunting, gardening, and feeding the rabbit. Yet opportunities for children's thinking to go beyond what they were doing and to investigate the scientific concepts occurring in that moment were often missed due to the teachers' philosophical position of standing back and not interrupting. Therefore, the Montessori teachers in this study reflected on their role in asking questions and exploring children's thinking further within the philosophical approach of their centre. Teachers felt the Montessori approach encouraged questioning children, but they were careful not to give them the answer or take over their thinking. This was similar to the thoughts of one of the teachers in Rinke et al.'s (2013) study, who believed she needed to go beyond the Montessori-expected inquiry-orientated conversations "to provide greater explanation-based learning opportunities" (p. 1530).

In this study all teachers found the centre environment could be used as a catalyst for science experiences. Using provocations was found to be a valuable approach to introduce resources or experiences, to take advantage of happenstance occurrences and use the centre environment in a more thoughtful and planned way. The teachers planned the curriculum based on children's interests, questions, and ideas. This is like research by Inan et al. (2010), whose findings suggest teachers explore interests and "enthusiasm into a learning possibility through providing a provocative and interactive environment" (p. 1198). These pedagogical practices were synonymous with those found to foster science experiences in this study.

\subsubsection{Adjustments to the Centre Environment}

All teachers in this CAR study considered the centre environment in their action plan and planned ways they could use their spaces effectively or make changes to facilitate more science experiences for the children. Their consideration of their centre 
environment meant viewing what was in the space and how it would be used by children. Pairman and Terreni (2001) argued that the environment is like a third teacher in how it supports children's learning and speaks to children through the messages it conveys "about what they can do, how and where they can do it and how they can work together" (p. 1). In this study teachers considered the way their centre environments could work as the third teacher alongside themselves in supporting science experiences to happen. Small adjustments to the environment provided the stimulus for rich scientific experiences. This use of a flexible environment responsive to the interests of children is discussed by Biermeier (2015) as reflective of a Reggioinspired environment that is relationship-driven, where teachers actively facilitate learning opportunities based on the children's curiosities. Teachers in this study used their centre environments in a similar way, provoking and supporting children's scientific interests through the provocations and activities they provided.

Teachers observed that, while all changes made to the environment were intended to facilitate investigations, if children were not interested or the change remained teacherled, the expected explorations did not eventuate. This highlighted the value in finding a balance where children took responsibility for and interest in the activity and teachers worked alongside them exploring the everyday and scientific concepts involved in the experience.

\subsection{Role of the Teacher}

The teachers' role was a significant contributor to scientific experiences in the centres. In the survey, how interested, confident, and enthusiastic teachers were in science was identified as crucial to science happening in respondents' centres. Survey data indicated many of the respondents thought the role of the teacher was important for science experiences to occur in a centre's programme. Teachers who were interested in science, had some scientific knowledge and were enthusiastic to learn more were highlighted in the survey data as the ones who made science happen. Although a high percentage of the survey respondents felt science happened through child-driven free play within a rich environment, when asked to discuss the teachers' role several respondents identified intentional teaching practices as important to facilitate science experiences. 
Through being involved in the CAR study the participating teachers realised the value of their engagement alongside children. Reflecting on their own role as teachers and on the value of being part of a teaching team with a shared focus highlighted the importance of their role. In addition, the realisation of the significance of their role in turn empowered teachers to become more confident, and more enthusiastic about initiating and supporting scientific experiences in their centre.

\subsubsection{Reflecting on Teaching}

Teachers involved in the CAR process found reflecting on their role as teachers was beneficial. Through critical reflection they analysed their pedagogy and realised how valuable their role as a teacher was in enabling science in their programme. In this study, reflection of what practices worked well to support children's science experiences happened during focus groups, my visits and in reflective journals. This helped teachers identify their role as active participants in children's science investigations. Teachers came to realise that their job was to teach and that their intentional teaching practices meant they were the ones who introduced or opened doors to new science knowledge for children. They were the link between the resources in the centre and how children used them and what they gained from them. They brought provocations alive for children and it was appropriate for them to direct children's learning through the language they used and the resources they provided. This study helped teachers realise the valuable role they had to be active constructors of experiences, and therefore the centre's curriculum, alongside children. This reflects research by Alvestad et al. (2009) who found teachers' understandings of their implementation of curriculum shifted away from a passive child-oriented model to new ways to co-construct curriculum with children.

In this research the CAR process facilitated critical reflection by teachers of their role as teachers. They realised the value of being a teacher. This is in line with similar studies from Fleer and Hedegaard (2010), Hedges (2014), Krieg (2011), and Siraj-Blatchford (2009) who have stated that the re-positioning of teachers as active partners alongside children in co-constructing knowledge together should be a central tenet of ECE pedagogy. 


\subsubsection{Role of the Teaching Team}

As discussed in the previous chapter, many teachers noted that their involvement in this research and engaging in CAR was beneficial for themselves and their teaching team. They reflected that working alongside other teachers also interested in and focusing on science was hugely enabling for them. Teachers found the mutual support, having regular discussions about science and what scientific things children were interested in meant they were able to brainstorm together and identify how they could all support children's interests. This was one of the three key findings in Edward's (2010) study of how teachers support children's scientific learning; namely using the "collective knowledge and support of the teaching team as a deliberate teaching strategy" (Edwards \& Loveridge, 2011, p. 31). Other NZ research has emphasised how collaborative relationships amongst teaching teams in ECE centres can support learning more about the scientific interests shown by children in their centre (Bond et al., 2010; Jordan, 2010). In this study this support extended to practical support such as noticing when a teacher was engaged with a child or children, ensuring they were uninterrupted and able to capture the teachable moment and take it to its full potential. Additionally, building on research by Jordan and Smorti (2010), teachers in this study reflected on the value of being part of a team with a shared passion for viewing their practice through a science lens, noticing science more readily in their centre, having a shared approach to teaching science and supporting each other's scientific inquiries.

\subsection{Chapter Summary}

This research found a shift in teachers' pedagogical practices was key to facilitating scientific experiences in their centres. Using intentional teaching practices such as questioning, sustained conversations, and scientific language helped foster a culture of inquiry amongst the teaching team and children. Teachers' strong relationships with children were significant in aiding their intentional engagement. These relationships helped them access other funds of knowledge within their centres' community. Documentation of children's experiences helped acknowledge and make visible the scientific concepts they explored, as did group times and teachers' planning. Using provocations was another enabler of science in the centres. Teachers found their planned provocations were valuable in bringing in new knowledge or to support and extend current interests amongst children. Their role in being alongside these 
provocations was however key, as was their role in capturing the opportunities happenstance provocations offered for scientific experiences.

During this study teachers became more conscious of their use of the centre environment to support science; either through adjustments to the physical layout, in what manner they brought in new activities, or how they made the most of the space. Teachers discovered being more intentional and co-constructing knowledge alongside children helped children explore science ideas afforded by the environment to a greater depth. Consequently, teachers found reflecting on their practices and the resulting shift in their pedagogical approaches highlighted the value of their role as teachers; 'being a teacher' is a concept that emerged throughout the findings of this study. The next chapter examines the other key enablers and challenges to scientific experiences that occurred through this CAR study. 


\section{Enablers and Challenges to Scientific Experiences}

\subsection{Chapter Overview}

This chapter seeks to answer the final sub-question by discussing the enablers and challenges to facilitating scientific experiences in ECE centres involved in this research. Referencing the research findings and relevant literature this chapter explores the role of curriculum documents, use of ICT, animals, and resources such as books, nature or science tables, and science materials have in enabling science. In contrast there were challenges identified during this study that created barriers or difficulties for teachers. These challenges included: the age range of children in the centre; routines; teacher-tochild ratios; and non-contact time, and these are explored alongside relevant literature later in this chapter.

\subsection{Enablers}

There were a variety of enablers that were found to either provoke science investigations or support children's explorations of their scientific interests. In the survey $48 \%$ of respondents suggested specific science resources, such as magnifying glasses, magnets, and compasses, were important for facilitating science experiences. Other materials identified were books, use of the internet and resources to help support teachers' knowledge or provide ideas of what to do. Activities in the outside environment were seen to be another way to support science, for instance water play. Also, when asked what would support scientific learning, $73 \%$ of respondents indicated curriculum resources would be very helpful and extremely helpful.

Teachers in the participating CAR centres also discussed what they thought enabled science in their centres and how they used them. The following sections outline each of the factors that teachers felt enabled science experiences in their centres. Each teaching team explored how curriculum documents and other articles might support them, in what way they used ICT and the role of animals in their centres. Additionally, focus groups and conversations reflected on ways in which teaching teams used excursions and resources. 


\subsection{Curriculum and Other Guiding Documents}

As discussed in chapter 2, the original version of Te Whäriki (MOE, 1996) was critiqued for its lack of direction in how to support science within ECE, giving little guidance on how to teach and what to teach (Hedges \& Cullen, 2012). In this CAR study I therefore provided teachers in each centre with documents I thought could support and give them direction on how they could enable science in their centres. I offered a range of scienceoriented documents in the form of curriculum guidelines such as the NZ Curriculum: Science (MOE, 2007), research reports including It's a Bugs Life (Browne \& Te Papa, 2016), and relevant articles, which they could use in their centre as they saw fit.

\subsubsection{The NZ Curriculum: Science}

The NZ Curriculum: Science has very clear objectives and guidelines for what science concepts children could explore as they progress through school. Levels 1 and 2 are designed for children aged 5-7-years-old and provide a comprehensive outline of science concepts relating to the five learning areas: living world, physical world, material world, planet earth and beyond and the overarching strand the nature of science, that young children can explore and achieve. Many of the concepts are scientific ideas that children in ECE explore daily and could easily be investigated and understood by young children within their ECE environment. For this reason, I saw the achievement objectives for these two levels as useful guidelines for science experiences teachers could facilitate in their centre. All teachers were shown the curriculum but only a few teachers found them useful for activities they could introduce to extend children's interests or for planned science investigations.

\subsubsection{Research Reports}

It's a Bugs Life (Browne \& Te Papa, 2016) was suggested to all centres as a resource worth exploring. Teachers from all the CAR centres used parts they felt were relevant for them. It provides a section on the scientific process outlining the five science capabilities, this was discussed by teachers with me on several occasions when I visited. It's a Bugs Life provided a comprehensive outline of how to use the science capabilities to foster science experiences and have children explore ideas in a scientific way. Gerde et al. (2013) have suggested a similar approach; they recommend including the scientific processes of observing, asking questions, generating hypotheses and 
predictions, experimenting, summarising, or analysing data, communicating discoveries, and then asking a new question to show teachers "how to teach science that supports children's development" (p. 315).

As the CAR process progressed, discussions with teachers indicated the areas they wanted to explore further or needed support with. I sourced articles that I thought might be beneficial for them. For those working with toddlers, I suggested an article by Sikder and Fleer (2014), which presents the findings from their research investigating how everyday activities and play at home could facilitate the development of scientific concepts in children under 3-years-old. It provided ideas of how science could be found in the everyday activities young children do in an ECE centre. Teachers in this study found this article particularly helpful, and for teachers in Kowhai it helped them move from seeing science as only happening through experiments to recognising its occurrence in the daily activities toddlers were doing with and alongside them in their centre. Another article, by Hedges and Cooper (2018), was beneficial for both Kowhai and Ngaio teaching teams as it provided an overview of how to use relational playbased pedagogy to extend children's thinking. This supported many conversations teachers from both centres had with me about intentional teaching pedagogy to support science experiences. Overall, teachers in this study found the information I provided useful for them to use within their teams.

\subsection{Use of ICT}

Using ICT to assist science experiences was discussed often during conversations and the focus groups. Five of the six centres in this study used ICT to support science during investigations. Teachers used search engines in various ways to access further information for science investigations within their centres; sharing videos to the whole class during mat-time or searching via tablets with one child or a small number of children to explore information together. According to Uçar (2015), searching for information is the main use of technology in schools and ECE, although younger children are limited by their language skills and therefore reliant on teachers to assist them.

Again, the role of the teacher was highlighted in this CAR study through their facilitation of searching for information using ICT. Teachers' scaffolding and construction of 
knowledge with the children was vital. This supports research by Stephen and Plowman (2008) who emphasised the value in teachers scaffolding learning through "guided interaction" alongside children when working with ICT (p. 653). It also reinforces a recent survey of tablet use in Sweden which found 46\% of ECE teachers used tablets to learn collaboratively alongside children (Otterborn et al., 2019).

\subsection{Animals in the Centre}

If centres in this research had animals, these were often sources of scientific experiences, especially if the care of them involved children. Care of animals, feeding or cleaning their habitat often prompted discussion about them and their needs. When a teacher needed to be involved in the task, these conversations would go deeper and extend the children's prior knowledge. In this study some animals came into the centre environment through happenstance provocations, and these experiences prompted much exploration of their needs, and involved co-construction of knowledge between both researcher, teachers, and children. An analysis of research looking at the role of animals in ECE led Bone (2013), drawing on the concept within Reggio Emilia of the environment as the third teacher, to contend that animals could be reconceptualised as "the fourth educator in early childhood settings" (p. 57). She argued, based on various research findings, that there are many pedagogical possibilities in having animals in ECE environments, for instance through their role in educating about the cycle of life, encouraging love of the natural world and as emotional companions and teachers of life and love. This was certainly the case in the experiences children had with animals in this study.

\subsection{Excursions}

Taking the children on excursions outside the centre was found to be an enabler of science occurrences and an opportunity to extend their interests through new experiences. Walks to areas within the community prompted investigations into various animals and their habitats. Teachers in this study saw a significant value in excursions and often mentioned the opportunities for scientific investigations that were provoked. However, exploration of how to make more use of these possibilities did not eventuate over the CAR. Similarly, research in Sweden found excursions offered by three preschools provided "opportunities to experience and learn about science" (Sundberg et 
al., 2016, p. 571), yet the findings indicated how teachers made use of those incidents influenced the engagement of children.

In this study some excursions were more intentional and provoked planned investigations or extended children's inquiries. Teachers used excursions to support children's interests and provide first-hand experiences and chances to gain new knowledge for children's various inquiries. This approach is like the research undertaken by Hedges (2007) who investigated the use of excursions to explore children's interests. Hedges (2005) has argued for the value of well-planned excursions in offering experiences that extend children's interests through dialogue and the support of teachers' own knowledge suggesting that they also afford chances for adults and children to "co-construct science knowledge in meaningful contexts" (p. 15).

One centre, who had children stay until 6-years-old, initiated a regular bush walk into the local bush area for each class's group of 5-year-olds. Children had access to a creek, an area where they could build shelters and explore the natural environment. The intention was to create a place-based educational experience, where children connected with their local environment on a regular basis. The teachers in Torquati and colleagues' research discovered much the same; the best way to support children's learning in nature came via hands on experiences, cultivating curiosity and respect of their environment and exploring the cyclic changes that happen somewhere they felt connected to (Torquati et al., 2013). The choice to give older children experiences beyond their centre's gates corresponds to a large body of research arguing the benefits for children experiencing diverse natural spaces: by revisiting locations to form deeper connections, offering risk-rich opportunities, and less adult defined spaces which in turn offer multiple possibilities for children to explore their interests (e.g., Campbell et al., 2018; Cooper, 2015; MacQuarrie et al., 2015).

\subsection{Resources}

Each centre participating in the CAR was able to resource their centres in a variety of ways, with some having access to resources more easily than others. Furthermore, each centre identified how best to facilitate science experiences through the resources available in their settings. How they did so was influenced significantly by the context of 
their centre, the resources they already had available, their ability to buy more, and the contribution of their community.

\subsubsection{Books}

All centres identified the value of books in supporting science experiences, either through an area for nonfiction books available to children or providing nonfiction books to support interests occurring at the time. Teachers provided books to support scientific activities that they had set up. They found having books readily available when exploring scientific concepts with children meant they were able to do so more confidently. As a resource, nonfiction books were found to be a significant factor in initiating and supporting science investigations in this study. This supports two studies that looked at children's literature and its influence in teaching science. Saçkes et al. (2009) found their review of appropriate children's science literature showed that these provided a "unique opportunity for introducing science concepts in the early years" (p. 421). Similarly, Mantzicopoulos and Patrick (2011) ascertained science picture books allowed children to engage with scientific language and concepts. They argued books are most effective for this if there is discussion and chances to re-visit the concepts often with children. Mantzicopoulos and Patrick also emphasised the teachers' role through "sustained engagement" with science books fosters "children's vocabulary, conceptual development, comprehension and content knowledge" (p. 274). As was the case in this CAR study the value of the books was accentuated when teachers were able to facilitate engagement with them for children.

\subsubsection{Nature or Science Tables}

Using a nature or science table to introduce science topics into the centre provided a great way for families to contribute scientific discoveries they had made at home. Documentation through photos allowed children to revisit what they had found.

There is very little research specific to nature tables in ECE. Research in the UK by Tomkins and Tunnicliffe (2007) did explore children's responses to a display of natural objects on a nature table. Two different age groups (ages 5-6-years and 9-10-years) were asked to choose three objects from the 13 shown to them and were interviewed about them. The results indicated some key reasons why children chose what they did: the animacy of the object, children's prior knowledge, and their interest and wonder to 
find out more about the object. Tomkins and Tunnicliffe (2007) felt the initial findings showed the value in having natural objects available for observation and to develop "children's knowledge, language and communication skills" (p. 155). A key part of the methodology of this research was the engagement of the researchers in firstly introducing (but not naming) the objects to children, participating in a sustained conversation about the object in an interview, then using a questionnaire to find out how much the child knew about the object. As a mechanism to introduce new scientific knowledge or make links between children's prior experiences and new understandings, Tomkins and Tunnicliffe's research certainly indicates the value of well thought out displays on nature tables. Their research clearly showed, and they therefore argued, that teachers should explore the objects with children. This study found similar results with teachers' needing to participate alongside children as they explored various science objects.

In this CAR research some centres discovered that as they noticed science within the daily activities happening throughout the centre their need for a dedicated science table was no longer necessary. In addition, the study found the value of objects to facilitate science experiences came about through the engagement of teachers. It was through their relationships with and knowledge of children at their centre that they were able to ensure the objects provided opportunities for children to share what they already knew and to explore new scientific knowledge and understandings. In this study, as discussed in the previous chapter, these opportunities often came via provocations teachers set up in their centres.

\subsubsection{Science Resources}

Discussion within the CAR study occurred around science resources for centres; exploring what sort of science equipment would be useful and how to make it available to children. For example, all centres had magnifying glasses which were well used and therefore often scratched and ineffectual. To avoid this happening to new ones, one centre gave children clear instructions on how they were to be used and why, and provided a place for them to live on a shelf. This encouraged children to look after them and use them appropriately for science investigations. 
While the resources available varied from centre to centre, their effectiveness in facilitating science experiences for children rested with the way teachers utilised them or created a culture of inquiry around them. Predominantly teachers found provocations, with their presence alongside them, to be the most influential way to bring in resources to extend children's interests or to bring in new scientific experiences. As discussed in Chapter 2, Section 2.6.2, literature specific to science resources in ECE was difficult to find. Like the findings in this study, Tu's (2006) research indicated that "effectively utilizing the science materials is more important than just having science materials available in the classroom" (p. 250). Similarly, research by Nayfeld et al. (2011) supports this through their "baseline observations show[ing] that the mere presence of science materials ensures neither independent exploration of them nor resulting learning from them" (p. 985). They therefore concluded that teachers were critical to introducing science areas and equipment to children and to ensure their resulting engagement with resources were valuable learning experiences (Nayfeld et al., 2011).

\subsection{Challenges}

Respondents to this study's survey felt teachers' lack of knowledge, confidence and/or enthusiasm for science was a factor influencing a low level of science engagement in their centres. The challenges identified by the centres involved in the CAR are outlined next and were similar to the issues identified in the survey, although teacher knowledge, confidence and enthusiasm was not a factor identified by teachers participating in phase two of this study. Over the CAR phase of the study the challenges identified were structural issues such as mixed-age settings, teacher-to-child ratios, the number of teachers within a centre and regulations surrounding outings with children. Furthermore, respondents saw a lack of time for teachers to observe children, respond to their interests, document, and then follow up those interests as influential in the lack of science experiences for children in their centre. A lack of time and opportunity to unpackage the curriculum documents or research reports given to each centre was identified as a barrier to teachers engaging with them and realising their potential to influence their programmes. Additionally, a lack of funds meant a limitation on the resources they could have available. 


\subsubsection{Mixed-age Settings}

In the CAR study, teachers in two centres found the age range of children in their centre affected their ability to best meet the needs of the older children's interests and hold sustained engagements with them. At Kanuka, with 20 children, teachers reflected that the range of behavioural and learning needs amongst children meant it was a challenge to have uninterrupted time with one child or small groups to co-construct or engage in sustained shared thinking over an area of interest. If one teacher was outside, one changing nappies, and one inside, they all needed to be available to react to any incidents that may occur. They found this meant it was difficult to meet the interests of all children, engage in sustained investigations with them and therefore cultivate a culture of inquiry in their centre over the CAR study.

The other centre, Ngaio, with 45 children, was busy with children engaging in a variety of activities both inside and outside with teachers moving between the areas where they were needed. Teachers felt their sustained engagements with older children were often interrupted by younger children, or activities such as looking through a microscope became compromised when trying to accommodate the range of abilities when younger children were involved. The whole teaching team reflected on this and so a solution was found during their teacher only day to set aside a room especially for older children to explore activities and engage with concepts to a greater depth uninterrupted.

These difficulties in supporting children in their centres due to their range of ages and needs resembled findings by Duncan et al. (2006) who explored issues around children under 3-years in kindergartens. Teachers in their study identified the challenges of having less time to engage with individual children or in small groups, being in a supervisory role rather than as an educator and being interrupted by the younger children and their needs. They also talked about when they were interrupted, they struggled to return to the original child they were engaged with, so the moment was often missed. Teachers in this study identified that constant interruptions, from children, other staff, or phone calls, was a significant threat to their ability to sustain intentional teaching moments or to return to them. This sentiment was also expressed by teachers in research investigating intentional teaching practices in Australia (Leggett \& Ford, 2013). 
While research investigating mixed-age settings is limited, studies have examined the impact these have had on children's development and learning. For example, Rouse's (2015) study looked at one full day-care centre in Australia with a mixed-age area outside for the 125 children in their care. There were a few concerns raised regarding the safety of babies and toddlers in the space, but Rouse concluded that these concerns could be mitigated and ensure the benefits of having babies, toddlers and older children together would be realised, a finding also identified by others (e.g., Di Santo, 2000; McClellan \& Kinsey, 1999; Rameka \& Glasgow, 2015).

In general, research on mixed-age settings views them as beneficial for children, especially if seen through a sociocultural lens (e.g., Edwards et al., 2009; Fagan, 2009). For the teachers in the two mixed-age centres the challenges highlighted by this research were situated within approaches that sought to view children's learning through the curriculum framework of Te Whäriki (MOE, 2017), and within a philosophy that emphasised the values of community and placed-based learning, and so they too were supportive of mixed-age environments. However, there were still challenges for teachers to support explorations with children through sustained engagements without being interrupted by the younger children's needs.

\subsubsection{Routines}

An extra challenge the Ngaio teachers raised was the demands of their centre's daily routines and their impact on times when teachers were engaged with children in an activity. The requirement to meet the needs of their centre's routines often presented challenges to teachers' commitment to sustained conversations and engagement with children's scientific experiences. The impact of workplace (such as breaks and rosters) and programme routines was felt by the Kowhai teachers who often discussed the demands of the extra duties they needed to attend to throughout the day which meant one teacher seemed to be constantly unavailable. They felt they therefore struggled to engage with children in sustained conversations or follow through with an investigation.

In this study the struggle some teachers had with routines in their centre's daily programme and workplace routines is described well by Nuttall and Edwards (2004) who argued that 'routine events 'interrupted' teachers' attempts to capture and build upon the emergent nature of children's interests" (pp. 15-16). In addition, the findings 
support Nuttall's (2003) research which looked at the influences on how teachers construct their role within the ECE curriculum. She noted a "persistent tension" between teachers' roles as “'active supporter of children's learning' and 'enforcer of children's compliance to centre routines'" and that the duty roster influenced a practice where "facilitating 'children's play and learning' is what teachers do between routine events" (p. 28, italics in original).

\subsubsection{Teacher-to-child Ratios}

One centre, Kanuka, had a high teacher-to-child ratio of 1:6 or 7 but due to the wide age range and needs of the children, there were not enough teachers to support prolonged sustained thinking with an individual child or a small group without being interrupted. A large longitudinal study in England showed that sustained shared thinking was more likely to happen when teachers could work one-on-one with children or in small groups (Sylva et al., 2004).

The experience of the Kanuka teachers supports research by Purdon (2016) who also found teachers identified numerous hurdles to their ability to facilitate sustained shared thinking. In her study teachers noted challenges such as teacher-to-child ratios or not enough staff, not enough time, a busy environment, others distracting, and a lack of understanding and support from other staff.

The demands on teachers' time were found to be significant challenges to enable sustained engagements in science experiences in the centres in this study. This was also found in studies by Edwards (2003a) and Nuttall (2004). Drawing on their separate studies, Nuttall and Edwards (2004) conclude that there were significant influences on how curriculum was enacted in NZ ECE centres and Australia. They argued that teachers use "professional discrimination" (p. 17) when making decisions about curriculum in their centres; using their knowledge and understandings of teaching and learning, and then negotiating the demands of structural features of ECE such as teacher-to-child ratios, group size and routines to put those ideas into practice.

Similarly, in Mahoe's sessions for younger children the increase in the number of children who needed help and no additional teacher meant teachers were busy either attending to nappy changing and toileting or sitting with children at the kai table. This impacted their ability to facilitate meaningful or sustained science experiences in those 
sessions. This finding builds on research which investigated the increase in group size in kindergartens and found that when the number of children increased but the number of teachers remained the same, the impact for teachers was significant. Teachers mentioned constant interruptions, having less time to work with children or in small groups, and being pulled in many directions. Consequently, their job became supervisory and they felt "less effective as teachers" (Renwick \& McCauley, 1995, p. 22).

\subsubsection{Lack of Non-contact Time}

The amount of non-contact time was discussed by all teachers in the CAR although the impact varied between different centres. Teachers at Matai, Kanuka and Mahoe, found the amount of non-contact time available to them meant they were often able to have discussions as a teaching team. This was because their session schedule allowed for time at the end of the day, or with just two-three teachers in their teams it was easier to catch up on the science experiences that had happened or interests that needed to be followed up.

At Kowhai, the lack of non-contact time for each teacher and time to meet as a teaching team was a significant challenge to their ability to support science experiences in their centre. Using their 2 hours per week of non-contact time to keep on top of learning stories and then be able to find or make resources, prepare the environment, or extend their own knowledge to then better support children's science interests and investigations was near impossible. Likewise, the opportunity to reflect and discuss as a team was limited and affected their ability to support each other, to consider how they fostered science as a team, and to ensure there was consistency and continuity in the experiences they offered. The value in meeting to participate in the CAR was identified by teachers across all centres and highlighted for many the importance of being able to meet regularly as a team. This time together allowed them to discuss children's interests and how they could best nurture these in their programme and how they could support each other in doing so.

Kowhai's 2 hours per week was the same as the average amount of paid non-contact time per week found across ECE in research by Meade et al. (2012), which also found this time was easily filled with planning and assessment tasks. Other research had comparable results, with kindergartens indicating more than 3 hours a week, and ECE centres, home-based, and playcentre indicating none or up to 3 hours per week 
(Mitchell \& Brooking, 2007). Further research by Mitchell $(2008,2011)$ concluded that centres which were rated as "low quality" had teachers who "had either one to three hours or no non-contact time per week" and a staff meeting once a month meant there was little opportunity for planning, assessment or team discussions about children or their programme (2011, p. 74).

The teachers at Ngaio reflected that limited opportunities for them to gather as a teaching team meant it was a challenge to share what science they had been involved with and therefore be able to support each other well. This was found to be the case in studies by Cherrington and Wansbrough (2007) and Grey (2011) which also showed the difficulties teachers had in finding time to get together regularly to reflect on and discuss their practice. Grey (2011) argued the time set aside for teachers to engage in professional dialogue was important "for collaboration to enrich their teaching practices" (p. 26).

\subsubsection{Lack of Support to Engage with the Documents}

While curriculum documents and/or research reports were used in various ways by teachers involved in the CAR, they reflected during focus groups that they probably could have used them more. The consensus from most of the teachers was engaging with the documents and exploring how to use them would have been more likely if they had investigated the documents together as a teaching team.

Research indicates that when teachers are given instruction in how or what to teach regarding science their confidence and knowledge of NOS increases, which in turn affects their teaching of science in practice (Bulunuz, 2012; Heap, 2007; Piasta et al., 2015). Similarly, Burgess et al. (2010) note that PLD supporting a curriculum initiative is a factor in teachers' engagement and implementation of that project. On reflection, their value may have been better realised by introducing these supporting documents to teachers in this study in a way that enabled them to engage with them and reflect on how they could be incorporated into their practice.

\subsection{Chapter Summary}

This chapter has highlighted what this research identified as the significant enablers of science experiences for children in NZ ECE and the challenges encountered by teachers in the CAR. The survey data identified environments and resources as important factors 
to enable science experiences for young children. Teachers involved in the CAR research explored how curriculum documents, their centre environment and resourcing supported science occurring in their centres through their action plans. For some teachers the curriculum documents and/or research reports I provided were useful. However, exploring them through a group discussion would have perhaps meant better realisation of their value. ICT was helpful in supporting teachers and children to find further information during their science investigations. In general, any adjustments to centre environments that occurred were in response to children's interests, who were often motivated by animals, which became significant sources of scientific investigations and discussions.

Resourcing relied on the centre's financial ability to so. Some centres were able to do this well and so created rich opportunities for science experiences through the resources they provided. Overall, teachers in this CAR study found bringing in science resources that could prompt science experiences via a provocation was the best way to use resources successfully. This meant teachers viewing themselves as a significant participant in the way the resources could be utilised more effectively by children in their centre.

All the CAR centres identified barriers to their efforts to facilitate science experiences for children in their centre. These varied from centre to centre, but a few were seen in more than one centre: non-contact time; time to meet as a team; routines; teacher-tochild ratios; and mixed-age settings were the key challenges identified. For all centres and all teachers, it was hugely valuable to have more than 2 hours a week non-contact time, and time to meet as a team. This was a significant difficulty for Kowhai because of the small amount of paid non-contact time available. Having to negotiate the demands of daily routines and a range of ages and needs in the children in their centre proved to be a considerable issue for Kanuka and Ngaio, with one able to find a solution. Managing the requirements of daily routines in the centre meant teachers having to leave sustained engagements with children, which proved frustrating when trying to explore intentional teaching approaches in their practice. In the following chapter the contribution this research makes to ECE is discussed. The implications from this study and recommendations for areas for further research are also examined. 


\section{Conclusion}

\subsection{Chapter Overview}

This study investigated what resources and practices influence scientific experiences for children in ECE centres. In this chapter the three sub-questions were used to identify the major findings and highlight key arguments of the study. The implications of the study for teachers' practice, their professional learning, for policy directions, and for research are discussed. Following this the contributions of this study to literature and research methodology are presented. The chapter finishes with a discussion of the study's limitations and then outlines suggestions for future research.

\subsection{Major Findings}

This section summarises how the process of CAR and the researcher's role enabled science in the participating centres. Pedagogical approaches used by teachers and the other enablers that increased opportunities for scientific experiences for children are examined. Finally, the enablers and challenges teachers encountered while trying to facilitate occurrences for science are outlined.

\subsubsection{Process of CAR and Researcher's Role}

Involvement in the CAR process was a significant motivator and enabler for teachers in influencing children's scientific experiences. This study highlighted the value in exploring how to facilitate scientific experiences as a teaching team, in their own centre and with a critical friend. Participation in CAR provided a framework that enabled teachers to work collaboratively together. The process empowered teachers to take ownership of the action plan and to set goals specific to their needs. They were supported to critically reflect on their practice with the encouragement and critique of each other and with my contribution as a critical friend. They appreciated the chance to improve their knowledge and skills in teaching science, noted the benefits for children in their centre, and observed the changes they could see in their centre's daily practice.

My presence as a critical friend in their centre on a weekly basis for 12 weeks encouraged teachers to focus on how they could enable scientific experiences for children. Conversations and planning as a teaching team were orientated towards science and following children's scientific interests. Teachers responded willingly to the opportunity to critically reflect on their own practice within their centres. In addition, 
my facilitation kept the busy teachers focussed on their goals. As I often taught alongside them, I demonstrated intentional teaching alongside approaches that encouraged them to critically reflect on their own practice. My support and encouragement and the ability to view their practice with an outsider's critical eye meant teachers gained confidence and professional learning from the process. As a critical friend I opened doors for teachers to critically reflect and shift their practice to more intentional approaches which in turn opened doors to science for children in their centres. My intention was always for the research to be beneficial to teachers as well as providing data for my study. I believe this happened in this study.

\subsubsection{Pedagogical Approaches}

In relation to sub-question two: How do teachers' pedagogical approaches enable children's scientific experiences? the findings of this study suggest the shift in teachers' practice to intentional teaching strategies was the key enabler of scientific experiences in their centre. Teachers' engagement in questioning, having conversations that involved sustained shared thinking, introducing scientific language, opening doors for children to co-constructing and scaffolding new knowledge, and validating children's working theories are all consistent with the intentions of the revised curriculum Te Whāriki (MOE, 2017). As argued by Fleer (2009b), these intentional teaching practices facilitate meaningful and authentic engagement in scientific experiences which result in children moving beyond their everyday understandings to connect with scientific concepts. Through this study these approaches were strengthened or added to teachers' kete of practice. Their attitudes towards science shifted as well. Most teachers were interested in science but lacked confidence to engage with it often. However, the success of their intentional strategies with children increased their confidence and they became more excited about the regular occurrences of science. Overall, the changes in teachers' practice and in their attitude towards science; their wondering and enthusiasm for science investigations, resulted in a growing community of inquiry amongst children. The consequence was children asked questions, wondered, and even identified themselves as scientists. These resulting positive experiences fostered through the CAR study meant an increase in teachers' confidence, capability, and enthusiasm for science. Teachers' strong relationships with children and families was also key to their ability to support and extend children's scientific interests. Knowing children well meant they 
were able to draw on children's funds of knowledge to better understand their interests and how to extend them. This reflects the concept of relational pedagogy where teachers are responsive to the interests of children and facilitate knowledge through scaffolding and mediation.

Introducing and extending science occurrences for children through provocations was an additional strategy teachers found effective. Provocations helped teachers think critically and purposefully about how to best support and extend children's interests in meaningful ways. Happenstance provocations were also found to be valuable in enabling scientific experiences; situations that were not planned, that captured the children's interest and were responded to by teachers. The value and potential of provocations (planned or happenstance) was realised significantly more if teachers worked alongside children as they engaged with it.

In this study teachers found their role was crucial in enabling scientific experiences, either through the intentional strategies they used or being the link between the centre environment and children. It was teachers who realised what opportunities the environment afforded for science. Critically reflecting on their role over this CAR study meant teachers identified their value and their importance as teachers. The study also highlighted the value in being part of a supportive teaching team who were focussed on the same goal, could encourage each other, and on a more practical level protect each other from the demands that could interrupt their sustained engagements with children.

\subsubsection{Enablers and Challenges}

Alongside teachers' intentional teaching strategies, other enablers of scientific experiences were afforded through the centre environment and resources. Scienceorientated resources and nonfiction books, clearly displayed and easily available for children and teachers, helped cultivate and support their investigations. The NZ Curriculum: Science (MOE, 2007) and It's a Bugs Life (Browne \& Te Papa, 2016) provided guidance on how to facilitate science for those that engaged with them. Animals were also a source of scientific experiences, either those already in the centre which required children to be engaged in their care, or animals that happened to come into the centre. They all provided opportunities for questions, discussion, and learning. 
Outside spaces or excursions into the community afforded chances to explore beyond the centre and offered scientific experiences related to the natural world.

Challenges were also investigated through sub-question three. In this study these were found to be: having a large range of ages and needs within the group of children in the centre; the daily routines within the programme; the teacher-to-child ratios; and the amount of non-contact time available to teachers. In those centres with toddlers and young children in the same space, teachers found catering for the variety of demands within that age range affected their ability to best meet the needs of older children's interests and hold sustained conversations with them. Linked to this were the obligations of the daily routines in centre programmes. Teachers found the routines often interrupted sustained investigations with children. The result often being that if they left, children moved onto something else. Both challenges are linked to not having enough teachers available to support those who were involved in sustained shared thinking with one child or small groups. In addition, teachers in centres offering fulltime education and care had limited non-contact time, often as little as 2 hours per week, which meant there was scarcely any time left for planning and preparation for science experiences after fulfilling their regular planning and assessment requirements. Furthermore, meeting once a fortnight did not allow sufficient opportunities for staff to share and discuss with each other how they were supporting science in their practice.

\subsection{Implications of This Study}

Gluckman (2011, p. 1) has highlighted the importance of scientific knowledge with a call for science education to be an "essential element" of the NZ education system so citizens can be scientifically literate and informed participants in society's scientific issues. While Gluckman was arguing for a focus on science in the primary and secondary sectors, I would argue the need is just as important in ECE, especially if many young children's patterns for learning are laid during the early years (Sylva et al., 2010). Therefore, exploring what resources and practices influence scientific experiences for children before going to school contributes to understanding and improving the nature of science in ECE, with possible effects for those children's later science learning.

There are four implications arising from this study. The first is the role of teachers' practice in fostering children's scientific experiences, which was found to be significant. 
The second is teachers' knowledge of science and how to teach science affected their ability to recognise and respond to science opportunities. Therefore, how teachers access this knowledge needs to be examined. Thirdly, this study raises implications for policy in relation to teachers' professional learning and structural issues within ECE. Finally, the implications from this study highlighted the value CAR and the involvement of a critical friend in enabling an increase in science experiences for children.

\subsubsection{Teachers' Practice}

The implications of this study for teachers' practice are significant. The main enabler of scientific experiences for children in ECE is the teacher. Important factors are how they notice children's scientific interests, and how they recognise the value in these interests and where they may have come from. Significantly, intentional teaching strategies mean teachers respond to children's interests and extend them in meaningful and authentic ways. Teachers' shift to making science visible in the everyday practices in their centres was hugely valuable. The authentic nature of science beyond occasional and obscure experiments reinforced the pedagogies teachers were using and emphasised the value in exploring scientific processes as well as scientific knowledge. Using provocations, planned and happenstance, helped teachers think purposefully about how to support children's interests. This study found the potential of provocations was only realised if teachers were present to engage in them alongside children. Working within a supportive teaching team enabled teachers to engage with children for prolonged periods of time without interruptions and therefore extend children's investigations to deeper learning through sustained shared thinking.

Through this study teachers realised the important role they had in helping children work through the scientific process of asking questions, observing, hypothesising, testing, and sharing their findings. This scientific process was a useful guide and helped extend science investigations, so children's inquiries went deeper and often led to increased conceptual learning for children (and teachers).

\subsubsection{Teachers' Professional Learning}

The findings of this study have identified clear implications for teachers' practice. Bringing about changes in pedagogy requires thoughtful adjustments to teachers' initial teacher education and PLD. Overall, there also needs to be an examination of the teachers' role in general, re-positioning teachers as active participants in children's 
experiences and learning in ECE. This has been argued by many NZ academics previously (e.g., Hedges, 2007; McLaughlin \& Cherrington, 2018; Meade, 2002). The need to explore intentional teaching pedagogies in ECE teachers' initial teacher education programmes was also identified. This would position teachers as more active participants in young children's learning, reflecting the shift in the revised Te Whäriki (MOE, 2017) to intentional pedagogies. Additionally, those already teaching in the sector need opportunities to critically reflect on their practice and engage with approaches that forefront their role as intentional mediators of learning experiences alongside children.

\section{Initial Teacher Education Programmes.}

As this study emphasised the importance of intentional teaching practices in increasing the occurrence of science experiences, it is strongly suggested that it is imperative to include intentional teaching strategies in initial teacher education programmes. Regarding teacher preparation, research indicates teachers' completing courses on scientific knowledge and how to teach science positively influences their inclination and ability to teach science (Akerson et al., 2008; Bulunuz, 2012).

This in turn highlights the significance of the teacher in facilitating meaningful scientific experiences for children. Both through intentional teaching strategies capturing children's science interests and through their presence alongside the thoughtful provocations they offer in their centres. Therefore, it would be worth initial teacher education providers considering how their programmes forefront the role of teaching as central to children's learning (Fleer \& Hedegaard, 2010; Siraj-Blatchford, 2008), particularly when previous research indicates a strong prevalence towards developmental theories in NZ ECE initial teacher education programmes (Kane, 2005). To do so would highlight the value of the teachers' role alongside children's learning, and that within a sociocultural-historical approach teachers teaching is valued as much as children learning (Fleer et al., 2009).

\section{Professional Learning and Development.}

This study highlighted the value in creating an opportunity for teachers to critically reflect on their practice and identify the areas they wanted to improve within their own centre. In this study CAR was found to be successful in effecting change in teachers' practices resulting in increased occurrences of scientific experiences. The process of 
CAR provided time where, with the involvement of the researcher, teachers focussed on science and how it could be supported more through changes to their pedagogy, their centre environment, or with additional resourcing. CAR has been identified as a useful method for teachers to critically reflect on their practice with the intention for change and creation of new knowledge (MacNaughton \& Hughes, 2008). Additionally, my role as a critical friend working alongside teachers in this CAR study facilitated collaborative discussion and prompted the teachers to critically reflect on their practice. This has also been found in other CAR studies (e.g., Avgitidou, 2009; Goodnough, 2003; Sigurdardottir \& Puroila, 2018).

Through the CAR cycle of focus groups, reflective journals, my visits, and observational notes, teachers were able to critically analyse what they wanted to change in their own practice or the centre programme. All centres had a child-centred approach to their programme and so for many teachers the change to intentional teaching required a significant shift for them. The CAR process seemed to give them permission to view themselves as teachers and see that they could be active contributors in scientific experiences either through co-constructing knowledge with children or sharing new information with them. The increase in scientific interest and children's ability to grasp scientific language and explore ideas to a deeper level, highlighted the value of teachers' intentional strategies. This meant teachers became more confident with science and they appreciated the validation of their role as teachers. Their participation in the CAR facilitated this, as did my involvement as a critical friend who could encourage and support them.

This study showed that while having available time and a supportive teaching team are a significant influence, it was the process of CAR and the researcher's role as a critical friend that brought about the critical reflection needed to instigate a change in practice. CAR allows researchers to work collaboratively alongside teachers and provide them with support and advice and their expertise is valued by teachers (Avgitidou, 2009; Bruce et al., 2011). The researcher's role as a critical friend allows them to have intimate knowledge of the realities of teachers' everyday tasks and therefore be in a valid position to constructively critique and challenge their practices and encourage change (Hedges, 2010a). 


\subsubsection{For Policy}

The policy implications highlighted by this study are the need for professional learning opportunities for teachers and how structural issues impact on teachers. This study revealed the need for teachers to be able to access appropriate and effective PLD that is empowering and relevant to them and their centre's needs. The structural challenges identified in this study were mixed-age settings, routines, and the teacher-to-child ratios. This study emphasised the need for more teachers to be available for children so uninterrupted and sustained investigations could be enabled, and the demands of daily routines could be mitigated. A reasonable amount of non-contact time was also identified as important to support teachers' time to connect as a team.

\section{Professional Learning and Development.}

A key finding of this study was the value of CAR and a critical friend in increasing the teachers' capacity to facilitate science experiences in their centres. Therefore, exploring how best to deliver PLD in science for teachers in NZ ECE should be considered. In addition, ERO (2021a) highlighted the limited opportunities available for teachers to access PLD in science. Participants mentioned one-off science courses they had attended and reflected on their value in giving them exciting ideas and experiments they could do with children but, once back in their centres, were often difficult to do or were not an authentic fit for their programme. A much more effective option is a switch to PLD that empowers teachers to explore how best to offer science experiences within their own settings and embraces the input of researchers to help critique and guide their investigations, as revealed by this study and others such as Hedges (2007). Using collaborative research such as CAR or PLCs offer mechanisms that give teachers access to a research-based discourse, encourage critical reflection of their practice, and enable them to explore evidence-informed inquiries, all characteristics of effective PLD (Mitchell \& Cubey, 2003).

\section{Ratios and Routines.}

In this study structural issues were highlighted as challenges for teachers. Implementing intentional teaching strategies that would benefit children's experiences and learning was difficult if there were not enough teachers for the number or needs of the children. This raises issues for policy makers. High teacher-to-child ratios, the age range of children, routines and limited non-contact time were all identified as 
detrimental to teachers' efforts to follow an intentional teaching approach. The challenges relate to not enough teachers available in centres to ensure those teachers working with children in planned or spontaneous sustained investigations were not interrupted by the needs of other (often younger) children or the demands of centre routines. These challenges have been identified in previous studies (e.g., Duncan et al., 2006; Leggett \& Ford, 2013; Meade et al., 2012) and so were not a surprise to find in this study as well.

\section{Non-contact Time.}

A lack of non-contact time was a significant issue for some of the teachers who could barely cover their planning and assessment requirements let alone consider and propose other ways they could support or extend children's science interests. While 2 hours per week has been identified as the average in the ECE sector (Meade et al., 2012), more time was available to most participants, who all felt they were able to document children's learning and prepare well for any science investigations planned for the children.

\subsubsection{For Research}

This research used CAR to enable teachers to investigate what practices within their own centre could influence an increase in scientific experiences. This study highlighted the value of CAR for teachers and for this researcher. For teachers, support from a critical friend helped them critically reflect on their practice and consider other teaching approaches. For the researcher, this study provided rich qualitative data through real and rewarding experiences with teachers and children, in their centres, and exploring science in authentic ways.

The researcher's involvement over a long period of time created shared expectations and intentions. The collaborative relationships built between the researcher and teachers formed a trusting community of inquiry and allowed the researcher to ask questions and challenge teachers' assumptions and practice. This provides validation of the role researchers can have in helping teachers transform their practice, through trusting long-term relationships with lasting benefits for teachers and their centre communities. 
During the CAR process I provided access to curriculum documents, research reports, and various journal articles that were relevant to and supported teachers' reflections. Teachers discussed that they only had access to recent research if they were studying or if they attended a course. This raises an issue of whether there is true dissemination of research to teachers, which is something to consider if the expectation is that teachers' practice be informed by recent research. As discussed by Hedges (2007), NZ academics are encouraged to publish internationally, so recent studies are often not accessible to teachers. In this study all teachers appreciated the information provided but wished they had had time to discuss them as a team. Using shared conversations with their peers to connect their experiences to the ideas in the documents or articles would ensure meaningful understanding and knowledge building for them. Therefore, perhaps the method of dissemination of research needs to be reconsidered, such as through workshops and PLD sessions with teaching teams in their sites of practice.

This study provides a useful model for future research of professional learning in the ECE sector, much like the COI programme between 2003 and 2009 and studies such as those by Hedges (2007) and Thornton (2009). Research that has ECE teachers building their capacity as teacher-researchers is a powerful means for transformation of their practice. Professional learning for teachers has been identified as having positive effects on teaching and learning in ECE settings (Meade, 2010; Mitchell \& Cubey, 2003). The key factors reflected in this study and those mentioned above are:

- Teachers who have identified the intentions of the investigation were therefore motivated to reflect on their own practice and seek change.

- Teachers involved in research, analysis of the data and dissemination of the findings felt empowered and confident and were able to articulate any changes to their practice.

- Either the whole (or majority of) the teaching team was involved, and it was situated in their own centre over a long period of time.

- An external advisor or researcher as a critical friend was involved to help facilitate engagement with new ideas and critical reflection of their practice.

- Collaboration with others, reflective journals, critical analysis of data, and challenging conversations exploring theoretical alternatives leads to a change in perspectives and practice. 
Therefore, the implications for research are twofold; researchers with new information need to look beyond academic journals to considering teacher journals or workshop their conclusions with teachers to disseminate their ideas. Or even better, researchers with possible areas for research work alongside teachers to create a collaborative relationship that explores the issue within the teachers' setting. Opportunities for researchers to foster communities of inquiry or PLCs that empower teachers to critically engage with new ideas, transform their practice, and confidently articulate and share that information with others is worth exploring further. Government funding for projects such as this is possible through the TLRI who encourage "collaborative research about teaching and learning" (TLRI, n.d., para. 2).

\subsection{Contributions of This Study}

This thesis makes several contributions, both empirically and theoretically, to the literature on ECE pedagogy, professional learning for teachers, and CAR methodology. Those contributions are the role of the teacher as an active participant and contributor to children's science experiences through intentional teaching pedagogies, and the role of provocations and a science rich environment. The methodological contributions are two-fold: the process of CAR and the role of the researcher as a critical friend.

\subsubsection{To Literature}

Firstly, the study emphasises that science experiences for children can be fostered through intentional teaching practices by thoughtful and interested teachers. A focus on science helps teachers recognise and respond to children's science interests in authentic and meaningful ways. Intentional engagement with children can be fostered with questions, sustained conversations and using scientific language. Teachers feel able to then co-construct and/or share knowledge with children, deepening their learning and taking investigations further. This in turn gives teachers confidence, creates a culture of inquiry within centres where children view themselves as scientists. The role of the teacher as central to the learning and teaching nexus is a significant contribution of this study. A way to increase and support scientific investigations has been proposed by this study that reinforces the importance of sustained shared thinking in engaging with and extending children's thinking identified by Sylva et al. (2010). 
Secondly, this study highlights how teachers see ways to support and extend those interests through adjustments to their centre environment or by bringing in additional resources. Resourcing that is specific to science can be added to environments to provide opportunities to capture children's interests. Additionally, it provides support to the Reggio Emilia practice of using provocations to bring in resources to support children's interests or to stimulate new investigations (Edwards, 2002). This study also reinforces the practice of capturing happenstance provocations as teachable moments and recognising opportunities for teachers to notice the sciencing that may occur in a spontaneous event (Inan et al., 2010).

Thirdly, this study adds to the sociocultural-historical literature through the discussion of intentional teaching practices and the influence of the teachers' role in shifting children's thinking from everyday concepts to scientific concepts. The study emphasises the cultural-historical view that the teacher has an essential role in play-based, child interest-led ECE programmes where sustained shared thinking and the introduction of new concepts is valued. It also shows how teachers' own interests and knowledge can contribute to an ECE programme without hi-jacking or altering children's curiosities and investigations. Teachers co-constructing and scaffolding children's knowledge through intentional teaching practices fits alongside the sociocultural concepts of reciprocal and responsive relationships, and the concept that children's learning leads their development within social interactions with people, places, and things. This pedagogy is expressly outlined in the revised Te Whāriki (MOE, 2017), which therefore places an expectation on the sector to review their practices and explore a shift to intentional teaching to ensure more scientific experiences occur for children.

\subsubsection{To Practice}

The three contributions to literature outlined above all highlight how the pedagogical approaches used in this study led to more rich scientific experiences for children. These approaches contributed to the emergence of a culture of inquiry in the centres of this study. This was evident in children identifying themselves as scientists and alongside teachers, sharing their new knowledge with others and using science terms when doing so. The characteristics that enabled a culture of inquiry to flourish included pedagogical features such as teachers:

- Noticing and responding to children's scientific interests. 
- Using intentional teaching practices to move the science experiences beyond occasional and obscure experiments to exploring scientific concepts and processes in authentic ways.

- Using scientific language, asking questions, wondering alongside children, and having sustained conversations with children to co-construct knowledge or share what they know.

- Encouraging children to use the scientific process of asking questions, observing, hypothesising, testing, being interested in investigating ideas over time, and sharing their working theories and conclusions.

- Purposefully thinking about how the environment afforded opportunities for science - either through spaces in their centre environment like a garden, an outdoor 'wild space' or outside the centre like bush walks.

- Using provocations, planned and happenstance, to extend children's science interests or bring in new explorations.

- Having a supportive team who enabled teachers in the space to engage with children for long periods of time.

This study therefore shows how a culture of inquiry emerges once teachers shift from setting up, standing back, and observing children perhaps learning science through osmosis, to one where they consider the relationship between the child and the environment and play a significant role in opening doors to science knowledge and extending children's science investigations, so inquiries go deeper and lead to increased conceptual learning for children (and teachers). The role of the teachers to facilitate environments that "encourage critical thought, wonder" and "challenge children to explore and become fully involved in a wide variety of learning experiences" has been identified in the indicators of quality outlined by ERO (2020, p. 20)

\subsubsection{Methodological Contributions}

This study highlighted two methodological contributions. Firstly, the involvement in CAR was significant in enabling teachers' critical reflection and changes to their practice. Secondly the role of the researcher as a critical friend working collaboratively with teaching teams helped motivate, support, and provoke their thinking and facilitated their shift to pedagogical approaches that enabled scientific experiences in their centres. 


\section{The Process of CAR.}

An approach to create change in teachers' practice is the methodological contribution of this study. CAR with six centres created data that through collaborative analysis fore fronted key findings that have been outlined in this chapter. The findings alone are noteworthy, but it is also the process of the research that makes this study significant. The active participation of teachers in identifying the areas they wanted to work on, the critical thinking, reflection, and analysis of the data ensured changes that occurred were authentic and relevant to them. The role of teachers as thoughtful researchers of their own practice, critically reflecting in and after the moment, has been endorsed by this study. Additionally, the production of new knowledge of how best to facilitate science experiences in ECE confirms the statement that CAR "inform[s] professional practice with practical knowledge" (MacNaughton \& Hughes, 2008, p. 44).

Working with teaching teams in their own setting meant the benefits of the research were authentic and meaningful for them and the children in their centre. This is one of the features of effective PLD identified by Mitchell and Cubey (2003). Having a group of teachers who know the children and their context well and who come together in a supportive environment ensures "effective teacher education and curriculum development" (Pedretti, 1996, p. 324). The CAR process of this study was an effective way to explore teachers' practice and build trust and a collaborative culture where they supported each other's critical reflection. The increase in worthwhile scientific experiences resulted in richer inquiries for children and created a strong interest in science in their centres. This evidence of more scientific experiences that engaged children and teachers, an increase in wondering (Fleer \& Pramling, 2015) and scientific inquiries meant the teachers could see the effect of the change in their practice. According to Guskey (2002), this is the most effective way to change teachers' attitudes and practice, through the evidence of an improvement in children's experiences and learning.

\section{The Role of the Researcher.}

My involvement in the process (as discussed in chapter 7) was more significant than I had originally thought it would be. The role combined being a researcher who was there to collect data and keep the process moving and being a critical friend who built strong relationships with the teachers. I was a facilitator of the process, their supporter and 
motivator, a teacher who worked alongside them and a challenger who helped them critically reflect on their practice. Like Hedges (2010a), in her study there was a "blurring [of] the boundaries" between my role as a researcher and an expert sharing knowledge with teachers to support their professional learning (p. 300). By moving between researching, PLD, and practice, the data gained can be seen to be more robust and authentic and therefore more likely to influence change (Anning \& Edwards, 2006; Hedges, 2010a). Research indicates teachers gain more from action research when supported by a researcher or facilitator (Ponte et al., 2004).

Visiting centres weekly and engaging with teachers and children meant I was able to spend time understanding the context of the centre, an important element of a critical friend (Costa \& Kallick, 1993). My support and encouragement of teachers built their skills as critical thinkers and fostered their view of themselves as researchers (Goodfellow \& Hedges, 2007). In addition, this study has validated researchers working alongside teachers to model intentional teaching strategies (Anning \& Edwards, 2006).

Collaborative analysis of data through focus groups, reflections, and by bringing all teachers together for a research hui was valuable in creating a sense that the teachers were part of a community of inquiry building knowledge through dialogue and sharing (Wells, 2002). They were being asked to think openly about and discuss their daily practice; "interpreting and re-interpreting their practice so that they can act more 'wisely'” (MacNaughton \& Hughes, 2008, p. 105).

\subsection{Limitations}

As this study was a qualitative case study carried out in one region, the findings are unable to be generalised across the whole ECE sector in NZ. However, by involving six centres which included full-day and sessional, private and community based, mixed-age and over threes there can be some transferability. Many of the solutions (and challenges) found in this study to increase science experiences could resonate for other teachers and they can interpret what might be relevant for their setting. This study will provide food for thought to instigate reflection of teachers' own practices regarding scientific experiences and their teaching pedagogy. Teachers in this study were all interested in improving their science programme and no one indicated that they were afraid or uncomfortable sciencing with children. This may have meant their enthusiasm 
to engage with scientific experiences was likely to be more than most NZ ECE teachers. Nevertheless, the pedagogical strategies of intentional teaching can be applied across all content areas within ECE and therefore the findings can be applicable for all teachers. The focus of this study was enabling science for children in ECE over 3-years-old, however three centres also catered for infants and toddlers. Additionally, only two of those centres had teachers participating in the CAR who worked specifically with infants and toddlers. Therefore, the findings in relation to infants and toddlers are tentative. The shifts in the infant and toddler teachers' pedagogy focussed on finding science in the everyday activities children were involved in and verbalising "I wonder" statements more often to foster a culture of inquiry. These practices could be considered by infant and toddler teachers and open the door to further research that explores practices that increase scientific experiences for children under three.

Furthermore, my inexperience as a researcher and focus group facilitator was evident while transcribing the first focus group and hearing myself talk too much. As an experienced teacher I did find it difficult not to contribute my ideas, I also often wanted to fill the gaps in the discussion. In the focus groups that followed I tried to avoid speaking too much, to avoid influencing their thinking or them seeing me as the expert and not equal to them (Herr \& Anderson, 2015). However, like Avgitidou (2009) and Platteel et al. (2010) I did find my role shifted and my participation was valuable in providing critique and suggestions regarding their practice during later focus groups in the CAR process.

\subsection{Future research}

Research has revealed the value in quality early experiences for children's later learning and in doing so has explored what those quality experiences should look like. More recently the discussion has centred around sociocultural-historical theoretical influences and the implication for teachers' practice. The limitations of this study suggest there are areas that need further investigation in relation to scientific experiences for children in ECE.

Considering those limitations and the findings of this study the following areas for research could be considered: 
- Researching mixed-age settings and the implementation of intentional teaching practices such as sustained shared thinking.

- Facilitating scientific experiences for infants and toddlers.

- Investigating science within cultural contexts, specifically alongside te ao Māori practices.

- Implementing curriculum documents and/or research reports: unpackaging them before they land on the shelf.

- Analysing how technology, such as tablets, can be integrated into the science experiences. This study just touches on how ICT could be used to enable science in ECE.

\subsection{Final word}

This study has shown that facilitating more scientific experiences for children in ECE can happen easily. A focus on science with enthusiastic, engaged, and intentional teachers can increase opportunities for authentic science experiences that are connected to children's interests and their wonderings and desire to make sense of their world. As stated by French (2004) "science is privileged as a content area in the preschool classroom because it fits so naturally with young children's natural way of processing experience and their inherent curiosity about the functioning of the everyday world" (p. 140). Therefore, science should not be considered a scary thing or content that is beyond young children, it should be a part of everyday investigations and noticed often in children's interests and explorations of their world. Being thoughtful and purposeful in their intentional teaching practices means teachers can notice, recognise, and respond to children's scientific interests in authentic and meaningful ways. They can provoke new interests and share information to help deepen children's scientific knowledge. The interactions between the child and the centre environment "through [emphasis added] the teacher ... provides the best opportunities for maximising the learning of science" (Fleer \& Pramling, 2015, p. 201).

To conclude, this study sought to find out what resources and practices influence scientific experiences for children in NZ ECE centres. The findings from each of the six centres involved in this study highlighted the role of the teacher in:

- recognising and supporting children's scientific experiences, 
- fostering their engagement through intentional teaching practices; questioning, using scientific language, and sustained shared thinking,

- supporting and extending their interests through provocations, adjustments to the centre environment and introducing scientific resources,

- co-constructing and opening doors to new knowledge alongside children in authentic and meaningful interactions.

In addition, it is hoped the method of exploring how to facilitate more science experiences in ECE through CAR with a critical friend will provide a framework for future ECE PLD. It is vital that teaching teams access professional learning about pedagogy that foregrounds the teacher as an active participant in children's ECE experiences, both in science and other content areas. 


\section{References}

Abd-El-Khalick, F., Bell, R., \& Lederman, N. (1998). The nature of science and instructional practice: Making the unnatural natural. Science Education, 82(4), 417-436.

Akerson, V., Buzzelli, C., \& Donnelly, L. (2008). Early childhood teachers' views of nature of science: The influence of intellectual levels, cultural values, and explicit reflective teaching. Journal of Research in Science Teaching, 45(6), 748-770. https://doi.org/10.1002/tea.20236

Alan, P., Peter, M., \& Gunilla, D. (2007). Beyond quality in early childhood education and care: Languages of evaluation. Taylor and Francis. https://doi.org/10.4324/9780203966150

Alexander, P. (2000). An investigation into teacher and student teacher confidence in their own understanding and abilities to teach science and technology effectively in primary schools in Northern Ireland [Unpublished master's thesis]. Queen's University of Belfast. https://repositorio.leon.uia.mx/xmlui/handle/2428/6009

Alvestad, M., Duncan, J., \& Berge, A. (2009). New Zealand ECE teachers talk about Te Whāriki. New Zealand Journal of Teachers' Work, 6(1), 3-19.

Amankwaa, L. (2016). Creating protocols for trustworthiness in qualitative research. Journal of Cultural Diversity, 23(3), 121-127.

Anning, A., Cullen, J., \& Fleer, M. (2009). Early childhood education: Society and culture (2nd ed.). SAGE.

\section{http://site.ebrary.com/lib/vuw/docDetail.action?docID=10546205}

Anning, A., \& Edwards, A. (2006). Promoting children's learning from birth to five: Developing the new early years professional. Open University Press. https://ebookcentral-proquestcom.helicon.vuw.ac.nz/lib/vuw/detail.action?docID=287858\&pq-origsite=primo

Areljung, S. (2019). Why do teachers adopt or resist a pedagogical idea for teaching science in preschool? International Journal of Early Years Education, 27(3), 238253. https://doi.org/10.1080/09669760.2018.1481733 
Avgitidou, S. (2009). Participation, roles and processes in a collaborative action research project: A reflexive account of the facilitator. Educational Action Research, 17(4), 585-600. https://doi.org/10.1080/09650790903309441

Backshall, B. (2016). A culture for science in early childhood education: Where cultures meet cultures [Unpublished doctoral thesis]. University of Waikato. https://researchcommons.waikato.ac.nz/handle/10289/10702

Batchelar, S. (2016). Intentional teaching in New Zealand early childhood education: Aspirations, decisions, and actions [Unpublished doctoral thesis]. University of Auckland https://researchspace.auckland.ac.nz/handle/2292/28107

Bennett, J. (2005). Curriculum issues in national policy-making. European Early Childhood Education Research Journal, 13(2), 5-23. https://doi.org/10.1080/13502930585209641

Biermeier, M. (2015). Inspired by Reggio Emilia: Emergent curriculum in relationshipdriven learning environments. Young Children, 70(5), 72-79. https://search.proquest.com/docview/1789779366?accountid=14782

Birbili, M. (2019). Children's interests in the early years classroom: Views, practices and challenges. Learning, Culture and Social Interaction, 23, 1-13. https://doi.org/https://doi.org/10.1016/j.lcsi.2018.11.006

Bloch, M. (1991). Critical science and the history of child development's influence on early education research. Early Education and Development, 2(2), 95-108. https://doi.org/10.1027/s15566935eed0202 2

Bond, L., Cooper, R., Jordan, B., Sargent, J., Smorti, S., \& First Years Preschool Over-Twos Teaching Team. (2010). Fearless science: Engaging community. In A. Meade (Ed.), Dispersing waves: Innovation in early childhood education (pp. 57-61). NZCER Press.

Bone, J. (2013). The animal as fourth educator: A literature review of animals and young children in pedagogical relationships. Australasian Journal of Early Childhood, 38(2), 57-64. https://doi.org/10.1177/183693911303800208 
Boud, D. (2001). Using journal writing to enhance reflective practice. New Directions for Adult and Continuing Education, 90, 9-17.

Braun, V., \& Clarke, V. (2013). Successful qualitative research: A practical guide for beginners. SAGE.

Brennan, M. (2007). A culture of tenderness: Teachers' socialisation practices in group care settings. European Early Childhood Education Research Journal, 15(1), 137146. https://doi.org/10.1080/13502930601089950

Brenneman, K. (2011). Assessment for preschool science learning and learning environments. Early Childhood Research \& Practice, 13(1), 1-9. https://ecrp.illinois.edu/v13n1/brenneman.html

Broström, S. (2015). Science in early childhood education. Journal of Education and Human Development, 4(2(1)), 107-124.

https://doi.org/10.15640/jehd.v4n2 1a12

Broström, S., Johansson, I., Sandberg, A., \& Frøkjær, T. (2014). Preschool teachers' view on learning in preschool in Sweden and Denmark. European Early Childhood Education Research Journal, 22(5), 590-603. https://doi.org/10.1080/1350293X.2012.746199

Browne, R., \& Te Papa. (2016). It's a bug's life. How to help young children do science. Museum of New Zealand Te Papa Tongarewa. https://www.tepapa.govt.nz/learn/for-educators/teaching-resources/its-bugslife-science-resource-for-ece-and-primary

Bruce, C., Flynn, T., \& Stagg-Peterson, S. (2011). Examining what we mean by collaboration in collaborative action research: A cross-case analysis. Educational Action Research, 19(4), 433-452. https://doi.org/10.1080/09650792.2011.625667

Bruner, J. (1983). Child's talk: Learning to use language. Oxford University Press.

Bruner, J. (1996). The culture of education. Harvard University Press.

Bulunuz, M. (2012). Developing Turkish preservice preschool teachers' attitudes and understanding about teaching science through play. International Journal of 
Environmental and Science Education, 7(2), 141-166.

http://helicon.vuw.ac.nz/login?url=http://search.ebscohost.com/login.aspx?dir $\underline{\text { ect }=\text { true } \& \mathrm{db}=\text { eue } \& A N=88857757 \& \text { site }=\text { ehost-live }}$

Burgess, J., Robertson, G., \& Patterson, C. (2010). Curriculum implementation: Decisions of early childhood teachers. Australasian Journal of Early Childhood, 35(3), 51-59. https://doi.org/10.1177/183693911003500307

Burns, M., Kidd, K., Nasser, I., Aier, D., \& Stechuk, R. (2012). An interaction, a conversation, often in the context of play: Constructing intentional teaching in early childhood education. NHSA Dialog, 15(3), 272-285. https://doi.org/10.1080/15240754.2012.694496

Campbell, C., Speldewinde, C., Howitt, C., \& MacDonald, A. (2018). STEM practice in the early years. Creative Education, 9(1), 11-25.

https://doi.org/10.4236/ce.2018.91002

Carr, M. (2014). Play and playfulness: Issues of assessment. In L. Brooker, M. Blaise, \& S. Edwards (Eds.), The SAGE handbook of play and learning in early childhood (pp. 264-275). SAGE.

Carr, M., Peters, S., Davis, K., Bartlett, C., Bashford, N., Berry, P., Greenslade, S., Molloy, S., O’Connor, N., \& Simpson, M. (2008). Key learning competencies across place and time: Kimihia te ara tōtika, hei oranga mō to ao. Wilf Malcolm Institute of Educational Research.

Cherrington, S. (2011). Early childhood teachers' thinking and reflection within their communities of practice [Unpublished doctoral thesis]. Victoria University of Wellington.

https://viewer.waireto.victoria.ac.nz/client/viewer/IE160212/details?dps_dvs= $1618555043595 \sim 767$

Cherrington, S. (2016, 14 May). Making teaching visible: Challenges and opportunities for intentional teaching? [Paper presentation]. Institute for Early Childhood Studies Autumn Research Seminar, Victoria University, Wellington. 
Cherrington, S. (2018). Early childhood teachers' thinking and reflection: A model of current practice in New Zealand. Early Years, 38(3), 316-332.

https://doi.org/10.1080/09575146.2016.1259211

Cherrington, S., \& Thornton, K. (2013). Continuing professional development in early childhood education in New Zealand. Early Years, 33(2), 119-132. https://doi.org/10.1080/09575146.2013.763770

Cherrington, S., \& Wansbrough, D. (2007). Final report to the Ministry of Education on the national evaluation of ECE professional development programmes. MOE.

Christians, C. (2018). Ethics and politics in qualitative research. In N. Denzin \& Y. Lincoln (Eds.), The SAGE handbook of qualitative research (5th ed., pp. 66-82). SAGE.

Church, A., \& Bateman, A. (2019). Children's right to participate: How can teachers extend child-initiated learning sequences? International Journal of Early Childhood, 51(3), 265-281. https://doi.org/10.1007/s13158-019-00250-7

Cohen, L., Manion, L., \& Morrison, K. (2017). Research methods in education. Routledge. http://ebookcentral.proquest.com

Connelly, L. (2016). Trustworthiness in qualitative research. MedSurg Nursing, 25(6), 435-436.

https://link.gale.com/apps/doc/A476729520/AONE?u=vuw\&sid=AONE\&xid=d b92540a

Cooper, A. (2015). Nature and the outdoor learning environment: The forgotten resource in early childhood education. International Journal of Early Childhood Environmental Education, 3(1), 85-97. https://eric.ed.gov/?id=E]1108430

Corbin, J., \& Strauss, A. (2008). Basics of qualitative research (3rd ed.). SAGE.

Cornish, F., Gillespie, A., \& Zittoun, T. (2014). Collaborative analysis of qualitative data. In U. Flick (Ed.), The SAGE handbook of qualitative data analysis (pp. 79-93). SAGE. https://doi.org/10.4135/9781446282243

Costa, A., \& Kallick, B. (1993). Through the lens of a critical friend. Educational Leadership, 51(2), 49-51.

https://search.proquest.com/docview/1290155926? accountid=14782 
Cremin, T., Glauert, E., Craft, A., Compton, A., \& Stylianidou, F. (2015). Creative little scientists: Exploring pedagogical synergies between inquiry-based and creative approaches in early years science. Education 3-13: International Journal of Primary, Elementary and Early Years Education, 43(4), 404-419.

\section{https://doi.org/10.1080/03004279.2015.1020655}

Creswell, J. (2012). Educational research: Planning, conducting and evaluating quantitative and qualitative research (4th ed.). Pearson Education Inc.

Creswell, J., \& Poth, C. (2018). Qualitative inquiry \& research design: Choosing among five approaches (4th ed.). SAGE.

Cullen, J. (1996). The challenge of Te Whāriki for future developments in early childhood education. Delta, 48(1), 113-126.

Dalli, C., Kibble, N., Cairns-Cowan, N., Corrigan, J., \& McBride, B. (2009). Reflecting on primary caregiving through action research: The centre of innovation experience at Childspace Ngaio infants and toddlers' centre. The First Years: Nga Tau Tuatahi, 11(2), 38-45.

Davis, G., \& Tsung-Hui, T. (2008). Mathematics and science in the early years: International perspectives and theoretical views. In P. Grotewell \& Y. Burton (Eds.), Early childhood education: Issues and developments (pp. 23-45). Nova Science Publishers.

DEEWR. (2009). Belonging, being and becoming - The early years learning framework for Australia. Department of Education and Training. https://docs.education.gov.au/documents/belonging-being-becoming-earlyyears-learning-framework-australia

Denscombe, M. (2014). The good research guide: For small-scale research projects (5th ed.). Open University Press. https://ebookcentral.proquest.com

Denzin, N. (2003). Performance ethnography. SAGE. https://doi.org/10.4135/9781412985390

Denzin, N., \& Lincoln, Y. (Eds.). (2003). The landscape of qualitative research (2nd ed.). SAGE. 
Denzin, N., \& Lincoln, Y. (Eds.). (2011). The SAGE handbook of qualitative research (4th ed.). SAGE.

https://doi.org/http://catdir.loc.gov/catdir/toc/fy12pdf01/2010052892.html.

Denzin, N., \& Lincoln, Y. (Eds.). (2018). The SAGE handbook of qualitative research (5th ed.). SAGE.

Di Santo, A. (2000). Multi-age groupings in early childhood education: The affordances and opportunities of a multi-age child care model [Unpublished master's thesis]. University of Toronto. https://tspace.library.utoronto.ca/handle/1807/14260

Duncan, J., Dalli, C., \& Lawrence, J. (2006). The changing face of kindergarten: A national picture of two-year olds within kindergartens. New Zealand Annual Review of Education, 16, 119-140.

https://www.wgtn.ac.nz/education/research/nzaroe/issuesindex/2006/pdf/text-duncan.pdf

Early, D., Iruka, I., Ritchie, S., Barbarin, O., Winn, D., Crawford, G., Frome, P., Clifford, R., Burchinal, M., Howes, C., Bryant, D., \& Pianta, R. (2010). How do prekindergarteners spend their time? Gender, ethnicity, and income as predictors of experiences in pre-kindergarten classrooms. Early Childhood Research Quarterly, 25(2), 177-193. https://doi.org/https://doi.org/10.1016/j.ecresq.2009.10.003

Education Review Office. (2013). Working with Te Whāriki.

https://www.ero.govt.nz/publications/working-with-te-whariki/

Education Review Office. (2018a). Awareness and confidence to work with Te Whāriki. https://www.ero.govt.nz/assets/Uploads/Awareness-and-confidence-to-workwith-Te-Whariki.pdf

Education Review Office. (2018b). Engaging with Te Whāriki (2017). https://www.ero.govt.nz/assets/Uploads/Engaging-with-Te-Whariki.pdf

Education Review Office. (2019). Preparedness to implement Te Whāriki (2017). https://www.ero.govt.nz/assets/Uploads/Preparedness-to-implement-TeWhariki-2017.pdf 
Education Review Office. (2020). Indicators of quality for early childhood education: what matters most. https://ero.govt.nz/how-ero-reviews/early-childhoodservices/akarangi-quality-evaluation/te-ara-poutama-indicators-of-quality-forearly-childhood-education-what-matters

Education Review Office. (2021a). Science in the early years. Early childhood and Years 14. https://www.ero.govt.nz/assets/Uploads/Science-in-the-Early-Years-EarlyChildhood-and-Years-1-to-4.pdf

Education Review Office. (2021b). Shining a light on science: Good practice in early childhood services. https://www.ero.govt.nz/assets/Uploads/Shining-a-Lighton-Science-Good-Practice-in-Early-Childhood-Services.pdf

Edwards, C. (2002). Three approaches from Europe: Waldorf, Montessori, and Reggio Emilia. Early Childhood Research \& Practice, 4(1), 2-14.

Edwards, K. (2010). The inside story: Early childhood practitioners' perceptions of teaching science [Unpublished Master's thesis]. Victoria University of Wellington.

Edwards, K. (2011). Learning scientific knowledge from and with others. Early Childhood Folio, 15, 7-11.

http://go.galegroup.com.helicon.vuw.ac.nz/ps/i.do?id=GALE\%7CA265977350\& $\mathrm{v}=2.1 \& \mathrm{u}=\mathrm{vuw} \& \mathrm{it}=\mathrm{r} \& \mathrm{p}=\mathrm{AONE} \& \mathrm{sw}=\mathrm{w} \& \mathrm{asid}=\mathrm{b} 1 \mathrm{fa} 86 \mathrm{e} 544 \mathrm{da} 39 \mathrm{e} 7 \mathrm{f} 91 \mathrm{ec} 575892 \mathrm{~d} 4 \mathrm{~b}$ $\underline{\mathrm{ad}}$

Edwards, K., \& Loveridge, J. (2011). The inside story: Looking into early childhood teachers' support of children's scientific learning. Australasian Journal of Early Childhood, 36, 28-35.

http://go.galegroup.com.helicon.vuw.ac.nz/ps/i.do?id=GALE\%7CA260494530\& $\underline{v}=2.1 \& u=v u w \& i t=r \& p=A O N E \& s w=w \& a s i d=f 11 c 64 e 3 e 8 d 32 c 8663 a 4 f a 339483 b 0$ $\underline{95}$

Edwards, S. (2003a). "The curriculum is..." Early childhood educators' conceptions of curriculum and developmentally appropriate practice [Unpublished doctoral Thesis]. Monash University. 
Edwards, S. (2003b). New directions: Charting the paths for the role of sociocultural theory in early childhood education and curriculum. Contemporary Issues in Early Childhood, 4(3), 251-266. https://doi.org/10.2304/ciec.2003.4.3.3

Edwards, S., Blaise, M., \& Hammer, M. (2009). Beyond developmentalism? Early childhood teachers' understandings of multiage grouping in early childhood education and care. Australasian Journal of Early Childhood, 34(4), 55-63. https://journals.sagepub.com/doi/pdf/10.1177/183693910903400408

Edwards, S., \& Cutter-Mackenzie, A. (2011). Environmentalising early childhood education curriculum through pedagogies of play. Australasian Journal of Early Childhood, 36(1), 51-59.

Elliott, J. (1991). Action research for educational change. Open University Press.

Elo, S., Kääriäinen, M., Kanste, O., Pölkki, T., Utriainen, K., \& Kyngäs, H. (2014). Qualitative content analysis: A focus on trustworthiness. SAGE Open, 4(1), 1-10.

Epstein, A. (2007). The intentional teacher: Choosing the best strategies for young children's learning. National Association for the Education of Young Children.

Epstein, A. (2014). The intentional teacher: Choosing the best strategies for young children's learning (Revised ed.). National Association for the Education of Young Children.

Erickson, F. (2018). A history of qualitative inquiry in social and educational research In N. Denzin \& Y. Lincoln (Eds.), The SAGE handbook of qualitative research (Vol. 5th, pp. 36-65). SAGE.

Eshach, H., \& Fried, M. (2005). Should science be taught in early childhood? Journal of Science Education \& Technology, 14(3), 315-336.

\section{https://doi.org/10.1007/s10956-005-7198-9}

Fagan, T. (2009). Younger and older together: Children's interactions in a mixed-age early childhood centre [Unpublished master's thesis]. Victoria University of Wellington.

Farquhar, S., \& Fleer, M. (2007). Developmental colonisation of early childhood education in Aotearoa/New Zealand and Australia. In L. Keesing-Styles \& H. 
Hedges (Eds.), Theorising early childhood practice: Emerging dialogues (pp. 2649). Pademelon Press.

Fenwick, T. (2001). Responding to journals in a learning process. New Directions for Adult and Continuing Education, 90, 37-48. https://doi.org/10.1002/ace.19

File, N., Mueller, J., \& Wisneski, D. (2012). Curriculum in early childhood education: Reexamined, rediscovered, renewed. Routledge.

Fleer, M. (1993). Science education in child care. Science Education, 77(6), 561-573. https://doi.org/10.1002/sce.3730770602

Fleer, M. (2009a). Supporting scientific conceptual consciousness or learning in 'a roundabout way' in play-based contexts. International Journal of Science Education, 31(8), 1069-1089. https://doi.org/10.1080/09500690801953161

Fleer, M. (2009b). Understanding the dialectical relations between everyday concepts and scientific concepts within play-based programs. Research in Science Education, 39(2), 281-306. https://doi.org/10.1007/s11165-008-9085-X

Fleer, M. (2013). Theoretical plurity in curriculum design: The many voices of Te Whāriki and the Early Years Learning Framework. In J. G. Nuttall (Ed.), Weaving Te Whāriki: Aotearoa New Zealand's early childhood curriculum framework in theory and practice (pp. 217-238). NZCER Press.

Fleer, M. (2015). Learning science in everyday life - a cultural-historical framework. In M. Fleer \& N. Pramling (Eds.), A cultural-historical study of children learning science: Foregrounding affective imagination in play-based settings (pp. 3-22). Springer Netherlands. https://doi.org/10.1007/978-94-017-9370-4 1

Fleer, M., Anning, A., \& Cullen, J. (2009). A framework for conceptualising early childhood education. In A. Anning, J. Cullen, \& M. Fleer (Eds.), Early childhood education society and culture (2nd ed., pp. 187-204). SAGE. https://doi.org/http://helicon.vuw.ac.nz/login?url=http://site.ebrary.com/lib/v $\underline{\text { uw/docDetail.action?docID }=10546205}$ 
Fleer, M., Gomes, J., \& March, S. (2014). Science learning affordances in preschool environments. Australasian Journal of Early Childhood, 39(1), 38-48. https://journals.sagepub.com/doi/pdf/10.1177/183693911403900106

Fleer, M., \& Hedegaard, M. (2010). Early learning and development: Cultural-historical concepts in play. Cambridge University Press. http://ebookcentral.proquest.com/lib/vuw/detail.action?docID=1543596

Fleer, M., \& Hoban, G. (2012). Using 'Slowmation' for intentional teaching in early childhood centres: Possibilities and imaginings. Australasian Journal of Early Childhood, 37(3), 61-70.

http://helicon.vuw.ac.nz/login?url=http://search.ebscohost.com/login.aspx?dir ect=true $\& \mathrm{db}=\mathrm{a} 2 \mathrm{~h} \& \mathrm{AN}=82073830 \&$ site $=$ ehost-live

Fleer, M., \& Pramling, N. (2015). A cultural-historical study of children learning science. Foregrounding affective imagination in play-based settings. Springer. https://doi.org/http://helicon.vuw.ac.nz/login?url=http://dx.doi.org/10.1007/ 978-94-017-9370-4

Fleer, M., \& Robbins, J. (2003). "Hit and run research" with "hit and miss" results in early childhood science education. Research in Science Education, 33, 405-431.

French, L. (2004). Science as the center of a coherent, integrated early childhood curriculum. Early Childhood Research Quarterly, 19, 138-149.

Gadamer, H. (1975). Truth and method. Seabury Press.

Garbett, D. (2003). Science education in early childhood teacher education: Putting forward a case to enhance student teachers' confidence and competence. Research in Science Education, 33, 467-481.

Garbett, D., \& Yourn, B. (2002). Student teacher knowledge: Knowing and understanding subject matter in the New Zealand context. Australian Journal of Early Childhood, 27(3), 1-6.

Gerde, H., Schachter, R., \& Wasik, B. (2013). Using the scientific method to guide learning: An integrated approach to early childhood curriculum. Early Childhood Education Journal, 41(5), 315-323. https://doi.org/10.1007/s10643-013-0579-4 
Gibbs, R., \& Poskitt, J. (2009). Report on the evaluation of the early childhood Centres of Innovation programme. Evaluation Associates Ltd.

Gluckman, P. (2011). Looking ahead: Science education for the twenty-first century. A report from the Prime Minister's chief science advisor. Office of the Prime Minister's Science Advisory Committee. http://www.pmcsa.org.nz/scienceeducation-for-the-twenty-first-century/

Gonzalez, N., Amanti, C., \& Moll, L. (2005). Funds of knowledge: Theorizing practices in households, communities and classrooms. Erlbaum. https://doi.org/10.4324/9781410613462

Goodfellow, J., \& Hedges, H. (2007). Practitioner research 'centre stage': Contexts, contributions and challenges. In L. Keesing-Styles \& H. Hedges (Eds.), Theorising early childhood practice: Emerging dialogues (pp. 187-209). Pademelon Press.

Goodnough, K. (2003). Facilitating action research in the context of science education: Reflections of a university researcher. Educational Action Research, 11(1), 41-64. https://doi.org/10.1080/09650790300200203

Grbich, C. (2007). Qualitative data analysis: An introduction. SAGE.

Grey, A. (2011). Professional dialogue as professional learning. New Zealand Journal of Teachers' Work, 8(1), 21-32.

http://web.a.ebscohost.com/ehost/pdfviewer/pdfviewer?vid=2\&sid=439c5099c8b5-4e69-bc48-7b1a7f6e97c7\%40sdc-v-sessmgr02

Guest, G., Namey, E., \& Mitchell, M. (2013). Collecting qualitative data: A field manual for applied research. SAGE. https://doi.org/10.4135/9781506374680

Guskey, T. (2002). Professional development and teacher change. Teachers and Teaching, 8(3), 381-391. https://doi.org/10.1080/135406002100000512

Hammer, A., \& He, M. (2016). Preschool teachers' approaches to science: A comparison of a Chinese and a Norwegian kindergarten. European Early Childhood Education Research Journal, 24(3), 450-464.

https://doi.org/10.1080/1350293X.2014.970850 
Hanley, G., Tiger, J., Ingvarsson, E., \& Cammilleri, A. (2013). Influencing preschoolers' free-play activity preferences: An evaluation of satiation and embedded reinforcement. Journal of Applied Behavior Analysis, 42(1), 33-41.

\section{https://doi.org/https://doi.org/10.1901/jaba.2009.42-33}

Hatch, A. (2010). Rethinking the relationship between learning and development: Teaching for learning in early childhood classrooms. The Educational Forum, 74(3), 258-268. https://doi.org/10.1080/00131725.2010.483911

Hatch, A. (2012). From theory to curriculum. Developmental theory and its relation to curriculum and instruction in early childhood education. In N. File, J. Mueller, \& D. Wisneski (Eds.), Curriculum in early childhood education: Re-examined, rediscovered, renewed (pp. 42-53). Routledge.

Heap, R. (2007). Myth busting and tenet building: Primary and early childhood teachers' understanding of the nature of science [Unpublished master's thesis]. The University of Auckland.

Hedges, H. (2002). Subject content knowledge in early childhood curriculum and pedagogy [Unpublished master's Thesis]. Massey University.

Hedges, H. (2004). Subject knowledge in early childhood education: Risks and possibilities. Auckland College of Education Papers, 14, 29-44.

Hedges, H. (2005). "I will see more because I am bigger". Primary Science, (88), 13-15.

Hedges, H. (2007). Funds of knowledge in early childhood communities of inquiry [Unpublished doctoral thesis]. Massey University.

Hedges, H. (2010a). Blurring the boundaries: connecting research, practice and professional learning. Cambridge Journal of Education, 40(3), 299-314. https://doi.org/10.1080/0305764X.2010.502884

Hedges, H. (2010b). Whose goals and interests? The interface of children's play and teachers' pedagogical practices. In L. Brooker \& S. Edwards (Eds.), Engaging Play (pp. 25-38). ProQuest Ebook Central. 
Hedges, H. (2011). Connecting 'snippets of knowledge': Teachers' understandings of the concept of working theories. Early Years, 31(3), 271-284. https://doiorg.helicon.vuw.ac.nz/10.1080/09575146.2011.606206

Hedges, H. (2014). Children's content learning in play provision: Competing tensions and future possibilities. In L. Brooker, M. Blaise, \& S. Edwards (Eds.), The SAGE handbook of play and learning in early childhood (pp. 192-203). SAGE.

Hedges, H., \& Cooper, M. (2016). Inquiring minds: Theorizing children's interests. Journal of Curriculum Studies, 48(3), 303-322. https://doi.org/10.1080/00220272.2015.1109711

Hedges, H., \& Cooper, M. (2018). Relational play-based pedagogy: Theorising a core practice in early childhood education. Teachers and Teaching, 24(4), 369-383. https://doi.org/10.1080/13540602.2018.1430564

Hedges, H., \& Cullen, J. (2005). Subject knowledge in early childhood curriculum and pedagogy: Beliefs and practices. Contemporary Issues in Early Childhood, 6(1), 6679. http://cie.sagepub.com/content/6/1/66.full.pdf+html

Hedges, H., \& Cullen, J. (2012). Participatory learning theories: A framework for early childhood pedagogy. Early Child Development and Care, 182(7), 921-940. https://doi.org/10.1080/03004430.2011.597504

Hedges, H., Cullen, J., \& Jordan, B. (2011). Early years curriculum: Funds of knowledge as a conceptual framework for children's interests. Journal of Curriculum Studies, 43(2), 185-205. https://doi.org/10.1080/00220272.2010.511275

Heron, J., \& Reason, P. (2001). The practice of co-operative inquiry: Research 'with' rather than 'on' people. In P. Reason \& H. Bradbury (Eds.), Handbook of action research. Participative inquiry and practice. (Vol. 1, pp. 179-188). SAGE.

Herr, K., \& Anderson, G. (2005). The action research dissertation: A guide for students and faculty. SAGE. https://doi.org/10.4135/9781452226644

Herr, K., \& Anderson, G. (2015). The action research dissertation. A guide for students and faculty (2nd ed.). SAGE. 
Hong, S., \& Diamond, K. (2012). Two approaches to teaching young children science concepts, vocabulary, and scientific problem-solving skills. Early Childhood Research Quarterly, 27, 295-305. https://doi.org/10.1016/i.ecresq.2011.09.006

Hyson, M. (2003). Putting early academics in their place. Educational Leadership, 60(7), 20-23.

http://helicon.vuw.ac.nz/login?url=http://search.ebscohost.com/login.aspx?dir ect=true $\& \mathrm{db}=\mathrm{f} 6 \mathrm{~h} \& \mathrm{AN}=9490604 \&$ site $=$ ehost-live

Inan, H., Trundle, K., \& Kantor, R. (2010). Understanding natural sciences education in a Reggio Emilia-inspired preschool. Journal of Research in Science Teaching, 47(10), 1186-1208. https://doi.org/10.1002/tea.20375

Jordan, B. (2010). Co-constructing knowledge. Children, teachers and families engaging in a science-rich curriculum. In L. Brooker \& S. Edwards (Eds.), Engaging play (pp. 96-107). ProQuest Ebook Central.

Jordan, B., \& Smorti, S. (2010). Fearless science in the early years: Co-construction in a rural childcare centre. International Journal of Science in Society, 1(4), 85-103.

Kallery, M., \& Psillos, D. (2001). Pre-school teachers' content knowledge in science: Their understanding of elementary science concepts and of issues raised by children's questions. International Journal of Early Years Education, 9(3), 165179. https://doi.org/10.1080/09669760120086929

Kamberelis, G., \& Dimitriadis, G. (2008). Focus groups: Strategic articulations of pedagogy, politics, and inquiry. In N. K. Denzin \& Y. S. Lincoln (Eds.), Collecting and interpreting qualitative materials (3rd ed., pp. 375-402). SAGE.

Kane, R. (2005). Initial teacher education policy and practice. Ministry of Education.

Kashin, D. (2017, May 14). Invitations, provocations and reflective practice. Technology Rich Inquiry based Research.

https://tecribresearch.wordpress.com/2017/05/14/invitations-provocationsand-reflective-practice/ 
Kemmis, S., \& McTaggart, R. (2005). Participatory action research: Communicative action and the public sphere. In N. Denzin \& Y. Lincoln (Eds.), The SAGE handbook of qualitative research. (3 ed., pp. 271-330). SAGE.

Kemmis, S., McTaggart, R., \& Nixon, R. (2014). The action research planner: Doing critical participatory action research. Springer. https://doi.org/10.1007/978-981-4560$\underline{67-2}$

Kessler, S. (1991). Alternative perspectives on early childhood education. Early Childhood Research Quarterly, 6(2), 183-197.

Kilderry, A. (2015). Intentional pedagogies: Insights from the past. Australasian Journal of Early Childhood, 40(3), 20-28.

\section{https://doi.org/10.1177/183693911504000304}

Kincheloe, J., McLaren, P., Steinberg, S., \& Monzo, L. (2018). Critical pedagogy and qualitative resarch. In N. Denzin \& Y. Lincoln (Eds.), The SAGE handbook of qualitative research (5th ed., pp. 235-260). SAGE.

Koch, T. (1999). An interpretive research process: Revisiting phenomenological and hermeneutical approaches. Nurse Researcher, 6(3), 20-34.

https://search.proquest.com/docview/200806755?accountid=14782

Krieg, S. (2011). The Australian Early Years Learning Framework: Learning what? Contemporary Issues in Early Childhood, 12(1), 46-55.

https://doi.org/10.2304/ciec.2011.12.1.46

Kumar, K., \& Whyte, M. (2018). Interactive science in a sociocultural environment in early childhood. He Kupu The Word, 5(3), 20-27.

Laevers, F. (2005). The curriculum as means to raise the quality of early childhood education. Implications for policy. European Early Childhood Education Research Journal, 13(1), 17-29. https://doi.org/10.1080/13502930585209531

Lee, K., \& Johnson, A. (2007). Child development in cultural contexts: Implications of cultural psychology for early childhood teacher education. Early Childhood Education Journal, 35(3), 233-243. https://doi.org/10.1007/s10643-007-0202-7 
Leggett, N., \& Ford, M. (2013). A fine balance: understanding the roles educators and children play as intentional teachers and intentional learners within the Early Years Learning Framework. Australasian Journal of Early Childhood, 38, 42-50. http://go.galegroup.com.helicon.vuw.ac.nz/ps/i.do?id=GALE\%7CA357035149\& $\underline{v}=2.1 \& u=v u w \& i t=r \& p=A O N E \& s w=w \& a s i d=0 c 6 f 929939995391 c 6 b 163973857 b$ $\underline{09 \mathrm{e}}$

Lemke, J. (2001). Articulating communities: Sociocultural perspectives on science education. Journal of Research in Science Teaching, 38(3), 296-316. https://doi.org/10.1002/1098-2736(200103)38:3

Lewin, K. (1997). Action research and minority problems (1946). In Resolving social conflicts, and field theory in social science (pp. 143-152). American Psychological Association. https://doi.org/http://dx.doi.org/10.1037/10269-013

Lewis, R., Fleer, M., \& Hammer, M. (2019). Intentional teaching: Can early-childhood educators create the condotions for children's conceptual development when following a child-centred programme? Australasian Journal of Early Childhood, 44(1), 6-18. https://doi.org/10.1177/1836939119841470

Lillard, P. (1996). Montessori today: A comprehensive approach to education from birth to adulthood. Schocken Books.

Lincoln, Y. (2001). Engaging sympathies: Relationships between action research and social constructivism. In P. Reason \& H. Bradbury (Eds.), Handbook of action research: Participative inquiry and practice (pp. 124-132). SAGE.

Lincoln, Y., \& Guba, E. (1985). Naturalistic inquiry. SAGE.

Lincoln, Y., \& Guba, E. (2013). The constructivist credo. Taylor \& Francis Group. http://ebookcentral.proquest.com/lib/vuw/detail.action?docID=1187038

MacNaughton, G. (2001). Action research. In G. MacNaughton, S. Rolfe, \& I. SirajBlatchford (Eds.), Doing early childhood research: International perspectives on theory and practice (pp. 208-223). Allen \& Unwin.

MacNaughton, G., \& Hughes, P. (2008). Doing action research in early childhood studies: A step-by-step guide. McGraw-Hill Education. http://ebookcentral.proquest.com 
MacNaughton, G., Rolfe, S., \& Siraj-Blatchford, I. (2001). Doing early childhood research: International perspectives on theory and practice. Allen \& Unwin.

MacNaughton, G., Smith, K., \& Davis, K. (2006). Researching with children. The challenges and possibilities for building "child friendly" research. In J. A. Hatch (Ed.), Early childhood qualitative research (pp. 167-184). Routledge Taylor \& Francis Group. http://ebookcentral.proquest.com

MacQuarrie, S., Nugent, C., \& Warden, C. (2015). Learning with nature and learning from others: Nature as setting and resource for early childhood education. Journal of Adventure Education and Outdoor Learning, 15(1), 1-23. https://doi.org/10.1080/14729679.2013.841095

Mantzicopoulos, P., \& Patrick, H. (2011). Reading picture books and learning science: Engaging young children with informational text. Theory Into Practice, 50(4), 269-276. https://doi.org/10.1080/00405841.2011.607372

May, H. (2009). Politics in the playground: The world of early childhood in New Zealand (Rev. ed.). Otago University Press.

May, H. (2019). Politics in the playground: The world of early childhood in Aotearoa New Zealand (Rev ed.). Otago University Press.

McClellan, D., \& Kinsey, S. (1999). Children's social behavior in relationship to participation in mixed-age or same-age classrooms. Early Childhood Research \& Practice, 1(1), 36-42.

http://citeseerx.ist.psu.edu/viewdoc/download?doi=10.1.1.490.3331\&rep=rep1 $\underline{\text { \&ype }=\text { pdf }}$

McLachlan, C. (2005). Focus group methodology and its usefulness in early childhood research. New Zealand Research in Early Childhood Education, 8, 113-123.

McLachlan, C. (2017). 'Not business as usual': Reflections on the 2017 update of Te Whāriki. Early Education, 62, 8-14.

McLachlan, C. (2018). Te Whāriki revisited: How approaches to assessment can make valued learning visible. He Kupu The Word, 5(3), 45-56.

https://hdl.handle.net/10289/11854 
McLachlan, C. (2019). The promise of Te Whāriki (2017): Insights into teachers' and leaders' perspectives on teaching, learning, and assessment of literacy in the revised curriculum. Early Childhood Folio, 23(2), 3-8.

\section{https://doi.org/10.18296/ecf.0068}

McLachlan, C., Fleer, M., \& Edwards, S. (2013). Early childhood curriculum. Planning, assessment and implementation (2nd ed.). Cambridge University Press.

McLachlan, C., Fleer, M., \& Edwards, S. (2018). Early childhood curriculum. Planning, assessment and implementation (3rd ed.). Cambridge University Press.

McLaughlin, T., Aspden, K., \& McLachlan, C. (2015). How do teachers build strong relationships? A study of teaching practices to support child learning and social emotional competence. Early Childhood Folio, 19(1), 31-38.

McLaughlin, T., Aspden, K., \& Snyder, P. (2016). Intentional teaching as a pathway to equity in early childhood education: Participation, quality, and equity. New Zealand Journal of Educational Studies, 51(2), 175-195. https://doi.org/10.1007/s40841-016-0062-z

McLaughlin, T., \& Cherrington, S. (2018). Creating a rich curriculum through intentional teaching. Early Childhood Folio, 22(1), 33-38. https://doi.org/10.18296/ecf.0050

McNerney, K., \& Hall, N. (2016). Developing a framework of scientific enquiry in early childhood: An action research project to support staff development and improve science teaching. Early Child Development and Care, 1-15.

\section{https://doi.org/10.1080/03004430.2016.1237564}

McNiff, J., \& Whitehead, J. (2010). You and your action research project (3rd ed.). Routledge.

McNiff, J., \& Whitehead, J. (2011). All you need to know about action research (2nd ed.). SAGE.

Meade, A. (2002). Remembering: Knowing the moment cannot be repeated. Childrenz Issues, 6(2), 12-17.

Meade, A. (2005). Introduction. In A. Meade (Ed.), Catching the waves: Innovation in early childhood education (pp. 2-5). NZCER Press. 
Meade, A. (2006). It's about working with ideas. In A. Meade (Ed.), Riding the waves: Innovation in early childhood education (pp. 2-7). NZCER Press.

Meade, A. (2009). Giving back. In A. Meade (Ed.), Generating waves: Innovation in early childhood education (pp. 3-8). NZCER Press.

Meade, A. (2010, November 12). The contribution of ECE Centres of Innovation to building knowledge about teaching and learning 2003-2010. TLRI Early Years Symposium, NZCER, Wellington, New Zealand.

Meade, A., Robinson, L., Smorti, S., Stuart, M., \& Williamson, J. (2012). Early childhood teachers' work in education and care centres profile, patterns and purposes. Te Tari Puna Ora o Aotearoa / NZ Childcare Association.

Mena, J., \& Russell, T. (2017). Collaboration, multiple methods, trustworthiness: Issues arising from the 2014 international conference on self-study of teacher education practices. Studying Teacher Education, 13(1), 105-122. https://doi.org/10.1080/17425964.2017.1287694

Merriam, S. (2010). Qualitative case studies. In P. Peterson, E. Baker, \& B. McGaw (Eds.), International Encyclopaedia of Education (3rd ed., pp. 456-462). Elsevier. https://doi.org/https://doi.org/10.1016/B978-0-08-044894-7.01532-3

Merriam, S., \& Tisdell, E. (2016). Qualitative research: A guide to design and implementation (Vol. 19). Jossey-Bass.

http://search.ebscohost.com/login.aspx?direct=true \&db=nlebk\&AN=1022562\& site=ehost-live

Merton, R., \& Kendall, P. (1946). The focused interview. American Journal of Sociology, 51(6), 541-557. http://www.jstor.org/stable/2770681

Miles, M., Huberman, A., \& Saldana, J. (Eds.). (2014). Qualitative data analysis: A methods sourcebook (3rd ed.). SAGE.

Mills, A., Durepos, G., \& Wiebe, E. (2010). Encyclopedia of case study research. SAGE. https://doi.org/10.4135/9781412957397

Mills, G. (2011). Action research: A guide for the teacher researcher (4th ed.). Pearson. 
Ministry of Education. (1996). Te Whāriki: He whāriki mātauranga mō ngā mokopuna o Aotearoa, Early childhood curriculum. Learning Media.

Ministry of Education. (2007). The New Zealand curriculum for English-medium teaching and learning in years 1-13. Learning Media.

Ministry of Education. (2014). Introducing five science capabilities. Science Online.

https://scienceonline.tki.org.nz/Science-capabilities-forcitizenship/Introducing-five-science-capabilities

Ministry of Education. Te Tāhuhu o te Mātauranga. (2017). Te Whāriki. He whāriki mātauranga mō ngā mokopuna o Aotearoa. Early childhood curriculum. Author.

Ministry of Education. (n.d.-a). Annual ECE Census 2020: Fact Sheets.

https://www.educationcounts.govt.nz/publications/series/annual-earlychildhood-education-census/annual-ece-census-2020-fact-sheets

Ministry of Education. (n.d.-b). Te Whāriki online.

https://tewhariki.tki.org.nz/en/professional-learning-anddevelopment/webinars-and-resources/introduction-to-te-whariki-2017/

Minkler, M. (2004). Ethical challenges for the "outside" researcher in community-based participatory research. Health Education \& Behavior, 31(6), 684-697. https://doi.org/10.1177/1090198104269566

Mitchell, L. (2008). Locality-based evaluation of Pathways to the Future - Ngā huarahi arataki: Stage 1 report. Ministry of Education. https://ndhadeliver.natlib.govt.nz/delivery/DeliveryManagerServlet?dps pid=IE $\underline{758803}$

Mitchell, L. (2011). Locality-based evaluation of Pathways to the Future - Ngā huarahi arataki. Integrated report 2004, 2006 and 2009: Report to the Ministry of Education. Ministry of Education. https://ndhadeliver.natlib.govt.nz/delivery/DeliveryManagerServlet?dps pid=IE $\underline{8860943}$

Mitchell, L., \& Brooking, K. (2007). First NZCER national survey of early childhood education services 2003-2004. New Zealand Council for Educational Research. 
https://ndhadeliver.natlib.govt.nz/delivery/DeliveryManagerServlet?dps pid=IE $\underline{781410}$

Mitchell, L., \& Cubey, P. (2003). Characteristics of professional development linked to enhanced pedagogy and children's learning in early childhood settings: Best evidence synthesis. Ministry of Education.

Morse, J. (2018). Reframing rigor in qualitative inquiry. In N. Denzin \& Y. Lincoln (Eds.), The SAGE handbook of qualitative research (5th ed., pp. 796-817). SAGE.

National Research Council. (2000). Inquiry and the national science education standards: A guide for teaching and learning. National Academies Press. http://ebookcentral.proquest.com/lib/vuw/detail.action?docID=3375585

National Research Council, Bowman, B., Donovan, S., \& Burns, S. (Eds.). (2001). Eager to learn. Educating our preschoolers. National Academy Press. https://doi.org/http://site.ebrary.com/lib/vuw/Doc?id=10038591.

Nayfeld, I., Brenneman, K., \& Gelman, R. (2011). Science in the classroom: Finding a balance between autonomous exploration and teacher-led instruction in preschool settings. Early Education and Development, 22(6), 970-988. https://doi.org/10.1080/10409289.2010.507496

Neuman, D. (1972). Sciencing for young children. Young Children, 27(4), 214-226. www.jstor.org/stable/42724010

Nuttall, J. (2002). Early childhood curriculum in theory, ideology and practice: Using Te Whāriki. Delta, 54(1 \& 2), 91-104.

Nuttall, J. (2003). Influences on the co-construction of the teacher role in early childhood curriculum: Some examples from a New Zealand childcare centre. International Journal of Early Years Education, 11(1), 23-31. https://doi.org/10.1080/0966976032000066064

Nuttall, J. (2004). Why don't you ask someone who cares? Teacher identity, intersubjectivity, and curriculum negotiation in a New Zealand childcare centre [Unpublished doctoral thesis]. Victoria University of Wellington. 
Nuttall, J. (2005a). Looking back, looking forward: Three decades of early childhood curriculum development in Aotearoa New Zealand. Curriculum Matters, 1, 12-28. http://go.galegroup.com.helicon.vuw.ac.nz/ps/i.do?id=GALE\%7CA180748219\& $\underline{v}=2.1 \& u=v u w \& i t=r \& p=A O N E \& s w=w \& a s i d=5 f 0 e 271 b d 189752 f 12458 b b 9192 a 8$ $\underline{892}$

Nuttall, J. (2005b). Pathway to the future? Doing childcare in the era of New Zealand's Early Childhood Strategic Plan. Institute for Early Childhood Studies, Victoria University of Wellington.

Nuttall, J. (2013). Weaving Te Whāriki: Ten years on. In J. Nuttall (Ed.), Weaving Te Whāriki: Aotearoa New Zealand's early childhood curriculum framework in theory and practice (pp. 1-5). NZCER Press.

Nuttall, J., \& Edwards, S. (2004). Theory, context, and practice. Exploring the curriculum decision-making of early childhood teachers. Early Childhood Folio, 8, 14-18. https://www.nzcer.org.nz/nzcerpress/early-childhood-folio/articles/theorycontext-and-practice-exploring-curriculum-decision

Nyisztor, D., \& Marcus, B. (2008). Concepts and content belong in early childhood curriculum. Canadian Children, 33(2), 16-19.

http://helicon.vuw.ac.nz/login?url=http://search.ebscohost.com/login.aspx?dir ect=true $\& \mathrm{db}=$ eue $\& A N=35301587 \&$ site $=$ ehost-live

Otterborn, A., Schönborn, K., \& Hultén, M. (2019). Surveying preschool teachers' use of digital tablets: General and technology education related findings. International Journal of Technology and Design Education, 29(4), 717-737. https://doi.org/10.1007/s10798-018-9469-9

Pairman, A., \& Terreni, L. (2001). If the environment is the third teacher what language does she speak?, 1-17. http://olivepress.co.nz/TheThirdTeacher.html

Papatheodorou, T. (2008). Exploring relational pedagogy. In T. Papatheodorou \& J. Moyles (Eds.), Learning together in the early years: Exploring relational pedagogy (pp. 3-17). Taylor and Francis.

https://doi.org/https://doi.org/10.4324/9780203894163 
Papatheodorou, T., \& Moyles, J. (2008). Learning together in the early years: Exploring relational pedagogy. Taylor and Francis. https://doi.org/10.4324/9780203894163

Patrick, H., Mantzicopoulos, P., \& Samarapungavan, A. (2009). Motivation for learning science in kindergarten: Is there a gender gap and does integrated inquiry and literacy instruction make a difference. Journal of Research in Science Teaching, 46(2), 166-191. https://doi.org/10.1002/tea.20276

Patton, M. (1980). Qualitative evaluation methods. SAGE.

Pedretti, E. (1996). Facilitating action research in science, technology and society (STS) education: An experience in reflective practice. Educational Action Research, 4(3), 307-327. https://doi.org/10.1080/0965079960040303

Peters, S. (2008). Responsive, reciprocal relationships. The heart of the Te Whāriki curriculum. In T. Papatheodorou \& J. Moyles (Eds.), Learning together in the early years: Exploring relational pedagogy. Routledge.

http://ebookcentral.proquest.com/lib/vuw/detail.action?docID=348498.

Peterson, S., \& French, L. (2008). Supporting young children's explanations through inquiry science in preschool. Early Childhood Research Quarterly, 23(3), 395-408. https://doi.org/http://dx.doi.org/10.1016/i.ecresq.2008.01.003

Phelps, R. (2005). The potential of reflective journals in studying complexity in action. Complicity: An International Journal of Complexity and Education, 2(10), 37-54.

Phillips, D., \& Carr, K. (2009). Dilemmas of trustworthiness in preservice teacher action research. Action Research, 7(2), 207-226.

https://doi.org/10.1177/1476750308097027

Piaget, J. (1968). The construction of reality in the child. Routledge \& Kegan Paul Ltd.

Piasta, S., Logan, J., Pelatti, C., Capps, J., \& Petrill, S. (2015). Professional development for early childhood educators: Efforts to improve math and science learning opportunities in early childhood classrooms. Journal of Educational Psychology, 107(2), 407-422. https://doi.org/10.1037/a0037621 
Piasta, S., Pelatti, C., \& Miller, H. (2014). Mathematics and science learning opportunities in preschool classrooms. Early Education and Development, 25(4), 445-468. https://doi.org/http://dx.doi.org.helicon.vuw.ac.nz/10.1080/10409289.2013.81 $\underline{7753}$

Platteel, T., Hulshof, H., Ponte, P., van Driel, J., \& Verloop, N. (2010). Forming a collaborative action research partnership. Educational Action Research, 18(4), 429-451. https://doi.org/10.1080/09650792.2010.524766

Ponte, P., Ax, J., Beijaard, D., \& Wubbels, T. (2004). Teachers' development of professional knowledge through action research and the facilitation of this by teacher educators. Teaching and Teacher Education, 20(6), 571-588. https://doi.org/10.1016/j.tate.2004.06.003

Postholm, M., \& Skrøvset, S. (2013). The researcher reflecting on her own role during action research. Educational Action Research, 21(4), 506-518. https://doi.org/10.1080/09650792.2013.833798

Prasad, P. (2005). Crafting qualitative research: Working in the postpositivist traditions. M.E. Sharpe.

Prasad, P. (2015). Crafting qualitative research: Working in the postpositivist traditions. Routledge. https://ebookcentral-proquestcom.helicon.vuw.ac.nz/lib/vuw/reader.action?docID=1977457\&ppg=22

Punch, K. (2014). Introduction to social research: Quantitative \& qualitative approaches (3rd ed.). SAGE.

Purdon, A. (2016). Sustained shared thinking in an early childhood setting: An exploration of practitioners' perspectives. Education 3-13, 44(3), 269-282. https://doi.org/10.1080/03004279.2014.907819

Rameka, L., \& Glasgow, A. (2015). A Māori and Pacific lens on infant and toddler provision in early childhood education. Mai Journal, 4(2), 134-150. https://researchcommons.waikato.ac.nz/bitstream/handle/10289/11191/MAIJ

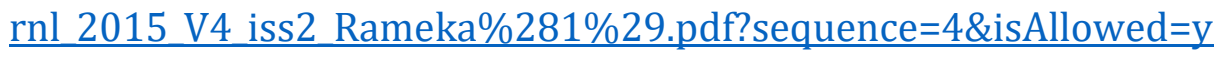


Rearick, M., \& Feldman, A. (1999). Orientations, purposes and reflection: A framework for understanding action research. Teaching and Teacher Education, 15(4), 333349. https://doi.org/10.1016/S0742-051X(98)00053-5

Reason, P., \& Bradbury, H. (2001). Introduction: Inquiry and participation in search of a world worthy of human aspiration. In P. Reason \& H. Bradbury (Eds.), Handbook of action research: Participative inquiry and practice (pp. 1-14). SAGE.

Reason, P., \& Bradbury, H. (2006). Handbook of action research: The concise paperback edition. SAGE.

https://doi.org/http://www.loc.gov/catdir/enhancements/fy0664/200592856 4-d.html

Reinoso, R., Delgado-Iglesias, J., \& Fernández, I. (2019). Pre-service teachers' views on science teaching in early childhood education in Spain. European Early Childhood Education Research Journal, 27(6), 801-820. https://doi.org/10.1080/1350293X.2019.1678720

Renwick, M., \& McCauley, L. (1995). Group size in kindergartens. Issues arising from changes to group size and other policy developments in the Wellington Region Free Kindergarten Association in 1994. New Zealand Council for Educational Research.

Rinke, C., Gimbel, S., \& Haskell, S. (2013). Opportunities for inquiry science in Montessori classrooms: Learning from a culture of interest, communication, and explanation. Research in Science Education, 43(4), 1517-1533.

https://doi.org/10.1007/s11165-012-9319-9

Robbins, J. (2005). "Brown paper packages"? A sociocultural perspective on young children's ideas in science. Research in Science Education, 35, 151-153), p.151172. https://doi.org/10.1007/s11165-005-0092-x

Robinson, P., \& Bartlett, C. (2011). "Stone crazy": A space where intentional teachers and intentional learners meet. Early Childhood Folio, 15(2), 10-14.

Rouse, E. (2015). Mixed-age grouping in early childhood - creating the outdoor learning environment. Early Child Development and Care, 185(5), 742-751. https://doi.org/10.1080/03004430.2014.953138 
Rust, F. (2006). Action research in early childhood contexts. In J. A. Hatch (Ed.), Early childhood qualitative research. Taylor \& Francis Group. https://ebookcentral.proquest.com

Saçkes, M. (2014). How often do early childhood teachers teach science concepts? Determinants of the frequency of science teaching in kindergarten. European Early Childhood Education Research Journal, 22(2), 169-184. https://doi.org/http://dx.doi.org/10.1080/1350293X.2012.704305

Saçkes, M., Trundle, K., Bell, R., \& O'Connell, A. (2011). The influence of early science experience in kindergarten on children's immediate and later science achievement: Evidence from the early childhood longitudinal study. Journal of Research in Science Teaching, 48(2), 217-235.

\section{https://doi.org/10.1002/tea.20395}

Saçkes, M., Trundle, K., \& Flevares, L. (2009). Using children's literature to teach standard-based science concepts in early years. Early Childhood Education Journal, 36(5), 415-422. https://doi.org/10.1007/s10643-009-0304-5

Sandberg, F., \& Wallo, A. (2013). The interactive researcher as a virtual participant: A Habermasian interpretation. Action Research, 11(2), 194-212. https://doi.org/10.1177/1476750313484503

Schwandt, T., \& Gates, E. (2017). Case study methodology. In N. Denzin \& Y. Lincoln (Eds.), The SAGE handbook of qualitative research (5th ed., pp. 341-358). SAGE.

Shaji, M., \& Indoshi, F. (2008). Conditions for implementation of the science curriculum in early childhood development and education centres in Kenya. Contemporary Issues in Early Childhood, 9(4), 389-399.

https://doi.org/10.2304/ciec.2008.9.4.389

Shulman, L. (1986). Those who understand: Knowledge growth in teaching. Educational Researcher, 15(2), 4-14. http://www.jstor.org/stable/1175860

Sigurdardottir, I., \& Puroila, A. (2018). Encounters in the third space: Constructing the researcher's role in collaborative action research. Educational Action Research, 28(1), 83-97. https://doi.org/10.1080/09650792.2018.1507832 
Sikder, S., \& Fleer, M. (2014). Small science: Infants and toddlers experiencing science in everyday family life. Research in Science Education, 45(3), 445-464. https://doi.org/10.1007/s11165-014-9431-0

Sikes, P., \& Potts, A. (2008). Researching education from the inside. Routledge.

Siraj-Blatchford, I. (2007). Creativity, communication and collaboration: The identification of pedagogic progression in sustained shared thinking. Asia Pacific Journal of Research in Early Childhood Education, 1(2), 3-23.

Siraj-Blatchford, I. (2008). Quality teaching in the early years. In A. Anning, J. Cullen, \& M. Fleer (Eds.), Early Childhood Education: Society and Culture (2nd ed., pp. 147157). SAGE.

Siraj-Blatchford, I. (2010). A focus on pedagogy. Case studies of effective practice. In K. Sylva, E. Melhuish, P. Sammons, I. Siraj-Blatchford, \& B. Taggart (Eds.), Early childhood matters: Evidence from the effective pre-school and primary education project (pp. 149-165). Routledge.

Siry, C. (2013). Exploring the complexities of children's inquiries in science: Knowledge production through participatory practices. Research in Science Education, 43(6), 2407-2430. https://doi.org/10.1007/s11165-013-9364-z

Smidt, S. (2011). Introducing Bruner: A guide for practitioners and students in early years education. Routledge. https://doi.org/10.4324/9780203829639

Smorti, S. (2005). Why don't we teach science? Early Education, 38, 13-20.

Somekh, B. (2005). Action research: A methodology for change and development. McGraw-Hill Education. http://ebookcentral.proquest.com/lib/vuw/detail.action?docID=295487

Spektor-Levy, O., Baruch, Y., \& Mevarech, Z. (2013). Science and scientific curiosity in pre-school-the teacher's point of view. International Journal of Science Education, 35(13), 2226-2253. https://doi.org/10.1080/09500693.2011.631608

Srivastava, P., \& Hopwood, N. (2009). A practical iterative framework for qualitative data analysis. International Journal of Qualitative Methods, 8(1), 76-84. 
Stake, R. (2006). Multiple case study analysis. The Guilford Press.

\section{https://ebookcentral.proquest.com}

Stegelin, D. (2003). Application of the Reggio Emilia approach to early childhood science curriculum. Early Childhood Education Journal, 30(3), 163-169.

https://doi.org/10.1023/a:1022013905793

Stenhouse, L. (1975). An introduction to curriculum research and development. Heinemann.

Stephen, C., \& Plowman, L. (2008). Enhancing learning with information and communication technologies in pre-school. Early Child Development and Care, 178(6), 637-654. https://doi.org/10.1080/03004430600869571

Stephenson, A. (2009). Skirmishes on the border: How children experienced, influenced and enacted the boundaries of curriculum in an early childhood education centre setting [Unpublished doctoral thesis]. Victoria University of Wellington.

Stieha, V. (2014). Critical friend. In D. Coghlan \& M. Brydon-Miller (Eds.), The SAGE encyclopedia of action research (Vol. 1-2, pp. 207-209). SAGE. https://doi.org/10.4135/9781446294406

Sue, V., \& Ritter, L. (2007). Conducting online surveys. SAGE. https://doi.org/10.4135/9781412983754

Sundberg, B., Areljung, S., Due, K., Ekström, K., Ottander, C., \& Tellgren, B. (2016). Understanding preschool emergent science in a cultural historical context through activity theory. European Early Childhood Education Research Journal, 24(4), 567-580. https://doi.org/10.1080/1350293X.2014.978557

Swaffield, S. (2007). Light touch critical friendship. Impoving Schools, 10(3), 205-219. https://doi.org/10.1177/1365480207077845

Sylva, K., Melhuish, E., Sammons, P., Siraj-Blatchford, I., \& Taggart, B. (2004). The effective provision of pre-school education (EPPE) project. Technical paper 12: The final report-effective pre-school education. Institute of Education, University of London. 
Sylva, K., Melhuish, E., Sammons, P., Siraj-Blatchford, I., \& Taggart, B. (2010). Early childhood matters: Evidence from the effective pre-school and primary education project. Routledge.

Te One, S. (2013). Te Whāriki: Historical accounts and contemporary influences 19902012. In J. Nuttall (Ed.), Weaving Te Whāriki: Aotearoa New Zealand's early childhood curriculum framework in theory and practice (pp. 7-34). NZCER Press.

Thomas, L., Warren, E., \& deVries, E. (2011). Play-based learning and intentional teaching in early childhood contexts. Australasian Journal of Early Childhood, $36(4), 69-75$.

Thornton, K., \& Cherrington, S. (2018). Professional learning communities in early childhood education: A vehicle for professional growth. Professional Development in Education, 45(3), 418-432. https://doi.org/10.1080/19415257.2018.1529609

Thornton, K., \& Yoong, P. (2011). The role of the blended action learning facilitator: An enabler of learning and a trusted inquisitor. Action Learning: Research and Practice, 8(2), 129-146.

Thorpe, V. (2015). Assessing complexity: Group composing and New Zealand's national certificates of educational achievement [Unpublished doctoral thesis]. Victoria University of Wellington.

Timoštšuk, I. (2018). Creating a science-rich environment for young children. In C. Pascal, T. Bertram, \& M. Veisson (Eds.), Early childhood education and change in diverse cultural contexts (pp. 179-191). Taylor \& Francis Group.

\section{http://ebookcentral.proquest.com/lib/vuw/detail.action?docID=5412709}

TLRI. (n.d.). TLRI research. http://www.tlri.org.nz/tlri-research

Tomkins, S., \& Tunnicliffe, S. (2007). Nature tables: Stimulating children's. Journal of Biological Education, 41(4), 150-155.

https://doi.org/10.1080/00219266.2007.9656090

Torquati, J., Cutler, K., Gilkerson, D., \& Sarver, S. (2013). Early childhood educators' perceptions of nature, science, and environmental education. Early Education \& Development, 24(5), 721-743. https://doi.org/10.1080/10409289.2012.725383 
Trundle, K., \& Saçkes, M. (Eds.). (2015). Research in early childhood science education (1st ed.). Springer Netherlands. https://doi.org/10.1007/978-94-017-9505-0.

Tu, T. (2006). Preschool science environment: What is available in a preschool classroom? Early Childhood Education Journal, 33(4), 245-251. https://doi.org/http://dx.doi.org/10.1007/s10643-005-0049-8

Uçar, S. (2015). The use of technology in teaching science to young children. In K. Cabe Trundle \& M. Saçkes (Eds.), Research in early childhood science education (pp. 167-184). Springer Netherlands. https://doi.org/10.1007/978-94-017-9505-0 8

Vecchi, V. (2010). Art and creativity in Reggio Emilia: Exploring the role and potential of ateliers in early childhood education. Routledge. http://ebookcentral.proquest.com/lib/vuw/detail.action?docID=496393

Vygotsky, L. (1978). Mind in society: The development of higher psychological processes. Harvard University Press.

Vygotsky, L. (1987). The development of scientific concepts in childhood. In R. W. Rieber \& A. S. Carton (Eds.), The collected works of l. S. Vygotsky: Problems of general psychology, including the volume thinking and speech (pp. 167-241). Springer US. https://doi.org/10.1007/978-1-4613-1655-8 9

Wagner, J. (1997). The unavoidable intervention of educational research: A framework for reconsidering researcher-practitioner cooperation. Educational Researcher, 26(7), 13-22. https://doi.org/10.3102/0013189X026007013

Walsh, D. (1991). Extending the discourse on developmental appropriateness: A developmental perspective. Early Education and Development, 2(2), 109-119. https://doi.org/10.1207/s15566935eed0202 3

Waters-Adams, S. (2006). The relationship between understanding of the nature of science and practice: The influence of teachers' beliefs about education, teaching and learning. International Journal of Science Education, 28(8), 919-944. https://doi.org/10.1080/09500690500498351

Watters, J., Diezmann, C., Grieshaber, S., \& Davis, J. (2001). Enhancing science education for young children: A contemporary initiative. Australian Journal of Early 
Childhood, 26(2), 1-7.

https://link.gale.com/apps/doc/A76626999/AONE?u=vuw\&sid=AONE\&xid=e2 $\underline{\mathrm{b} 62 \mathrm{~b} 60}$

Wells, G. (2002). Inquiry as an orientation for learning, teaching and teacher education. In G. Wells \& G. Claxton (Eds.), Learning for life in the 21st century: Sociocultural perspectives on the future of education (pp. 197-210). Blackwell Publishers.

Wells, G. (2009). Dialogic inquiry as collaborative action research. In S. Noffke \& B. Somekh (Eds.), The SAGE handbook of educational action research (pp. 50-61). SAGE.

Wood, E. (2008). Developing a pedagogy of play. In A. Anning, J. Cullen, \& M. Fleer (Eds.), Early childhood education: Society and culture (pp. 27-38). SAGE. http://ebookcentral.proquest.com/lib/vuw/detail.action?docID=880867

Yazan, B. (2015). Three approaches to case study methods in education: Yin, Merriam, and Stake. The Qualitative Report, 20(2), 134-152. https://nsuworks.nova.edu/tqr/vol20/iss2/12

Yin, R. (2012). Applications of case study research (3rd ed.). SAGE.

Yin, R. (2018). Case study research and applications: Design and methods (6th ed.). SAGE.

Yost, D., Sentner, S., \& Forlenza-Bailey, A. (2000). An examination of the construct of critical reflection: Implications for teacher education programming in the 21st century. Journal of Teacher Education, 51(1), 39-49. https://doi.org/10.1177/002248710005100105

Zhang, W., \& Birdsall, S. (2016). Analysing early childhood educators' science pedagogy through the lens of a pedagogical content knowing framework. Australasian Journal of Early Childhood, 41(2), 50-58. 


\section{Appendix A}


research you may contact Associate Professor Susan Corbett, Victoria University HEC Convener. (Email susan.corbett@vuw.ac.nz or phone +64-4-463 5480).

\section{Completing the Survey}

By choosing the consent button below and proceeding to the next page you are consenting to participate in this research and are consenting that the information you provide may be used in the data analysis.

If you have any difficulties accessing any questions please do not hesitate to contact me. I am happy to answer any questions you may have. My email address is sola.freeman@vuw.ac.nz

The survey will take approximately $10-15$ minutes to complete.

Thank you again for taking the time to consider this request.

\section{Informed Consent}

I understand the information that has been provided to me about this study, including the storage, access, and use of my data. Any question that I have asked has been answered.

Please select an one option below:

I consent to participate in this survey

I choose NOT to participate in this survey

What type of ECE service is your centre?

Kindergarten

Full day education and care

Sessional education and care

Other

Please select what type of kindergarten your service is

Belong to New Zealand Kindergartens Incorporated Te Pūtahi Kura Puhou o Aotearoa (NZK)

https://vuw.ca1.qualtrics.com/Q/EditSection/Blocks/Ajax/GetSurveyPrintPreview?ContextSurveyID=SV 24c1M9Tbqsr7wWN\&ContextLibraryID=U... 2 
Private Kindergarten

Does your service identify with any of the following organisations or have a particular approach/philosophy?

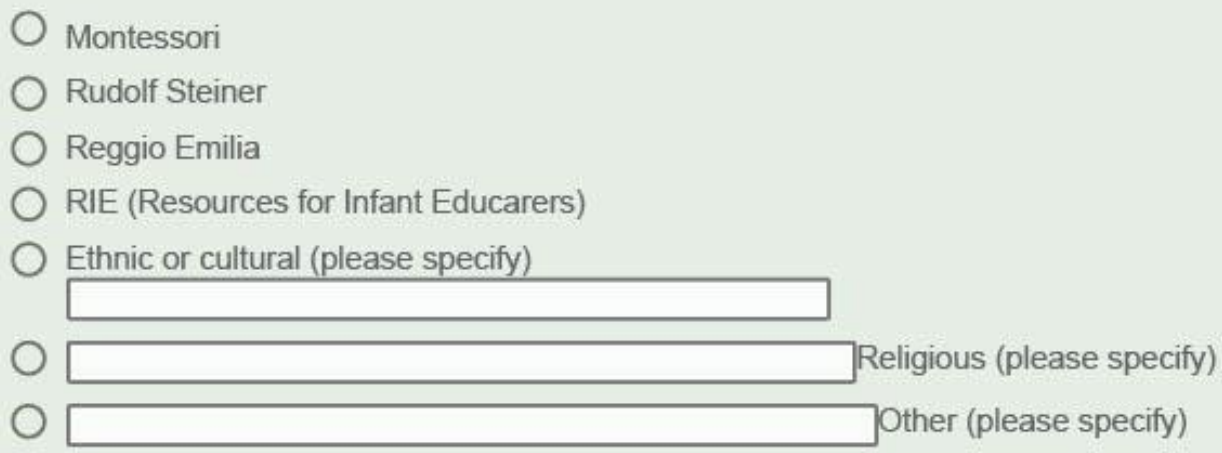

What ages are the children in your centre? Please select all those that apply.
$0-1$ year olds
$1-2$ year olds
2 - 3 year olds
$3-4$ year olds
$4-5$ year olds
$5-6$ year olds

Please identify your role within your service?

Centre Manager

Kindergarten Head Teacher

Centre Head Teacher

$\bigcirc$ Centre Supervisor

Assistant Centre Supervisor

Teacher/Educator

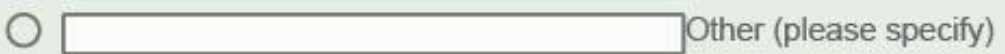

https://vuw.ca1.qualtrics.com/Q/EditSection/Blocks/Ajax/GetSurveyPrintPreview?ContextSurveyID=SV_24c1M9Tbqsr7wWN\&ContextLibraryID=U... 3/8 
What qualification do you have?

$\square$ Diploma of Teaching (ECE)

$\square$ BTchg (Primary)

$\square$ BTchg (ECE)

$\square$ NZ Steiner Teaching Diploma (EC)

Montessori Teaching Diploma

Other (please specify)

When did you last study science formally?

Many years ago at high school

Year 11 or 5 th form

Year 12 or 6 th form

Year 13 or 7 th form

Undergraduate level at University

Post graduate level (eg Masters or Phd)

During teacher training

Please indicate your support for the following statement: Teaching science is important in ECE?

$\begin{array}{cccccc}\begin{array}{c}\text { Strongly } \\ \text { agree }\end{array} & \begin{array}{c}\text { Agree } \\ \text { Somewhat }\end{array} & \begin{array}{c}\text { Neither } \\ \text { agree }\end{array} & \begin{array}{c}\text { Somewhat } \\ \text { disagree }\end{array} & \begin{array}{c}\text { Disagree } \\ \text { disagree }\end{array} & \begin{array}{c}\text { Strongly } \\ \text { disagree }\end{array} \\ \square & \square & \square & \square & \square\end{array}$

Please explain why?

How do you see science happening in practice in your service?

https://vuw.ca1.qualtrics.com/Q/EditSection/Blocks/Ajax/GetSurveyPrintPreview?ContextSurveylD=SV_24c1M9Tbqsr7wWN\&ContextLibrarylD=U. . . 
In what ways are considerations related to te ao Māori made visible in science experiences in your setting?

In your service how often are opportunities for scientific learning occurring?
Daily
4-6 times a week
2-3 times a week
Once a week
Never

What factors support this scientific learning to happen so often? Please give examples. Is it your service's environment, the materials, your or another teacher's interests, the teaching team's pedagogical approaches?

Why do you think scientific learning occurs so infrequently, if at all, in your service? Is it the environment, the materials, your or another teacher's interests or confidence, the teaching team's pedagogical approaches? 
What do you think are or would be helpful to support scientific learning in your service?

$\begin{gathered}\text { Extremely } \\ \text { helpful }\end{gathered}$
0

\begin{abstract}
Curriculum resources about science
\end{abstract}

Science areas in the centre environment

Science

materials/resources

for the children

Teacher professional development

What else do you think or have you found to be helpful to support scientific learning with children?

What sort of professional development?

Specific science knowledge

Science activities ideas

Pedagogical approaches to support scientific learning

Other

https://vuw.ca1.qualtrics.com/Q/EditSection/Blocks/Ajax/GetSurveyPrintPreview?ContextSurveyID=SV_24c1M9Tbqsr7wWN\&ContextLibraryID=U... 
Please explain

How confident do you feel supporting children's scientific learning?

$\begin{array}{ccccccc}\begin{array}{c}\text { Extremely } \\ \text { confident }\end{array} & \begin{array}{c}\text { Moderately } \\ \text { confident }\end{array} & \begin{array}{c}\text { Slightly } \\ \text { confident }\end{array} & \begin{array}{c}\text { Neither } \\ \text { confident nor unconfident } \\ \text { unconfident }\end{array} & \begin{array}{c}\text { Slightly } \\ \text { unconfident }\end{array} & \begin{array}{c}\text { Extremely } \\ \text { unconfident }\end{array} \\ \text { un } & \mathrm{O} & \mathrm{O} & \mathrm{O} & \mathrm{O} & \mathrm{O}\end{array}$

Why do you think that is?

If you are in the Wellington region and think your service might be interested in participating in an action research study and would like to receive more information please indicate below
$\mathrm{O}$ Yes
$\mathrm{O}$ No

Please provide the best contact details for me to contact you regarding your interest.

Powered by Qualtrics

https://vuw.ca1.qualtrics.com/Q/EditSection/Blocks/Ajax/GetSurveyPrintPreview?ContextSurveyID=SV_24c1M9Tbqsr7wWN\&ContextLibrarylD=U... 7/8 


\section{Appendix B}

\section{Guiding Questions for first Focus Group}

[Name of centre] and [date]

\section{Focus group introduction}

At the start of each focus group, the teachers and I will revisit the key points agreed in the teachers' consent forms;

- the discussion will be audio recorded and transcribed,

- participants will receive a written summary of the discussion and have the opportunity to review the material and provide clarifications, or corrections (member checking).

- participants identities will remain confidential.

\section{Focus group rules}

Together we can agree on some guidelines for the focus groups. The following are some suggestions, the teachers may add others, if agreed to by their colleagues. We will then agree to adhere to the final agreed guidelines.

- Listen actively - respect others when they are talking.

- Critique with respect - respectfully challenge one another by asking questions.

- The goal is not to agree - it is to gain a deeper understanding.

- Respect confidentiality - what is discussed in this room stays in this room.

\section{Main research questions}

"What influences scientific learning for children in early childhood settings in New Zealand?"

1. How did the process of action research, including the researcher's role, influence the occurrence of scientific experiences?

2. How do teachers' pedagogical approaches enable children's scientific experiences?

3. What are the enablers/challenges to scientific experiences in ECE centres? 
The intention is to identify the areas the teaching team wish to work on and formulate a plan of action using the questions below as provocations/starting points for further discussion.

Reviewing your observations and reflections over the last two weeks, what do you think is happening in the centre at the moment to support scientific learning (SL) with the children?

What is working well?

What isn't working well?

What could be done more/better?

After the "science walk" you noted the following areas [....] helped foster SL? Why do you think this?

Have you had any further thoughts to add since we did the "science walk"?

Thinking about the areas/materials that do support SL - what else could be added to these, or could the ideas be used elsewhere in the centre?

Could some areas be better set up/equipped to facilitate SL for children?

Prompts if needed...

Reflections in your journals have been great to read - picking up on a few threads.... Identification of curriculum resources as being beneficial... what could these look like do you think?

Your own scientific knowledge... what do you think you need to know to support children's SL?

Reflections on how you support children's learning in general.... Do you think your pedagogical approaches are helpful to support children's SL? If so why? If not, why not? 


\section{Appendix C}

MEMORANDUM

Phone $\quad 0-4-4635480$

Email susan.corbettoruw.acnz

\begin{tabular}{l|l}
\hline TO & Sola Freeman \\
\hline COPY TO & Mary-Jane Shuker \\
\hline FROM & AProf Susan Corbett, Convener, Human Ethics Committee \\
\hline DATE & 8 June 2017 \\
\hline PAGES & 1 \\
\hline & $\begin{array}{l}\text { Ethics Approval: } 24490 \\
\text { WUat influences scientific learning for children in early childhood } \\
\text { settings in New Zealand? } \\
\text { A case study to examine the enablers and challenges to scientific } \\
\text { learning in ECE centres. }\end{array}$ \\
\hline
\end{tabular}

Thank you for your application for ethical approval, which has now been considered by the Standing Committee of the Human Ethics Committee.

Your application has been approved from the above date and this approval continues until 30 June 2019 . If your data collection is not completed by this date you should apply to the Human Ethics Committee for an extension to this approval

Best wishes with the research

Kind regards

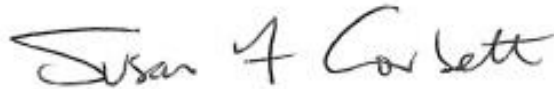

Susan Corbett

Convener, Victoria University Human Ethics Committee 


\section{Appendix D}

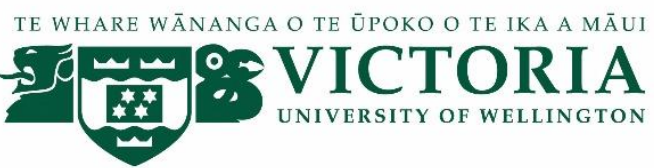

\section{What influences scientific learning for children in early childhood settings in New Zealand? DATE}

Kia ora,

My name is Sola Freeman. I am currently a PhD student at Victoria researching the influences on scientific learning for children in early childhood education (ECE) centres.

This project is a case study designed to take place in two stages. A national survey of teachers in kindergartens and education and care centres and collaborative action research in three centres.

Firstly thank you for completing the online survey. I really appreciate the time you took answering the questions. During the survey you indicated an interest in participating further in this research, again thank you. Your participation will provide a deeper insight into the complexities of how scientific learning is or can be supported within an early childhood setting.

I would very much appreciate your consent to be part of this research project. Please read the Information Leaflet attached and this letter before deciding whether or not to take part. I am very happy to discuss the study in more depth with you and to answer any questions. Please email me if you would like me to call you or meet with you. My email is sola.freeman@vuw.ac.nz.

You will find a consent form attached to this letter. If you decide to participate, thank you. If you decide not to take part, thank you for your interest.

\section{Phase Two - Collaborative action research (CAR)}

It is intended that the action research in each centre will explore what supports, such as curriculum, materials, the environment and teacher capabilities, are needed to help foster scientific learning to occur for children.

CAR involves the researcher working alongside teaching teams. You will be engaged in professional learning through the opportunity to reflect, critique, and possibly change their practice while working collaboratively within their teaching team.

This professional learning will utilise CAR methodology to gather data on your practice and children's learning through observing and documenting scientific teaching and learning interactions and activities using video-recordings, photographs and written observations. You may also seek parents' perspectives on scientific learning through, for example, informal conversations, parent meetings or parent feedback via the children's portfolios.

Only you, your teaching team, the other teachers in each participating centre, the researcher, supervisors, and transcriber will have access to the data. The transcriber will sign a confidentiality agreement.

The data will be used by you, alongside your teaching team and the researcher to improve scientific teaching and learning and be used as part of the action research process; provoking reflections and discussions amongst the teaching team during audio-recorded staff meetings, online reflective journals, and semi-structured focus group interviews.

The information gathered during this research project, including any photographs, video- or audiorecordings of scientific teaching and learning interactions and activities involving children, will be used 
only amongst the participating centres and for reporting in the PhD thesis, in conference presentations, in teaching sessions related to this topic and in published academic papers. No teachers, children or parents attending the participating centres will be identified. If you would like to choose a pseudonym (false name) to be used in the final thesis, conference or teaching presentations and any published material, indicate this preference on the consent form.

The data collected will be kept secure in a locked filing cabinet, or in password-protected computer files and destroyed 10 years after the research ends. You may withdraw from this study at any point before collection of the data is complete without giving any reason. However, once the focus group has started, you can withdraw but the data up until the point of withdrawal cannot be removed from the data set.

Teachers participating in this CAR study will be involved in the following:

- An initial hui involving all teachers from the other participating centres to form a collaborative learning community, approximately 1-2 hours.

- Usual staff meetings, where time (20-30 minutes) will be set aside to discuss and monitor the implementation of their action research plan

- Reflective journals, hosted on a dedicated, secure website using Moodle. I expect this will take approximately 1 hour a week.

- A video-recorded 'science walk' through the centre outside usual centre hours, involving 1-2 teachers, taking approximately 45 minutes.

- Three semi-structured focus groups facilitated by myself, to take about 1 hour each.

The CAR cycle for each centre will be 12 weeks and data will be collected through:

- Analysis of documents gathered during the project, such as learning stories, staff meeting minutes, assessment and planning documents, CAR plans and implementation documents

- Audio-recordings of staff meetings, audio- and video-recordings of scientific teaching and learning instances in the centre and video-recording of a 'science walk' through the centre outside usual centre hours

- Individual online reflective journals maintained by you.

- Audio-recorded semi-structured focus group interviews undertaken three times during and at the completion of the CAR cycle throughout, designed to capture teachers' views on the effectiveness of the changes made to facilitate scientific learning.

Further details are in the Information Leaflet provided. I am also happy to answer any questions you may have. My email address is sola.freeman@vuw.ac.nz.

The supervisors for this research are: Dr. Mary Jane Shuker, Mary-jane.shuker@vuw.ac.nz, Ph: 04 4639557 and Dr. Kate Thornton, kate.thornton@vuw.ac.nz, Ph: 044639776

This research has been approved by the Victoria University of Wellington Human Ethics Committee, Approval Number 0000024490. If you have any concerns about the ethical conduct of the research you may contact Associate Professor Susan Corbett, Victoria University HEC Convener. (Email susan.corbett@vuw.ac.nz or phone +64-4-463 5480).

Nga mihi,

Sola Freeman Sola.freeman@vuw.ac.nz 


\section{Appendix E}

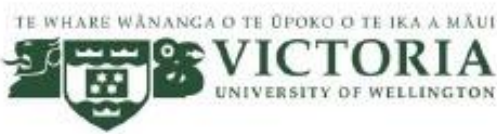

CONSENT TO PARTICIPATE IN RESEARCH FOR TEACHERS

\section{What influences scientific learning for children in early childhood settings in New Zealand?}

Researcher: Sola Freeman, PhD Student, School of Education, Victoria University of Wellington.

By signing this consent form I agree that:

- I have been given and have read the Information Sheet and the project has been explained to me. My questions have been answered to my satisfaction. I understand that I can ask further questions at any time.

- I understand involvement in this collaborative action research project will involve contribution to an online reflections journal, discussions around the topic at staff meetings and critical analysis of my teaching practice with the researcher and the rest of the teaching team.

- I understand I will be observed by the researcher, and agree to conversing with her about my teaching practice and the scientific learning experiences I am involved in with the children.

- I agree to take part in three audio recorded focus group interviews. I understand the recording will be transcribed and I will have the opportunity to review the transcription.

- I may withdraw from this study at any point before collection of the data is complete without giving any reason. However, once the focus group has started, I can withdraw but the data up until the point of withdrawal cannot be removed from the data set.

- The information I have provided will be destroyed 10 years after the thesis is presented.

- I understand that the results of this research will be used for a $\mathrm{PhD}$ thesis, in conference presentations, in teaching sessions related to this topic and in published academic papers.

- Any information I provide will be kept confidential to the researcher and the supervisors. My name will not be used in reports, nor will any information that would identify me. I will be given the opportunity to choose a pseudonym to be used in the final thesis, conference or teaching presentations and any published material.

\begin{tabular}{|l|l|}
\hline I consent to take part in this collaborative action research project. & Yes \\
\hline $\begin{array}{l}\text { I am willing to participate in an initial hui involving all teachers from all participating } \\
\text { centres to form a collaborative learning community }\end{array}$ & Yes \\
\hline $\begin{array}{l}\text { I consent to information or opinions which I have given being attributed to me and } \\
\text { shared with the other two participant centres only }\end{array}$ & Yes \\
\hline $\begin{array}{l}\text { I consent to the use of visual images of me being published as part of the final } \\
\text { thesis or in journal articles, or used in presentations. } \\
\text { Note: If you do not consent I will ensure that only images that obscure your identify } \\
\text { (or do not include you) are used in publications or presentations. }\end{array}$ & Yes $\square$ \\
\hline I am happy for a pseudonym to be used in this study. & No $\square$ \\
\hline $\begin{array}{l}\text { I would like to choose the pseudonym to be used } \\
\text { (If you indicate you do not want to choose and therefore have no preference, what it } \\
\text { might be will still be discussed with you). }\end{array}$ & Yes $\square$ \\
\hline $\begin{array}{l}\text { I would like a copy of the transcript of the focus groups } \\
\text { No }\end{array}$ \\
\hline $\begin{array}{l}\text { I would like a summary of the focus groups } \\
\text { below. }\end{array}$
\end{tabular}

Signed:

Date:

Name:

Email: 


\section{Appendix F}

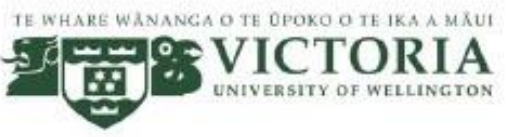

\section{CONSENT TO PARTICIPATE IN POST-CAR RESEARCH MEETINGS}

\section{What influences scientific learning for children in early childhood settings in New Zealand?}

Researcher: Sola Freeman, PhD Student, School of Education, Victoria University of Wellington.

By signing this consent form I agree that:

- I have been given and have read the Information Sheet and the project has been explained to me. My questions have been answered to my satisfaction. I understand that I can ask further questions at any time.

- I understand involvement in meetings following the participatory action research project will provide a forum to share experiences and may involve facilitated critical reflection of my teaching practice with the researcher and other participants involved in this research.

- I agree to these meetings being audio recorded. I understand the recordings may be transcribed and I will have the opportunity to review the transcription.

- I may withdraw from this study at any point before collection of the data is complete without giving any reason. However, once the focus group has started, I can withdraw but the data up until the point of withdrawal cannot be removed from the data set.

- The information I have provided will be destroyed 10 years after the thesis is presented.

- I understand that the results of this research will be used for a PhD thesis, in conference presentations, in teaching sessions related to this topic and in published academic papers.

- Any information I provide will be kept confidential to the researcher and the supervisors. My name will not be used in reports, nor will any information that would identify me. I will be given the opportunity to choose a pseudonym to be used in the final thesis, conference or teaching presentations and any published material.

\begin{tabular}{|l|l|}
\hline I consent to take part in any post-collaborative action research project meetings. & Yes $\square \quad$ No $\square$ \\
\hline $\begin{array}{l}\text { I am willing to participate in any hui involving all teachers from all participating } \\
\text { centres to form a collaborative learning community }\end{array}$ & Yes $\square \quad$ No $\square$ \\
\hline $\begin{array}{l}\text { I consent to information or opinions which I have given being attributed to me and } \\
\text { shared with the other participant centres only }\end{array}$ & Yes $\square \quad$ No $\square$ \\
\hline
\end{tabular}

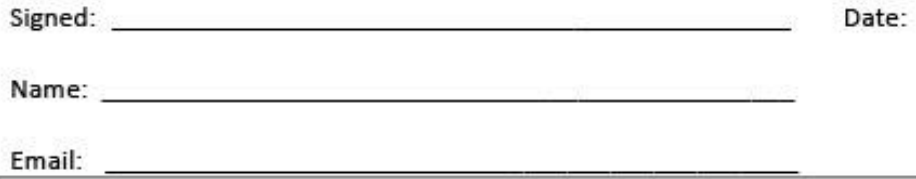




\section{Appendix G}

INFORMATION LEAFLET

What influences scientific learning for children in
early childhood settings in New Zealand?
Researcher: Sola Freeman
PhD Student, Victoria University, Wellington

Thank you for your interest in this project. Please read this leaflet which provides further details about the research project. It outlines the aims and intentions of the research, and highlights how the ethical issues will be managed.

The aim of the study is to examine what influences scientific learning for children in early childhood education (ECE) centres. Four questions will be addressed

1. What are the enablers/challenges to scientific learning occurring in ECE centres?

2. How do curriculum, the environment and/or materials help support scientific learning?

3. What support or learning is needed for the teachers?

4. How do teachers' pedagogical approaches help enable scientific learning to occur for children?

Research process and data collection

The project is a case study designed to take place in two stages. Phase 1 is a nationa survey of kindergartens and education and care centres. Phase 2 involves collaborative action research in three centres.

Phase One-Survey

The anonymous national survey of teachers will provide an overview of what sort of scientific learning in happening in ECE centres in NZ. Through the survey teachers could choose to participate further through the action research phase of the study.

In addition the teaching teams in each participating centre may wish to form community of learning where data may be shared.

Only the teachers in each participating centre, the researcher, supervisors, and transcriber will have access to the data. The transcriber will sign a confidentiality agreement.

The data will be used by teachers to improve scientific teaching and learning and the teachers and the researcher may refer to this data during the study, including in the following data collection activities: audio-recorded staff meetines, online reflective journals, and semi-structured focus group interviews.

The information gathered during this research project, including any photographs, video- or audio-recordings of scientific teaching and learning interactions and activities involving children, will be used only for reporting in the PhD thesis, in conference presentations, in teaching sessions related to this topic and in published academic papers. No teachers, children or parents attending the participating used in the final thesis, conference or teaching presentations and any published material, indicate this preference on the consent form.

Use of video

I am aware that the use of video cameras in research with young children raises specific issues. Consent will be sought from all before videoing commences. One issue that arises will be videoing children for whom consent has not been granted. It are involved in therefore it is likely that they will be videoed. Children who are not given consent will be identified by the researcher and if necessary stickers will be attached to their back to distinguish those who have consented and those who have not. No data will be collected from these children and the images of non-participant children will be blurred if necessary. All video footage will be kept in a secure environment and will be destroyed 10 years after the study has been completed.

Timeline

I expect Phase Two of the research to occur throughout the 2017 school year from June to December. Each participant centre will be involved in the collaborative action research cycle for 12 weeks.

Data security

The data collected will be kept secure in a locked filing cabinet, or in password-

protected computer files and destroyed 10 years after the research ends. centres will be identified. If you would like to choose a pseudonym (false name) to be is necessary that such children are not separated from their peers or the activity the
Phase Two - Collaborative Action Research (CAR)

I will be working alongside teaching teams in the three participating centres. Teachers will have the opportunity to reflect, critique, and possibly change their practice while working collaboratively within their teaching team. In return for this professional learning opportunity the teachers will agree to be observed and videotaped, share learning opportunity the teachers will agree to be observed and videotaped, share
centre documentation such as learning stories and planning notes, to be interviewed centre documentation such as learning stories and planning notes, to be interviewed through focus groups and allow their online journals, staff meetings and discussions
to form part of the research data. It is intended that the action research in each centre will gain a deeper insight into the complexities of how scientific learning is or can be supported within an early childhood setting; finding out what supports, such as curriculum, materials, the environment and teacher capabilities, are needed to help foster scientific learning to occur for children.

How can you help?

In each of the three action research centres, written consent will be sought from the teachers, the centres' children and their families. During phase two, once consent has been gained I would like to spend some time in the centre, make obsent has veen gand is videotape a 'science wak' wh the teachers, videotape scientic leaning if it is what is already working and the possible barriers to scientific learning in the centre. Through the collaborative action research cycle we will together plan the supports or resources needed or the changes to their environment or practice that will hopefully see scientific learning occur amongst the children in their centre. Ongoing monitoring of these changes will occur through their online reflection journals, the staff meetings and focus groups.

Permission will be sought to audiotape the focus groups. These will be transcribed. Transcripts and inferences will be made from it and will be returned for further comment and/or validation.

What will happen to the data collected?

Phase One - Survey

This will be anonymous and confidential as the software I will use to analyse the data does not identify the survey participants.

Phase Two - Collaborative Action Research

This research is confidential. This means that I will be aware of the participants' identities but the research data will be aggregated and their identity will not be disclosed in any reports, presentations, or public documentation. However, you do need to be aware that in small projects your identity could be obvious to others in your community.
What are your rights as a research participant?

You do not have to accept this invitation. If you do decide to participate, you have the right to:

- choose not to answer any question

- withdraw from this study at any point before collection of the data is complete without giving any reason. However, once the focus group has started, teachers can withdraw but the data up until the point of withdrawal cannot be removed from the data set.

- ask any questions about the study at any time;

- agree on a name to be used as your pseudonym;

- be able to read any reports of this research by emailing me to request a copy.

Thank you for considering this application to undertake research in your centre. If you have any questions at any time, please feel free to contact me using the information below.

Nga mihi,

Sola Freeman

sola.freeman@vuw.ac.nz

This research has been approved by the Victoria University of Wellington Human Ethics Committee, Approval Number 24490

The supervisors of this research project are:

Dr. Mary Jane Shuker - Mary-jane.shuker@vuw.ac.nz Phone: 044639557

Dr. Kate Thornton - Kate.thornton@vuw.ac.nz Phone: 044639776

If you have any concerns about the ethical conduct of the research you may contact the Victoria University HEC Convener:

Associate Professor Susan Corbett - susan.corbett@vuw.ac.nz Phone: 044635480. 


\title{
Appendix H
}

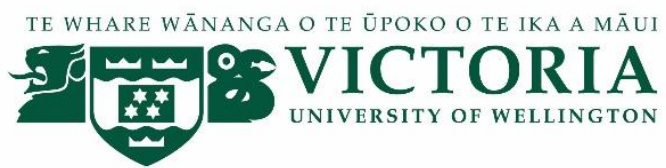

\author{
What influences scientific learning for children in early childhood settings in New Zealand? \\ DATE
}

Kia ora,

My name is Sola Freeman. I am currently a PhD student at Victoria researching the influences on scientific learning for children in early childhood education (ECE) centres.

This project is a case study designed to take place in two stages. A national survey of teachers in kindergartens and education and care centres and collaborative action research (CAR) in three centres.

The teachers at (centre name) are interested in participating in Phase Two of the study: CAR. Their participation will provide a deeper insight into the complexities of how scientific learning is or can be supported within an early childhood setting.

I would very much appreciate your consent for your child to be part of this research project. An Information Leaflet with more details is attached. I am very happy to discuss the study in more depth with you and to answer any questions. Please email me if you would like me to call you or meet with you. If other parents are interested I can organise a parent meeting if this is a preferable option. My email is sola.freeman@vuw.ac.nz. During my first visits to the centre I will also talk with the children about the research.

You will find a parent consent form attached to this letter. There is also an 'agreement form' for you to choose to fill in with your child if you think they are capable of understanding the letter and answering the questions. This research will focus on the teachers' practice with the children's involvement being through observations and informal conversations. Therefore I would like to give your child the opportunity to participate (or not) and to take part in the consent process. Your child will be asked for verbal consent as well. I am happy to answer any questions you or your child may have so feel free to contact me.

Phase Two - Collaborative action research (CAR)

CAR involves the researcher working alongside teaching teams. Teachers will be engaged in professional learning through the opportunity utilise CAR methodology to gather data on their practice and children's learning through observing and documenting scientific teaching and learning interactions and activities using video-recordings, photographs and written observations. Teachers may also seek your perspective on scientific learning through, for example, informal conversations, parent meetings or parent feedback via the children's portfolios.

The information gathered during this research project, including any photographs, video- or audiorecordings of scientific teaching and learning interactions and activities involving children, will be used only amongst the participating centres and for reporting in the PhD thesis, in conference presentations, in teaching sessions related to this topic and in published academic papers. No teachers, children or parents attending the participating centres will be identified. If you would like to choose a pseudonym (false name) to be used in the final thesis, conference or teaching presentations and any published material, indicate this preference on the consent form. 
The data collected will be kept secure in a locked filing cabinet, or in password-protected computer files and destroyed 10 years after the research ends. You may withdraw from this study at any point before collection of the data is complete without giving any reason.

I am aware that the use of video cameras in research with young children raises specific issues. Consent will be sought from all before videoing commences. One issue that arises will be videoing children for whom consent has not been granted. It is necessary that such children are not separated from their peers or the activity they are involved in therefore it is likely that they will be videoed. Children who were not given consent will be identified by the researcher and if necessary stickers will be attached to their back to distinguish those who have consented and those who have not. No data will be taken of these children and the images of non-participant children will be blurred if necessary. All video footage will be kept in a secure environment and will be destroyed 10 years after the study has been completed.

The CAR cycle for each centre will be 12 weeks, data will be gathered by the researcher and teachers through the following:

- An initial hui involving all teachers from the other participating centres to form a collaborative learning community,

- Analysis of documents gathered during the project, such as learning stories, staff meeting minutes, assessment and planning documents, CAR plans and implementation documents

- Audio-recordings of staff meetings, audio- and video-recordings of scientific teaching and learning instances in the centre and video-recording of a 'science walk' through the centre outside of centre hours.

- Individual online reflective journals.

- Audio-recorded semi-structured focus group interviews undertaken three times during and at the completion of the CAR cycle throughout, designed to capture teachers' views on the effectiveness of the changes made to facilitate scientific learning.

Further details are in the Information Leaflet provided. I am also happy to answer any questions you may have. My email address is sola.freeman@vuw.ac.nz.

The supervisors for this research are: Dr. Mary Jane Shuker, Mary-jane.shuker@vuw.ac.nz,Ph: 04 4639557 and Dr. Kate Thornton, kate.thornton@vuw.ac.nz, Ph: 044639776

This research has been approved by the Victoria University of Wellington Human Ethics Committee, Approval Number 0000024490. If you have any concerns about the ethical conduct of the research you may contact Associate Professor Susan Corbett, Victoria University HEC Convener. (Email susan.corbett@vuw.ac.nz or phone+64-4-463 5480).

Nga mihi,

Sola Freeman

Sola.freeman@vuw.ac.nz 


\section{Appendix I}

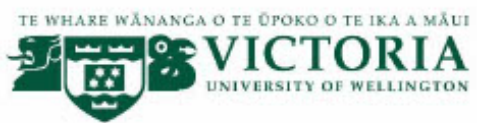

CONSENT TO PARTICIPATE IN RESEARCH FOR PARENTS/GUARDIANS

\section{What influences scientific learning for children in early childhood settings in New Zealand?}

Researcher: Sola Freeman, PhD Student, School of Education, Victoria University of Wellington.

By signing this consent form I agree that:

- I have been given and have read the Information Sheet and the project has been explained to me. My questions have been answered to my satisfaction. I understand that I can ask further questions at any time.

- I understand I can request summary feedback about the findings of this research (see below)

- I give permission for the teachers in (name of centre) to collect data for this collaborative action research project that may involve me or my child. Such data may be gathered through observations (written, audiorecorded or video-recorded) and/or photographs of scientific learning and teaching interactions and activities, and through activities involving me such as informal conversations and parent meetings.

- I understand that this data will be used by teachers to improve scientific teaching and learning in (name of centre) and that teachers and the researcher may refer to this data during the PAR study including in the following data collection activities: audio-recorded staff meetings, online reflective journals, and semistructured focus group interviews.

- I understand that the data collected will be kept secure. Only the teachers at (name of centre), the researcher, supervisors, transcriber and possibly teachers in the other two participating centres will have access to the data. The transcriber will sign a confidentiality agreement. I also understand that all the data collected will be destroyed 10 years after the conclusion of the study.

- I understand that the information gathered during this research project, including any photographs, video- or audio-recordings of scientific teaching and learning interactions and activities involving children, will be used only amongst the participating centres and for reporting in the PhD thesis, in conference presentations, in teaching sessions related to this topic and in published academic papers.

- I understand the identity of this centre and individual teachers, parents and children will be kept confidential to the researcher and the supervisors. Pseudonyms will be used in the thesis, conference or teaching presentations and any published material.

- I understand that I may withdraw my child or myself from this study without giving a reason up until the conclusion of data collection. 


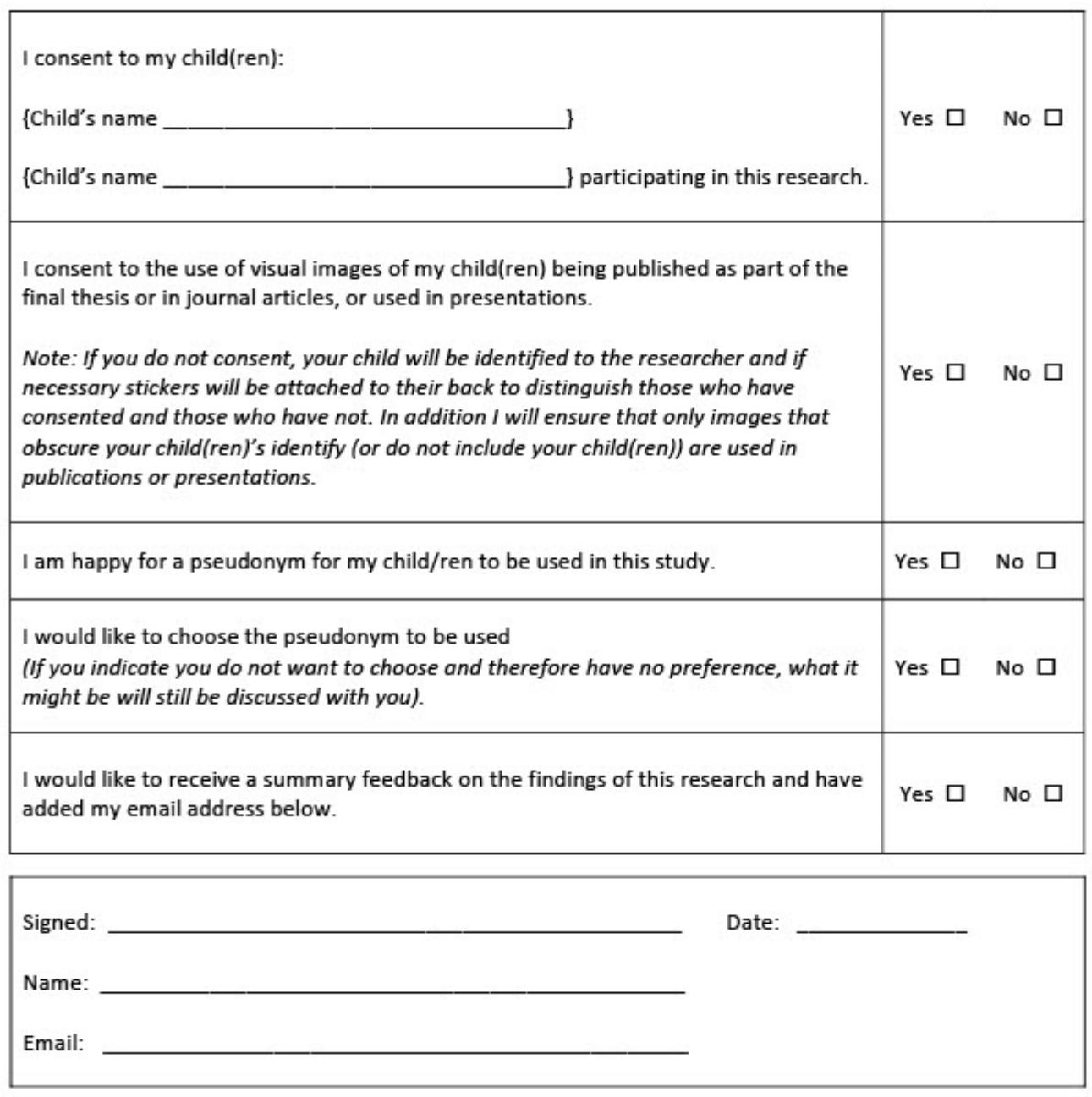




\section{Appendix J}

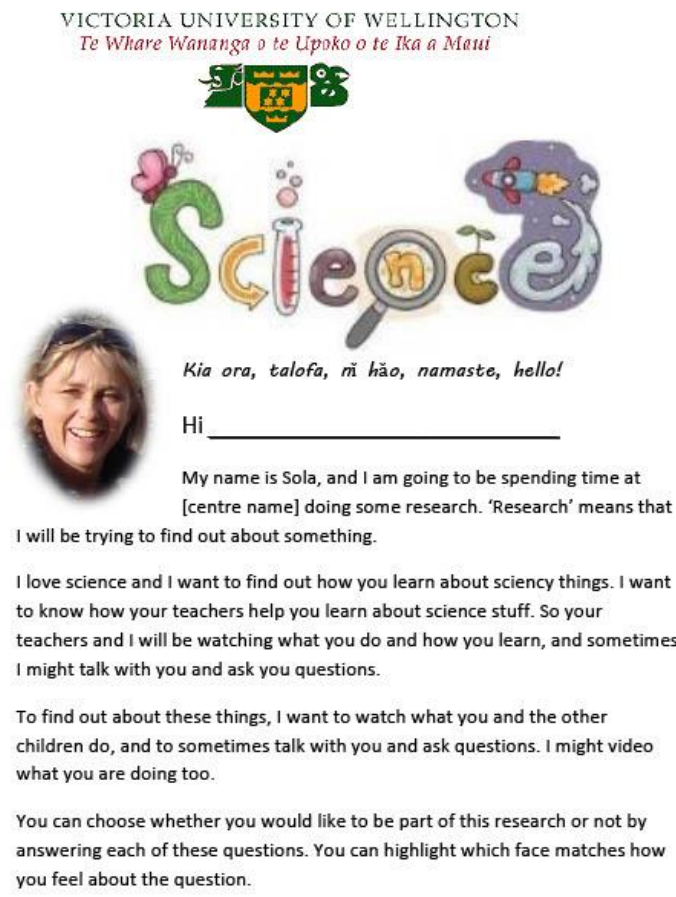

\begin{tabular}{|c|c|}
\hline $\begin{array}{c}\text { Are you happy if I sometimes watch you, and write } \\
\text { notes about what you are doing? }\end{array}$ & $\begin{array}{l}:-) \text { YES } \\
: \text { NO }\end{array}$ \\
\hline $\begin{array}{l}\text { Are you happy if I take some photographs or video of } \\
\text { you at the centre? (You can have your own copies of } \\
\text { the photographs of you) }\end{array}$ & $\begin{array}{l}\text { (:) YES } \\
: \text { NO }\end{array}$ \\
\hline $\begin{array}{l}\text { Are you happy if I sometimes make recordings of } \\
\text { what is being said? (I use this when everyone talks } \\
\text { fast and I find it hard to write all the words down) }\end{array}$ & $\begin{array}{l}\text { (:) YES } \\
: \text { NO }\end{array}$ \\
\hline $\begin{array}{l}\text { Are you happy if you talk with me sometimes? } \\
\text { (You can choose when you talk to me, so that I don't } \\
\text { interrupt you) }\end{array}$ & $\begin{array}{l}\text { :) YES } \\
: 2 \text { NO }\end{array}$ \\
\hline $\begin{array}{l}\text { Are you happy for your teachers to show me videos, } \\
\text { photos or what they have written about you too? }\end{array}$ & $\begin{array}{l}\text { (:) YES } \\
: 2 \text { NO }\end{array}$ \\
\hline
\end{tabular}

It is fine if you change your mind about what you have said. You just need to tell me or tell your family, or a teacher and they will let me know.

I am looking forward to seeing you at [centre name].

11 